University of Louisville

ThinkIR: The University of Louisville's Institutional Repository

Electronic Theses and Dissertations

$5-2012$

\title{
Emotional distress in older adults with cancer : a multilevel longitudinal study.
}

Tara J. Schapmire

University of Louisville

Follow this and additional works at: https://ir.library.louisville.edu/etd

\section{Recommended Citation}

Schapmire, Tara J., "Emotional distress in older adults with cancer : a multilevel longitudinal study." (2012). Electronic Theses and Dissertations. Paper 1269.

https://doi.org/10.18297/etd/1269

This Doctoral Dissertation is brought to you for free and open access by ThinkIR: The University of Louisville's Institutional Repository. It has been accepted for inclusion in Electronic Theses and Dissertations by an authorized administrator of ThinkIR: The University of Louisville's Institutional Repository. This title appears here courtesy of the author, who has retained all other copyrights. For more information, please contact thinkir@louisville.edu. 


\title{
EMOTIONAL DISTRESS IN OLDER ADULTS WITH CANCER: A MULTILEVEL LONGITUDINAL STUDY
}

\author{
by \\ Tara J. Schapmire \\ B.S., Western Kentucky University, 1994 \\ M.S.S.W., University of Louisville, 1996 \\ A Dissertation \\ Submitted to the Faculty of the \\ Raymond A. Kent School of Social Work of the University of Louisville \\ in Partial Fulfillment of the Requirements \\ for the degree of \\ Doctor of Philosophy \\ Kent School of Social Work \\ University of Louisville \\ Louisville, Kentucky
}

May 2012 
Copyright 2012 by Tara J. Schapmire

All rights reserved 


\title{
EMOTIONAL DISTRESS IN OLDER ADULTS WITH CANCER: A MULTILEVEL LONGITUDINAL STUDY

\author{
By
}

\author{
Tara J. Schapmire \\ B.S., Western Kentucky University, 1994 \\ M.S.S.W., University of Louisville, 1996
}

A Dissertation Approved on

March $29^{\text {th }}, 2012$

By the following Dissertation Committee:

\begin{tabular}{c}
\hline Anna C. Faul, PhD, Chair \\
\hline Barbara A. Head, PhD \\
\hline Jamie L. Studts, PhD \\
\hline Pamela A. Yankeelov, PhD \\
\hline Brad Zebrack, PhD
\end{tabular}




\section{DEDICATION}

For those affected by cancer. 


\section{ACKNOWLEDGEMENTS}

I have so much gratitude for those who have inspired, mentored, and supported me in the completion of my doctoral work and this dissertation. I must begin with my husband and best friend. Marty, from the very beginning this has been our decision, our work, our dissertation, and our Ph.D. There are no adequate words in the English language to express my appreciation and love for you. To my children, Lily and Nick, five years ago when I started this work you were babies! You've barely known a time when mommy wasn't glued to the computer. While I would have completed the dissertation much faster without you, my life would not have been as fun, as fulfilled, or as wonderful.

It is difficult to imagine that there could be a better mentor than my Chair, Anna Faul. Annatjie, your modeling of scholarly social work service, research, and teaching has had a tremendous impact on me personally, motivating my professional development in ways I did not think myself capable. Your council has been selfless, wise, and masterful. And as if that's not enough, you're fun to argue with, fun to be with, and you make me laugh—very hard; you introduced me to Professor Fringelier! I look forward to a life-long friendship with you.

My other committee members simply rock.

Barbara Head, you were one of the first people I sought when beginning my studies because of your local and national reputation. Little did I know how 
many gifts I would receive as a result. You gave me research ideas, helped me obtain grants, shared all your work, gave me a job, and introduced me to your world in the School of Medicine. I can't wait to see what comes next with you. I planned to ask health psychologist, Jamie Studts, to serve on my committee as soon as I discovered what a committee was. Jamie, my fellow introvert, by the time I asked you, l'd spent years hearing the members of my support group sing your praises as an amazing provider of psychosocial oncology care. Thank you for your experience, your brilliance, your perspective, and for encouraging me to find my "hotbed of psychosocial oncology openness".

My happiest of thanks goes to Pam Yankeelov. I knew I could count on your very thoughtful feedback and support through the years and you never failed me. I'm not sure what l'd have done if you hadn't been there to serve as an impartial observer during my meetings with Annatjie; you'd hear our goodnatured ranting and raving over some bit of theory, or some obstinate data, and you'd come into her office and settle us down or distract us with your heart warming laugh.

Brad Zebrack, as I got to know the literature in oncology social work, it was your name I kept running into. It is your leadership and your scholarship that serves as a guiding star in our field; your example set an amazing course for me to try to follow. My friend and honored mentor, I once again fail to find the words to describe my amazing luck at crossing paths with you all those years ago at an Association of Oncology Social Work conference. You encouraged me to pursue doctoral work, apply for American Cancer Society funding, you allowed me to tag 
along with you at research meetings, and then you proceeded to 'show up' for me every time I needed you through the years, giving me countless hours of your time in phone calls, e mails, and texts. You've also encouraged me to have fun and you're a great dancer!

Many funders helped make my doctoral training and research possible. My highest gratitude goes to The American Cancer Society for awarding me with four years of funding for doctoral training in oncology social work. The University of Louisville's School of Interdisciplinary and Graduate Studies, the Kent School of Social Work, the School of Medicine's Interdisciplinary Program for Palliative Care and Chronic Illness, and the Commission on Diversity and Racial Equality supported me tremendously as well.

Finally, I must thank the countless other people and organizations who supported me. To my mom, Cathy Brinton, and my sister, Lara Brinton; thanks for all of your child care help. Thanks to my best friend, JoAnne Morris, for growing with me professionally through these many years, and for being my partner in all things related to psychosocial oncology. Thanks also for your support and understanding through all the craziness. Kudos to fellow graduates, Joe D'Ambrosio and Dennis Feaster, and thanks for being my cohort buddies. Last but not least, thanks to my Association of Oncology Social Work, and to all the leaders and friends there who inspired, supported, and taught me, especially Krista Nelson, Kerry Irish, and Leora Lowenthal.

I write this section last, but my gratitude started before I ever typed a single word of this dissertation... 


\section{ABSTRACT \\ EMOTIONAL DISTRESS IN OLDER ADULTS WITH CANCER: A MULTILEVEL LONGITUDINAL STUDY \\ Tara J. Schapmire \\ March $29^{\text {th }}, 2012$}

Data from the Health and Retirement Study (HRS) were used to examine factors that influence emotional distress in older adults with cancer, and to learn whether these distress trajectories are different from older adults without cancer. The model investigated the influence of life course factors, internal, external and health-related resources on distress over eight years among a nationally representative sample of older adults ages 50-91.

Methods: This longitudinal panel study tested a multilevel random intercept multinomial ordered categorical model with a two-nested-level structure using empirical Bayes Markov chain Monte Carlo (MCMC) estimation. The model examined individual differences in distress over eight years (2000-2008), testing multiple potential predictors which were either time-variant within-person or timeinvariant between-person data measured at five consecutive time periods. All those with a first diagnosis of cancer in 1998-2000 were included in study $(n=200)$ together with a representative subsample of all noncancer cases $(n=1190)$, for a total of 1390 . 
Results: In each step, the model fit improved significantly using the DIC statistic. Overall, 33 percent of sample reported one or more depression symptoms in 2000 , and by 2008 the number decreased to 30 percent. Keeping all main effects constant, those with cancer had one percent lower probability of depression symptoms over time than those without cancer. Significant two-way interaction effects were detected between having cancer and absence of spouse/partner in the home, and cancer and lower life expectancy; each resulted in higher probabilities of depression symptoms. A significant three-way interaction effect was detected between cancer, gender, and social support with women with a cancer history and low social support having the highest probability of depression symptoms.

Conclusions: Those with four or five depression symptoms at the beginning of the study tended to stay the same over time, while those with one to three symptoms tended to improve slightly. A small significant protective factor of cancer on distress over time was detected. A large protective factor of cancer existed for older adults with a partner present in the home, but cancer became a significant risk factor for distress with no partner presence. The protective factor remained for older adults with cancer and longer life expectancy, but cancer became a significant risk factor for distress with low life expectancy. While there was a large protective factor of cancer among women with high social support, cancer history became a risk factor for women with low social support. 


\section{TABLE OF CONTENTS}

PAGE

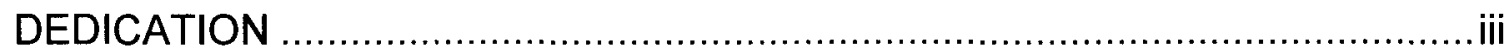

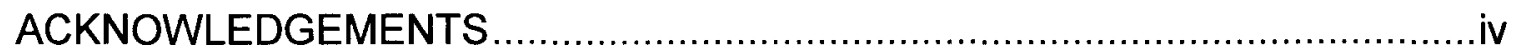

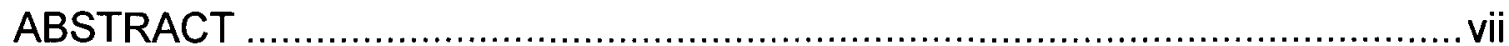

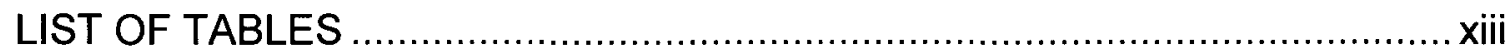

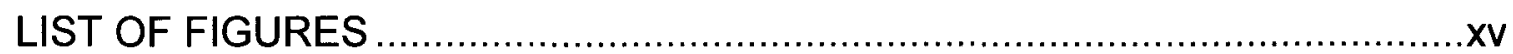

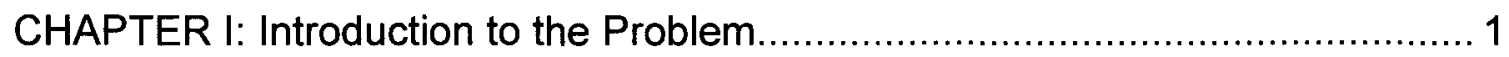

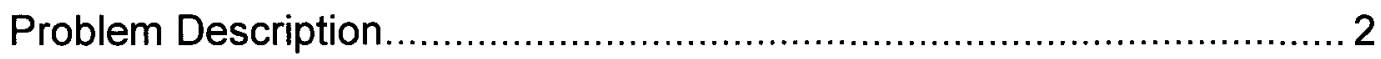

Cancer as a Chronic Illness ....................................................... 2

Psychosocial Adjustment to Cancer ........................................... 4

Psychosocial Adjustment to Cancer among Older Adults ................ 12

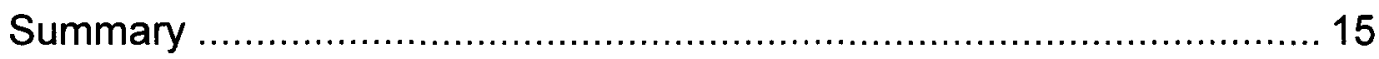

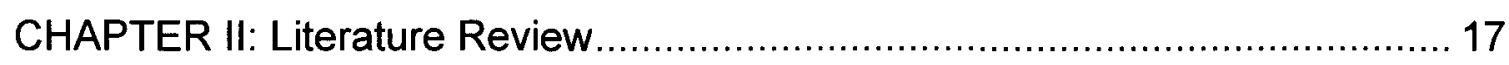

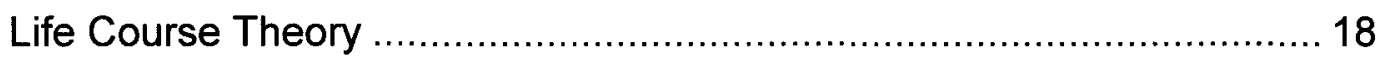

Interplay of Human Lives and Historical Time................................ 19

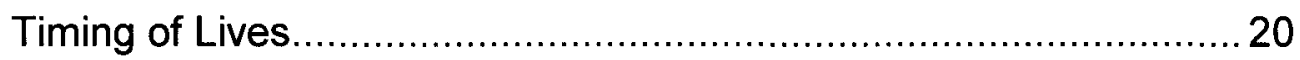

Linked or Interdependent Lives................................................... 21

Human Agency in Making Choices ................................................ 22

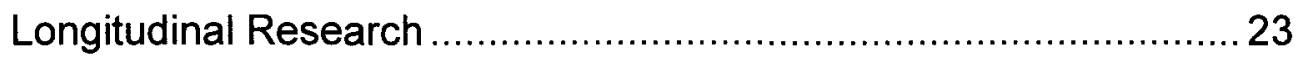

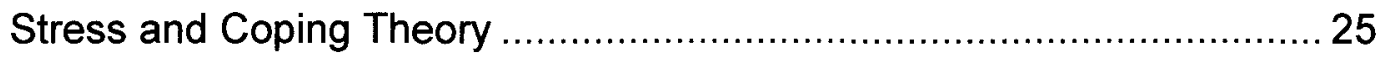


Stress

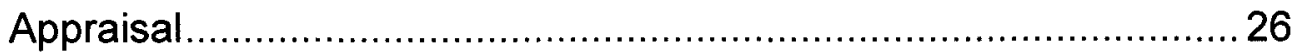

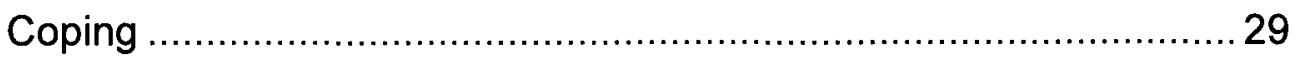

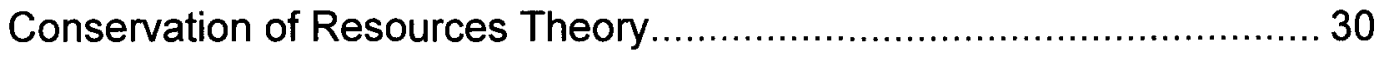

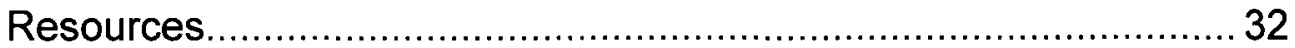

Resource Change and Emotional Distress .................................. 33

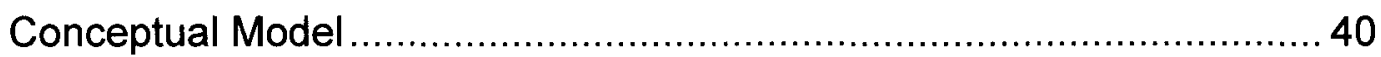

Main Predictor Variables............................................................ 41

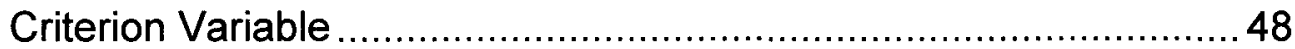

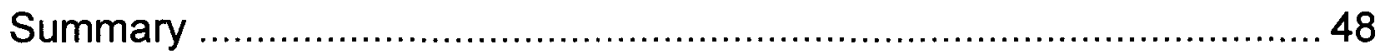

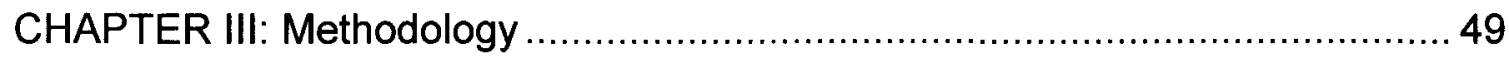

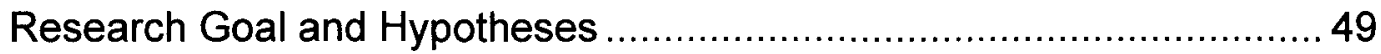

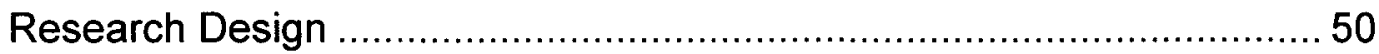

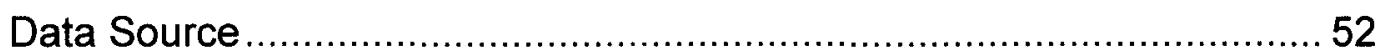

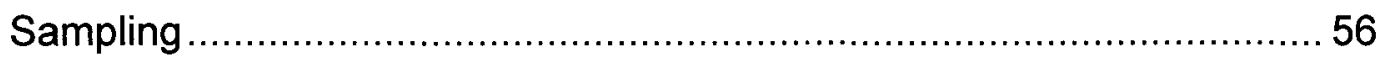

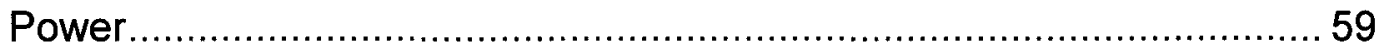

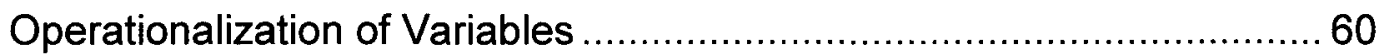

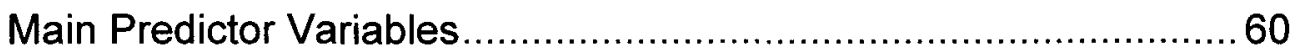

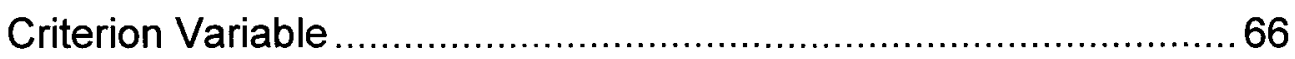

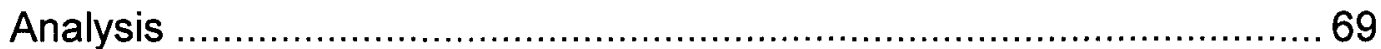


Summary

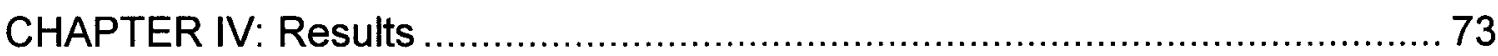

Data Preparation and Preliminary Analyses ........................................ 74

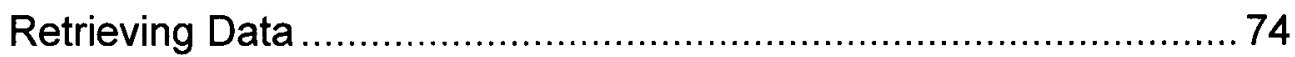

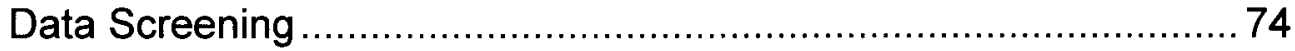

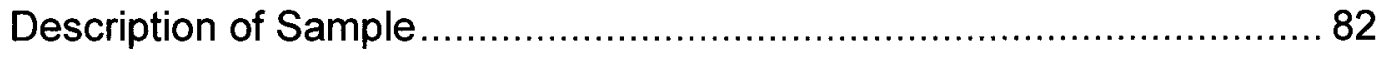

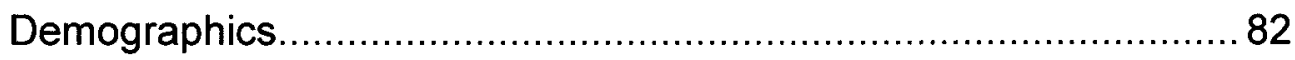

Life Course Factors ................................................................. 82

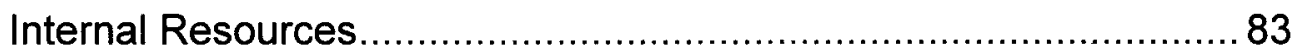

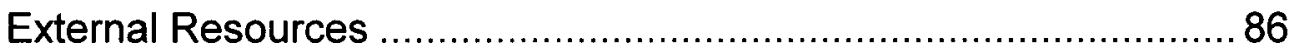

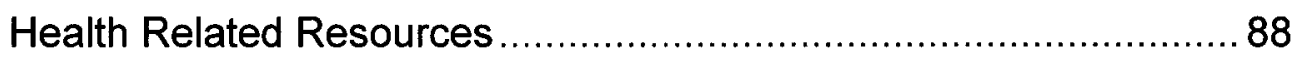

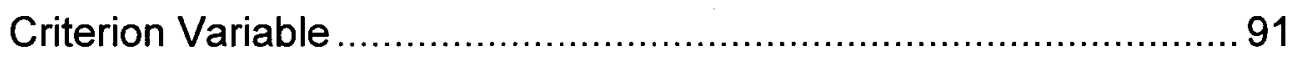

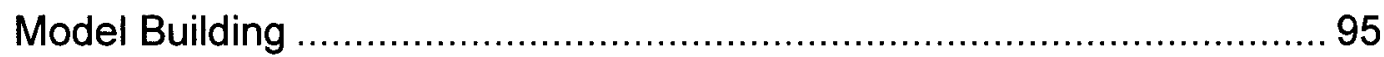

Assessing the Need for the Multilevel Model ................................ 95

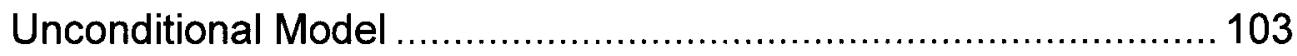

Unconditional Growth Model...................................................... 106

Conditional Growth Model........................................................ 108

Conditional Growth Model with Interaction Effects......................112

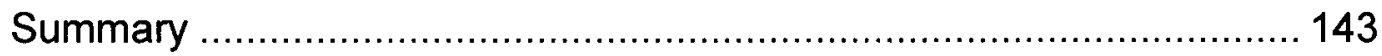

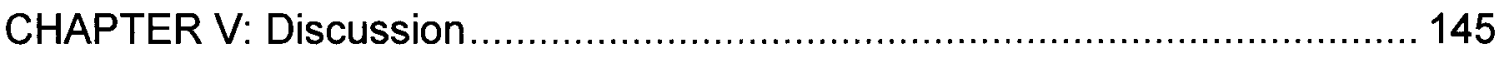


Implications for Health Social Work Practice and Education................ 150

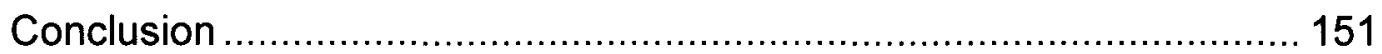

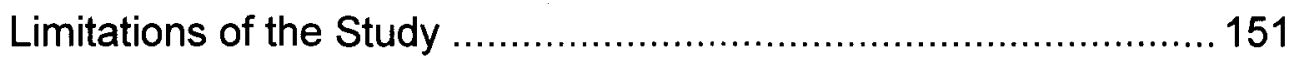

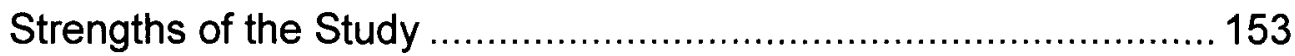

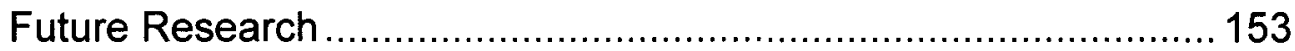

REFERENCES

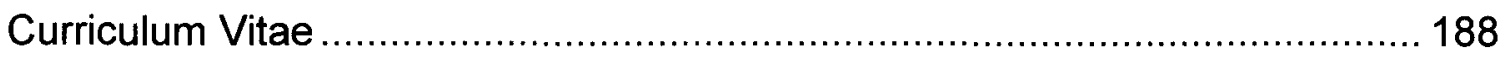




\section{LIST OF TABLES}

Table

Page

Table 1 Prevalence Studies of Psychological Distress (Including Symptoms of Depression) among Cancer Patients. 9

Table 2 Description of HRS Cohorts (Servais, 2009, p. 1) ................................ 54

Table 3 Attrition Rate of Cancer Sample ..................................................... 59

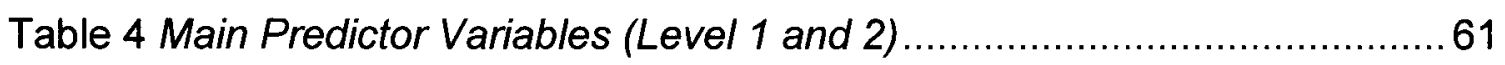

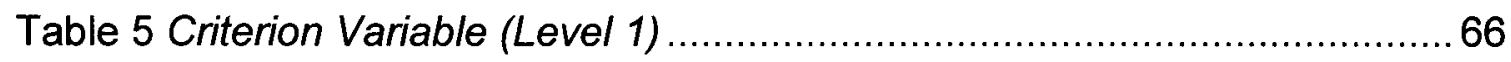

Table 6 Measurement Occasions Deleted per Case ID.................................. 75

Table 7 Study Participants per Wave with Complete Data on the DV ............... 76

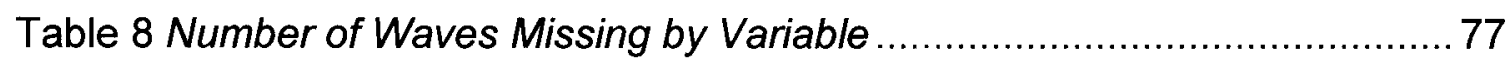

Table 9 Number of Missing Waves Replaced with Individual Mean ..................79

Table 10 Missing Values on Marital Status Replaced with Previous Wave Data 80

Table 11 Level 2 Demographics of Study Population $(N=1390)$...................... 82

Table 12 Level 2 Life Course Factors of Study Population $(N=1390)$................ 83

Table 13 Sample Characteristics for Ordinal and Interval Internal Resource

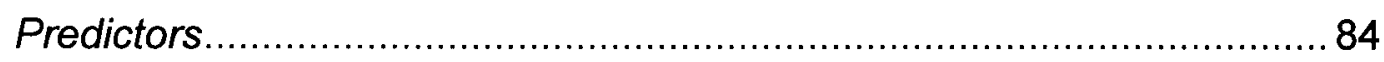

Table 14 Level 2 Internal Resource Factors of Study Population ...................... 85

Table 15 Level 2 External Resource Factors of Study Population ..................... 86

Table 16 Sample Characteristics for Ordinal and Interval External Resource

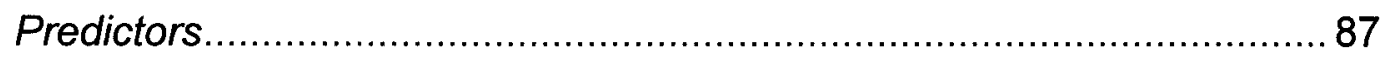


Table 17 Sample Characteristics for Categorical External Resource Predictors 88 Table 18 Sample Characteristics for Ordinal Health-Related Resource Predictors $(N=1390)$ 89

Table 19 Sample Characteristics for Categorical Health-Related Resource Predictors $(N=1390)$ 90

Table 20 Sample Characteristics of Criterion Variable: Distress 91

Table 21 Relationships between Criterion Variable and Continuous Predictors (Across All Measurement Occasions). 92

Table 22 Relationships Between Criterion Variable and Categorical Predictors (Across All Measurement Occasions).... .94

Table 23 Null Model 104

Table 24 Comparison of Null Model to Growth Model 107

Table 25 Comparison of Null Model, Growth Model and Growth Model with Main Effects. 109

Table 26 Comparison of All Models 114 


\section{LIST OF FIGURES}

$\begin{array}{ll}\text { Figure } & \text { Page }\end{array}$

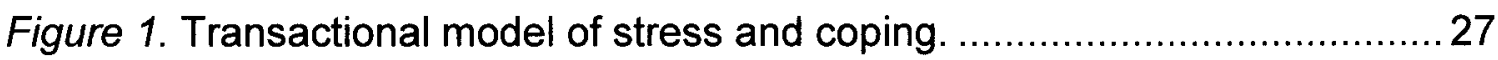

Figure 2. Conservation of Resource Theory ................................................ 38

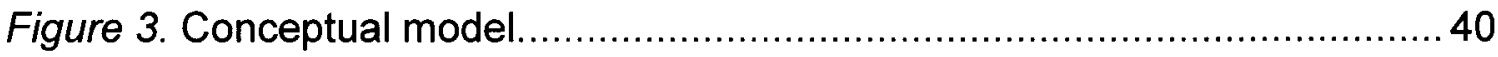

Figure 4. Multilevel structures and classifications....................................... 51

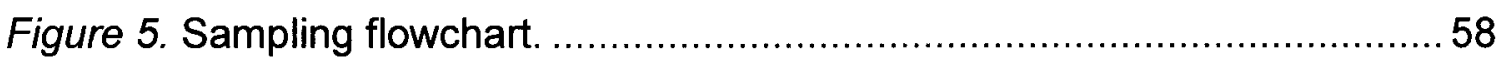

Figure 6. Psychometric properties of the CES-D in the HRS and AHEAD:........68

Figure 7. Empirical growth plots for a sample of the cancer cases................... 99

Figure 8. Empirical growth plots for a sample of the non-cancer cases........... 103

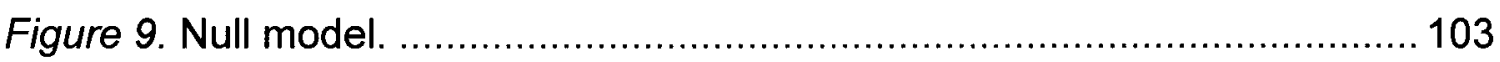

Figure 10. Unconditional growth model. ................................................ 107

Figure 11. Depression symptoms of whole sample over time...................... 108

Figure 12. Growth model with main effects................................................. 109

Figure 13. Depression symptoms of whole sample over time controlling for main

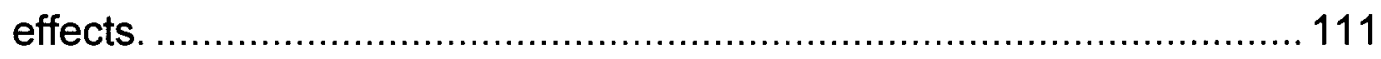

Figure 14. Growth model with main effects and interaction effects................ 112

Figure 15. Depression symptoms for whole sample over time controlling for all main and interaction effects in Model D ............................................ 117 
Figure 16. Unique predicted probabilities of symptoms of depression by gender.

Figure 17. Unique predicted probabilities of symptoms of depression by cancer history. 119

Figure 18. Unique predicted probabilities of symptoms of depression by history of depression. 121

Figure 19. Unique predicted probabilities of symptoms of depression by subjective physical health. 122

Figure 20. Unique predicted probabilities of symptoms of depression by subjective life expectancy. 124

Figure 21. Unique predicted probabilities of symptoms of depression by level of optimism. 125

Figure 22. Unique probabilities of symptoms of depression by level of pessimism.

Figure 23. Unique predicted probabilities of symptoms of depression by employment. 128

Figure 24. Unique predicted probabilities of symptoms of depression by social support 129

Figure 25. Unique predicted probabilities of symptoms of depression by marital status. 130

Figure 26. Unique predicted probabilities of symptoms of depression by psychological problems and support. 132 
Figure 27. Unique predicted probabilities of symptoms of depression by number of days in bed.. 133

Figure 28. Unique predicted probabilities of symptoms of depression by difficulty with ADLs and IADLs. 134

Figure 29. Cancer and partner presence interaction on unique probabilities of $k$ depression symptoms. 136

Figure 30. Cancer and partner presence interaction on predicted probabilities of one or more depression symptoms. 137

Figure 31. Cancer and life expectancy interaction on unique probabilities of $k$ depression symptoms.

Figure 32. Cancer and life expectancy interaction modeled as predicted probabilities of one or more symptoms of depression. 140

Figure 33. Cancer, gender, and social support interaction on unique probabilities of one or more depression symptoms. 142 


\title{
CHAPTER I: INTRODUCTION TO THE PROBLEM
}

\author{
I think the older cancer patient provides an opportunity for us to think of \\ all the issues that we face in cancer care, including quality of care, \\ access to care, survivorship concerns, and end of life. Patricia Ganz \\ (Institute of Medicine, 2007)
}

It has been estimated that more than eleven million people in the United States live with a past or current diagnosis of cancer, 41 percent of all Americans can expect to be diagnosed with cancer at some point in their life, and approximately two-thirds of those are over the age of 50 (Horner et al., 2009). Yet, cancer mortality rates continue to drop (Jemal et al., 2008). Given the enormity of these figures and the ever increasing number of those surviving the disease, the need to understand the associated long term psychosocial needsespecially for older adults-is more important than ever; of special significance is how those needs change over time.

This issue is highlighted when examining existing empirical evidence. Although a great deal of research has focused on the psychosocial effects of cancer, most studies examined these effects at one point in time and predominantly in the initial stages of the disease. Little is known about how cancer survivors' psychosocial adjustment changes over time and what factors 
contribute to the change trajectory; even less is known about older adult cancer survivors' psychosocial adjustment. This dissertation addresses this gap by generating a more complex model of change in emotional distress patterns of older adults with cancer by asking the following questions:

(1) Is there a significant relationship between older cancer survivors' life course factors, internal, external, and health-related resources, and emotional distress over time?

(2) How is this relationship different for those older adults with a cancer diagnosis vs. those without a cancer diagnosis?

Utilizing a nationally representative sample of older adults allows an increased understanding of the factors that predict emotional distress for those with cancer in addition to comparing those with and without cancer, thus clarifying whether or not cancer itself is a factor. This large, randomly selected sample also provides more generalizable results.

This introductory chapter reviews the evolution of cancer from an acute to a chronic illness and discusses the accompanying psychosocial adjustment issues. It introduces the main concepts for the study and reviews studies of emotional distress. Finally, it argues for the need for research on the unique adjustment issues that older adults face when confronted by cancer.

\section{Problem Description}

\section{Cancer as a Chronic Illness}

Although diagnosis of cancer still causes great emotional distress, there is much to hope for in terms of survival. The 5-year survival rate among adults for 
all cancers combined has grown from only 50 percent in the 1970 s to 66 percent as of today (National Cancer Institute [NCl], 2006). The NCl has reported that these increased survival rates are a result of combination chemotherapies which are now the standard in cancer treatment. In addition, vaccinations offer much hope in the prevention and treatment of several cancers. Targeted therapies increasingly represent the therapeutic arsenal, while refined radiation therapies combining maximum precision and intensity to targeted tumors with minimum damage to surrounding healthy tissues increases treatment effectiveness. Finally, the $\mathrm{NCl}$ (2006) has reported that treatment for side effects of cancer and its treatment, such as pain, nausea and vomiting, fatigue, and mouth sores is more effective than ever before.

With the improved screening and treatments now available and the subsequent reduction in mortality rates, cancer truly is beginning to be viewed as a chronic rather than a terminal illness (Jemal, et al., 2008). In fact, the Centers for Disease Control and Prevention (CDC) describe chronic diseases as "noncommunicable illnesses that are prolonged in duration, do not resolve spontaneously, and are rarely cured completely. Examples of chronic diseases include heart disease, cancer, stroke, diabetes, and arthritis" (2009, p. 2).

With cancer's shift from acute to chronic illness, the idea of survivorship has changed and evolved. When cancer was incurable, the term "survivors" referred to family members whose loved one had died from the disease; today a survivor is anyone living with and surviving cancer (Leigh, 2004). With this increase in the number of people living with cancer as a chronic disease-and 
even surviving it-more attention than ever is focused on the long term psychosocial adjustment and quality of life for cancer survivors. Socio-behavioral research has become a vital partner to biomedical research in attempts to learn more about the problems faced by those affected by cancer. In addition to medical problems, such as the permanent side effects of treatment, there are emotional and/or social challenges, like increasing costs of treatment, problems getting healthcare insurance, and discrimination by employers (American Cancer Society, 2010). Unfortunately, the accompanying impact on psychosocial adjustment and resulting overall health related quality of life of surviving this disease for many years is still not widely known (Zebrack, 2000; Zebrack, Ganz, Bernaards, Petersen, \& Abraham, 2006).

\section{Psychosocial Adjustment to Cancer}

In their review of the literature on adjustment to chronic illness, Stanton, Revenson, and Tennen (2007) found that three broad conclusions emerged: "(a) chronic disease requires adjustment across multiple life domains, (b) adjustment unfolds over time, and (c) there is marked heterogeneity across individuals in how they adjust to chronic illness" (p. 567). These conclusions are evident in examining the adjustment response to cancer.

In their review of the cancer-related psychosocial adjustment research over the last 30 years, Meyerowitz and Oh (2009) reported that the literature on resources that predict adjustment has made substantial theoretical and clinical contributions. Within the context of models based on stress and coping theories and emotional-cognitive processing, these personal or internal, social or external, 
and medical or health-related, situational resources have emerged as powerful and predominant predictors of psychosocial adjustment to cancer (Meyerowitz \& Oh, 2009).

Those affected by cancer are forced into a trajectory filled with uninvited opportunities for worry, stress, and loss. Demands on internal resources, such as one's ability to adjust and cope, begin even before diagnosis (i.e. anxiety brought on by screening), and continue through diagnosis and treatment related decision making. The lack of external resources which predate the diagnosis, such as inadequate or nonexistent health insurance, low income, and poor social supports, or the loss of them as a result of cancer heightens the inability to adjust and cope. The cancer trajectory forces patients and their families to cope with physically demanding treatments which threaten them with multiple losses including physical disabilities, health deficits, and relationship and job changes. Learning to cope with severe symptoms of the disease and treatment is also challenging. Whether the trajectory leads to end of life or long term survivorship, each brings new psychosocial demands. Unfortunately, the ubiquitous physical, psychological, and social demands and stressors are often entangled as they tax the internal and external resources of patients and families, both resulting from and contributing to each other.

Psychosocial adjustment to cancer is often determined by the presence or absence of both positive and negative responses (Andrykowski, Lykins, \& Floyd, 2008). Positive responses include benefit finding (Bower et al., 2005; Carter, 1993; Loescher, Clark, Atwood, Leigh, \& Lamb, 1990; Zebrack, et al., 2006), post 
traumatic growth (Stanton, Bower, \& Low, 2006) and wellbeing (Cella, 1992, 1994, 1998; Ferrell, Grant, \& Hassey Dow, 2004; Zebrack, 2000). Common negative psychosocial adjustment responses to those demands anywhere along the cancer trajectory range from the general: i.e. distress, negative affect and depressed mood (Meyerowitz \& Oh, 2009), to the specific: i.e. major depression (Breitbart, 2010) and anxiety (Bottomley, 1998; Epping-Jordan et al., 1999) meeting the criteria of the Diagnostic and Statistical Manual of Mental Disorders (American Psychiatric Association, 2000). These negative psychosocial responses are the focus here.

Emotional distress refers primarily to symptoms of anxiety, depression, and adjustment disorders related to the cancer experience (Carlson \& Bultz, 2003). Distress, as defined by the National Comprehensive Cancer Network (NCCN) (2009), is a "multifactorial unpleasant emotional experience of a psychological (cognitive, behavioral, emotional), social, and/or spiritual nature that may interfere with the ability to cope effectively with cancer, its physical symptoms and its treatment" (p. 2). This broad definition encompasses distress ranging from common individual feelings and concerns associated with the cancer trajectory to complex symptoms and problems having the potential to hinder patients' abilities to participate in their plan of care. The term 'distress' was chosen by NCCN to avoid the stigma and embarrassment associated with descriptive terms such as psychiatric, depressed, anxious or emotional (Holland, 1997) since these words could become barriers to addressing patients' concerns. 
For the purposes of this study, the literature exploring both depression and/or emotional distress (if depression symptoms were included in the screening measures used) is discussed. The two terms-'distress' and 'depression'-are often used interchangeably when discussing symptoms of depression, feelings of sadness, and difficulty in adjustment (e.g., Alfano \& Rowland, 2009; Massie, 2004; Rabkin, McElhiney, Moran, Acree, \& Folkman, 2009). In fact, in one review assessing recent research on the detection of depression in palliative care the authors pointed out the following: "The ability to detect cases of depressive disorder may be less important than the ability to detect depressive symptoms remediable to treatment. This is reflected in the recent interest in conceptualising and detecting psychological distress" (Rayner, Loge, Wasteson, Higginson, \& European Palliative Care Research Collaborative, 2009, p. 55). For these reasons, the focus in this study is on symptoms of depression as opposed to major depression.

In his keynote address at the Fifth Annual Chicago Supportive Oncology Conference, William S. Breitbart, MD, Professor and Chief of Psychiatry Services at Memorial-Sloan Cancer Center, reported depression has been found to be four times as prevalent in cancer patients as in the general population; most well conducted studies have found the prevalence of major depression to range from 10-25 percent and 40-50 percent in advanced disease (Breitbart, 2010). In another widely cited review of more than 100 studies of cancer patients, Massie found prevalence rates of depression symptomatology from 0-58 percent. Although she found that prevalence estimates varied due to lack of 
standardization in terms of population studied, disease site and stage, sample size, assessment instruments, cutoff score, type of interview, and diagnostic criteria employed (including major depression versus adjustment disorder with depressed mood versus depressive symptoms), she concluded that "cancer, exclusive of site or stage of illness, is associated with a high degree of depression" (2004, p. 69).

More recent studies of depression symptoms under the umbrella of 'distress', mirror Massie's (2004) review results. The significance of symptoms of depression and anxiety in cancer patients of all ages has led some to propose assessment for such symptoms as the sixth vital sign, suggesting that assessment of distress should be as important as evaluating pain levels and as routine as checking blood pressure, temperature, heart rate and respiration (Bultz \& Carlson, 2006; Bultz \& Holland, 2006; Holland \& Bultz, 2007; Thomas \& Bultz, 2008). Strong evidence of the scope of the problem highlights validity of this recommendation (see Table 1). 
Table 1 Prevalence Studies of Psychological Distress (Including Symptoms of Depression) among Cancer Patients

\begin{tabular}{|c|c|c|c|c|}
\hline Study & Disease & Measures & $\mathbf{N}$ & Rates of Poor Adjustment \\
\hline $\begin{array}{l}\text { Derogatis, et } \\
\text { al., } 1983\end{array}$ & $\begin{array}{l}\text { Mixed } \\
\text { Cancers }\end{array}$ & $\begin{array}{l}\text { SCL-90-R \& } \\
\text { psychiatric } \\
\text { interview }\end{array}$ & 215 & $\begin{array}{l}47 \% \text { DSM-III dx; of those } 68 \% \text { were } \\
\text { adjustment disorders with } \\
\text { depressed mood }\end{array}$ \\
\hline $\begin{array}{l}\text { Farber, et al., } \\
1984\end{array}$ & $\begin{array}{l}\text { Mixed } \\
\text { Cancers }\end{array}$ & SCL-90 & 141 & $\begin{array}{l}34.4 \% \text { distress } \\
39.9 \% \text { depression }\end{array}$ \\
\hline $\begin{array}{l}\text { Stefanek et al, } \\
1987\end{array}$ & $\begin{array}{l}\text { Mixed } \\
\text { Cancers }\end{array}$ & $\mathrm{BSI}$ & 126 & $\begin{array}{l}27.7 \% \Psi \text { distress } \\
32.5 \% \text { depression }\end{array}$ \\
\hline $\begin{array}{l}\text { Zabora, et al, } \\
2001\end{array}$ & $\begin{array}{l}\text { Mixed } \\
\text { Cancers }\end{array}$ & $\mathrm{BSI}$ & 4,496 & $\begin{array}{l}35.1 \% \Psi \text { distress } \\
\% \text { depression (NR) }\end{array}$ \\
\hline $\begin{array}{l}\text { Fallowfield, et } \\
\text { al, } 2001\end{array}$ & $\begin{array}{l}\text { Mixed } \\
\text { Cancers }\end{array}$ & GHQ12 & 2,297 & $\begin{array}{l}36.4 \% \Psi \text { morbidity } \\
\% \text { depression (NR) }\end{array}$ \\
\hline $\begin{array}{l}\text { Carlson, et al., } \\
2004\end{array}$ & $\begin{array}{l}\text { Mixed } \\
\text { Cancers }\end{array}$ & BSI-18 & 2,776 & $\begin{array}{l}37.8 \% \Psi \text { distress } \\
36.3 \% \text { depression }\end{array}$ \\
\hline $\begin{array}{l}\text { Hegel, et al., } \\
2006\end{array}$ & $\begin{array}{l}\text { Breast } \\
\text { Cancer }\end{array}$ & $\begin{array}{l}\text { DT } \\
\text { PHQ-9 }\end{array}$ & 236 & $\begin{array}{l}41 \% \text { general distress using DT } \\
61 \% \text { reported sadness \& } 50 \% \\
\text { reported depression; } 11 \% \text { major } \\
\text { depression DSM-IV dx using PHQ-9 }\end{array}$ \\
\hline $\begin{array}{l}\text { Dabrowski et } \\
\text { al, } 2007\end{array}$ & $\begin{array}{l}\text { Breast } \\
\text { Cancer }\end{array}$ & DT & 286 & $\begin{array}{l}34 \% \text { general distress; of those } 75 \% \\
\text { reported } \Psi \text { concerns as source of } \\
\text { distress on follow up phone call }\end{array}$ \\
\hline $\begin{array}{l}\text { Sellick \& } \\
\text { Edwardson, } \\
2007\end{array}$ & $\begin{array}{l}\text { Mixed } \\
\text { Cancers }\end{array}$ & HADS & 3,035 & $\begin{array}{l}25.7 \% \text { anxiety } \& / \text { or depression } \\
\% \text { depression (NR) }\end{array}$ \\
\hline $\begin{array}{l}\text { Graves, et al., } \\
2007\end{array}$ & $\begin{array}{l}\text { Lung } \\
\text { Cancer }\end{array}$ & DT & 333 & $\begin{array}{l}61.6 \% \text { general distress (problems } \\
\text { with depression most significant } \\
\text { predictor, } \beta=.232 \text { ) }\end{array}$ \\
\hline $\begin{array}{l}\text { Keir, et al., } \\
2008\end{array}$ & $\begin{array}{l}\text { Brain } \\
\text { Cancer }\end{array}$ & DT & 75 & $\begin{array}{l}52 \% \text { general distress; DT scores } \\
\text { were significantly \& positively } \\
\text { correlated with patient-reported } \\
\text { emotional sources of distress }\end{array}$ \\
\hline \multicolumn{5}{|c|}{$\begin{array}{l}\text { SCL-90-R: Symptom Checklist } 90-R \text { ( } 90 \text { items) } \\
\text { BSI: Brief Symptom Inventory (53 items) } \\
\text { BSI-18: Brief Symptom Inventory (18 items) } \\
\text { GHQ12: General Health Questionnaire (12 items) } \\
\text { DT: Distress Thermometer (1 item) } \\
\text { PHQ-9: The Nine Symptom Depression Scale } \\
\text { HADS: Hospital Anxiety and Depression Scale (14 items) } \\
\text { DSM III (\&) IV dx: Diagnostic \& Statistical Manual (versions } 3 \text { \& 4) diagnosis } \\
\Psi \text { : psychological } \\
\text { NR: not reported }\end{array}$} \\
\hline
\end{tabular}

As evidenced in Table 1, much of the research on emotional distress started by examining samples of participants with mixed types of cancer while 
recent research has looked at adjustment in more homogenous samples, such as by type of cancer or stage of illness. One of the largest and most widely cited studies, performed at Johns Hopkins in Baltimore (Zabora, Brintzenhofeszoc, Curbow, Hooker, \& Piantadosi, 2001) found 35 percent of the 4,496 patients studied were emotionally distressed (true prevalence rates of depression were not reported), and there was a significant difference by cancer site. This study found the greatest distress in lung cancer patients ( 43.4 percent), followed by brain (43 percent), Hodgkin's disease (38 percent), pancreas (37 percent), lymphoma (36 percent), liver (35.4 percent), head and neck (35.1 percent), unknown primary (35 percent), breast (32.8 percent), leukemia (32.7 percent), melanoma (32.7 percent), colon (31.6 percent), prostate (30.5 percent), and finally gynecological cancers (29.6 percent), suggesting that those with cancers of poorer prognoses are at increased risk for distress.

Findings from other large studies were consistent with Zabora et al. In Canada, Carlson et al. (2004) found that 38 percent of 2,776 patients studied in an ambulatory cancer center met criteria for general distress and 36 percent had depression; the researchers examined distress levels by disease type, compared them to Zabora et al.'s (2001) study and reported statistically significant correlations between the two sample's distress levels by disease type.

Likewise, researchers in the UK found that 34 percent of almost 2,300 cancer patients across 34 cancer centers were significantly distressed (Fallowfield, Ratcliffe, Jenkins, \& Saul, 2001); rates of depression were not measured separately from distress. Categorizing cancers slightly differently, this 
group found greatest prevalence of distress levels in those with central nervous system (CNS) malignancies (51 percent), gynecological (51 percent), gastrointestinal (51 percent), urological (51 percent), hematological (51 percent), unknown primaries (48.5 percent), lung (44.2 percent), other (40.6 percent), head and neck (39.8 percent), muscular-skeletal (36.8 percent), breast (36 percent), benign ( 32 percent), and lastly skin cancers ( 27.2 percent). Sellick and Edwardson (2007) more recently reported on a Canadian sample $(n=3,035)$ in which 26 percent met criteria for distress (Table 1). While overall prevalence rates of depression were not reported these researchers detected highest prevalence of anxiety and/or depression in those with lung (40.8 percent) followed by other ( 26.7 percent) breast ( 26.4 percent), colorectal ( 23.2 percent), and finally prostate cancer ( 14.3 percent).

The results of these larger studies were consistent with smaller previous studies on psychological distress among cancer patients (Derogatis et al., 1983; Farber, Weinerman, \& Kuypers, 1984; Stefanek, Derogatis, \& Shaw, 1987) (see Table 1). Finally, similar rates of distress have been found in smaller, more recent studies specific to cancer site (Dabrowski et al., 2007; Hegel et al., 2006; Keir, Calhoun-Eagan, Swartz, Saleh, \& Friedman, 2008) (see Table 1) with highest prevalence rates among samples of brain cancer patients (Keir, et al., 2008) and lung cancer patients (Graves et al., 2007) (see Table 1 for prevalence rates of distress and any reported results on depression). As these results differ slightly, it has been posited that the differences may indicate that disease stage, rather than diagnosis, may be the more significant predictor of distress (Carlson 
\& Bultz, 2003; Zabora, et al., 2001). For example, this assertion may support the higher rates of distress in lung cancer patients who are usually diagnosed in late stages (e.g., Graves, et al., 2007).

Failure to recognize and treat the range of negative psychosocial adjustment issues leads to multiple individual and health care system problems, including impaired cognition, weakened motivation and less effective coping (IOM, 2008), increased hospital emergency department and physician office visits (Carlson et al., 2004), decreased decision making capacity (Smith, Gomm, \& Dickens, 2003), less treatment adherence (DiMatteo, 2004; Kennard et al., 2004), decreased satisfaction with healthcare providers (Von Essen, Larsson, Oberg, \& Sjoden, 2002) and increased time and stress demands on healthcare providers (National Comprehensive Cancer Network [NCCN], 2009; Zabora, 1998). These studies provide compelling evidence for further study of emotional distress and how and why it changes over the course of long-term survival.

\section{Psychosocial Adjustment to Cancer among Older Adults}

Age is a primary risk factor for most cancers, with about 77 percent of all cancers diagnosed among people aged 55 or older (U.S. Department of Health and Human Services: Centers for Disease Control and Prevention, 2004). In an $\mathrm{NCl}$ press release on projects funded in aging and cancer, $\mathrm{NCl}$ Director Andrew C. von Eschenbach, M.D. stated the following:

Cancer is a disease of aging and is increasing in magnitude as people live longer. Ending the suffering and death due to cancer by 2015 requires us to understand the behavior of cancer, responses to therapy, 
and the after-effects that are unique to the older patient $(\mathrm{NCl}, 2003$, para.

3).

Given these facts, an important contribution to the knowledge base regarding psychosocial adjustment to cancer should focus on older adults. For these individuals who make up the majority of those affected by cancer, the demand on internal and external resources is even greater given their higher likelihood of presenting with a preexisting chronic disease and increased functional impairment and disability (Hewitt, Rowland, \& Yancik, 2003). Additionally, increased age has been associated with lower use of all forms of coping among long term cancer survivors (Deimling, Bowman, Sterns, Wagner, \& Kahana, 2006), and older adults are at greater risk than younger adults for difficulties with health-related decision making (Finucane et al., 2002).

With regard to normal developmental skills mastery, cancer and its associated stressors and demands on resources can interrupt or delay the activities typically engaged in during older adulthood; for example, older adults might face "unplanned retirement, limitations in grand-parenting abilities, inability to act as caregivers to others in the family, or limitations in their ability to work" (IOM, 2008, p. 32). Given the possibility of increased stressors and demand on resources, older adults affected by cancer may have greater negative adjustment and resulting need for psychosocial support.

The exploration of depression symptoms is particularly poignant in this group as general depressive conditions are very common; they are leading causes of functional disability and potent risk factors for mortality from general 
medical conditions as well as suicide in elderly persons (Charney et al., 2003; Conwell, Duberstein, \& Caine, 2002; Lebowitz et al., 1997; Lyness, 2004). In fact, later life depression has been called a "major public health problem" (Lyness, 2004, p. 1626).

Further support for the study of symptoms of depression as an appropriate measure of emotional distress in older adults can be found in the aging literature which indicates that depression is one of the most frequent causes of emotional distress in older adults and is one of five top concerns faced by the elderly (D. G. Blazer, 2003; Morley, 2004). The few existing studies of older adults with cancer further highlight the significance of depression in this group.

In a recent secondary analysis of cross sectional data, Nelson and colleagues (2009) examined general distress, anxiety and depression in 716 men with prostate cancer aged $50-93$ years (mean age, $68 \pm 10$ years). They found that aging was associated with greater depressive symptoms. The mean depression scores consistently trended upward with age and remained significant after controlling for stage of disease, hormone therapy use, time since diagnosis, and social, physical, and functional well-being.

In the Canadian study $(n=3,035)$ discussed earlier, Sellick and Edwardson (2007) found that older patients (those aged 70 years and older) reported significantly more symptoms of depression, and were more distressed overall, than those who were middle aged (between 40 and 69 years) or younger (less than 40). This was the case even though the older patients had significantly less anxiety than the other two groups. 


\section{Summary}

In summary, the evolution of cancer from an acute to a chronic illness has resulted in an increased need to understand long term psychosocial adjustment issues among those affected by cancer. With prevalence rates of such negative adjustment responses as distress, anxiety, and depression ranging from 26-62 percent in primarily cross-sectional examination, it is imperative to explore how and why psychosocial adjustment to cancer might change over time. As older adults make up the majority of those affected by this disease, understanding their unique psychosocial adjustment needs is vitally important. Given the fact that depression is such a prominent issue for older adults, it would also be informative to compare older adults with and without cancer to further understand and address their psychosocial needs.

Understanding the whole person response to cancer and related treatments has been called for by the Institute of Medicine (2008). Knowledge of predictors of emotional distress in cancer over the disease trajectory would assist oncology social workers in developing better assessment options and interventions to meet patient needs. In oncology settings, social workers are often called upon when patients experience resource and environmental limitations; they intervene to facilitate the strengthening of internal and external resources for those affected by cancer.

Understanding the influences of internal and external resources on levels of adjustment over time would help target critical points of intervention at the individual and social level, as well as improve research-based knowledge related 
to the impact of healthcare disparities on individuals and populations. This is particularly timely given the national interest in health care reform.

Chapter II provides a review of the literature related to emotional distress in response to cancer and the various influential risk and protective factors, which are categorized as life course factors, internal, external, and health related resources. Additionally, relevant theoretical perspectives are reviewed with introduction of a proposed conceptual model which integrates those theories and attempts to address a gap in the literature. 


\title{
CHAPTER II: LITERATURE REVIEW
}

\author{
If stress is in the mind, we change people's thoughts. If stress is in the \\ environment, we alter people's world, not their beliefs about the world. \\ If stress is psychodynamic, we dig deeper and intervene earlier. If \\ stress is endemic to life, we may choose to leave it be \\ and move on to more manageable pastures (Hobfoll, 1998, p. 4).
}

This chapter explores the foundational theoretical literature which informs an understanding of the psychosocial responses to cancer. The first is life course theory (Elder \& Shanahan, 2006; Elder Jr., 2002, November; Giele \& Elder Jr., 1998, 1998a), a developmental theory which looks at how chronological age, relationships, common life transitions, and social change shape people's lives from birth to death. The second is stress and coping theory (Lazarus \& Folkman, 1984), a contextual theory which emphasizes internal, subjective appraisals of resources to cope with cancer and reduce distress. The third is conservation of resources theory (COR) (Hobfoll, 1989, 1998, 2001; Hobfoll, Freedy, Lane, \& Geller, 1990; Hobfoll \& Schumm, 2002, 2009), an integrated causal model that focuses on both internal and external resources-highlighting objective over subjective resources-and how changes in these levels of 
resources can help or hinder psychosocial adjustment to cancer. Finally, a proposed conceptual model is presented that incorporates critical aspects of the theories reviewed and that forms the basis for the proposed research. The variables are then discussed as well as the literature that supports their inclusion.

\section{Life Course Theory}

Life course theory combines psychological developmental theories and sociology and proposes that in order to understand peoples' patterns of aging as well as their reactions to major life events (e.g. a cancer diagnosis), it is important to investigate the lived experiences of people in contexts (Elder Jr., 2002, November). An important distinction exists between life course theory and developmental psychology models. In their recent book on life course research, founders Glen Elder Jr. and Janet Giele (2000) referenced the work of Baltes (Hetherington \& Baltes, 1988) as an example in explaining that developmental models, including some in the life span field, typically focus on individual development in a "typical life course": the typical pathway from early childhood into adolescence and adulthood. From this perspective, Elder and Giele note that life course variation is not recognized as a potential source of behavioral change. "Such variation is of primary interest to the life course specialist, along with variation by cohorts and historical context" (Blossfeld, 2009, p. 6).

According to life course theory, events are combined in event histories or trajectories that are compared across persons or groups, focusing on differences in timing, duration and rates of change. Research questions derived from this theory seek to understand both individual characteristics and system properties 
and how both individual and system dynamics have an effect on how people experience life over time (Giele \& Elder Jr., 1998). The theory asks for research completed within a longitudinal framework where it is possible to follow the impact of earlier events and feelings on later ones as well as the interaction of these events within a given social milieu (O' Rand, 1998).

Certain specific themes and principles for investigating people are set within this theoretical perspective; they provide much of the framework for the proposed research. They are presented here with discussion of how they may be useful in understanding adjustment to cancer among older adults: interplay of human lives and historical time; timing of lives; linked or interdependent lives; and human agency in making choices.

\section{Interplay of Human Lives and Historical Time}

Development and aging are seen as lifelong processes which are dependent on historical time and place, thus the concept of a trajectory-a long term pattern of stability and change, involving multiple transitions (role and status changes) becomes useful (George, 2009; Hutchison, 2008). Peoples' lives can encompass many different and interlocking trajectories such as family, work, health, and psychosocial adjustment trajectories. With the study of individual and family life trajectories, researchers noted that persons born in different years face different historical worlds filled with different options and limitations, thus the birth year cohort concept is illuminated (Blossfeld, 2009; Hutchison, 2008; Riley, Johnson, \& Foner, 1972; Ryder, 1965). For example, given the advances in cancer treatment and resulting increases in survival in the last 20 years, the 
experience of cancer in older adulthood will be very different for a "baby boomer" (the cohort of individuals born in the post-World War II baby boom) than for someone born in the depression era (late 20's and 30's). While "cohort effects" (Blossfeld, 2009) have been found in sociology and labor market analysis (Glenn, 1977), less is known in the psychosocial and geriatric oncology realms. In their recent examination of cancer and aging from a gerontological perspective, Blank and Bellizzi wrote:

Everyone dealing with cancer now is experiencing a diagnosis and disease that is literally different from what their parents and grandparents experienced. Also, period of time is intertwined with cohort, such that persons brought up earlier when cancer was seen as a death sentence and not talked about openly may not respond to the changed environment in the same way as younger cohorts. Although it is not clear how cohort may affect the cancer experience, cohort effects are inextricably linked to 'age,' that is, chronologic age (2008, p. 2752).

\section{Timing of Lives}

Elder's principle of timing is based on the research of Neugarten (1996) who developed normative and subjective meanings of age in the 1950s. Timing of lives refers to life course researchers' interest in the age at which specific events occur (Blossfeld, 2009; Hutchison, 2008). Hutchison (2008) notes that age graded differences in roles and behaviors are not only a result of chronological age; life course research seeks to understand biological age, 
psychological age, social age (placing most emphasis here), and should even consider spiritual age.

The early or late timing of events and roles affects their impact (Elder Jr., 2002, November). Social norms or shared expectations about the timing of events and role transitions will dictate the classification of such events and role transitions as either "off-time" (unexpected) or "on-time" (expected) (Hutchison, 2008). For older adults, cancer may be much more of an expected, "on time" event than for younger adults who are not expecting the event of cancer to happen to them while they are dealing with more competition among life courserelated roles, such as work, caring for pre-adult children, and caring for elderly parents (Blank \& Bellizzi, 2008). In contrast, competition among the many roles associated with younger adulthood may make it more difficult for them to adjust to cancer because of its "off-time" arrival into their lives.

\section{Linked or Interdependent Lives}

Lives are closely interconnected with and influenced by relationships with other people (Elder Jr., 2002, November). Individual life course trajectories are influenced and altered by those around them. Relationships with others and with the world can both control and support an individual's behavior and adjustment, and social support is an obvious element of interdependent lives (Hutchison, 2008). It has been well established that patterns of mutual support are formed by life events and transitions across the life course (Hareven, 1996). The competition among roles faced by a spouse or caregiver of an older adult with cancer might change the impact of the cancer on that survivor, especially if the 
spouse or caregiver is a primary social supporter. This theme lines up well with the contextual focus of social work and its person in environment approach, and speaks to the importance of strong social support networks needed to support the psychosocial adjustment of long term cancer survivors.

\section{Human Agency in Making Choices}

People are seen as actors who make choices that set the context and direction of their lives (Elder Jr., 2002, November). Elder (1998) highlighted Bandura's (1986) research on self-efficacy (sense of personal competence) and efficacy expectation (expectation that one can personally accomplish a goal) in informing his emphasis on human agency. It is, however, important to recognize the delicate balance that exists between personal and social factors. Even Bandura pointed out that social inequality can result in low self efficacy and efficacy expectations among oppressed individuals (1986). For example, while an optimist may make different treatment choices than a pessimist, an older adult on a limited income and only the minimum Medicare coverage will make different choices about medication purchases than one with full coverage and more income (regardless of how optimistic he or she may have been upon receiving a cancer diagnosis). Cancer survivors make treatment decisions based on these same factors and such additional factors as transportation and social support.

In addition to presenting Elder's four themes of the life course perspective, Hutchison also highlights how those very themes (history, timing, linked lives, and human agency) illuminate the diversity in life course trajectories. The variance in the cancer trajectories of individuals from different cohorts, with 
differences in timing of arrival of cancer, differing role competitions, differences in social supports and different choices has been discussed and this is an important assumption of the study. Finally, Hutchison discussed the importance of developmental risk and protection, i.e. how earlier events shape later adjustment (2008). Elder also underscores this concept in more recent work by explaining how the "developmental impact of a succession of life transitions or events is contingent on when they occur in a person's life" (Elder, 1998, p. 3). For example, a prior history of cancer will influence the adjustment to a second cancer, regardless of timing ("on-" or "off-time") of the second cancer. Older adults with more experiences with prior negative events, may experience the impact of cancer differently (Blank \& Bellizzi, 2008). Research has shown that older prostate cancer survivors have reported that their cancer was "no big deal" because of either previous experiences or current comorbidities (Blank, Bellizzi, Murphy, \& Ryan, 2003).

\section{Longitudinal Research}

Life course scholars use longitudinal research to answer their questions. It is therefore important to examine the existing longitudinal psychosocial adjustment research in oncology. While a great deal of research has focused on the psychosocial effects of cancer, most studies examined these effects at one point in time and primarily in the initial stages of the disease.

Longitudinal studies on factors influencing adjustment among older adult cancer survivors are rare. Helgeson, Snyder, and Seltman (2004) found distinct trajectories of adjustment to illness in women aged 27 to $75(M=48)$ with breast 
cancer; additionally, personal and social resources that women bring with them to the cancer experience-self-image, sense of control, and support-affect the course of their long-term psychological and physical adjustment to breast cancer; age was only a marginally significant predictor of distress in that older women tended to have less distress than younger women. Deimling, Bowman, Sterns, Wagner, and Kahana (2006) found that about one-third of the older adult longterm survivors they studied worried about recurrence, about a second cancer, and that the symptoms they experience may be from cancer. Polsky et al. (2005) utilized data from the Health and Retirement Study (HRS) and examined prevalence rates of depression among various types of chronic illness in a longitudinal sample of more than 8,000 adults aged 51 to 61 without significant depressive symptoms at study onset. The diseases examined were cancer, stroke, diabetes, arthritis, hypertension, chronic lung disease, and heart disease. A diagnosis of cancer was associated with the greatest risk with 13 percent of those affected by cancer reporting significant depressive symptoms. Within two years after an initial diagnosis of cancer, diagnosed individuals had the highest risk of significant depressive symptoms (HR, 3.55; 95 percent $\mathrm{Cl}, 2.79-4.52)$, which decreased during the next six years (Polsky, et al., 2005).

What is still not clear is how older adult cancer survivors' psychosocial adjustment changes over time, and what factors contribute to the change trajectory. Ziegelmann and Lippke (2009) highlighted the need for such change research in their recent discussion of emerging themes and contemporary research on stress and coping theories. Finally, Alfano and Rowland (2009) 
highlighted the importance of this kind of research among older adults when they concluded that survivorship studies have tended to exclude large samples of older adults, stating that "this is a particularly troubling gap in researchers' knowledge base, given that approximately half of today's survivors are ages 75 or older" (p.414).

\section{Stress and Coping Theory}

Stress and coping theory, developed by Richard S. Lazarus and Susan Folkman (1984), has been widely used by the social sciences for more than 25 years (Folkman \& Moskowitz, 2004; Stanton, et al., 2007). When Lazarus and his colleagues first published their theory of psychological stress in 1966, main stream psychology was still stuck in the throes of behaviorism (Dember, 1974; Lazarus, 1966). Cognitive theory, which says the meaning of an event/stimulus is what shapes that individual's emotional and behavioral responses, was just being conceptualized by theorists such as Albert Ellis (1957) and Aaron Beck (1979). Lazarus and Folkman combined these theories in developing stress and coping theory. They examined personal and environmental resources, and situational factors as antecedents of psychosocial outcomes.

\section{Stress}

Building on the earlier works on "fight or flight" responses to stress of Cannon (1932), and the General Adaptation Syndrome research by Selye (1956), Lazarus and Folkman took a behavioral, transactional approach to stress, positing that it is the observed stimulus-response relationship, not one or the 
other, that defines stress. Using that relational framework, they blended behavioral theory with cognitive theory and defined psychological stress as a relationship between the person and the environment that is appraised by the person as taxing or exceeding his or her resources and endangering his or her well-being (Lazarus \& Folkman, 1984). Stress resides in neither the person nor the event, but is a reflection of the person's unique response to that event (Lazarus, 1990, 1990, 1993; Lazarus \& Folkman, 1984). In other words, the experience of distress results when demands-as appraised by the individualexceed resources (Helgeson, et al., 2004).

\section{Appraisal}

In general, stress and coping theory highlighted the importance of cognitive appraisal, which is seen in the context of a stressful situation as a mediating variable which contributes significantly to the outcome and accounts for individual variation in adjustment to stress. Stressful events, according to Lazarus and Folkman (1984), are those that are appraised by the individual as threatening or harmful (primary appraisal) and are perceived as placing considerable demand on the individual's resources, to the point that the individual explores his ability to cope with, or control, the event (secondary appraisal). In the context of the cancer experience, appraisal refers to evaluative processes that intervene between the encounter-cancer and its associated demands or stressors - and the reaction-emotional distress (see Figure 1). Through cognitive appraisal processes the person evaluates the significance of what is happening for his or her well-being. Primary appraisals include 
perceptions of susceptibility and severity, motivational relevance and causal

focus (Glanz \& Schwartz, 2008). Vulnerability is an important part of a person's response to stress. Lazarus and Folkman (1984) continued with their relational approach in defining psychological vulnerability as a deficiency in resources that matter to the individual.

Mediating Processes

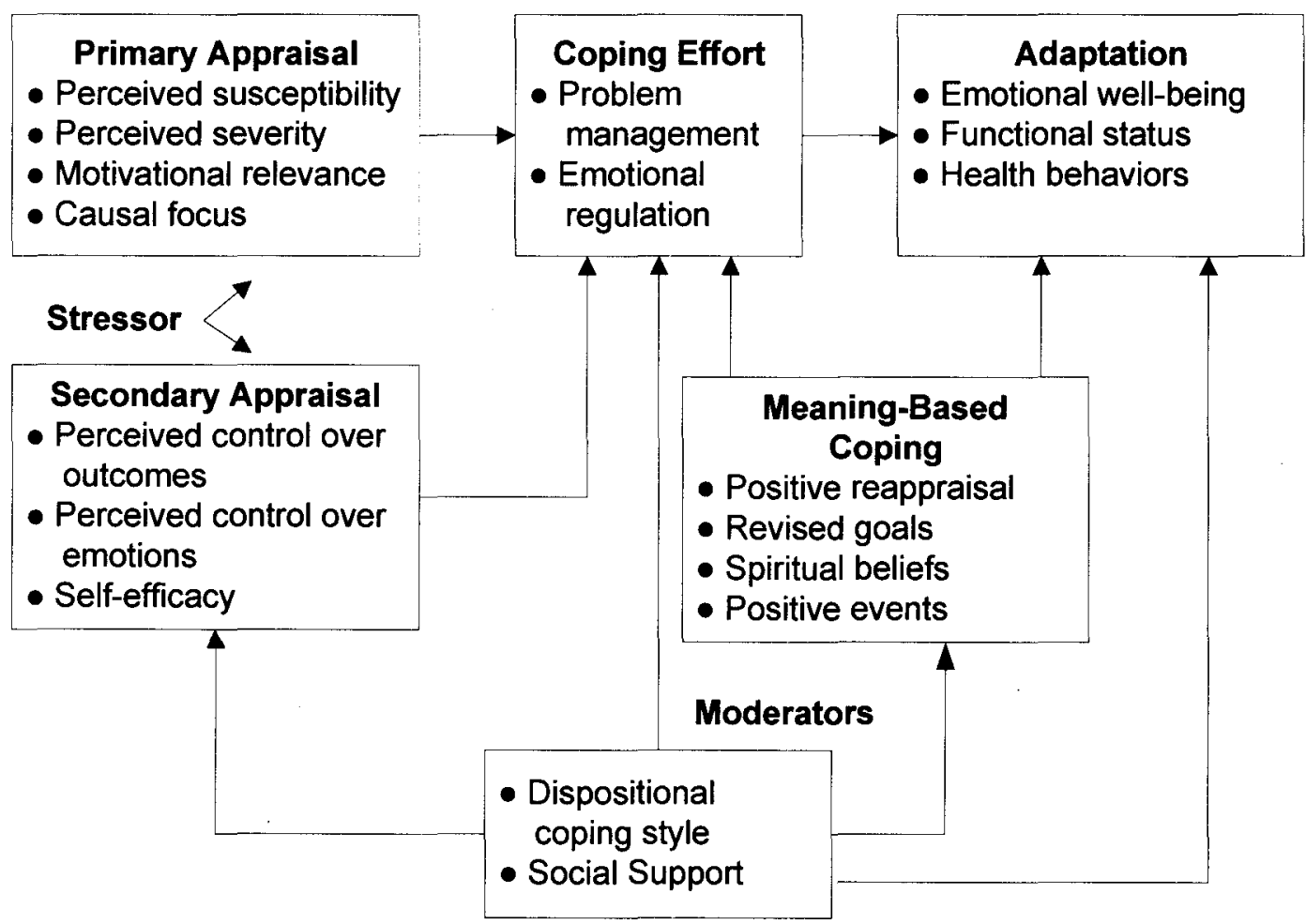

Figure 1. Transactional model of stress and coping.

Adapted from "Stress, Coping, and Health Behavior," by K. Glanz, and M. D. Schwartz, 2008, in Health Behavior and Health Education: Theory, Research, and Practice (4th ed.), by K. Glanz, B. K. Rimer and K. V. Viswanath (Eds.), p. 216. Copyright 2008 by Jossey-Bass.

Research with women experiencing heightened perceptions of susceptibility to cancer due to a family history of ovarian cancer revealed that they were more likely to experience psychological distress (Schwartz, Lerman, Miller, Daly, \& Masny, 1995). Escape-avoidance behaviors (Lazarus \& Folkman, 
1984) can arise from appraisals of high severity and susceptibility (Glanz \& Schwartz, 2008), thus reducing adherence to health promoting practices, such as breast cancer screenings (Lerman et al., 1993).

Secondary Appraisals include perceptions of control over outcomes and emotions, and self-efficacy (see Figure 1). Cancer can be devastating, biologically, physically, and psycho-socially, and it can cause great spiritual distress, yet those affected by it will report being challenged to maintain a positive outlook, or tolerate pain and distress without falling apart. Thus, the broadened definition of control in stress and coping theory was control over oneself and one's emotions, as well as control over environmental conditions. This aides in the understanding of how-even under the bleakest circumstances-people can be challenged.

Cancer patients are often not only severely incapacitated at diagnosis, but they often have to face a multitude of additional threats to future functioning, thus appraising each stressor as a threat, a challenge, or both. Cancer patients often appraise a cancer diagnosis as a challenge, even when there is little value or benefit in the outcome. They can also view cancer differently at different points over the course of their illness. It is the interplay of primary and secondary appraisals which shape "the degree of stress and the strength and quality (or content) of the emotional reaction" (Lazarus \& Folkman, 1984, p. 35). Empirical support for the positive relationship between perceptions of control over illness and psychological adjustment has been observed across many diseases (Glanz 
\& Schwartz, 2008), including cancer (Fife et al., 2000; Norton et al., 2005;

Stiegelis et al., 2003).

\section{Coping}

Coping strategies-which are used to mediate primary and secondary appraisals-were initially divided by theorists into two foci: the stressor itself (problem-focused coping) and on reducing the emotional impact of the stressor (palliative-focused coping) (Lazarus \& Folkman, 1984). Figure 1 highlights the further division—-through continued study—of coping into dispositional coping styles (i.e. cognitive or behavioral avoidance, distraction and denial or selfefficacy, information seeking, seeking social support, planful problem-solving and active coping), coping efforts such as problem management and emotional regulation, and meaning based coping (Glanz \& Schwartz, 2008).

Empirical evidence supports coping as an influential factor in adjustment to illness (Stanton, et al., 2007). How much a cancer patient engages or disengages with the stressor has been found to affect distress (Carver et al., 1993). Additionally, high levels of avoidance oriented coping and low social support has been identified as a risk factor for distress in cancer patients (Jacobsen et al., 2002). Meaning based coping strategies, including positive reinterpretation, acceptance, spirituality and use of religion, have been found to reduce distress (Carver, et al., 1993).

As it is believed that those affected by cancer can be taught new and alternative coping strategies, it is important for social workers to be aware of the various coping types. As Lazarus and Folkman (1984) highlighted well before 
any of the resulting research, however coping is defined or conceptualized, the prime importance of appraisal and coping processes is that they affect adaptational outcomes (see Figure 1).

It is clear that Lazarus and Folkman were groundbreakers in that they started with a behavioral theory, added cognitive and phenomenological theory and set the course of their careers for measuring stress, appraisal and copingusing their contextual approach—and teaching practitioners how to improve adaptational outcomes for those affected by stressful circumstances. This theory's utility in the psychosocial oncology world has been widely discussed in the literature for years.

\section{Conservation of Resources Theory}

In response to the need to incorporate both the objective and perceived environment into the process of coping with stress, Stevan Hobfoll $(1988,1989$, 1998) developed the conservation of resources theory (COR). Distinguishing COR from the earlier work of Lazarus and Folkman (1984) which was transactional, and emphasized individual perceptions, Hobfoll (2002) has emphasized the importance of the relative equal measure of environmental variables and person-centered variables in the coping process. COR and other resource-based theories (Antonovsky, 1979; Baltes, 1997; Bandura, 1997; Holahan \& Moos, 1987, 1991) suggest that the fit of personal, social, economic, and environmental resources with external demands determines the direction of the stress response and resulting outcomes; because of this-according to 
Hobfoll (2001) - they directly challenge what he calls appraisal-based stress theories.

At its core, COR is sociocultural, which distinguishes it from other resource-adaptation models, describing it as an integration of the "individualnested in family-nested in tribe, set in social context" (p. 338) indicating that predictive capacity becomes limited when pieces of this unit are separated without reference to the greater whole (Hobfoll, 2001). This is a basic assumption of COR theory: the individual self is derived from primary attachments within biological families and intimate social groups. Shared appraisal, then, is emphasized over individual idiographic appraisal (Hobfoll \& Schumm, 2009).

Taking the position that coping is a communal process (Lyons, Mickelson, Sullivan, \& Coyne, 1998), Hobfoll posits that stress-as experienced by the individual self-and the behavioral alternatives available to it, including thought, "are reflections of cultural processes and delineated by cultural scripts and formulations. Moreover, the encounter of the self with stress is primarily situated in social context or involving social consequences" (p. 338). Finally, because adopting the anthropological concept of tribe aides in understanding human behavior in groups, the term tribe refers to complex social aggregations of people into groups beyond the level of family which include formal and informal groups of friends, colleagues, organizations, and communities (Hobfoll, 2001).

Hobfoll (2002) explains that this view is a natural next step into integrated causal models given the strength and consistency of findings on several key 
individual resources such as self-efficacy (Bandura, 1997), optimism (Scheier \& Carver, 1992), and social support (Barrera, 1986; Sarason, Sarason, Shearin, \& Pierce, 1986).

\section{Resources}

The basic tenet of COR theory is that individuals seek to obtain, retain, protect and foster those things (i.e. resources) that they value (Hobfoll, 1989). Others have supported this tenet, positing that it expands stress and coping theory with respect to conservation of resources as the primary human motive in the struggle with stressful encounters (Freund \& Riediger, 2001; Schwarzer, 2001; Thompson \& Cooper, 2001).

This theory aides in the conceptualization of resources-which have been defined very broadly by Hobfoll (2002) as personal characteristics, objects, energies, or conditions; they are centrally valued themselves (e.g., close attachments, health, self-esteem, inner peace), or they act as means to acquire centrally valued ends (e.g., social support, money, and credit). Personal characteristics act as resources to aid in stress resistance. A second grouping of resources is personally held skills such as mastery and optimism. Objects are valued as resources due to aspects of their physical nature or because of status acquired due to their rarity or expense. Energies (such as money, time, and knowledge) hold intrinsic value in that they aid in the acquisition of other resources. Conditions (such as tenure, marriage, or health) are valued and sought after (Hobfoll \& Schumm, 2002). 
Lining up with many major theoretical perspectives that focus on-and broadly define-psychosocial resources (Baltes, 1987, 1997; Diener, Diener, \& Diener, 1995; Hobfoll, 1988; Holahan, Moos, Holahan, \& Cronkite, 1999; Kaplan, 1996), COR (2002) emphasizes the sociocultural component and delineates the constructs further to those resources that are held for a wide range of people who share a set of cultural traditions. In addition to the broad definition, it highlights the interrelatedness of resources, explaining that changes in one or more types of resources can affect the availability of other resources. Finally, Hobfoll (1998) suggested that the distinction of resources into internal and external categories can serve as a building block to more complex study of resources.

\section{Resource Change and Emotional Distress}

COR provides an important exception to the general tendency of researchers to overlook change in psychosocial resources (Holahan, et al., 1999). Applying COR theory to the cancer experience, it posits that those affected by cancer seek to obtain, retain, and protect resources and that stress occurs when resources, such as life, independence, etc. are threatened with loss or lost or when individuals are unsuccessful in gaining resources after substantive resource investment.

Investment refers to the ways individuals cope with or resist the negative effects of stress; they include resource replacement; the loss of physical function after treatment for cancer may be met with attempts-through physical therapy for example-to re-establish that physical function. Resource substitution is 
another option, where a lost resource is substituted by one from a different resource domain. For example, a cancer survivor facing multiple physical losses may seek out support groups and build new interpersonal relationships, or choose other resource substitutions like increasing alcohol consumption; as a result, adjustment can be positive or negative.

Thus, the acquisition and facilitation of resources is a central motivational construct. This process receives increased awareness and energy when resource loss occurs or when resources are threatened as when an individual is diagnosed with cancer. Resource loss, then, is central to the stress experience. Resource gain, in turn, becomes more prominent in the face of-and buffers against—resource loss. Furthermore, because resources are seen as the vital elements of an individual's stress resistance repository, loss of resources tends to lead to resource loss cycles that have increasing strength and speed (Hobfoll, 2002).

These loss spirals are of key importance. COR theory proposes that those who are already lacking in resources will have greater vulnerability to loss spirals, and those who start with ample resources will have more opportunity for resource gain. It follows that a person who starts the cancer experience poor, underinsured, with little social support, and no sense of personal control or self efficacy is as much greater risk for resource loss spirals after cancer than a person who comes to the cancer experience with good health insurance, high socioeconomic status, good social support and a strong sense of optimism. COR posits that initial loss, such as those just described leaves individuals, 
groups, and communities at increased vulnerability to the negative impact of ongoing resource challenges (Hobfoll, 2001).

Taylor (1991) posited that negative life experiences have an asymmetrically strong effect compared to positive experiences on various physiological, cognitive, emotional, and social outcomes. Additionally, Thoits (1991) theorized that negative psychological outcomes only result from lossrelated experiences, and that positive life experiences are only stressful to the extent they contain negative consequences. As Holahan, Moos, Holahan, and Cronkite, (1999) noted, "despite the central role of resources in contemporary theories of the stress and coping process, researchers know little about the nature, consequences or determinants of resource change" (p. 620). Evidence has supported the primacy of resource loss offered by COR and other theorists who have suggested similar ideas.

In examining how gains become important in response to loss circumstances, Wells, Hobfoll, and Lavin $(1999 ; 1997)$ found that resource loss, but not gain, was directly related to changes in anger and depressive mood among a group of pregnant women who were balancing multiple career and family roles. They found that women who experienced resource gains were significantly less negatively impacted by loss than those who had not experienced gains accompanying their losses, even though resource gain itself had no direct impact. Those who experienced losses, but not gains, were considerably more likely to experience psychological distress during this high 
demand period of work-life-family balance (Wells, et al., 1997; Wells, Hobfoll, \& Lavin, 1999).

Research on illness and stress supports COR theory as well. In a recent study of cardiac patients, (Luyster, Hughes, Waechter, \& Josephson, 2006), researchers supported COR theory when they found higher levels of perceived resource loss were associated with higher levels of both depression and anxiety after controlling for all other predictors. Another recent study examining the effects of resource loss on depression in women with cancer further supported COR when they found that interpersonal resource loss (i.e. relationship with partner and loyalty of friends) predicted depressive mood (Banou, Hobfoll, \& Trochelman, 2009).

Longitudinal studies examining resource change effects on psychosocial adjustment are harder to come by. One such study by Hobfoll and colleagues (Hobfoll, Johnson, Ennis, \& Jackson, 2003) examined how economic stress, measured in terms of material loss, alters women's personal and social resources and how these changed resources impact anger and depressive mood among inner city women. Greater loss of personal and social resources was associated with increased depressive mood and anger. Resource loss had more negative impact than resource gain had positive impact, suggesting the greater saliency of loss than gain. Another group of researchers (Holahan, et al., 1999; Holahan, Moos, Holahan, \& Cronkite, 2000) found over nine to ten years that losses in internal and external resources were directly predictive of increases in 
depressive symptoms whereas gains were associated with decreases in depressive symptoms.

To aid the summary of these processes most relevant to stress and adaptational outcomes on the individual level, the pathways depicted in the current discussion are schematized by Hobfoll (2001) in Figure 2. The processes of resource conservation are a product of both overall life conditions and chronic and acute resource loss circumstances, as can be seen in Figure 2 (Hobfoll, 2001). Conditions of resource lack tend to generate or enable resource loss processes. When losses occur individuals apply resource conservation strategies, whereby they utilize resources available to them in order to adapt successfully, thus generating new resources which, in turn, replenish people's resource pools and offset the conditions that produce acute and chronic resource losses. When adaptation is unsuccessful, however, both negative functional and emotional outcomes result leading to the diminishment of the resources invested. Additionally, unsuccessful adaptation generates secondary resource losses which result in exacerbation of the chronic or acute loss circumstances and weakens the resource pool (Hobfoll, 2001). 


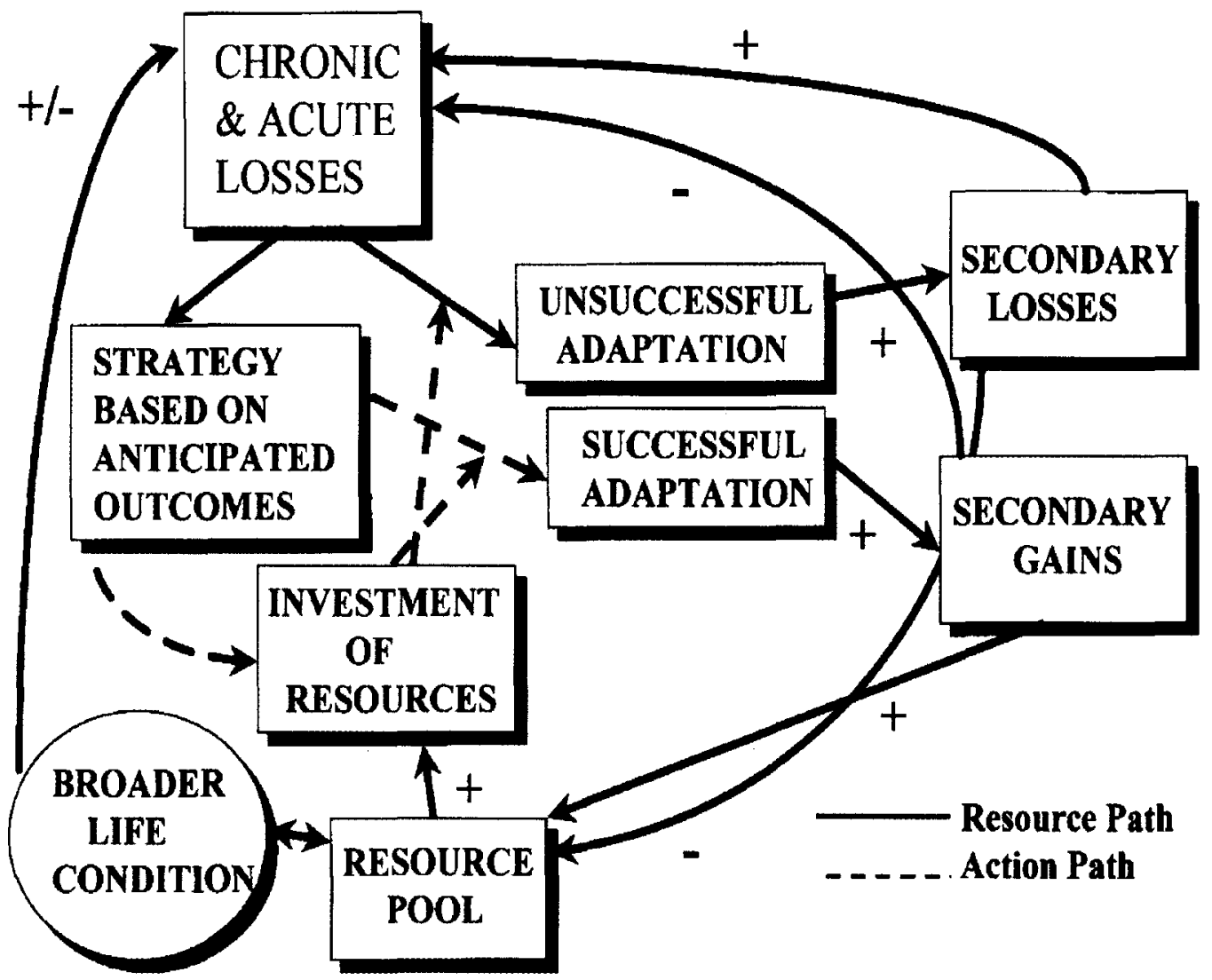

Figure 2. Conservation of Resource Theory.

Adapted from "The Influence of Culture, Community, and the Nested-Self in the Stress Process: Advancing Conservation of Resources theory," by S. E. Hobfoll, 2001, Applied Psychology: An International Review, 50, p. 358. Copyright 2001 by Blackwell Publishers.

Poverty, low social status, racism, unavailability of healthcare, and other fundamental condition resources are often beyond the scope of many health promotion interventions. COR theory highlights that, minimally, these fundamental resources conditions should remain foremost on our minds, both because they are primary in the potential success of any program and because failing to refer to them opens the risk of blaming the victim. No health promotion program can sidestep the 
resource reservoir that is ultimately available to people and pathways that are often denied those who lack resources or the status that allows them to use resources that they already possess (Hobfoll \& Schumm, 2002, p. 289).

COR can assist oncology social workers in efforts in targeting loss spirals and attempts at preventing future loss in individuals and communities, and it provides a model to instill resources necessary to the individual and community for promoting successful adaptation in the face of cancer.

In summary, life course theory explains how chronological age, relationships, common life transitions, and social change shape people's many life course trajectories. COR expands stress and coping theory and incorporates aspects of the earlier work, however, with different emphasis (Schwarzer, 2001). The difference lies mainly in the status of objective and subjective resources. Stress and coping theory sees objective resources only as antecedents that may have an indirect effect, whereas subjective resources (i.e. resource appraisals) represent the direct precursors of the stress process. Thus, simultaneous appraisal of demands and resources constitutes the beginning of a stress episode. COR theory, in considering both objective and subjective resources as components, lends more weight to the former. Thus, the difference between the two theories, in this respect, is a matter of degree, not a matter of principle, according to Schwarzer (2001). 


\section{Conceptual Model}

While it is clear that there is no single predominant factor (Zabora, 1998), the literature reveals certain risk and protective factors that influence the prevalence of emotional distress with cancer. These factors can roughly be grouped as demographics, life course factors, internal (personal) resources, external (social) resources, and health related resources such as physical health. The conceptual model for this study incorporates the principles of life course theory, stress and coping theory, and COR theory: (Figure 3). It focuses on the direct linkage between life course factors, internal and external resources, healthrelated resources and emotional distress while highlighting their interrelatedness: losses or gains in any of one of the predictor variables can lead to losses or gains in others, ultimately leading to changes in emotional distress levels.
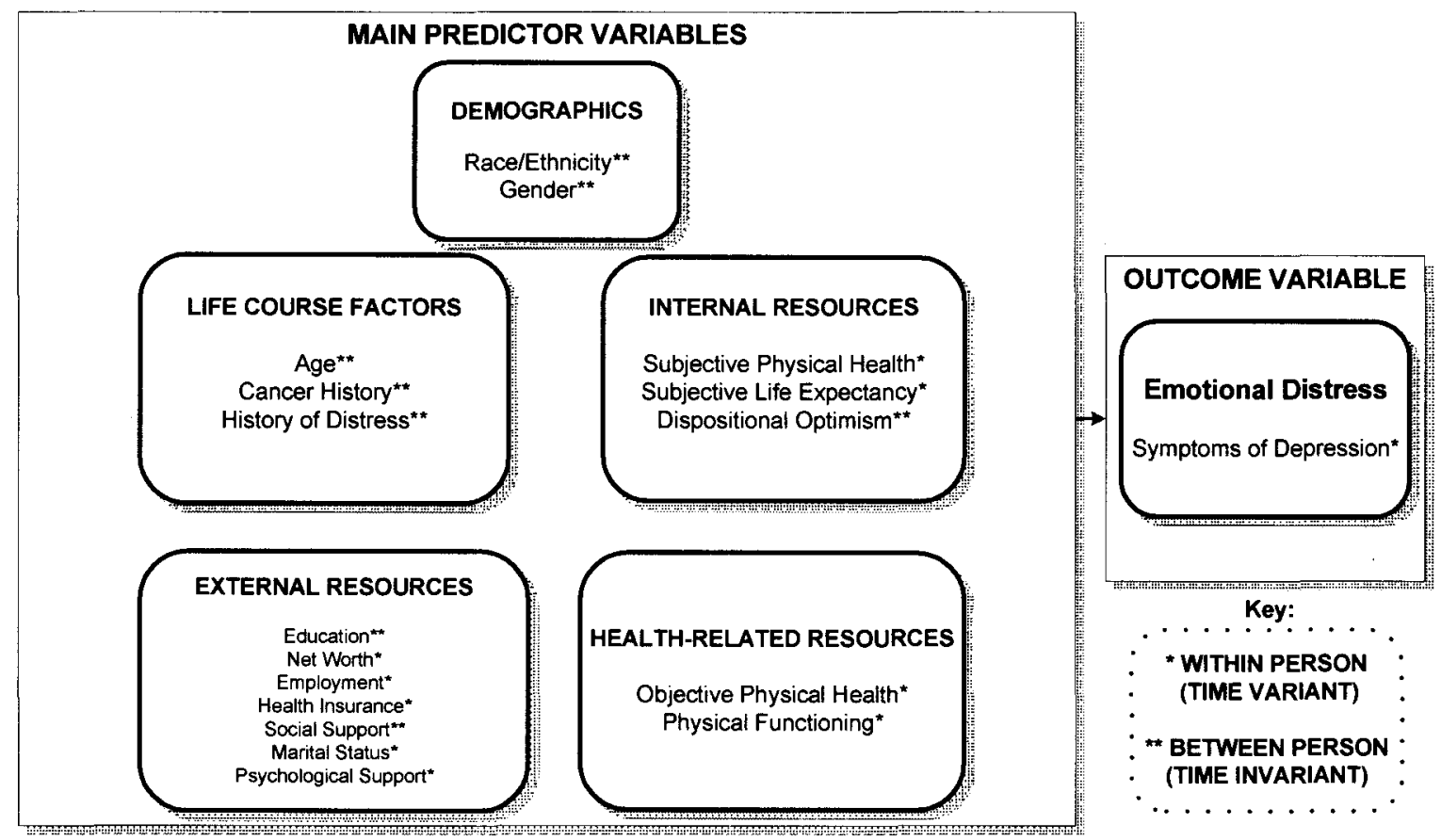

Figure 3. Conceptual model. 


\section{Main Predictor Variables}

Demographics. Race/Ethnicity has been considered an important area for research in adjustment to illness as it is believed that race and ethnicity can be markers related to risk factors and resources (Stanton, et al., 2007). Given the findings of within and between group differences in cross sectional studies, Stanton et al.-in their review of psychosocial predictors of adjustment to illness-offered the following "... it is clear that very little is known about implications of culture and ethnicity for disease related adjustment" (2007, p. 571). The same is true regarding whether and how different cultural and ethnic groups differ in their expression of distress in cancer specifically (Morrow et al., 2009).

Gender differences in emotional distress among cancer patients have mirrored those in the general population (Stanton, et al., 2007), with women experiencing more symptoms of distress (Sellick \& Edwardson, 2007; Skarstein, Aass, Fossa, Skovlund, \& Dahl, 2000; Zebrack et al., 2007).

Life course factors. Important life course factors include age and cohort membership, cancer history, and pre-cancer emotional distress.

Age has been inversely related to psychological distress in healthy individuals (D. Blazer, 1989). But in those with cancer, the literature has been contradictory (Helgeson, et al., 2004; Schnoll \& Harlow, 2001). In a recent review of the research, Meyerowitz and Oh (2009) reported older age is associated with less distress, but they highlighted the findings of Helgeson et al (2004) in offering that younger age is associated with better physical functioning 
and more rapid recovery. In comparing older groups to younger groups, older adults may be less distressed because they are more likely to expect declines in their health (Helgeson, et al., 2004). Sellick and Edwardson (2007) found that older cancer patients reported few symptoms of anxiety but more symptoms of depression. Increased age has been associated with lower use of all forms of coping among long term cancer survivors (Deimling, et al., 2006). Among older adults with cancer, age remains an important factor to consider.

Cancer history is another important life course factor, accounting for developmental risk and protection. First, having more experience with negative life events (i.e. a prior cancer) may minimize the impact of cancer and may even serve as a resource for older individuals (Blank \& Bellizzi, 2008). Second, in addition to prior experience with cancer, emotional distress varies by time since diagnosis with higher distress prevalence among those more recently diagnosed (Alfano \& Rowland, 2009; Institute of Medicine [IOM], 2008; Norton et al., 2004; Ronson \& Body, 2002). With time, the acuteness of the stressors along the cancer trajectory may lessen or new stressors may occur, resulting in changes in emotional distress.

According to Hobfoll, time is a major factor in adaptation as, major stress sequences, or trajectories_-such as illness and old age-_seldom change a person's or group's status to a more ennobled state" $(1998$, p. 113); rather, they involve stigmatized roles and changes in the degree to which limitations are placed on their resources, or forgiveness is no longer extended from their environmental demands. This leads to alterations in the need to match 
resources and psychological adaptations to demands (Hobfoll, 1998). This is especially important to consider in the context of long term survival as less is known about emotional distress beyond the first few years (Helgeson, et al., 2004; Polsky, et al., 2005). Hobfoll further points out that research often lumps people together who are at many different stages of the stress time line, or looked only at the imminent stress phase, resulting in a blurry time line (Hobfoll, 1998), thus it is included in the model.

History of distress may be an important factor in adjustment to illness. There is increasing evidence that psychosocial adaptation to a cancer diagnosis is significantly influenced by pre-existing psychosocial factors that patients bring to their cancer experience (Redd et al., 2001; Zabora, et al., 2001). A past history of distress has been established in the literature as a clear predictor of distress after cancer (Alfano \& Rowland, 2009; Harrison \& Maguire, 1994; Ronson \& Body, 2002). It is important to account for initial differences in this outcome variable (Stanton, et al., 2007).

Internal resources. A large body of theoretically-based literature has considered personal resources as predictors of adjustment (Meyerowitz \& Oh, 2009). Resources at the individual, proximal or internal level which influence adjustment include subjective physical health, subjective life expectancy, and optimism.

Subjective physical health, or self-rated health, is an important personal resource (Hobfoll, 1998) which has been considered a very useful indicator of patients' wellbeing (Fayers \& Sprangers, 2002). Poor perceived health is a 
strong risk factor for distress in cancer patients (Schnoll \& Harlow, 2001). It also compares favorably to more objective measures of physical health (Ferraro, 1980; Fisher, Faul, Weir, \& Wallace, 2005). Among cancer patients it has been found to be a strong predictor of survival (Coates, Porzsolt, \& Osoba, 1997; Osoba, 1999).

Subjective life expectancy has been considered an important factor in analyzing adjustment (Ziegelmann \& Lippke, 2009). Subjective life expectancy, or perceived time left in life measured in number of years left in life, has a significant positive correlation with 'sense of control' that does not disappear when controlling for race, sex, education, income, widowhood, inability to work because of a disability, physical impairment, and physical fitness (Mirowsky, 1997). Differences in subjective life expectancy have been linked to different types of health self-regulation (intention formation, planning, and enactment of health behaviors) (Ziegelmann, Lippke, \& Schwarzer, 2006). Evidence also links subjective life expectancy with engagement in health behaviors (Ross \& Mirowsky, 2002), and health-related information-seeking and influence attention, memory, and decision-making may be limited by differences in subjective life expectancy (Lockenhoff \& Carstensen, 2004).

Dispositional optimism, a tendency to expect positive outcomes, predicts lower symptoms of depression in cancer patients (Bardwell et al., 2006; Carver, et al., 1993; Epping-Jordan, et al., 1999; Meyerowitz \& Oh, 2009; Stanton \& Snider, 1993) and this has been consistent across the disease trajectory (Stanton, et al., 2007). Over time, optimism has not only predicted 
lower symptoms of depression, even when controlling for prior levels, but it has also predicted resistance to such symptoms in the year following surgical treatment for cancer (Carver, et al., 1993). It remains one of the most widely studied variables in psychosocial adjustment to cancer and is referred to consistently in review articles (Meyerowitz \& Oh, 2009; Scheier \& Carver, 2001; Stanton, et al., 2007).

External resources. Socioeconomic variables included in external resources include education, wealth, and employment. Other important factors include insurance lack, loss or changes, social support, and psychological support.

Lower levels of Education have been linked to greater psychosocial distress in cancer patients (Andrykowski \& Cordova, 1998; Schnoll \& Harlow, 2001). In their review Stanton et al. (2007) concluded that research on economic burden and associated factors such as low education are likely to constitute barriers to positive adaptation and they recommend more research in this area.

Household net worth—or household wealth—such as assets, pensions, social security and earnings may be the most critical determinant of well-being for those post retirement (National Institute on Aging [NIA], 2007), and may be more important resources to older adults than income alone (Silveira, Kabeto, \& Langa, 2005). Lower levels of income have been associated with greater psychosocial distress (Schnoll \& Harlow, 2001), disability, illness and death (IOM, 2008). Loss in wealth resources associated with cancer include high costs 
of medical treatment, drugs and medical supplies may increase distress (Head \& Faul, 2008; IOM, 2008).

Employment changes, including involuntary job loss or forced retirement due to illness, and not being able to work during periods of treatment can increase distress (IOM, 2008; Meyerowitz \& Oh, 2009). Involuntary job loss has been linked to depression in older adults (Gallo et al., 2006).

Health insurance can improve health (Levy \& Meltzer, 2001), especially for older adults as they become eligible for Medicare (McWilliams, Meara, Zaslavsky, \& Ayanian, 2007). Under and uninsured patients receive delayed or no treatment (Culica, Rohrer, Ward, Hilsenrath, \& Pomrehn, 2002; Sanmartin et al., 2006), and they are unable to obtain needed prescriptions, and worse outcomes of medical treatment (IOM, 2002; IOM, 2008; IOM \& NRC, 2005; Tu, 2004).

Social support has been studied extensively as a resource for cancer patients and is consistently associated with better adjustment (Alferi, Carver, Antoni, Weiss, \& Duran, 2001; Helgeson \& Cohen, 1996; Meyerowitz \& Oh, 2009; Molassiotis, Van Den Akker, \& Boughton, 1997). This external resource reduces an individual's vulnerability during times of stress (S. Cohen \& Wills, 1985; Hobfoll, 2002, 2009) and has helped explain distinct trajectories of distress among those affected by the disease (Helgeson, et al., 2004).

Marital status is another important aspect of social support. Loss of spouse can profoundly affect social support and is a primary risk factor for depression in older adults (Given \& Given, 2010). 
Psychological support, including therapy and psychotropic medication have been shown to be effective in treating depression in cancer patients (Holland \& Alici, 2010). It is therefore important to account for this important external resource as it could explain variations in emotional distress.

Health-related resources. In addition to internal and external resources, personal health and independence are important resources (Hobfoll, 1998) which can affect emotional distress. They are included under health-related resources as they are threatened by illness onset. A recent IOM report indicated amount of symptoms, and impairments in physical status and roles (IOM, 2008) affects adjustment. This is consistent with evidence indicating prevalence of depression symptoms among those with cancer increases with disease severity and symptoms such as pain and fatigue (Spiegel \& Bloom, 1983; Spiegel \& GieseDavis, 2003; Spiegel, Sands, \& Koopman, 1994) and that those who experience disease progression or metastatic recurrences are at high risk for distress (Oh et al., 2004; Schnoll \& Harlow, 2001).

Objective physical health is proposed as a health-related resource in this model as a comparison to the subjective physical health variable included in internal resources. They are considered objective, in spite of self reports, in that all the questions concern some well defined disease, disability, condition or symptom (Angner, Ray, Saag, \& Allison, 2009; Fisher, et al., 2005). Number of days spent in bed due to illness are seen as important quality of life factors, especially in older adult cancer survivors (IOM, 2007). Comorbid conditions 
(Ronson \& Body, 2002) and pain (Spiegel, et al., 1994) have been consistently linked with psychosocial adjustment in cancer patients.

Physical functioning can be greatly reduced by cancer and is seen as a significant stressor for survivors (2008) and loss of independence has been associated with increased distress among long term survivors (Hoffman, McCarthy, Recklitis, \& Ng, 2009).

\section{Criterion Variable}

The conceptual model used here proposes the study of symptoms of depression as an appropriate measure of emotional distress in older adults as aging literature indicates that depression is one of the most frequent causes of emotional distress in older adults and is one of five top concerns faced by the elderly (D. G. Blazer, 2003; Morley, 2004).

\section{Summary}

In conclusion, much theory-based literature exists in informing the understanding of psychosocial adjustment to cancer, yet very few longitudinal studies exist, and even fewer for older adults. Prior research on adjustment to cancer lays the ground work for the application of life course theory, stress, appraisal and coping theory, and conservation of resources theory in the development of a proposed conceptual model for use in longitudinal analysis in this critically understudied population. The next chapter will describe the plan and analytic strategy for addressing that gap by studying life course and resource variables and how they affect emotional distress for older adults over time, comparing those with and without cancer. 


\section{CHAPTER III: METHODOLOGY}

Emphasis is placed on: (1) the dynamic interplay between individuals' aging; (2) their changing biomedical, social, and physical environments; and (3) multilevel interactions among psychological, physiological, social, and cultural levels. -National Institute on Aging, Division of Behavioral and Social Research, 2009

\section{Research Goal and Hypotheses}

The purpose of this study was to develop an understanding of the factors that influence emotional distress, specifically symptoms of depression, in older adults with cancer, and to see if these distress trajectories are different from older adults without cancer. More specifically, the study tested a conceptual model integrating the work of Elder (Giele \& Elder Jr., 1998a), Lazarus and Folkman (1984), and Hobfoll $(1988,1989,1998)$. This model investigated the influence of life course factors, demographics, internal, external and healthrelated resources on emotional distress over a period of eight years, and focused on how these resources and factors influence people with a cancer diagnosis differently than those without a cancer diagnosis. The following overarching research questions guided this study: 
(1) Is there a significant relationship between demographics, life course factors, internal, external, and health-related resources and emotional distress over a period of eight years among older adults with cancer?

(2) How is this relationship different for those older adults with a cancer diagnosis vs. those without a cancer diagnosis?

Based on the questions stated above, the following specific aims and hypotheses were formulated:

Specific Aim 1: To determine if older adults with cancer differ in their emotional distress levels from those without cancer over a period of eight years.

Hypothesis 1: Older adults with cancer will have a different eight year emotional distress change trajectory than those without cancer.

Specific Aim 2: To determine if differences and changes in life course factors, internal, external, and health-related resources within and between older adults will have a differential effect on eight year emotional distress change trajectories for those with and without a cancer diagnosis.

Hypothesis 2: Differences in life course factors, internal, external, and healthrelated resources within and between older adults will have a differential effect on eight year emotional distress change trajectories for individuals with and without a cancer diagnosis.

\section{Research Design}

This study is a secondary analysis of existing data from the Health and Retirement Study (HRS). The design is a longitudinal panel study testing a multilevel growth model with a two-nested-level structure (Figure 4). The growth 
model will examine individual differences in emotional distress over a eight year time period, testing multiple potential predictors. Changes in individual growth profiles will be investigated, and possible explanations for observed differences will be tested. This study is multilevel, because it proposes the use of time variant within person and time invariant between person data measured at five consecutive time periods over eight years.

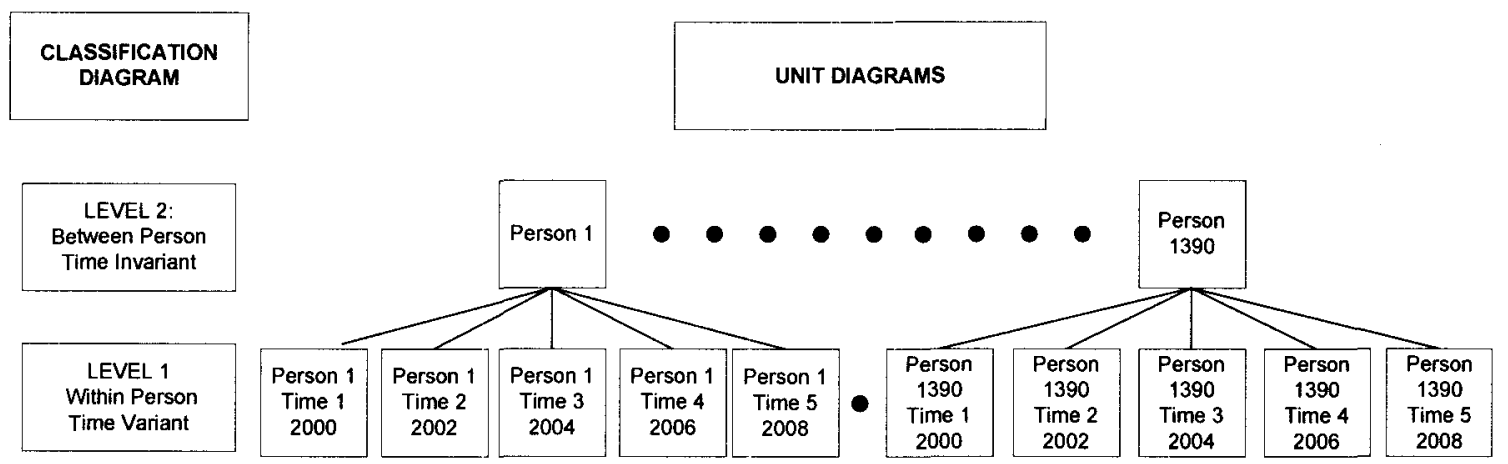

Figure 4. Multilevel structures and classifications.

This study analyzes change. Change studies were not common until the 1980s, when methodologists developed statistical models that could investigate change over time. Until then, researchers were advised to frame their questions in ways that did not specifically address change (Singer \& Willett, 2003). In social work, the analysis of change is relatively new, with only a few social work researchers engaging in this type of design and analysis. As evidenced by the literature, few change studies have focused on predictors of depression among those affected by cancer over time.

Not every longitudinal study can analyze change over time. Singer and Willet (2003) identified three requisite methodological features for any study of change. First, there must be three or more waves of data. In the proposed study, 
four waves of data will be examined, making it possible to look at patterns of change over time. Second, the values of the outcome must change systematically over time. The assumption for this study is that as time passes and older adults move away from the acuteness of the cancer diagnosis, their depression levels will have a tendency to decrease, with the understanding that there will be enough resources in place to support the individual in his/her journey (Alfano \& Rowland, 2009; Institute of Medicine [IOM], 2008; Norton, et al., 2004; Ronson \& Body, 2002). Third and finally, there must be a sensible metric for clocking time. Much of the research on psychosocial adjustment in cancer survivors explored levels of adjustment during treatment, in the year following, or every so many months for approximately two years following diagnosis. The current benchmark for measuring survival in cancer is five years post diagnosis (Welch, Schwartz, \& Woloshin, 2000). The rationale for examining emotional distress trajectories for an eight year period was that it would include all of that five year period in addition to the period immediately following the "five year mark" in an attempt to begin to differentiate between acute and long term psychosocial adjustment issues. This study addresses a gap in knowledge about long term psychosocial adjustment to cancer among older adults.

\section{Data Source}

This study utilizes data between 1998 and 2008 from the Health and Retirement Study (HRS), a biennial longitudinal survey of a nationally representative cohort of U.S. adults aged 50 or older, born in 1947 or before 
(Brown et al., 2008). The HRS, funded by the National Institute on Aging and performed by the Institute for Social Research at the University of Michigan, is designed to provide representative data on the aging of the U.S. population. HRS questionnaire topics include: health, cognitive status, retirement planning, subjective probabilities, family structure, caregiving, employment status, job demands, disability, and demographics, housing, income, net worth, health insurance and pension plans. The HRS is designed as a panel study, permitting longitudinal as well as cross-sectional analyses. The HRS began to collect data on a sample of 9,824 adults aged 51 to 61 in 1992 who were subsequently reinterviewed every two years with response rates ranging from a low of 84 percent to a high of 93 percent. Across samples, there was a downward trend from 89 percent to 87 percent between 1994 and 1998, stability at just below 87 percent from 1998 to 2002 , and then a percentage point increase to 88 percent in 2004 (Health and Retirement Study, 2008a).

Although the HRS began in 1992, it was in 1998 that the researchers combined the HRS study with a companion study, Assets and Health Dynamics of the Oldest Old (AHEAD) which covered cohorts born in 1923 or before (see Table 2) (Hauser \& Willis, 2005). The newly combined HRS added two new cohorts-making 1998 the year the HRS became a cross-sectional representative sample of US adults aged 50 and over-and committed to a steady state design by planning to add a new cohort of study participants every six years thereafter (2004 and 2010 to date) (Hauser \& Willis, 2005). 
Looking at data from the 1998 wave onward, the HRS sample is comprised of four sub-samples, namely the Asset and Health Dynamics Among the Oldest Old (AHEAD), the Children of the Depression Age (CODA), the HRS, and the War Babies (WB) (Table 2). The AHEAD sub-sample consists of people who were born in 1923 or earlier, were household residents of the U.S. in the spring 1992, and were still household residents at the time of their first interview in 1993 or 1994; and of their spouses or partners (regardless of age) at the time of the initial interview. This sub-sample was interviewed in 1993-94, 1995-96, 1998 and every two years thereafter (University of Michigan, 2003).

Table 2 Description of HRS Cohorts (Servais, 2009, p. 1)

\begin{tabular}{|c|c|c|c|c|}
\hline $\begin{array}{l}\text { Sub-sample } \\
\text { Abbreviation }\end{array}$ & $\begin{array}{l}\text { Sub-sample } \\
\text { Name }\end{array}$ & $\begin{array}{l}\text { Birth Year of } \\
\text { Age-Eligible } \\
\text { Respondents }\end{array}$ & $\begin{array}{l}\text { First } \\
\text { Wave }\end{array}$ & Data Collected \\
\hline AHEAD & $\begin{array}{l}\text { Aging \& Health } \\
\text { Dynamics }\end{array}$ & $1890-1923$ & 1993 & $\begin{array}{l}1993199519982000 \\
2002200420062008 \\
2010\end{array}$ \\
\hline CODA & $\begin{array}{l}\text { Children Of the } \\
\text { Depression Age }\end{array}$ & $1924-1930$ & 1998 & $\begin{array}{l}1998200020022004 \\
200620082010\end{array}$ \\
\hline HRS & $\begin{array}{l}\text { Health \& } \\
\text { Retirement Study }\end{array}$ & $1931-1941$ & 1992 & $\begin{array}{l}1992199419961998 \\
2000200220042006 \\
20082010\end{array}$ \\
\hline WB & War Baby & $1942-1947$ & 1998 & $\begin{array}{l}1998200020022004 \\
200620082010\end{array}$ \\
\hline $\mathrm{EBB}^{*}$ & $\begin{array}{l}\text { Early Baby } \\
\text { Boomer }\end{array}$ & $1948-1953$ & 2004 & 2004200620082010 \\
\hline MBB $^{*}$ & Mid Baby Boomer & 1954-1959 & 2010 & $\ldots$ \\
\hline
\end{tabular}

* EBB \& MBB not included in proposed study due to late entrance in HRS study and subsequent lack of longitudinal data

The CODA sub-sample consists of people who were born 1924 through 1930, were household residents of the U.S. when first interviewed in 1998, and 
who, at that time, did not have a spouse or partner who was born before 1924 or between 1931 and 1947. The CODA sub-sample was interviewed in 1998 and every two years thereafter (University of Michigan, 2003).

The HRS sub-sample consists of people who were born 1931 through 1941 and were household residents of the U.S. in the spring 1992; and of their spouses or partners (regardless of age) at the time of the initial interview in 1992. The HRS sub-sample was interviewed in 1992, 1994, 1996, 1998 and every two years thereafter (University of Michigan, 2003).

The WB sub-sample consists of people who were born 1942 through 1947, were household residents of the U.S. in the spring 1992, and were still household residents at the time of the first interview in 1998; and their of spouses or partners (regardless of age) at the time of the initial interview. This subsample was interviewed in 1998 and every two years thereafter (University of Michigan, 2003).

The HRS sample is selected under a multi-stage area probability sample design and includes four distinct selection stages based on 1990 Census Definitions (Heeringa \& Connor, 1995). The primary stage of sampling involves probability proportionate to size (PPS) selection of U.S. Metropolitan Statistical Areas (MSAs) and non-MSA counties. This stage is followed by a second stage sampling of area segments (SSUs) within sampled primary stage units (PSUs). The third stage of sample selection is preceded by a complete listing of all housing units (HUs) that are physically located within the bounds of the selected SSU. The third sampling stage is a systematic selection of housing units from 
the HU listings for the sample SSUs. The fourth and final stage in the multi-stage design is the selection of an age eligible person within a sample HU (Heeringa \& Connor, 1995).

In addition to the nationally-representative, multi-stage area probability sample, the HRS design includes oversamples to increase the numbers of Black and Hispanic HRS respondents to match population characteristics, as well as the number of HRS respondents who are residents of the state of Florida due to the higher numbers of adults aged 50 and older (Heeringa \& Connor, 1995).

\section{Sampling}

The dataset used was the longitudinal HRS RAND data file (version j) with additional variables from the HRS RAND-enhanced Fat Files data for years 2000 through 2008 (waves 5 through 9). This merging was completed in order to obtain additional variables only available in the individual wave files.

For each of the samples (cancer and non-cancer) specific inclusion and exclusion criteria were set. For both samples, the criteria were as follows: (a) participants had to be 50 years of age or older in 2000; (b) took part in the 2000 wave (wave 5); (c) took part in at least one wave of the Leave Behind Surveys in 2004,2006 , or 2008 (written questionnaires containing optimism and social support scales administered to a random subsample). For the cancer sample the criteria were (a) participants had a first cancer diagnosis (excluding minor skin cancers) between 1998 and 2000 (waves 4 and 5); (b) had at least one wave of completed score on the dependent variable. All of the cancer cases that met the above criteria were selected for inclusion in the study for a total sample of 200 
cancer cases. For the non-cancer sample the criteria were: (a) participants had no history of a cancer diagnosis through 2008; (b) participants had completed scores on the dependent variable in waves between 1998 and 2008. From all the non-cancer cases that met the above criteria, a representative sample was drawn, accepting a 3.5 percent margin of error and a 99 percent confidence interval (Krejcie \& Morgan, 1970; The Research Advisors, 2006). Based on these parameters a sample of 1,190 non cancer cases was selected. See sampling flowchart in Figure 5. 


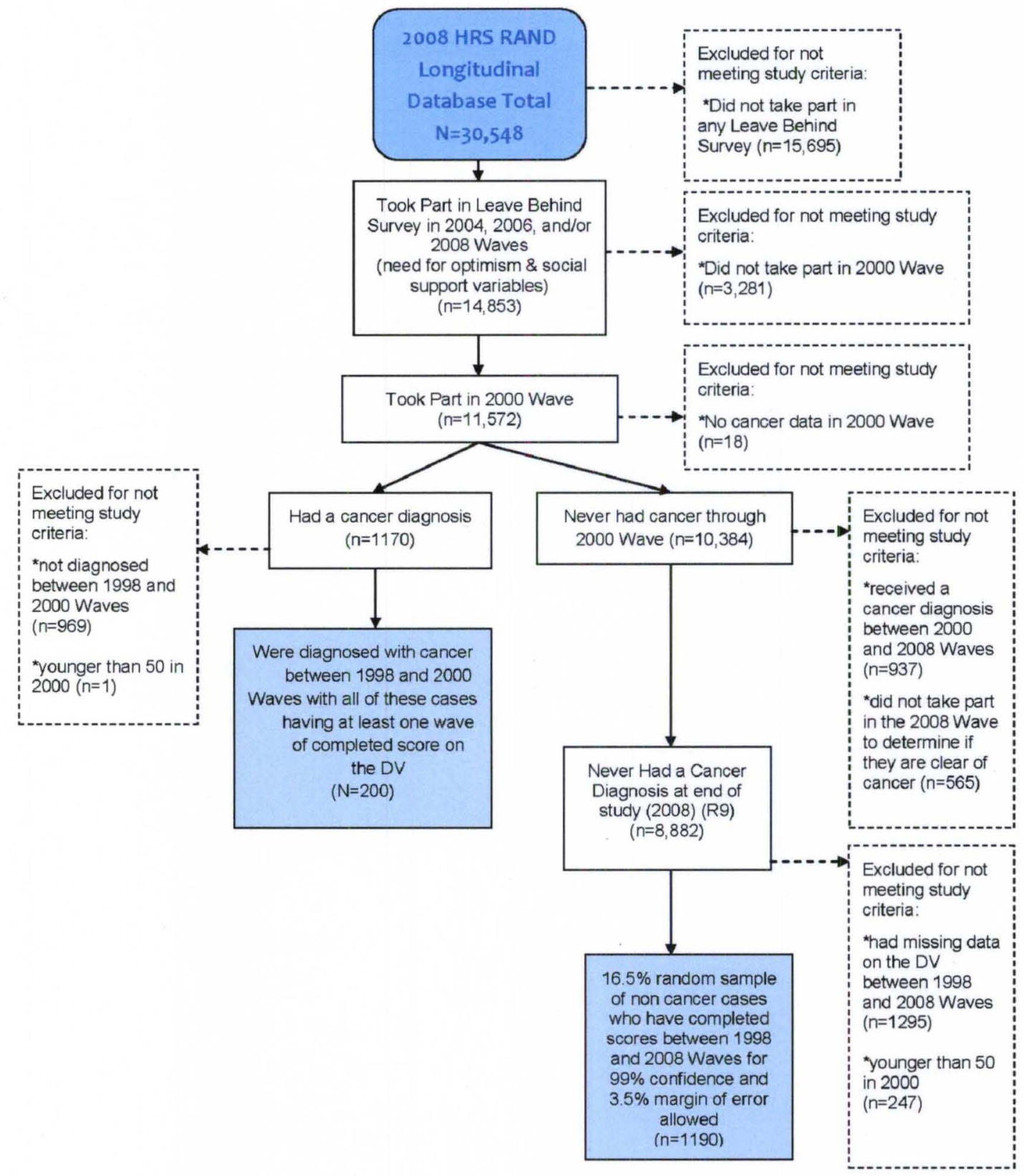

Figure 5. Sampling flowchart.

Table 3 displays the attrition rate of the cancer sample. There was no attrition for the non cancer sample. 
Table 3 Attrition Rate of Cancer Sample

\begin{tabular}{lll}
\hline Year & Participation & Reason \\
\hline 2000 & 200 & \\
2002 & 199 & Did not participate: Still alive \\
2004 & 199 & Did not participate: Still alive \\
2006 & 198 & Did not participate: Still alive \\
2008 & 190 & Did not participate: Still alive \\
\hline
\end{tabular}

\section{Power}

Power depends on sample size and other design aspects - effect size or parameter values and the level of significance. With multilevel modeling, statistical power must be addressed on all levels. Power for level 1 (time variant) depends on the number of observations, while power for level 2 depends on the number of individuals (Snijders, 2005). Statistical power issues in multilevel modeling are complicated as the power differs for fixed effects versus random effects as a function of effect size, intraclass correlation, and the number of groups and cases per group (J. Cohen, Cohen, West, \& Aiken, 2003).

Sample size in multilevel models refers to the number of units at each level (Kreft \& De Leeuw, 1998; Snijders, 2005). Simulation studies (Kreft \& De Leeuw, 1998) suggest that large samples are needed for adequate power in multilevel models, and the number of individuals included is more important than the number of measurement occasions per individual. According to Snijders (2005), it is desirable to have as many units as possible at the top level of the multilevel hierarchy. Kreft and De Leeuw (1998) suggested that at least 20 units are needed on the highest level to detect cross-level interactions. In this study, there were 1390 individuals at Level 2, and 6906 measurement occasions at Level 1 , suggesting sufficient power in terms of sample size. 
As is the convention, significance levels for this study were set at 0.05 and the model sought to detect at least a medium effect size (0.04) and achieve at least 80 percent power. Another convention is to set the intraclass correlation at a minimum size of 0.05 . This small size is recommended for health and mental health research (Spybrook, Raudenbush, Liu, Congdon, \& Martinez, 2008). As will be discussed in the next chapter, significant small effect sizes were detected for many of the predictors, indicating that power was sufficient to detect even small effects. As is detailed in the next chapter, the different variables used in the model had sufficient variability, and intraclass correlations exceeded 0.05 .

\section{Operationalization of Variables}

The conceptual model presented in Figure 3 includes a range of independent variables as predictors that were either time variant (within person) or time invariant (between person), and that were selected based on a review of the literature that suggested their influence on psychosocial adjustment among those with cancer. The dependent variable, symptoms of depression, was time variant (within person).

\section{Main Predictor Variables}

Main predictor variables are measured mainly on Level 1 unless otherwise noted and include life course factors (age, cancer history, and pre-cancer distress levels (all measured at Level 2), internal/personal resources (subjective physical health, subjective life expectancy, and optimism [Level 2]), external/social resources (education [Level 2], net worth, employment, health insurance, social support [Level 2], marital status, and psychological support) 
and health-related resources (objective physical health, disease characteristics, and physical functioning). Table 4 indicates which variables were included in the analysis, together with how they were operationalized and how the values were changed after data screening. In cases where variables represent standardized measures used in the HRS study, relevant psychometric characteristics are also provided.

Table 4 Main Predictor Variables (Level 1 and 2)

\begin{tabular}{|c|c|c|}
\hline Variable & Operationalization & $\begin{array}{l}\text { Values used in } \\
\text { analysis }\end{array}$ \\
\hline \multicolumn{3}{|c|}{ DEMOGRAPHICS (Level 2) } \\
\hline Race/Ethnicity & $\begin{array}{l}\text { Do you consider yourself } \\
\text { primarily white or Caucasian, } \\
\text { Black or African American, } \\
\text { American Indian, or Asian, or } \\
\text { something else? 1- } \\
\text { White/Caucasian; 2- } \\
\text { Black/African American; 3- } \\
\text { Other. } \\
\text { Do you consider yourself } \\
\text { Hispanic? 0-Not Hispanic; 1- } \\
\text { Hispanic }\end{array}$ & $\begin{array}{l}\text { 0-White Non Hispanic; } \\
\text { 1-Other }\end{array}$ \\
\hline Gender & $\begin{array}{l}\text { Is respondent male or } \\
\text { female? 1-Male; 2-Female }\end{array}$ & 0-Male; 1-Female \\
\hline \multicolumn{3}{|c|}{ LIFE COURSE FACTORS (Level 2) } \\
\hline Age & $\begin{array}{l}\text { Age in years at the end of the } \\
\text { interview in } 2000\end{array}$ & n.a. \\
\hline Cancer History & $\begin{array}{l}\text { Has a doctor ever told you } \\
\text { that you have cancer or a } \\
\text { malignant tumor, excluding } \\
\text { minor skin cancers? } \\
\text { O-No; } 1 \text {-Yes } \\
\text { The cancer history variable } \\
\text { was addressed during } \\
\text { sampling and therefore the } \\
\text { final sample only contains } \\
\text { participants who either never } \\
\text { had cancer, or were } \\
\text { diagnosed with a first cancer }\end{array}$ & $0-N o ; 1-Y e s$ \\
\hline
\end{tabular}




\begin{tabular}{|c|c|c|}
\hline & $\begin{array}{l}\text { between } 1998 \text { and } 2000 \\
\text { waves. }\end{array}$ & \\
\hline $\begin{array}{l}1998 \text { (pre-cancer) } \\
\text { Depression Levels } \\
\text { Same as criterion } \\
\text { variable in terms of } \\
\text { reliability and validity. }\end{array}$ & $\begin{array}{l}\text { Same as criterion variable. } \\
\text { The symptoms of depression } \\
\text { measured in } 1998 . \\
\text { You felt depressed. (yes/no) } \\
\text { You were happy. (yes/no) } \\
\text { You felt lonely. (yes/no) } \\
\text { You enjoyed life. (yes/no) } \\
\text { You felt sad. (yes/no) } \\
\text { O-no; 1-yes (with the positive } \\
\text { items reverse-scored) }\end{array}$ & $\begin{array}{l}\text { 0-No Symptoms; 1-One } \\
\text { Symptom; } 2=T \text { wo or } \\
\text { more Symptoms }\end{array}$ \\
\hline \multicolumn{3}{|c|}{ INTERNAL RESOURCES } \\
\hline $\begin{array}{l}\text { Subjective Physical } \\
\text { Health (Level 1, 2000- } \\
\text { 2008, } 5 \text { waves) } \\
\text { Test-retest reliability: } \\
\text { Alpha = } 0.92 \text { (Lorig et } \\
\text { al., 1996) }\end{array}$ & $\begin{array}{l}\text { Would you say your health is } \\
\text { excellent (1), very good (2), } \\
\text { good (3), fair (4), or poor (5)? } \\
\text { Compared with your health } \\
\text { when we talked with you in } \\
\text { (previous wave), would you } \\
\text { say that your health is much } \\
\text { better now (1), somewhat } \\
\text { better now (2), about the } \\
\text { same (3), somewhat worse } \\
\text { (4) or much worse (5)? }\end{array}$ & n.a. \\
\hline $\begin{array}{l}\text { Subjective Life } \\
\text { Expectancy (Level 1, } \\
2000-2008,5 \text { waves) } \\
\text { Good predictive } \\
\text { validity - participants' } \\
\text { subjective survival } \\
\text { probabilities predicted } \\
\text { actual survival (those } \\
\text { who survived in the } \\
\text { panel reported survival } \\
\text { probabilities } 50 \% \\
\text { greater at baseline } \\
\text { than those who died } \\
\text { (Hurd \& McGarry, } \\
2002 \text { ) } \\
\text { Subjective probabilities } \\
\text { of survival are good } \\
\text { approximations to } \\
\text { population } \\
\text { probabilities, they are }\end{array}$ & $\begin{array}{l}\text { What is the percent chance } \\
\text { that you will live to age } \\
\text { (as specified in RWLIV10 } \\
\text { variable on question wording; } \\
\text { age } 80-100 \text { based on current } \\
\text { age)? } \\
0 \% \text { chance to } 100 \% \text { chance }\end{array}$ & n.a. \\
\hline
\end{tabular}




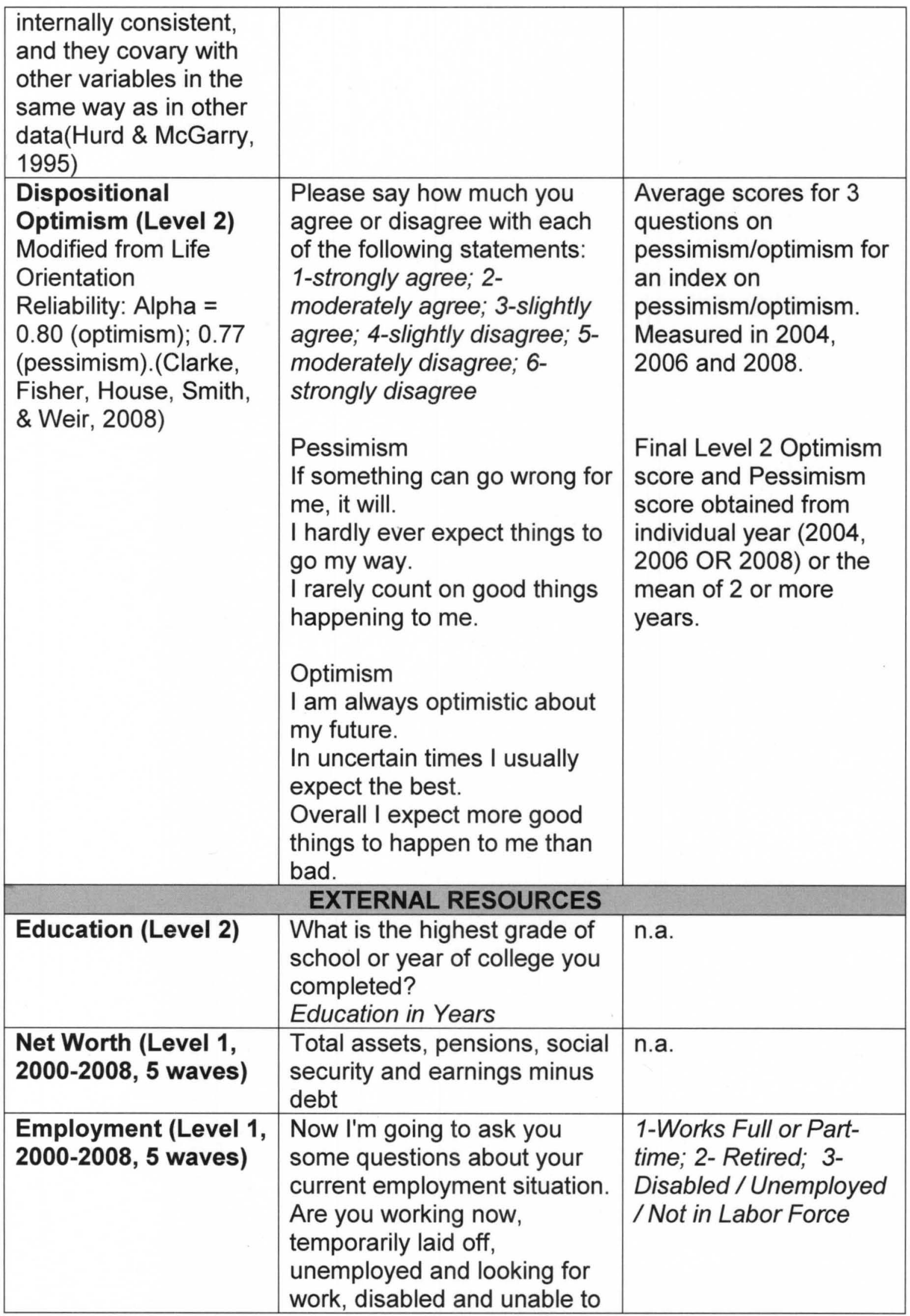




\begin{tabular}{|c|c|c|}
\hline & $\begin{array}{l}\text { work, retired, a homemaker, } \\
\text { or what? } \\
\text { 1-works full time; 2-works } \\
\text { part time; 3-unemployed; 4- } \\
\text { partly retired; 5-retired; 6- } \\
\text { disabled; 7-not in labor force }\end{array}$ & \\
\hline $\begin{array}{l}\text { Health Insurance } \\
\text { (Level 1, 2000-2008, } 5 \\
\text { waves) }\end{array}$ & $\begin{array}{l}\text { How many health insurance } \\
\text { plans do you have? }\end{array}$ & Total \# of health plans \\
\hline $\begin{array}{l}\text { Social Support } \\
\text { (Level 2) } \\
\text { Series of questions } \\
\text { assessing social } \\
\text { integration (number of } \\
\text { social ties) and the } \\
\text { quality of interaction } \\
\text { with those social ties. } \\
\text { Questions are } \\
\text { repeated for } \\
\text { spouse/partner, } \\
\text { children, family, and } \\
\text { friends. } \\
\text { Reliability: Positive } \\
\text { social support: Alpha= } \\
0.81 \text { (spouse); } 0.83 \\
\text { (children); } 0.86 \text { (other } \\
\text { family); } 0.84 \text { (friends). } \\
\text { Negative social } \\
\text { support: Alpha=0.78 } \\
\text { (spouse); } 0.78 \\
\text { (children); } 0.78 \text { (other } \\
\text { family); } 0.76 \\
\text { (friends).(Clarke, et al., } \\
\text { 2008) }\end{array}$ & $\begin{array}{l}\text { Positive Social Support } \\
1-A \text { lot, } 2-\text { Some, } 3-A \text { little, } 4- \\
\text { Not at all } \\
\text { How much do they really } \\
\text { understand the way you feel } \\
\text { about things? } \\
\text { How much can you rely on } \\
\text { them if you have a serious } \\
\text { problem? } \\
\text { How much can you open up } \\
\text { to them if you need to talk } \\
\text { about your worries? } \\
\text { Negative Social Support } \\
\text { How often do they make too } \\
\text { many demands on you? (Not } \\
\text { asked in } 2004 \text { ) } \\
\text { How much do they criticize } \\
\text { you? } \\
\text { How much do they let you } \\
\text { down when you are counting } \\
\text { on them? } \\
\text { How much do they get on } \\
\text { your nerves? } \\
\text { Index for each relationship } \\
\text { category created by } \\
\text { averaging the scores within } \\
\text { each dimension }\end{array}$ & $\begin{array}{l}\text { Recoded Likert } \\
\text { responses so that high } \\
\text { scores on the items } \\
\text { indicated high levels of } \\
\text { support. } \\
\text { Index for each } \\
\text { relationship category } \\
\text { created by averaging } \\
\text { the scores within each } \\
\text { dimension. Measured in } \\
2004,2006 \text { and } 2008 \text {. } \\
\text { Level } 2 \text { scores for each } \\
\text { relationship category } \\
\text { obtained from individual } \\
\text { year (2004, } 2006 \text { OR } \\
\text { 2008) or the mean of } 2 \\
\text { or more years. } \\
\text { Factor analysis on the } \\
\text { relationship categories } \\
\text { indicated one factor. } \\
\text { Factor loadings were } \\
\text { used to calculate a final } \\
\text { weighted social support } \\
\text { score. }\end{array}$ \\
\hline $\begin{array}{l}\text { Marital status } \\
\text { (Level 1, 2000-2008, } 5 \\
\text { waves) }\end{array}$ & $\begin{array}{l}\text { What is your current marital } \\
\text { status? } \\
\text { 1-Married; 2-Married, spouse } \\
\text { absent; 3-Partnered; 4- } \\
\text { Separated; 5-Divorced; 6- } \\
\text { Separated/Divorced; } \\
\text { 7-Widowed; 8-Never Married }\end{array}$ & $\begin{array}{l}\text { 0-No Spouse or Partner } \\
\text { Present } \\
\text { 1-Spouse or Partner } \\
\text { Present }\end{array}$ \\
\hline $\begin{array}{l}\text { Psychological } \\
\text { Support (Level 1, } \\
2000-2008,5 \text { waves) }\end{array}$ & $\begin{array}{l}\text { Do you now get psychiatric or } \\
\text { psychological treatment for }\end{array}$ & $\begin{array}{l}\text { Recoded into one } \\
\text { combined variable }\end{array}$ \\
\hline
\end{tabular}




\begin{tabular}{|c|c|c|}
\hline $\begin{array}{l}\text { Psychological / } \\
\text { psychiatric treatment }\end{array}$ & $\begin{array}{l}\text { your problems? } \\
\text { 1-Yes; 5-No; Blank } \\
\text { Inapplicable } \\
\\
\text { Do you now take } \\
\text { tranquilizers, } \\
\text { antidepressants, or pills for } \\
\text { nerves? } \\
\text { 1-Yes; 5-No; Blank } \\
\text { Inapplicable }\end{array}$ & $\begin{array}{l}\text { where 0-No Psychiatric } \\
\text { /Psychological } \\
\text { Problems; } \\
\text { 1-Psychiatric / } \\
\text { Psychological Problems } \\
\text { with Counseling and/or } \\
\text { Medication; } \\
\text { 2-Psychiatric / } \\
\text { Psychological Problems } \\
\text { with no Counseling or } \\
\text { Medication }\end{array}$ \\
\hline \multicolumn{3}{|c|}{ HEALTH-RELATED RESOURCES } \\
\hline $\begin{array}{l}\text { Objective Physical } \\
\text { Health (Level 1, 2000- } \\
2008,5 \text { waves) } \\
\text { Days in bed }\end{array}$ & $\begin{array}{l}\text { Aside from any hospital or } \\
\text { nursing home stays, about } \\
\text { how many days did you stay } \\
\text { in bed more than half the day } \\
\text { because of illness or injury } \\
\text { during the last month? }\end{array}$ & $\begin{array}{l}\text { Due to lack of incidence } \\
\text { in national sample } \\
\text { (between } 88 \% \text { and } 91 \% \\
\text { of sample did not spend } \\
\text { any days in bed), } \\
\text { recoded into } 2 \text { groups: } \\
\text { 0-No Days in Bed; } 1 \text { - } \\
\text { One or More Days in } \\
\text { Bed }\end{array}$ \\
\hline $\begin{array}{l}\text { Presence of absence } \\
\text { of co-morbid } \\
\text { conditions }\end{array}$ & $\begin{array}{l}\text { Since we last talked to you, } \\
\text { has a doctor told you that you } \\
\text { have high blood pressure or } \\
\text { hypertension/diabetes/lung } \\
\text { disease/heart } \\
\text { problems/stroke/psychiatric } \\
\text { problems/arthritis? } \\
1 \text {-Yes; } 5 \text {-No }\end{array}$ & $\begin{array}{l}\text { Score is sum of yes } \\
\text { answers to } 7 \text { items. }\end{array}$ \\
\hline Pain & $\begin{array}{l}\text { Are you often troubled with } \\
\text { pain? } \\
1-Y e s ; 5-N o \\
\text { If Yes, rate degree of pain } \\
\text { most of the time: } \\
\text { 1-Mild; 2-Moderate; 3- } \\
\text { Severe; 8-Don't Know }\end{array}$ & $\begin{array}{l}\text { Combined the two } \\
\text { variables to: } \\
\text { 0-No Pain; 1-Mild; 2- } \\
\text { Moderate; 3-Severe; 8- } \\
\text { Don't Know coded as } \\
\text { missing }\end{array}$ \\
\hline $\begin{array}{l}\text { Physical Functioning } \\
\text { (Level 1, 2000-2008, } 5 \\
\text { waves) } \\
\text { Activities of Daily } \\
\text { Living } \\
\text { Activities of Daily }\end{array}$ & $\begin{array}{l}\text { Because of a health problem } \\
\text { or memory problem do you } \\
\text { have any difficulty with: } \\
\text { Bathing (yes/no) } \\
\text { Dressing (yes/no) }\end{array}$ & $\begin{array}{l}\text { Due to lack of incidence } \\
\text { in national sample } \\
\text { (between } 85 \% \text { and } 91 \% \\
\text { of sample did not have } \\
\text { any ADL or IADL }\end{array}$ \\
\hline
\end{tabular}




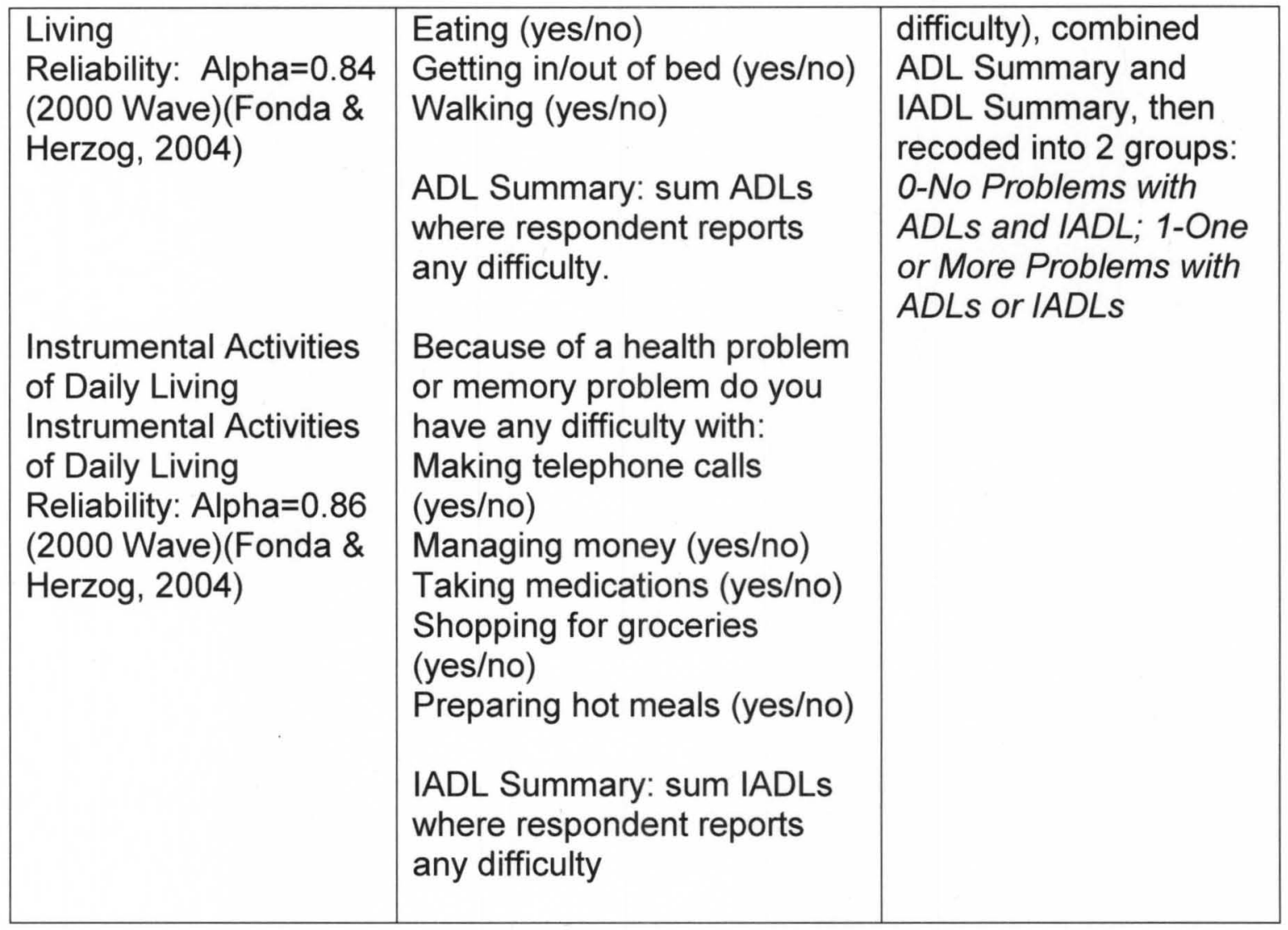

\section{Criterion Variable}

The criterion variable was measured on Level 1 and includes symptoms of depression as an indicator of emotional distress. Table 5 indicates which standardized measure was used in the HRS study together with relevant psychometric characteristics.

Table 5 Criterion Variable (Level 1)

\begin{tabular}{|c|c|c|}
\hline Variable & Operationalization & $\begin{array}{l}\text { Values used in } \\
\text { analysis }\end{array}$ \\
\hline \multicolumn{3}{|c|}{ Emotional Distress } \\
\hline $\begin{array}{l}\text { Symptoms of Depression } \\
\text { Subset of } 8 \text { items from the } \\
\text { Center for Epidemiological } \\
\text { Studies Depression Scale } \\
\text { (CES-D) } \\
\text { Reliability: Alpha }=0.77- \\
0.83 \text { (Steffick et al., } 2000 \text { ) }\end{array}$ & $\begin{array}{l}\text { Now think about the past } \\
\text { week and the feelings you } \\
\text { have experienced. Please } \\
\text { tell me if each of the } \\
\text { following was true for you } \\
\text { much of the time this past } \\
\text { week. }\end{array}$ & $\begin{array}{l}\text { Somatization } \\
\text { variables removed. } \\
\text { 0-Zero Symptoms } \\
\text { 1-One Symptom } \\
\text { 2-Two Symptoms } \\
\text { 3-Three Symptoms } \\
\text { 4-Four Symptoms }\end{array}$ \\
\hline
\end{tabular}




\begin{tabular}{|c|c|c|}
\hline $\begin{array}{l}\text { A cutoff point of } 3 \text { or more } \\
\text { on the } 8 \text { item CES-D } \\
\text { indicates clinical } \\
\text { depression. } \\
\text { Sensitivity }=71 \% \text {; } \\
\text { Specificity }=79 \% \text {.(Turvey, } \\
\text { Wallace, \& Herzog, 1999) }\end{array}$ & $\begin{array}{l}\text { Emotional: } \\
\text { You felt depressed. (yes/no) } \\
\text { You were happy. (yes/no) } \\
\text { You felt lonely. (yes/no) } \\
\text { You enjoyed life. (yes/no) } \\
\text { You felt sad. (yes/no) } \\
\text { Somatic: } \\
\text { You felt that everything you } \\
\text { did was an effort. (yes/no) } \\
\text { Your sleep was restless. } \\
\text { (yes/no) } \\
\text { You could not get going. } \\
\text { (yes/no) } \\
\text { Summary score ranging } \\
\text { from 0-8 created by } \\
\text { summing the number of } \\
\text { "yes" answers across the } \\
\text { eight items (with the positive } \\
\text { items reverse-scored). }\end{array}$ & 5-Five Symptoms \\
\hline
\end{tabular}

The measure of distress, or symptoms of depression, consists of a subset of eight items from the Center for Epidemiologic Studies Depression Scale (CESD) (Radloff, 1977). The CES-D scale measures a continuum of psychological distress (symptoms of depression), rather than determining the presence or absence of recognized psychiatric disorders. A summary score ranging from zero to eight is created by summing the number of "yes" answers across the eight items (with the positive items reverse-scored) (Steffick, et al., 2000). 


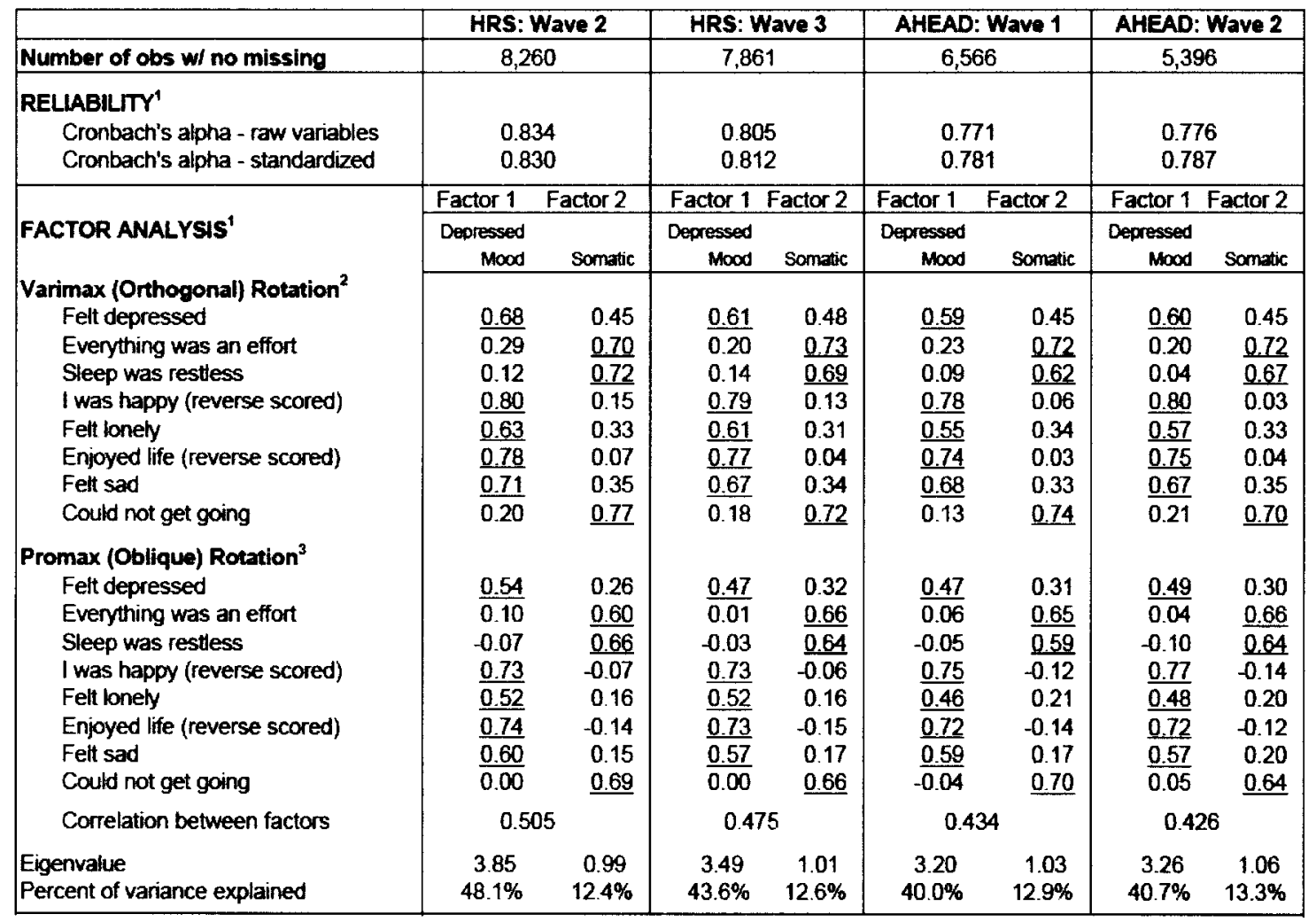

NOTES:

1

Principal components analysis is weighted. Weights from HRS 2 are also used for HRS 3; weights from AHEAD 1 are used for AHEAD 2

${ }^{2}$ Rotated factor pattem shown. Rotated factors are uncorrelaled

${ }^{3}$ The reference structure (semipartial correlations) is shown for the rotated factors

Figure 6. Psychometric properties of the CES-D in the HRS and AHEAD:

Results from factor analysis and internal consistency investigations. Adapted from "Documentation of Affective Functioning Measures in the Health and Retirement Study. HRS/AHEAD," by D. E. Steffick, R. B. Wallace, A. R. Herzog, M. B. Ofstedal, D. Steffick, S. Fonda, and K. M. Langa, 2000, Documentation Report, p. 27. Copyright 2000 by University of Michigan.

Fechner-Bates, Coyne, and Schwenk (1994) provide results of research

on the relationship of the CES-D to both depressive disorders and anxiety

disorders, as well as other psychiatric diagnoses. Psychometric evaluation done

by HRS researchers (Steffick, et al., 2000) on the eight-item CES-D scale used in Waves 2 and 3 of HRS, and all of AHEAD Waves (originally HRS and AHEAD 
were two separate studies but were combined in 1996) revealed Cronbach alphas ranging from 0.77 to 0.83 (see Figure 6).

For this study, the three items assessing somatic symptoms were removed due to their unreliability in cancer patients (Akechi et al.; Breitbart, 2010; Endicott, 1984). A summary score ranging from zero to five was therefore created by summing the number of "yes" answers across the five items (with the positive items reverse-scored).

\section{Analysis}

After obtaining institutional review board approval to review and report on these data, IBM SPSS Statistics 19 was used for data management and preliminary analyses. After conducting person-level descriptive analyses using the conventional horizontal data file, the file was restructured a person-period (vertical) data file in which each person had multiple records, one for each wave (measurement occasion) on which the person completed the interview survey. This vertical file was used for measurement occasion-level descriptive analysis. The vertical file was uploaded to a specialized multilevel software package, MLwiN Version 2.24 was used for this analysis (Rasbash, Steele, Browne, \& Goldstein, 2009). MLwiN is a sophisticated program that can fit complex multilevel models with ML estimation. In preparing the dataset for analysis, the data were organized and sorted into level 2 and level 1 data, with level 2 data comprising time invariant between person data of each individual and level 1 data comprising of time variant within person data of each individual. 
The most appropriate analysis for this study is multilevel modeling of ordered categorical count data; in this study event rates are low and there are many zeros (assumption of normality cannot be met and transformation not possible); hierarchical generalized linear modeling (HGLM) (Raudenbush \& Bryk, 2002), allows for the identification of patterns within and between individuals, as well as for testing potential interactions between predictors and time. The model fit is accomplished with Bayesian modeling using Markov Chain Monte Carlo (MCMC) estimation. MCMC methods are stochastic; unlike classical methods that converge to a point, they converge to a distribution. MLwiN utilizes a Metropolis Hastings sampling method to sample diffuse prior distributions. A 'burnin' period is used to allow the chains to converge to the distribution of interest. The chains are then a dependent sample of values from the distribution of interest. Because of this dependence, a recommended effective sample size (ESS) of 250 is recommended for model convergence (Browne, Clarke, Jones, Leckie, \& Steele, 2012). As will be discussed in the next chapter ESS values exceeded 1000 with 50,000 iterations.

Preliminary analysis investigated the structure of each variable on each level, and bivariate analysis allowed for the investigation of the relationship among variables and the testing for multicollinearity. The distribution of each variable, including outliers, was inspected and corrected as needed to prevent any violation of functional form in the predictor variables.

After the preliminary analysis, the analytic model for the dependent variable (count of scores on the depression symptoms-with an ordered 
hierarchical nature-as measured by the modified CES-D) was developed in five steps, using random intercept multinomial ordered categorical model fitting strategies: (a) fitting the unconditional model which describes probability of having depression symptoms across individuals (Model A) using the following formula: resp $p_{i j k} \sim$ Ordered Multinomial (Constant $\left.t_{j k}, \pi_{i j k}\right) Y_{0 j k}=\pi_{0 j k}($ probability of 0 depression symptoms); $Y_{1 j k}=\pi_{0 j k}+\pi_{1 j k} ; Y_{2 j k}=\pi_{0 j k}+\pi_{1 j k}+\pi_{2 j k} ; Y_{3 j k}=\pi_{0 j k}+\pi_{1 j k}+$ $\Pi_{2 j k}+\pi_{3 j k} ; Y_{4 j k}=\Pi_{0 j k}+\pi_{1 j k}+\pi_{2 j k}+\pi_{3 j k}+\pi_{4 j k} ; Y_{5 j k}=1$; (cumulative probabilities of having 0 depression symptoms through 5 depression symptoms) $=\beta_{0 i j} \ldots \beta_{4 i j}$ (intercept $=0$ depression symptoms $\ldots 4$ depression symptoms across individuals and time) $+h_{\mathrm{jk}}$ (between person error); (b) fitting the unconditional growth model depicting probability of having depression symptoms over time across individuals (Model B); (c) fitting the main effects to explain the change in the dependent variable (Model C); and (d) fitting the interaction effects of cancer with main effects to explain the change in the dependent variable (Model D). In the interest of parsimony, predictor variables that did not contribute to the model fit were excluded from the final model (Model D).

As O'Connell (2010) points out, proportional odds models can be characterized as extensions of hierarchical logistic regression models for dichotomous outcomes usually coded as 0 or 1 , where 1 represents the "success" outcome or event of interest. The logistic regression model predicts the probability of success conditional on a collection of categorical or continuous predictors through application of the logit-link. The logit is the natural log of the odds, where the odds is a quotient that conveniently compares the probability of 
success to the probability of failure (2010, pp. 1-2). For the ordinal outcome in this study, an ascending cumulative probability is of "success" determined, starting with the probability of having 0 symptoms, then the probability of having 0 or 1 symptoms, then 0,1 , or 2 , and so on. For this reason, MLwiN created a third level of data in the analysis, (Level 0 ) which is that of the probabilities of the ordered outcome categories.

\section{Summary}

This chapter detailed the methodological plan and analytic strategy for studying life course and resource variables and how they affect emotional distress for older adults over time, comparing those with and without cancer. The next chapter will provide details of each step of the analysis as well as results. 


\section{CHAPTER IV: RESULTS}

Essentially, all models are wrong, but some are useful (Box \& Draper, 1987).

The purpose of this study was to develop an understanding of the factors that influence emotional distress, specifically symptoms of depression, in older adults with cancer, and to see if these depression trajectories were different from older adults without cancer. More specifically, the study attempted to test a conceptual model integrating the work of Elder (Giele \& Elder Jr., 1998a), Lazarus and Folkman (1984), and Hobfoll $(1988,1989,1998)$. This model investigated the influence of life course factors, internal, external and healthrelated resources, and demographics on depression over a period of eight years, and focused on how these resources and factors influenced people with a cancer diagnosis differently than those without a cancer diagnosis.

Findings related to the following research questions will be described in this chapter: a) Is there a significant relationship between life course factors, internal, external, and health-related resources, and demographics and distress over a period of eight years among older adults with cancer? and b) How is this relationship different for those older adults with a cancer diagnosis vs. those without a cancer diagnosis? This chapter will explain data preparation activities and preliminary analyses, describe the study sample, detail the model building 
process and present the results. The final chapter will discuss the implications of the study, describe its limitations, and outline ideas for future research.

\section{Data Preparation and Preliminary Analyses}

\section{Retrieving Data}

In order to draw the sample, the publicly available HRS data from the Institute for Social Research at the University of Michigan was downloaded. HRS RAND-enhanced Fat Files data (comprised of individual files per Wave) and the longitudinal HRS RAND data files (version j) were downloaded from the online HRS (http://hrsonline.isr.umich.edu/concord/index.html).

The HRS RAND data file was chosen as the primary database due to its preparation as a longitudinal file; it is a cleaned, easy-to-use, and streamlined version of the HRS with derived variables covering a broad though not complete range of measures and named consistently across waves; RAND HRS researchers have included elaborate documentation, with special attention to comparability of variables across survey waves (RAND Center for the Study of Aging, 2010, 2010). Additional variables were obtained from the Fat Files which contained a much more extensive list of variables per study wave. The two data files were matched using the combined household and person number identifier (HHIDPN).

\section{Data Screening}

Criterion variable. As indicated previously, use of somatic items to measure depression in cancer patients has been found to be unreliable (Akechi, et al.). Therefore, the following three items scores were removed from the pre- 
calculated CES-D score in the HRS RAND longitudinal file, to create a total score of only the five emotion items of the CES-D scale: 1) you felt that everything you did was an effort; 2) your sleep was restless; and 3) you could not get going.

Data investigation revealed 30 measurement occasions among those with cancer with missing CES-D scores; all missing measurement occasions were deleted.

Non-cancer participants had no missing measurement occasions due to the way they were sampled. Table 6 shows the people from whom measurement occasions were deleted, the total amount of occasions deleted per person, as well as the total amount of occasions deleted by year.

Table 6 Measurement Occasions Deleted per Case ID

\begin{tabular}{|c|c|c|c|c|c|c|}
\hline ID & 2000 & 2002 & 2004 & 2006 & 2008 & Total Deleted \\
\hline 10994010 & $\checkmark$ & $\sqrt{ }$ & $\checkmark$ & $x$ & $x$ & 2 \\
\hline 21671010 & $x$ & $x$ & $x$ & $x$ & $\sqrt{ }$ & 4 \\
\hline 34644011 & $x$ & $x$ & $\checkmark$ & $\sqrt{ }$ & $\checkmark$ & 2 \\
\hline 40913020 & $x$ & $\checkmark$ & $\checkmark$ & $\sqrt{ }$ & $\sqrt{ }$ & 1 \\
\hline 41173010 & $x$ & $\sqrt{ }$ & $\sqrt{ }$ & $\sqrt{ }$ & $\sqrt{ }$ & 1 \\
\hline 51577010 & $x$ & $\sqrt{ }$ & $\checkmark$ & $\sqrt{ }$ & $\sqrt{ }$ & 1 \\
\hline 53279010 & $x$ & $\sqrt{ }$ & $\sqrt{ }$ & $\sqrt{ }$ & $\checkmark$ & 1 \\
\hline 62108011 & $x$ & $x$ & $\sqrt{ }$ & $\sqrt{ }$ & $x$ & 3 \\
\hline 74260040 & $x$ & $x$ & $\checkmark$ & $\checkmark$ & $\checkmark$ & 2 \\
\hline 80339040 & $\checkmark$ & $\checkmark$ & $x$ & $\sqrt{ }$ & $\checkmark$ & 1 \\
\hline 85214010 & $\sqrt{ }$ & $\sqrt{ }$ & $\checkmark$ & $x$ & $x$ & 2 \\
\hline 201899020 & $\sqrt{ }$ & $\sqrt{ }$ & $\checkmark$ & $\sqrt{ }$ & $x$ & 1 \\
\hline 202218020 & $x$ & $x$ & $\checkmark$ & $\sqrt{ }$ & $\sqrt{ }$ & 2 \\
\hline 203241010 & $\checkmark$ & $\checkmark$ & $\checkmark$ & $\checkmark$ & $x$ & 1 \\
\hline 203879020 & $\checkmark$ & $x$ & $x$ & $\sqrt{ }$ & $\sqrt{ }$ & 2 \\
\hline 207052020 & $\sqrt{ }$ & $\checkmark$ & $\checkmark$ & $\sqrt{ }$ & $x$ & 1 \\
\hline 207857010 & $\checkmark$ & $\checkmark$ & $\sqrt{ }$ & $\sqrt{ }$ & $x$ & 1 \\
\hline 211921010 & $\sqrt{ }$ & $\checkmark$ & $\sqrt{ }$ & $x$ & $\sqrt{ }$ & 1 \\
\hline 213225010 & $\sqrt{ }$ & $x$ & $\sqrt{ }$ & $\checkmark$ & $\sqrt{ }$ & 1 \\
\hline Total & 9 & 7 & 3 & 4 & 7 & 30 \\
\hline
\end{tabular}


Table 7 highlights the number of study participants per wave with complete data on the dependent variable.

Table 7 Study Participants per Wave with Complete Data on the DV

\begin{tabular}{cccc}
\hline Year & \multicolumn{3}{c}{ Study Participants Per Wave } \\
\hline & Overall & $\frac{\text { Cancer }}{191}$ & Non-Cancer \\
2000 & 1381 & 1190 \\
2002 & 1382 & 196 & 1190 \\
2004 & 1386 & 196 & 1190 \\
2006 & 1384 & 183 & 1190 \\
2008 & 1373 & & 1190 \\
\hline
\end{tabular}

Demographics. In the original HRS RAND longitudinal file, two questions were asked related to race/ethnicity; the first question focused on race group and the second question on Hispanic origins. These two variables were combined for this analysis, where White Non-Hispanics were coded as 0 and everyone else as 1. It was not possible to differentiate more between other race and/or ethnic groups, due to the Other group representing only 18 percent of the sample. Gender was recoded with $0=$ male and $1=$ female. These two variables had no cases with unknown gender and/or race/ethnicity designations.

Life course factors. Age was recorded as the actual age of participants in 2000. The cancer history variable was addressed during sampling and therefore the final sample only contains participants who either never had cancer (0), or were diagnosed with a first cancer between 1998 and 2000 waves (1). The history of depression variable represented the score participants received on the five emotion symptom CES-D items in 1998. Seven individuals had missing values that were replaced with the individual's personal mode; six of these individuals never had any symptoms over the course of the study. 


\section{Internal resources. Subjective physical health and subjective life}

expectancy variables were used as is from the HRS RAND longitudinal file. Table 8 indicates the number of people who had between 1 and 5 waves of missing data. For those who had between 1 and 4 waves missing, the missing values were replaced with their own individual mean value. For those who had all 5 waves missing, the missing values were replaced with the mean of the specific year.

Table 8 Number of Waves Missing by Variable

\begin{tabular}{lccccc}
\hline Predictor Variable & $\begin{array}{c}\text { Missing 1 } \\
\text { wave }\end{array}$ & $\begin{array}{c}\text { Missing 2 } \\
\text { waves }\end{array}$ & $\begin{array}{c}\text { Missing 3 } \\
\text { waves }\end{array}$ & $\begin{array}{c}\text { Missing 4 } \\
\text { waves }\end{array}$ & $\begin{array}{c}\text { Missing 5 } \\
\text { waves }\end{array}$ \\
\hline Subjective Physical Health & 5 & 0 & 0 & 0 & \\
Subjective Life Expectancy & 153 & 52 & 34 & 20 & 8 \\
\hline
\end{tabular}

\section{Dispositional optimism variables formed part of the Leave Behind} Survey that was completed in 2004, 2006 and 2008 and were obtained from the HRS RAND Fat Files by individual years, resulting in an optimism and pessimism score for each year. Both the optimism and pessimism scores represent the mean of the three items on the Optimism Index and the three items on the Pessimism Index. To represent a valid score, at least two of the items had to be answered. If this was not the case, a score was not reported for that year. The same respondents did not necessarily participate in each of the years. Some of the respondents only participated once in the Leave Behind Survey, therefore only one score could be used for dispositional optimism. In cases where respondents participated more than once, the mean of their scores over the 
different years were used. For this reason the dispositional optimism variables were treated as a level 2 variable.

External resources. The education variable was treated as a level 2 variable where the first non-missing value for each case in the HRS RAND longitudinal file was used. The net worth variable was part of the HRS RAND longitudinal file and represented a combination of multiple income and asset measures. RAND researchers used a multistage approach to imputing values for missing income and assets for those respondents who did not provide answers to the net worth questions. After investigating the distribution of the net worth variable, it was determined that, as expected, it was highly skewed with outlying values mostly at the top end of the distribution. To diminish the influence of outlying values, negative assets were set to zero and positive values were truncated at the $90^{\text {th }}$ percentile for each survey year (see Angel, Jimenez, \& Angel, 2007; Avendano \& Glymour, 2008).

The employment variable was part of the HRS RAND longitudinal file and was assigned by examining all waves of data and tracker files, combining multiple labor force measures. The seven response categories were collapsed after per wave one-way ANOVAs with Tamhane's T2 post hoc tests found no statistical differences between the mean CES-D scores of those who worked full and part time, between those who were partially or fully retired, and between those who were disabled, unemployed or not in labor force. The responses were therefore recoded into 1=works full or part-time; $2=$ retired; and 3=disabled, unemployed, or not in labor force. 
The health insurance variable was used as prepared by the HRS RAND longitudinal file and was taken from a direct question that asks how many plans each respondent had. A small number of missing values were replaced with the individual's mean over the other 4 waves (see Table 9).

Table 9 Number of Missing Waves Replaced with Individual Mean

\begin{tabular}{lcccc}
\hline Predictor Variable & $\begin{array}{c}\text { Missing 1 } \\
\text { wave }\end{array}$ & $\begin{array}{c}\text { Missing 2 } \\
\text { waves }\end{array}$ & $\begin{array}{c}\text { Missing 3 } \\
\text { waves }\end{array}$ & $\begin{array}{c}\text { Missing 4 } \\
\text { waves }\end{array}$ \\
\hline Total \# of Heath Plans & 36 & 0 & 0 & 0 \\
\hline
\end{tabular}

Social support variables formed part of the Leave Behind Survey that was completed in 2004, 2006 and 2008 and were obtained from the HRS RAND Fat Files by individual years. Social support indices consist of a series of questions assessing social integration (number of social ties) and the quality of interaction with those social ties. Seven questions in 2004 and eight questions in 2006 and 2008 are repeated for spouse/partner, children, family, and friends, resulting in a positive and negative social support index for each relationship category for each year. Scores on both the Positive and Negative Social Support indices for each relationship category represent the mean of the three items on the Positive Social Support index and the three items (in 2004) or four items (2006 and 2008) on the Negative Social Support index. To represent a valid score, at least two of the items had to be answered. If this was not the case, a score was not reported for that year. Factor analysis on the relationship categories indicated one factor. Factor loadings were used to calculate a final weighted social support score. The same respondents did not necessarily 
participate in each of the years. Some of the respondents only participated once in the Leave Behind Survey, therefore only one score could be used for social support. In cases where respondents participated more than once, the mean of their scores over the different years was used. For this reason the social support variables were treated as a level 2 variable. The marital status variable had seven response categories with skewed values; these were collapsed after per wave one-way ANOVAs with Tamhane's T2 post hoc tests found no statistical differences between the mean CES-D scores of those who were married ( 82 percent) and those who were divorced ( 8 percent) or widowed ( 25 percent). The remaining values represented less than 5 percent of cases. All response categories were therefore recoded to $0=$ no spouse or partner present; $1=$ spouse or partner present. Five participants had missing values which were replaced with the data from the previous wave (see Table 10) Table 10 Missing Values on Marital Status Replaced with Previous Wave Data

\begin{tabular}{llllll}
\hline Participant ID & 2000 & 2002 & 2004 & 2006 & 2008 \\
\hline 212618010 & Set to 0 & & \\
13296010 & & & & \\
176718010 & Set to 0 & & & \\
32996010 & Set to 0 & & Set to 1 \\
183944020 & & & \\
\hline
\end{tabular}

Psychological support was a recoded variable created by combining two variables: psychiatric or psychological treatment (yes/no) and psychotropic medications (yes/no) into one combined variable where $0=$ no psychiatric $/$ 
psychological problems; 1 =psychiatric / psychological problems with counseling and/or medication; 2=psychiatric / psychological problems with no counseling or medication. There were no missing values on this variable.

Health related resources. Objective physical health was measured with three separate variables, namely days in bed, comorbid conditions and pain. The days in bed variable was recoded due to lack of incidence in national sample (between 88 percent and 91 percent of sample did not spend any days in bed) into 2 groups: $0=$ no days in bed; $1=$ one or more days in bed. Twenty-five measurement occasions had missing values which were replaced with previous year's data. The comorbid conditions variable represented the sum of yes answers to seven questions asking about presence of high blood pressure or hypertension, diabetes, lung disease, heart problems, stroke, psychiatric problems, or arthritis. The pain variable was a combination of two variables asking about (1) presence of absence of pain and (2) degree of pain; the combined variable was recoded as $0=$ no pain; $1=$ mild; $2=$ moderate; $3=$ severe; "don't know" was recoded as missing. Eight measurement occasions had missing values which were replaced with previous year's data.

Physical functioning was a recoded variable based on scores obtained for Activities of Daily Living (ADLs) and Instrumental Activities of Daily Living (IADLs). Due to lack of incidence in national sample (between 85 percent and 91 percent of sample did not have any ADL or (ADL difficulty), ADL Summary and IADL Summary were combined, then recoded into 2 groups: $0=$ no problems with ADLs and IADL; $1=$ one or more problems with ADLs or IADLs. 
One measurement occasion contained missing data and was replaced with data from prior wave.

\section{Description of Sample}

\section{Demographics}

The final sample included 6906 Level 1 units (measurement occasions) for 1390 Level 2 units (participants). Table 11 presents demographic characteristics of the study sample. Most were white non-Hispanic and female. Of the cancer sample, 87 percent (174) were white, while 81 percent were of the non-cancer sample was white.

Table 11 Level 2 Demographics of Study Population ( $N=1390)$

\begin{tabular}{lccc}
\hline Characteristic & Overall $f(\%)$ & Cancer $f(\%)$ & Non Cancer $f(\%)$ \\
\hline $\begin{array}{l}\text { Race } \\
\text { White Non-Hispanic }\end{array}$ & $1142(82.2)$ & $174(87)$ & $968(81.3)$ \\
Other & $248(17.8)$ & $26(13)$ & $222(18.7)$ \\
Gender & & & $755(63.4)$ \\
Female & $857(61.7)$ & $102(51)$ & $435(36.6)$ \\
Male & $533(38.3)$ & $98(49)$ & \\
\hline
\end{tabular}

\section{Life Course Factors}

Table 12 details descriptive statistics for life course variables. Mean age for the total sample was $64.34(S D=8.33)$ in 2000 , ranging between 50 and 91 years. Just under one half (45.2 percent) were 65 and older. Of the cancer cases, 52 percent (103) were diagnosed in 1999, 27 percent (53) in 1998, and 21 percent (44) were diagnosed in 2000 (prior to when the 2000 data was collected). The mean age for the non-cancer sample in 2000 was $64.02(S D=8.36)$, ranging between 50 and 91 . The mean age for the cancer sample in 2000 was 66.26 
$(S D=7.89)$, ranging between 52 and 85$)$. Forty-three percent of the non-cancer cases were 65 and older; 56 percent of the cancer cases were 65 and older. No one in the sample died during the study period. Overall, 15 percent of the sample had two or more symptoms of distress in 1998 (prior to any cancer diagnosis). Among those with cancer, 14 percent had two or more symptoms of distress while 15 percent of non-cancer cases had two or more symptoms. Table 12 Level 2 Life Course Factors of Study Population ( $N=1390)$

\begin{tabular}{|c|c|c|c|c|c|c|c|c|c|}
\hline \multirow{3}{*}{ Variable } & \multirow{2}{*}{\multicolumn{3}{|c|}{$\begin{array}{l}\text { Overall } \\
N=1390\end{array}$}} & \multirow{2}{*}{\multicolumn{3}{|c|}{$\begin{array}{l}\text { Cancer } \\
\mathrm{N}=200\end{array}$}} & \multirow{2}{*}{\multicolumn{3}{|c|}{$\begin{array}{c}\text { Non-Cancer Cases } \\
\mathrm{N}=1190\end{array}$}} \\
\hline & & & & & & & & & \\
\hline & $f(\%)$ & $\overline{\bar{X}}(\mathrm{SD})$ & Range & $f(\%)$ & $\bar{X}(\mathrm{SD})$ & Range & $f(\%)$ & $\overline{\bar{X}}(\mathrm{SD})$ & Range \\
\hline Age in 2000 & & $64.34(8.33)$ & $50-91$ & & $66.26(7.87)$ & $52-85$ & & $64.02(8.36)$ & $50-91$ \\
\hline \multicolumn{10}{|l|}{$\begin{array}{l}1998 \text { Distress } \\
\text { Symptoms }\end{array}$} \\
\hline None & $977(70.3)$ & & & $145(72.5)$ & & & $832(69.9)$ & & \\
\hline 1 Symptom & $202(14.5)$ & & & $27(13.5)$ & & & $175(14.7)$ & & \\
\hline 2-5 Symptoms & $211(15.2)$ & & & $28(14.0)$ & & & $183(15.4)$ & & \\
\hline
\end{tabular}

Internal Resources

Detailed descriptive statistics for internal resource predictors are provided in Tables 13 (level one variables) and 14 (level two variables). 
Table 13 Sample Characteristics for Ordinal and Interval Internal Resource Predictors

\begin{tabular}{|c|c|c|c|c|c|c|c|c|c|c|}
\hline \multirow[b]{2}{*}{ Variable } & \multirow[b]{2}{*}{ Year } & \multicolumn{3}{|c|}{ Overall $(\mathrm{N}=1390)$} & \multicolumn{3}{|c|}{ Cancer Cases } & \multicolumn{3}{|c|}{ Non-Cancer Cases $\underline{\mathrm{N}=1190}$} \\
\hline & & $\bar{X}(\mathrm{SD})$ & Median & Range & $\bar{X}(S D)$ & Median & Range & $\bar{X}(\mathrm{SD})$ & Median & Range \\
\hline \multirow{6}{*}{$\begin{array}{l}\text { Subjective } \\
\text { Life } \\
\text { Expectancy }\end{array}$} & 2000 & $51.81(29.96)$ & & $0-100$ & $48.13(28.32)$ & & $0-100$ & $52.40(30.18)$ & & $0-100$ \\
\hline & 2002 & $50.72(30.24)$ & & $0-100$ & $48.60(29.63)$ & & $0-100$ & $51.07(30.33)$ & & $0-100$ \\
\hline & 2004 & $50.68(31.20)$ & & $0-100$ & $49.01(30.54)$ & & $0-100$ & $50.95(31.31)$ & & $0-100$ \\
\hline & 2006 & $47.29(30.82)$ & & $0-100$ & $43.00(31.30)$ & & $0-100$ & $47.98(30.79)$ & & $0-100$ \\
\hline & 2008 & $49.63(31.04)$ & & $0-100$ & $48.07(29.92)$ & & $0-100$ & $49.87(31.21)$ & & $0-100$ \\
\hline & All Yrs & $50.03(30.68)$ & & $0-100$ & $47.35(29.98)$ & & $0-100$ & $50.45(30.78)$ & & $0-100$ \\
\hline \multirow{6}{*}{$\begin{array}{l}\text { Self-Report } \\
\text { of Health }\end{array}$} & 2000 & $2.60(1.05)$ & 3.00 & $1-5$ & $3.04(1.06)$ & 3.00 & $1-5$ & $2.51(1.03)$ & 2.00 & $1-5$ \\
\hline & 2002 & $2.65(1.04)$ & 3.00 & $1-5$ & $2.81(1.00)$ & 3.00 & $1-5$ & $2.61(1.05)$ & 3.00 & $1-5$ \\
\hline & 2004 & $2.72(1.06)$ & 3.00 & $1-5$ & $2.93(1.00)$ & 3.00 & $1-5$ & $2.69(1.07)$ & 3.00 & $1-5$ \\
\hline & 2006 & $2.75(1.07)$ & 3.00 & $1-5$ & $2.90(1.00)$ & 3.00 & $1-5$ & $2.72(1.08)$ & 3.00 & $1-5$ \\
\hline & 2008 & $2.87(1.07)$ & 3.00 & $1-5$ & $3.02(1.03)$ & 3.00 & $1-5$ & $2.84(1.07)$ & 3.00 & $1-5$ \\
\hline & All Yrs & $2.71(1.06)$ & 3.00 & $1-5$ & $2.94(1.02)$ & 3.00 & 1.5 & $2.67(1.06)$ & 3.00 & $1-5$ \\
\hline
\end{tabular}


Table 14 Level 2 Internal Resource Factors of Study Population

\begin{tabular}{|c|c|c|c|c|c|c|c|c|c|}
\hline \multirow[b]{3}{*}{ Variable } & \multicolumn{3}{|c|}{ Overall $(\mathrm{N}=1390)$} & \multirow{2}{*}{\multicolumn{3}{|c|}{$\begin{array}{c}\text { Cancer Cases } \\
\qquad \begin{array}{c}\mathrm{N}=\mathbf{2 0 0} \\
\end{array}\end{array}$}} & \multicolumn{3}{|c|}{ Non-Cancer Cases $\mathrm{N}=1190$} \\
\hline & & & & & & & & & \\
\hline & $\bar{X}(\mathrm{SD})$ & Median & Range & $\bar{X}(S D)$ & Median & Range & $\bar{X}(\mathrm{SD})$ & Median & Range \\
\hline Optimism & $4.30(1.15)$ & 4.33 & $1-6$ & $4.17(1.08)$ & 4.00 & $1-6$ & $4.32(1.15)$ & 4.33 & $1-6$ \\
\hline Pessimism & $2.73(1.23)$ & 2.67 & $1-6$ & $2.77(1.17)$ & 3.00 & $1-6$ & $2.72(1.24)$ & 2.67 & $1-6$ \\
\hline
\end{tabular}




\section{External Resources}

Descriptive statistics for level two external resource predictors, continuous and categorical predictors are presented in Tables 15, 16, and 17 respectively. Table 15 Level 2 External Resource Factors of Study Population

\begin{tabular}{|c|c|c|c|c|c|c|}
\hline \multirow[b]{2}{*}{ Variable } & \multicolumn{2}{|c|}{$\begin{array}{c}\text { Overall } \\
(N=1390)\end{array}$} & \multicolumn{2}{|c|}{$\begin{array}{c}\text { Cancer Cases } \\
N=200\end{array}$} & \multicolumn{2}{|c|}{$\begin{array}{c}\text { Non-Cancer Cases } \\
\underline{\mathrm{N}=1190}\end{array}$} \\
\hline & $\bar{X}(\mathrm{SD})$ & Range & $\bar{X}(S D)$ & Range & $\bar{X}(\mathrm{SD})$ & Range \\
\hline Education & $12.63(3.02)$ & $0-17$ & $12.48(2.88)$ & $3-17$ & $12.66(3.05)$ & $0-17$ \\
\hline Social Support & $2.32(0.29)$ & $\begin{array}{l}1.14- \\
3.17\end{array}$ & $2.33(0.29)$ & $\begin{array}{l}1.50- \\
3.17\end{array}$ & $2.32(0.29)$ & $\begin{array}{l}1.14- \\
3.13\end{array}$ \\
\hline
\end{tabular}


Table 16 Sample Characteristics for Ordinal and Interval External Resource Predictors

\begin{tabular}{|c|c|c|c|c|c|c|c|c|c|c|}
\hline \multirow[b]{2}{*}{ Variable } & \multirow[b]{2}{*}{ Year } & \multicolumn{3}{|c|}{ Overall $(\mathrm{N}=1390)$} & \multicolumn{3}{|c|}{ Cancer Cases } & \multicolumn{3}{|c|}{ Non-Cancer Cases $\mathbf{N}=1190$} \\
\hline & & $\bar{X}(\mathrm{SD})$ & Median & Range & $\bar{X}(S D)$ & Median & Range & $\bar{X}(\mathrm{SD})$ & Median & Range \\
\hline \multirow{6}{*}{$\begin{array}{l}\text { Net Worth } \\
\text { (\$) }\end{array}$} & 2000 & $\begin{array}{c}309,644 \\
(327,110)\end{array}$ & 176,500 & $0-1,029,900$ & $\begin{array}{c}281,676 \\
(307,950)\end{array}$ & 155,000 & $0-1,029,900$ & $\begin{array}{c}314,971 \\
(330,886)\end{array}$ & 176,500 & $0-1,029,900$ \\
\hline & 2002 & $\begin{array}{c}316,564 \\
(314,603)\end{array}$ & 195,000 & $0-976,858$ & $\begin{array}{c}277,221 \\
(298,939)\end{array}$ & 145,000 & $0-976,858$ & $\begin{array}{c}322,804 \\
(317,489)\end{array}$ & 205,500 & $0-976,858$ \\
\hline & 2004 & $\begin{array}{c}345,347 \\
(340,210)\end{array}$ & 224,300 & $0-1,051,000$ & $\begin{array}{c}318,607 \\
(332,918)\end{array}$ & 184,250 & $0-1,051,000$ & $\begin{array}{c}350,178 \\
(341,565)\end{array}$ & 230,000 & $0-1,051,000$ \\
\hline & 2006 & $\begin{array}{c}396,191 \\
(391,816)\end{array}$ & 257,001 & $0-1,186,000$ & $\begin{array}{c}368,086 \\
(382,094)\end{array}$ & 218,500 & $0-1,186,000$ & $\begin{array}{c}401,870 \\
(393,476)\end{array}$ & 264,150 & $0-1,186,000$ \\
\hline & 2008 & $\begin{array}{c}402,240 \\
(402,996)\end{array}$ & 255,750 & $0-1,261,600$ & $\begin{array}{c}377,061 \\
(384,714)\end{array}$ & 227,000 & $0-1,261,600$ & $\begin{array}{c}407,695 \\
(406,159)\end{array}$ & 258,863 & $0-1,261,600$ \\
\hline & $\begin{array}{l}\text { Across } \\
\text { measurement } \\
\text { occasions }\end{array}$ & $\begin{array}{c}354,609 \\
(359,508)\end{array}$ & 221,369 & $0-1,261,600$ & $\begin{array}{c}324,147 \\
(344,704)\end{array}$ & 182,000 & $0-1,261,600$ & $\begin{array}{c}359,504 \\
(361,618)\end{array}$ & 225,900 & $0-1,261,600$ \\
\hline \multirow{6}{*}{$\begin{array}{c}\text { Health } \\
\text { Insurance }\end{array}$} & 2000 & $0.66(0.60)$ & 1.00 & $0.00-4.00$ & $0.63(0.61)$ & 1.00 & $0.00-4.00$ & $0.66(0.60)$ & 1.00 & $0.00-4.00$ \\
\hline & 2002 & $0.83(0.54)$ & 1.00 & $0.00-5.00$ & $0.81(0.54)$ & 1.00 & $0.00-4.00$ & $0.83(0.54)$ & 1.00 & $0.00-5.00$ \\
\hline & 2004 & $0.80(0.55)$ & 1.00 & $0.00-4.00$ & $0.81(0.54)$ & 1.00 & $0.00-2.00$ & $0.79(0.55)$ & 1.00 & $0.00-4.00$ \\
\hline & 2006 & $0.72(0.57)$ & 1.00 & $0.00-5.00$ & $0.73(0.61)$ & 1.00 & $0.00-4.00$ & $0.72(0.56)$ & 1.00 & $0.00-5.00$ \\
\hline & 2008 & $0.65(0.55)$ & 1.00 & $0.00-5.00$ & $0.67(0.55)$ & 1.00 & $0.00-2.00$ & $0.64(0.56$ & 1.00 & $0.00-5.00$ \\
\hline & $\begin{array}{c}\text { Across } \\
\text { measurement } \\
\text { occasions }\end{array}$ & $0.73(0.57)$ & 1.00 & $0.00-5.00$ & $0.73(0.57)$ & 1.00 & $0.00-4.00$ & $0.73(0.57)$ & 1.00 & $0.00-5.00$ \\
\hline
\end{tabular}


Table 17 Sample Characteristics for Categorical External Resource Predictors

\begin{tabular}{|c|c|c|c|c|c|c|c|c|c|c|c|c|c|c|c|}
\hline & \multicolumn{5}{|c|}{ Overall } & \multicolumn{5}{|c|}{ Cancer Cases } & \multicolumn{5}{|c|}{ Non Cancer Cases } \\
\hline & 2000 & 2002 & 2004 & 2006 & 2008 & 2000 & 2002 & 2004 & 2006 & 2008 & 2000 & 2002 & 2004 & 2006 & 2008 \\
\hline & $f(\%)$ & $f(\%)$ & $f(\%)$ & $f(\%)$ & $f(\%)$ & $f(\%)$ & $f(\%)$ & $f(\%)$ & $f(\%)$ & $f(\%)$ & $f(\%)$ & $f(\%)$ & $f(\%)$ & $f(\%)$ & $f(\%)$ \\
\hline \multicolumn{16}{|c|}{ Employment } \\
\hline $\begin{array}{l}\text { Works Full } \\
\text { or Part Time }\end{array}$ & $\begin{array}{c}480 \\
(34.8)\end{array}$ & $\begin{array}{c}392 \\
(28.4)\end{array}$ & $\begin{array}{c}315 \\
(22.7)\end{array}$ & $\begin{array}{c}262 \\
(18.9)\end{array}$ & $\begin{array}{c}206 \\
(15.0)\end{array}$ & $\begin{array}{c}55 \\
(28.8)\end{array}$ & $\begin{array}{c}38 \\
(19.8)\end{array}$ & $\begin{array}{c}28 \\
(14.3)\end{array}$ & $\begin{array}{c}25 \\
(12.9)\end{array}$ & $\begin{array}{c}19 \\
(10.4)\end{array}$ & $\begin{array}{c}425 \\
(35.7)\end{array}$ & $\begin{array}{c}354 \\
(29.7)\end{array}$ & $\begin{array}{c}287 \\
(24.1)\end{array}$ & $\begin{array}{c}237 \\
(19.9)\end{array}$ & $\begin{array}{c}187 \\
(15.7)\end{array}$ \\
\hline $\begin{array}{l}\text { Partially or } \\
\text { fully retired }\end{array}$ & $\begin{array}{c}700 \\
(50.7)\end{array}$ & $\begin{array}{c}787 \\
(56.9)\end{array}$ & $\begin{array}{c}903 \\
(65.2)\end{array}$ & $\begin{array}{c}971 \\
(70.2)\end{array}$ & $\begin{array}{c}1045 \\
(76.1)\end{array}$ & $\begin{array}{c}116 \\
(60.7)\end{array}$ & $\begin{array}{c}136 \\
(70.8)\end{array}$ & $\begin{array}{c}151 \\
(77.0)\end{array}$ & $\begin{array}{c}158 \\
(81.4)\end{array}$ & $\begin{array}{c}155 \\
(84.7)\end{array}$ & $\begin{array}{c}584 \\
(49.1)\end{array}$ & $\begin{array}{c}651 \\
(54.7)\end{array}$ & $\begin{array}{c}752 \\
(63.2)\end{array}$ & $\begin{array}{c}813 \\
(68.3)\end{array}$ & $\begin{array}{c}890 \\
(74.8)\end{array}$ \\
\hline $\begin{array}{l}\text { Disabled/ } \\
\text { Unemployed/ } \\
\text { Not in Labor } \\
\text { Force }\end{array}$ & $\begin{array}{c}201 \\
(14.6)\end{array}$ & $\begin{array}{c}203 \\
(14.7)\end{array}$ & $\begin{array}{c}168 \\
(12.1)\end{array}$ & $\begin{array}{c}151 \\
(10.9)\end{array}$ & $\begin{array}{c}122 \\
(8.9)\end{array}$ & $20(10.5)$ & $18(9.4)$ & $18(9.4)$ & $11(5.7)$ & $9(4.9)$ & $181(15.2)$ & $185(15.5)$ & $\begin{array}{c}151 \\
(12.7)\end{array}$ & $\begin{array}{c}140 \\
(11.8)\end{array}$ & $\begin{array}{c}113 \\
(9.5)\end{array}$ \\
\hline \multicolumn{16}{|c|}{ Marital Status } \\
\hline $\begin{array}{l}\text { No Spouse } \\
\text { or Partner } \\
\text { Present }\end{array}$ & $\begin{array}{c}372 \\
(26.9)\end{array}$ & $\begin{array}{c}401 \\
(29.0)\end{array}$ & $\begin{array}{c}426 \\
(30.7)\end{array}$ & $\begin{array}{c}470 \\
(34.0)\end{array}$ & $\begin{array}{c}500 \\
(36.4)\end{array}$ & $\begin{array}{c}58 \\
(30.4)\end{array}$ & $\begin{array}{c}61 \\
(31.8)\end{array}$ & $\begin{array}{c}60 \\
(30.6)\end{array}$ & $\begin{array}{c}64 \\
(33.0)\end{array}$ & $\begin{array}{c}65 \\
(35.5)\end{array}$ & $\begin{array}{c}314 \\
(26.4)\end{array}$ & $\begin{array}{c}340 \\
(28.6)\end{array}$ & $\begin{array}{c}366 \\
(30.8)\end{array}$ & $\begin{array}{c}406 \\
(34.1)\end{array}$ & $\begin{array}{c}435 \\
(36.6)\end{array}$ \\
\hline $\begin{array}{l}\text { Spouse or } \\
\text { Partner } \\
\text { Present }\end{array}$ & $\begin{array}{c}1009 \\
(73.1)\end{array}$ & $\begin{array}{c}981 \\
(71.0)\end{array}$ & $\begin{array}{c}960 \\
(69.3)\end{array}$ & $\begin{array}{c}914 \\
(66.0)\end{array}$ & $\begin{array}{c}873 \\
(63.6)\end{array}$ & $\begin{array}{c}133 \\
(69.6)\end{array}$ & $\begin{array}{c}131 \\
(68.2)\end{array}$ & $\begin{array}{c}136 \\
(69.4)\end{array}$ & $\begin{array}{c}130 \\
(67.0)\end{array}$ & $\begin{array}{c}118 \\
(64.5)\end{array}$ & $\begin{array}{c}876 \\
(73.6)\end{array}$ & $\begin{array}{c}850 \\
(71.4)\end{array}$ & $\begin{array}{c}824 \\
(69.2)\end{array}$ & $\begin{array}{c}784 \\
(65.9)\end{array}$ & $\begin{array}{c}755 \\
(63.4)\end{array}$ \\
\hline \multicolumn{16}{|c|}{ Psychological /Psychiatric Tx } \\
\hline $\begin{array}{l}\text { No } \\
\text { psychiatric } \\
\text { problems }\end{array}$ & $\begin{array}{c}1360 \\
(98.5)\end{array}$ & $\begin{array}{c}1189 \\
(86.0)\end{array}$ & $\begin{array}{c}1181 \\
(85.2)\end{array}$ & $\begin{array}{c}1161 \\
(83.9)\end{array}$ & $\begin{array}{c}1153 \\
(84.0)\end{array}$ & $\begin{array}{c}170 \\
(89.0)\end{array}$ & $\begin{array}{c}171 \\
(89.1)\end{array}$ & $\begin{array}{c}176 \\
(89.8)\end{array}$ & $\begin{array}{c}170 \\
(87.6)\end{array}$ & $\begin{array}{c}165 \\
(90.2)\end{array}$ & $\begin{array}{c}1190 \\
(100.0)\end{array}$ & $\begin{array}{c}1018 \\
(85.5)\end{array}$ & $\begin{array}{c}1005 \\
(84.5)\end{array}$ & $\begin{array}{c}991 \\
(83.3)\end{array}$ & $\begin{array}{c}988 \\
(83.0)\end{array}$ \\
\hline $\begin{array}{l}\text { Psychiatric } \\
\text { problems } \\
\text { with } \\
\text { counseling } \\
\text { and/or meds }\end{array}$ & $11(0.8)$ & $\begin{array}{c}193 \\
(14.0)\end{array}$ & $\begin{array}{c}205 \\
(14.8)\end{array}$ & $\begin{array}{c}223 \\
(16.1)\end{array}$ & $\begin{array}{c}220 \\
(16.0)\end{array}$ & $11(5.8)$ & $\begin{array}{c}21 \\
(10.9)\end{array}$ & $\begin{array}{c}20 \\
(10.2)\end{array}$ & $\begin{array}{c}24 \\
(12.4)\end{array}$ & $\begin{array}{c}18 \\
(9.8)\end{array}$ & 0 & $\begin{array}{c}172 \\
(14.5)\end{array}$ & $\begin{array}{c}185 \\
(15.0)\end{array}$ & $\begin{array}{c}199 \\
(16.7)\end{array}$ & $\begin{array}{c}202 \\
(17.0)\end{array}$ \\
\hline $\begin{array}{l}\text { Psychiatric } \\
\text { problems/no } \\
\text { support }\end{array}$ & $10(0.7)$ & 0 & 0 & 0 & 0 & $10(5.2)$ & 0 & 0 & 0 & 0 & 0 & 0 & 0 & 0 & 0 \\
\hline
\end{tabular}

\section{Health Related Resources}


Descriptive statistics for health related variables are highlighted in Tables 18 and 19.

Table 18 Sample Characteristics for Ordinal Health-Related Resource Predictors ( $N=1390)$

\begin{tabular}{|c|c|c|c|c|c|c|c|c|c|c|}
\hline \multirow[b]{2}{*}{ Variable } & \multirow[b]{2}{*}{ Year } & \multicolumn{3}{|c|}{ Overall $(\mathrm{N}=1390)$} & \multicolumn{3}{|c|}{ Cancer Cases } & \multicolumn{3}{|c|}{ Non-Cancer Cases $N=1190$} \\
\hline & & $\bar{X}(\mathrm{SD})$ & Median & Range & $\bar{X}(S D)$ & Median & Range & $\bar{X}(\mathrm{SD})$ & Median & Range \\
\hline \multirow{6}{*}{$\begin{array}{l}\text { Co-morbid } \\
\text { Conditions } \\
\text { (sum) }\end{array}$} & 2000 & $\begin{array}{c}1.55 \\
(1.25)\end{array}$ & 1.00 & $0.00-6.00$ & $2.53(1.16)$ & 2.00 & $1.00-6.00$ & $\begin{array}{c}1.40 \\
(1.20)\end{array}$ & 1.00 & $0.00-6.00$ \\
\hline & 2002 & $\begin{array}{l}1.76 \\
(1.31)\end{array}$ & 2.00 & $0.00-7.00$ & $2.74(1.19)$ & 3.00 & $1.00-7.00$ & $\begin{array}{c}1.60 \\
(1.26)\end{array}$ & 2.00 & $0.00-6.00$ \\
\hline & 2004 & $\begin{array}{l}1.98 \\
(1.38)\end{array}$ & 2.00 & $0.00-7.00$ & $2.96(1.34)$ & 3.00 & $1.00-7.00$ & $\begin{array}{l}1.82 \\
(1.32)\end{array}$ & 2.00 & $0.00-6.00$ \\
\hline & 2006 & $\begin{array}{c}2.18 \\
(1.42)\end{array}$ & 2.00 & $0.00-7.00$ & $3.19(1.38)$ & 3.00 & $1.00-7.00$ & $\begin{array}{c}2.01 \\
(1.35)\end{array}$ & 2.00 & $0.00-7.00$ \\
\hline & 2008 & $\begin{array}{c}2.35 \\
(1.44)\end{array}$ & 2.00 & $0.00-7.00$ & $3.32(1.41)$ & 3.00 & $1.00-7.00$ & $\begin{array}{c}2.20 \\
(1.39)\end{array}$ & 2.00 & $0.00-7.00$ \\
\hline & $\begin{array}{c}\text { Across } \\
\text { measurement } \\
\text { occasions } \\
\end{array}$ & $\begin{array}{c}1.96 \\
(1.39)\end{array}$ & 2.00 & $0.00-7.00$ & $2.95(1.33)$ & 3.00 & $1.00-7.00$ & $\begin{array}{c}1.80 \\
(1.34)\end{array}$ & 2.00 & $0.00-7.00$ \\
\hline
\end{tabular}


Table 19 Sample Characteristics for Categorical Health-Related Resource Predictors ( $N=1390)$

\begin{tabular}{|c|c|c|c|c|c|c|c|c|c|c|c|c|c|c|c|}
\hline & \multicolumn{5}{|c|}{ Overall } & \multicolumn{5}{|c|}{ Cancer Cases } & \multicolumn{5}{|c|}{ Non Cancer Cases } \\
\hline & 2000 & 2002 & 2004 & 2006 & 2008 & 2000 & 2002 & 2004 & 2006 & 2008 & 2000 & 2002 & 2004 & 2006 & 2008 \\
\hline & $f(\%)$ & $f(\%)$ & $f(\%)$ & $f(\%)$ & $f(\%)$ & $f(\%)$ & $f(\%)$ & $f(\%)$ & $f(\%)$ & $f(\%)$ & $f(\%)$ & $f(\%)$ & $f(\%)$ & $f(\%)$ & $f(\%)$ \\
\hline \multicolumn{16}{|c|}{ Days In Bed } \\
\hline $\begin{array}{l}\text { No Days in } \\
\text { Bed }\end{array}$ & $\begin{array}{c}1224 \\
(88.6)\end{array}$ & $\begin{array}{c}1241 \\
(89.8)\end{array}$ & $\begin{array}{c}1267 \\
(91.4)\end{array}$ & $\begin{array}{c}1260 \\
(91.0)\end{array}$ & $\begin{array}{l}1232 \\
(89.7)\end{array}$ & $\begin{array}{l}168 \\
(88)\end{array}$ & $\begin{array}{c}174 \\
(90.6)\end{array}$ & $\begin{array}{c}177 \\
(90.3)\end{array}$ & $\begin{array}{c}175 \\
(90.2)\end{array}$ & $\begin{array}{c}164 \\
(89.6)\end{array}$ & $\begin{array}{c}1056 \\
(88.7)\end{array}$ & $\begin{array}{c}1067 \\
(89.7)\end{array}$ & $\begin{array}{l}1090 \\
(91.6)\end{array}$ & $\begin{array}{l}1085 \\
(91.2)\end{array}$ & $\begin{array}{l}1068 \\
(89.7\end{array}$ \\
\hline $\begin{array}{l}\text { One or More } \\
\text { Days in Bed }\end{array}$ & $\begin{array}{c}157 \\
(11.4)\end{array}$ & $\begin{array}{c}141 \\
(10.2)\end{array}$ & $\begin{array}{c}119 \\
(8.6)\end{array}$ & $\begin{array}{c}124 \\
(9.0)\end{array}$ & $\begin{array}{c}141 \\
(10.3)\end{array}$ & $\begin{array}{c}23 \\
(12.0)\end{array}$ & $\begin{array}{c}23 \\
(12.0)\end{array}$ & $\begin{array}{c}19 \\
(9.7)\end{array}$ & $\begin{array}{c}19 \\
(9.8)\end{array}$ & $\begin{array}{c}19 \\
(10.4)\end{array}$ & $\begin{array}{c}134 \\
(11.3)\end{array}$ & $\begin{array}{c}123 \\
(10.3)\end{array}$ & $\begin{array}{c}100 \\
(8.4)\end{array}$ & $\begin{array}{c}105 \\
(8.8)\end{array}$ & $\begin{array}{c}122 \\
(10.2)\end{array}$ \\
\hline \multicolumn{16}{|c|}{ Pain } \\
\hline None & $\begin{array}{l}1008 \\
(73.0)\end{array}$ & $\begin{array}{c}983 \\
(71.1)\end{array}$ & $\begin{array}{c}951 \\
(68.6)\end{array}$ & $\begin{array}{c}927 \\
(67.0)\end{array}$ & $\begin{array}{c}922 \\
(67.2)\end{array}$ & $\begin{array}{c}140 \\
(73.3)\end{array}$ & $\begin{array}{c}138 \\
(71.9)\end{array}$ & $\begin{array}{c}128 \\
(65.3)\end{array}$ & $\begin{array}{c}122 \\
(62.9)\end{array}$ & $\begin{array}{c}113 \\
(61.7)\end{array}$ & $\begin{array}{c}868 \\
(72.9)\end{array}$ & $\begin{array}{c}845 \\
(71.0)\end{array}$ & $\begin{array}{c}823 \\
(69.2)\end{array}$ & $\begin{array}{c}805 \\
(69.2)\end{array}$ & $\begin{array}{c}809 \\
(68.0)\end{array}$ \\
\hline Mild & $\begin{array}{c}121 \\
(8.8)\end{array}$ & $\begin{array}{c}118 \\
(8.5)\end{array}$ & $\begin{array}{c}132 \\
(9.5)\end{array}$ & $\begin{array}{c}140 \\
(10.1)\end{array}$ & $\begin{array}{l}110 \\
(8.0)\end{array}$ & $\begin{array}{c}16 \\
(8.4)\end{array}$ & $\begin{array}{c}12 \\
(6.3)\end{array}$ & $\begin{array}{c}19 \\
(9.7)\end{array}$ & $\begin{array}{c}25 \\
(12.9)\end{array}$ & $\begin{array}{c}20 \\
(10.9)\end{array}$ & $\begin{array}{c}105 \\
(8.8)\end{array}$ & $\begin{array}{c}106 \\
(8.9)\end{array}$ & $\begin{array}{c}113 \\
(9.5)\end{array}$ & $\begin{array}{c}115 \\
(9.7)\end{array}$ & $\begin{array}{c}90 \\
(7.6)\end{array}$ \\
\hline Moderate & $\begin{array}{c}209 \\
(15.1)\end{array}$ & $\begin{array}{c}227 \\
(16.4)\end{array}$ & $\begin{array}{c}255 \\
(18.4)\end{array}$ & $\begin{array}{c}240 \\
(17.3)\end{array}$ & $\begin{array}{c}283 \\
(20.6)\end{array}$ & $\begin{array}{c}30 \\
(15.7)\end{array}$ & $\begin{array}{c}37 \\
(19.3)\end{array}$ & $\begin{array}{c}42 \\
(21.4)\end{array}$ & $\begin{array}{c}40 \\
(20.6)\end{array}$ & $\begin{array}{c}41 \\
(22.4)\end{array}$ & $\begin{array}{c}179 \\
(15.0)\end{array}$ & $\begin{array}{c}190 \\
(16.0)\end{array}$ & $\begin{array}{c}213 \\
(17.9)\end{array}$ & $\begin{array}{c}200 \\
(16.8)\end{array}$ & $\begin{array}{c}242 \\
(20.3)\end{array}$ \\
\hline Severe & $\begin{array}{c}43 \\
(3.1)\end{array}$ & $\begin{array}{c}54 \\
(3.9)\end{array}$ & $\begin{array}{c}48 \\
(3.5)\end{array}$ & $\begin{array}{c}77 \\
(5.6)\end{array}$ & $\begin{array}{c}58 \\
(4.2)\end{array}$ & $5(2.6)$ & $5(2.6)$ & $7(3.6)$ & $7(3.6)$ & $9(4.9)$ & $\begin{array}{c}38 \\
(3.2)\end{array}$ & $\begin{array}{c}49 \\
(4.1)\end{array}$ & $\begin{array}{c}41 \\
(3.4)\end{array}$ & $\begin{array}{c}70 \\
(5.9)\end{array}$ & $\begin{array}{c}49 \\
(4.1)\end{array}$ \\
\hline \multicolumn{16}{|c|}{ ADL \& IADL Summary } \\
\hline No Difficulty & $\begin{array}{c}1213 \\
(87.8)\end{array}$ & $\begin{array}{c}1188 \\
(86.0)\end{array}$ & $\begin{array}{c}1171 \\
(84.5)\end{array}$ & $\begin{array}{l}1148 \\
(82.9)\end{array}$ & $\begin{array}{l}1103 \\
(80.3)\end{array}$ & $\begin{array}{c}160 \\
(83.8)\end{array}$ & $\begin{array}{c}161 \\
(83.9)\end{array}$ & $\begin{array}{c}147 \\
(75.0)\end{array}$ & $\begin{array}{c}150 \\
(77.3)\end{array}$ & $\begin{array}{c}136 \\
(74.3)\end{array}$ & $\begin{array}{r}1053 \\
\mathbf{( 8 8 . 5 )}\end{array}$ & $\begin{array}{c}1027 \\
(86.3)\end{array}$ & $\begin{array}{c}1024 \\
(86.1)\end{array}$ & $\begin{array}{c}998 \\
(83.9)\end{array}$ & $\begin{array}{c}967 \\
(81.3)\end{array}$ \\
\hline $\begin{array}{l}\text { Difficulty } \\
\text { with } 1 \text { or } \\
\text { More }\end{array}$ & $\begin{array}{c}168 \\
(12.2)\end{array}$ & $\begin{array}{c}194 \\
(14.0)\end{array}$ & $\begin{array}{c}215 \\
(15.5)\end{array}$ & $\begin{array}{c}236 \\
(17.1)\end{array}$ & $\begin{array}{c}270 \\
(19.7)\end{array}$ & $\begin{array}{c}31 \\
(16.2)\end{array}$ & $\begin{array}{c}31 \\
(16.1)\end{array}$ & $\begin{array}{c}48 \\
(25.0)\end{array}$ & $\begin{array}{c}44 \\
(22.7)\end{array}$ & $\begin{array}{c}47 \\
(25.7)\end{array}$ & $\begin{array}{c}137 \\
(11.5)\end{array}$ & $\begin{array}{c}163 \\
(13.7)\end{array}$ & $\begin{array}{c}166 \\
(13.9)\end{array}$ & $\begin{array}{c}192 \\
(16.1)\end{array}$ & $\begin{array}{c}223 \\
(18.7)\end{array}$ \\
\hline
\end{tabular}




\section{Criterion Variable}

The final set of tables (20 and 21) provides descriptive statistics for the criterion variable as well as its bivariate relationship with the predictor variables.

Table 20 Sample Characteristics of Criterion Variable: Distress

\begin{tabular}{|c|c|c|c|c|c|c|c|c|c|c|}
\hline \multirow[b]{2}{*}{ Variable } & \multirow[b]{2}{*}{ Year } & \multicolumn{3}{|c|}{ Overall $(\mathrm{N}=1390)$} & \multicolumn{3}{|c|}{ Cancer Cases N=200 } & \multicolumn{3}{|c|}{ Non-Cancer Cases $N=1190$} \\
\hline & & $\bar{X}(\mathrm{SD})$ & Median & Range & $\bar{X}(S D)$ & Median & Range & $\bar{X}(\mathrm{SD})$ & Median & $\overline{\text { Range }}$ \\
\hline \multirow{6}{*}{$\begin{array}{l}\text { Distress } \\
\text { Symptoms }\end{array}$} & 2000 & $\begin{array}{c}0.66 \\
(1.17)\end{array}$ & 0.00 & $0-5.00$ & $0.71(1.19)$ & 0.00 & $0-5.00$ & $\begin{array}{c}0.65 \\
(1.17)\end{array}$ & 0.00 & $0-5.00$ \\
\hline & 2002 & $\begin{array}{c}0.66 \\
(1.22)\end{array}$ & 0.00 & $0-5.00$ & $0.51(1.02)$ & 0.00 & $0-4.00$ & $\begin{array}{c}0.68 \\
(1.25)\end{array}$ & 0.00 & $0-5.00$ \\
\hline & 2004 & $\begin{array}{c}0.62 \\
(1.18)\end{array}$ & 0.00 & $0-5.00$ & $0.65(1.03)$ & 0.00 & $0-5.00$ & $\begin{array}{c}0.62 \\
(1.20)\end{array}$ & 0.00 & $0-5.00$ \\
\hline & 2006 & $\begin{array}{c}0.64 \\
(1.19)\end{array}$ & 0.00 & $0-5.00$ & $0.58(1.05)$ & 0.00 & $0-5.00$ & $\begin{array}{c}0.65 \\
(1.21)\end{array}$ & 0.00 & $0-5.00$ \\
\hline & 2008 & $\begin{array}{c}0.57 \\
(1.13)\end{array}$ & 0.00 & $0-5.00$ & $0.62(1.14)$ & 0.00 & $0-5.00$ & $\begin{array}{c}0.57 \\
(1.13)\end{array}$ & 0.00 & $0-5.00$ \\
\hline & $\begin{array}{l}\text { Across } \\
\text { measurement } \\
\text { occasions }\end{array}$ & $\begin{array}{c}0.63 \\
(1.18)\end{array}$ & 0.00 & $0-5.00$ & $0.62(1.08)$ & 0.00 & $0-5.00$ & $\begin{array}{c}0.63 \\
(1.19)\end{array}$ & 0.00 & $0-5.00$ \\
\hline
\end{tabular}


Table 21 Relationships between Criterion Variable and Continuous Predictors (Across All Measurement Occasions)

\begin{tabular}{|c|c|c|c|c|c|c|c|c|c|c|c|}
\hline & $\begin{array}{l}\text { Age years } \\
\text { in } 2000\end{array}$ & $\begin{array}{c}\text { Subjective } \\
\text { Physical } \\
\text { Health }\end{array}$ & $\begin{array}{c}\text { Subjective } \\
\text { Life } \\
\text { Expectancy }\end{array}$ & Optimism & Pessimism & $\begin{array}{c}\text { Education in } \\
\text { Years }\end{array}$ & $\begin{array}{c}\text { Net } \\
\text { Worth }\end{array}$ & $\begin{array}{l}\text { Health } \\
\text { Plans }\end{array}$ & $\begin{array}{l}\text { Social } \\
\text { Support }\end{array}$ & $\begin{array}{l}\text { Comorbid } \\
\text { Conditions }\end{array}$ & Pain \\
\hline \multicolumn{12}{|c|}{ Spearman Rho } \\
\hline Distress & $0.027^{\star}$ & $.292^{\star *}$ & $-.141^{\star \star}$ & $-.120^{* *}$ & $.154^{\star \star}$ & $-.143^{\star \star}$ & $-.187^{\star \star}$ & $-.095^{\star \star}$ & $-.107^{\star \star}$ & $.172^{\star \star}$ & $.180^{\star \star}$ \\
\hline
\end{tabular}


Poorer self-rated health was significantly associated with higher distress.

Increasing pessimism, co-morbid conditions, and pain were all significantly associated with increased distress. Finally, as rates of subjective life expectancy, optimism, education, net worth, health plans, and social support went down, rates of distress increased significantly. 
Table 22 Relationships Between Criterion Variable and Categorical Predictors (Across All Measurement Occasions)

\begin{tabular}{|c|c|c|c|}
\hline \multicolumn{4}{|c|}{ Overall Distress Symptoms } \\
\hline & $\%$ of sample & $\%$ above median & $d f$ \\
\hline \multicolumn{4}{|l|}{ Race/Ethnicity } \\
\hline White & 82.2 & 27.72 & \multirow{2}{*}{$95.12^{\star \star \star}$} \\
\hline Other & 17.8 & 41.80 & \\
\hline \multicolumn{4}{|l|}{ Gender } \\
\hline Males & 61.7 & 23.83 & \multirow{2}{*}{$81.39^{\star \star \star}$} \\
\hline Females & 38.3 & 34.15 & \\
\hline \multicolumn{4}{|l|}{ Cancer History } \\
\hline No & 85.6 & 29.89 & \multirow{2}{*}{2.29} \\
\hline Yes & 14.4 & 32.32 & \\
\hline \multicolumn{4}{|l|}{1998 (pre-cancer) Distress } \\
\hline None & 69.9 & 20.04 & \multirow{3}{*}{$869.53^{\star \star \star}$} \\
\hline 1 Symptom & 15.0 & 46.16 & \\
\hline 2-5 Symptoms & 15.3 & 62.27 & \\
\hline \multicolumn{4}{|l|}{ Employment } \\
\hline Works Full or Part Time & 24.0 & 27.31 & \multirow{3}{*}{$46.16^{\star \star \star}$} \\
\hline Partially or Fully Retired & 63.8 & 29.46 & \\
\hline $\begin{array}{l}\text { Disabled / Unemployed / } \\
\text { Not in Labor Force }\end{array}$ & 12.2 & 40.00 & \\
\hline \multicolumn{4}{|l|}{ Marital Status } \\
\hline No Spouse or Partner Present & 31.4 & 43.98 & \multirow{2}{*}{$283.38^{\star \star \star}$} \\
\hline Spouse or Partner Present & 68.6 & 23.94 & \\
\hline \multicolumn{4}{|l|}{ Psych Support } \\
\hline No Psych Problems & 87.5 & 26.57 & \multirow{3}{*}{$309.19^{\star \star \star}$} \\
\hline Psych Problems with Support & 12.3 & 56.10 & \\
\hline Psych Problems with No Support & 0.10 & 40.00 & \\
\hline \multicolumn{4}{|l|}{ Days in Bed } \\
\hline No Days in Bed & 90.1 & 28.36 & \multirow{2}{*}{$105.22^{\star \star \star}$} \\
\hline 1 or More Days in Bed & 9.9 & 47.36 & \\
\hline \multicolumn{4}{|l|}{ ADLs and IADLs } \\
\hline No Problems with ADLs and IADLs & 84.3 & 26.19 & \multirow{2}{*}{$288.08^{\star \star \star}$} \\
\hline One or More Problems with ADLs and IADLs & 15.7 & 51.99 & \\
\hline
\end{tabular}

Average distress ratings differed significantly by race/ethnicity, with those in the other category having greater distress. Females had greater average distress than males and those with a cancer history had greater distress than those without cancer. Those with a mild and severe history of distress in 1998 
(pre study period and prior to cancer) had greater overall distress than those with no history of distress. Part and full time workers and retired individuals had less distress on average than those who were disabled, unemployed or not in the labor force. Those with a spouse or partner present in the household were less distressed, on average, than those with no spouse or partner present. Participants who had psychological problems and were receiving psychological support had greater average distress than those with no psychological problems or those with problems but no support. Average distress was higher for those who spent one or more days in bed in past 30 days than those who had no beds days. Finally, those who had problems with one or more activities of daily living had more average distress than those who had no problems with ADLs.

The next sections describe the model building process. First, initial considerations related to the multilevel structure of the data are discussed. Following that, the details of building several sub-models and the final model are described. Discussion of results is organized by the two research questions.

\section{Model Building}

\section{Assessing the Need for the Multilevel Model}

An easy way to initially assess patterns of change in a study population is to graph actual growth trajectories for a sample of cases and visually inspect them (Singer \& Willett, 2003). Values of the criterion variable were plotted for each of 20 randomly selected individuals with cancer on each of their measurement occasions. These are presented in Figure 7. In these individual growth plots, several things can be observed. First, some cases (e.g., case 
number 10395010) reported no symptoms of depression on all measurement occasions, while others (e.g., case number 10994010) reported three or more symptoms of depression across all measurement occasions. Between these extremes, cases experienced a variety of differing trajectories. Some (e.g., case number 12573010 ) reported high levels of depression symptoms in 2000 , then symptoms went down over the remaining measurement occasions.
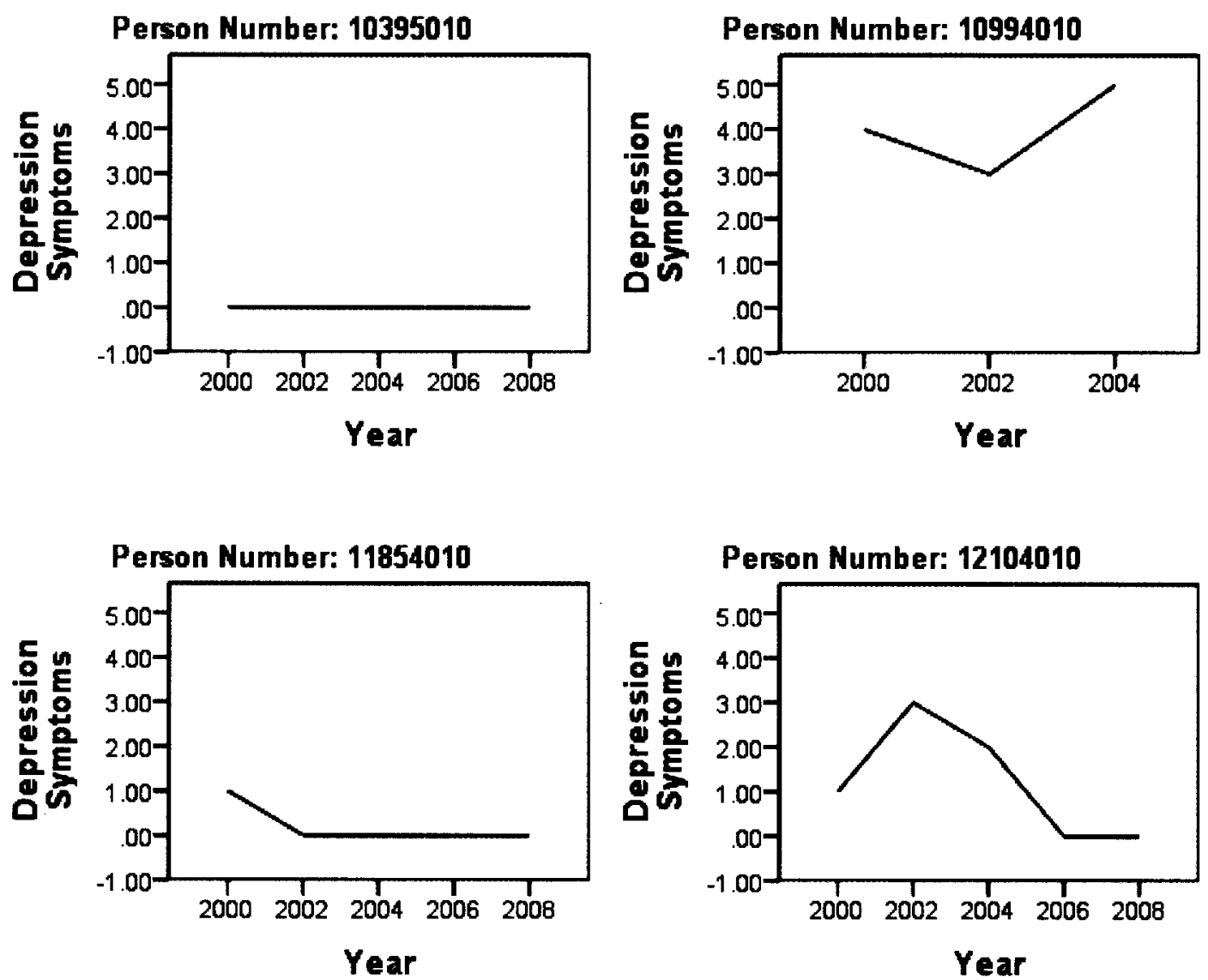

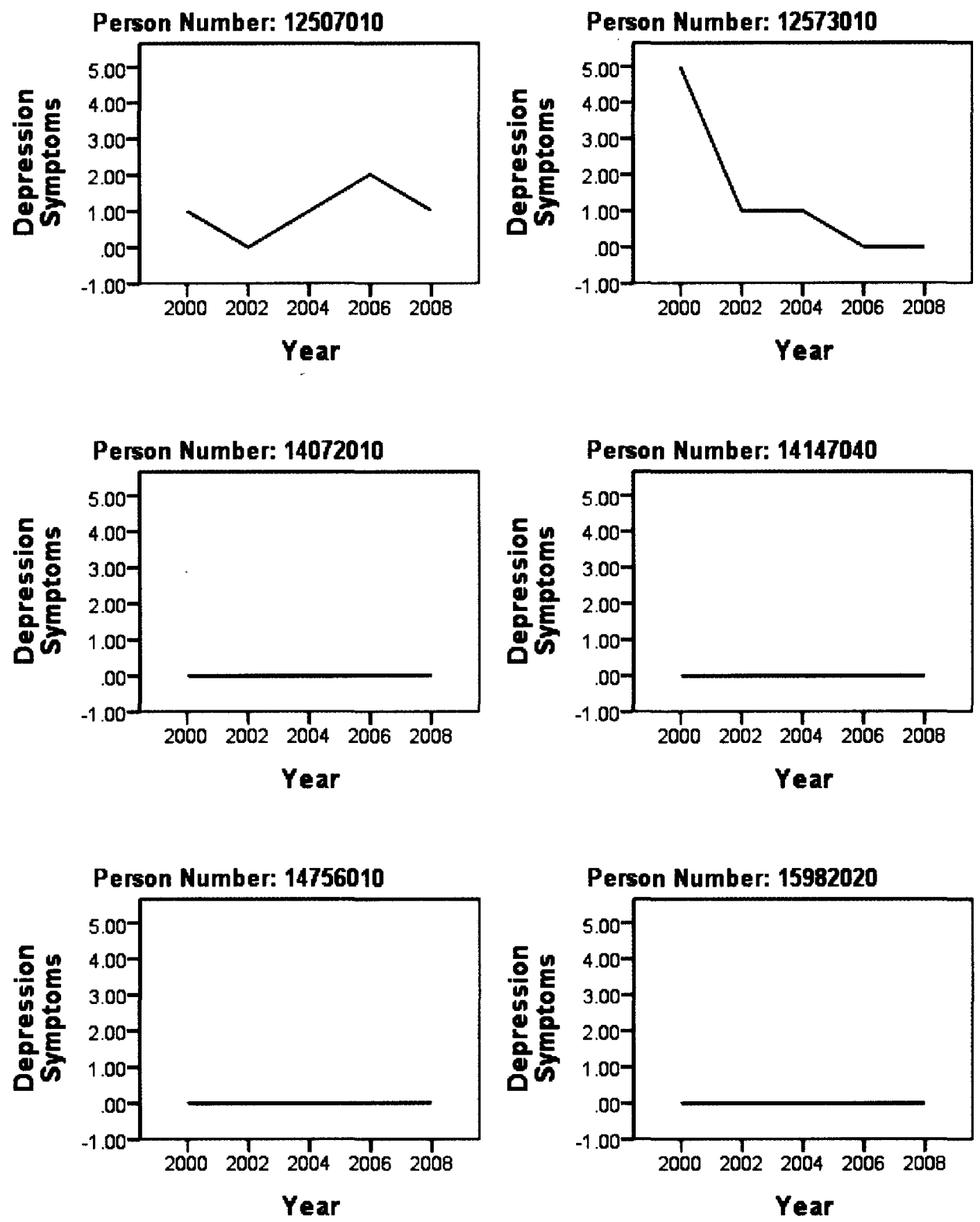

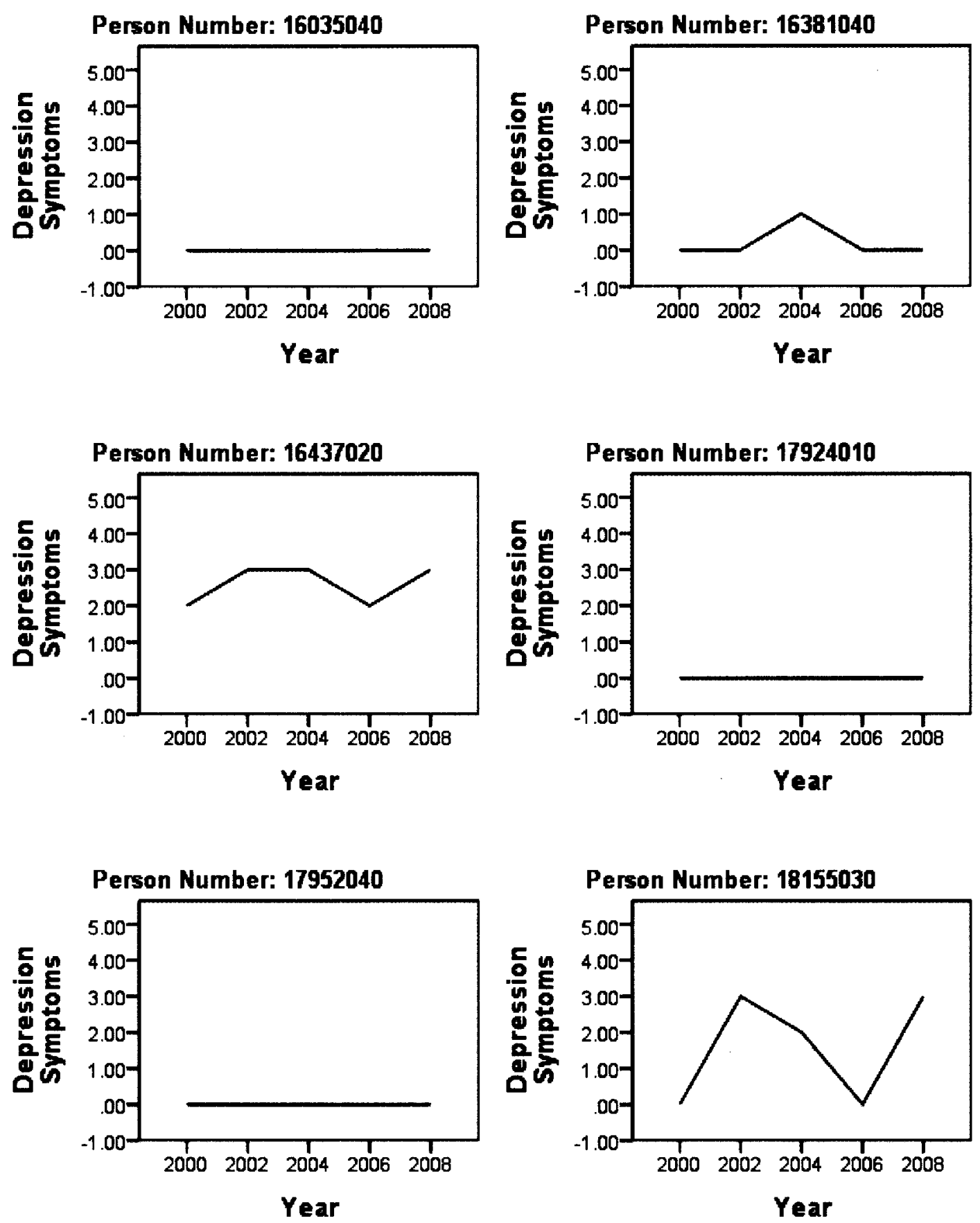

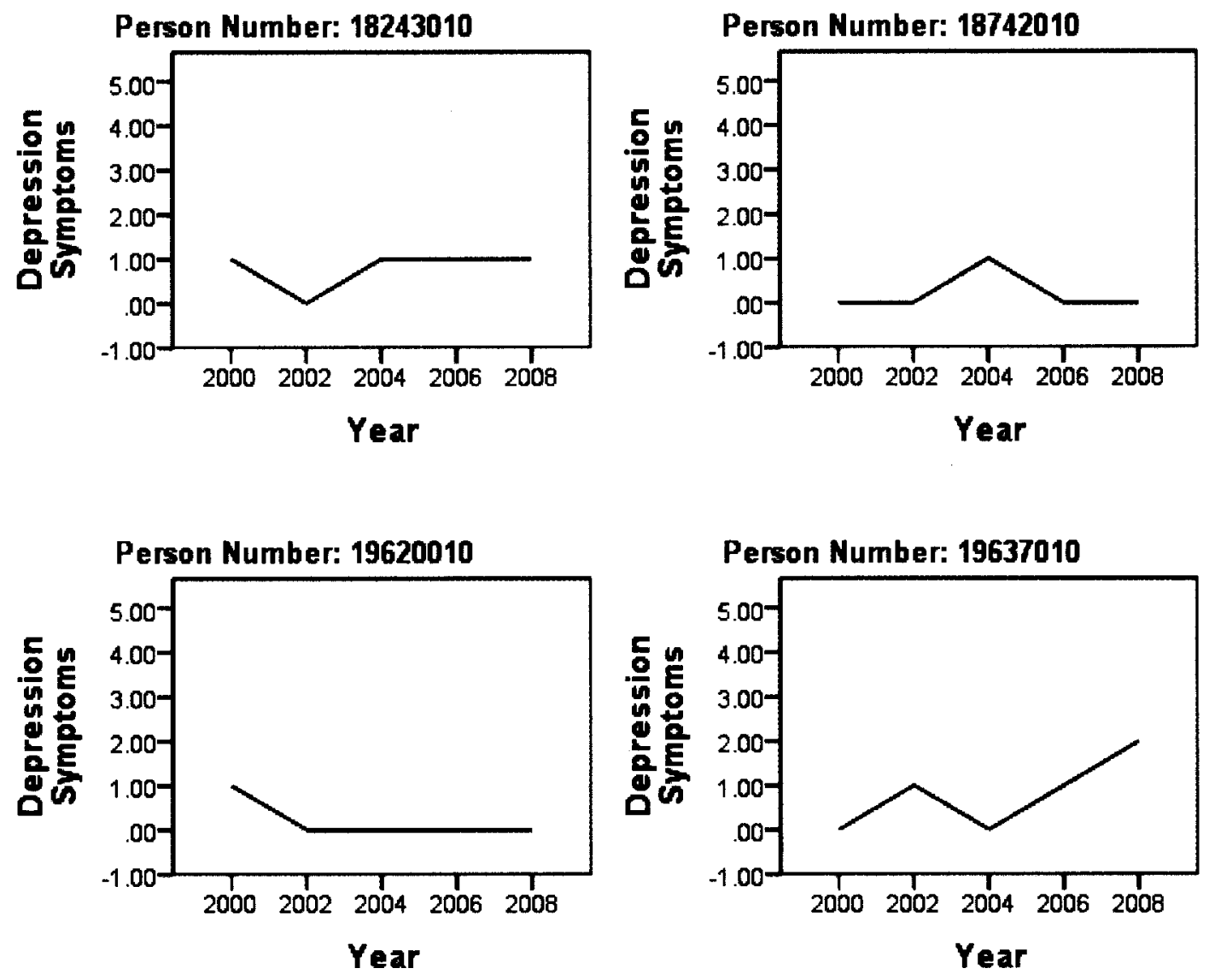

Figure 7. Empirical growth plots for a sample of the cancer cases.

Next, values of the criterion variable were plotted for each of 20 randomly selected individuals with no history of cancer on each of their measurement occasions. These are presented in Figure 8 . In these individual growth plots, similar patterns were observed than for the cancer cases, namely some cases (e.g., case number 10397010) reported no symptoms of depression on all measurement occasions, while others (e.g., case number 10210020) reported three or more symptoms of depression across all measurement occasions. Between these extremes, cases experienced a variety of differing trajectories. 

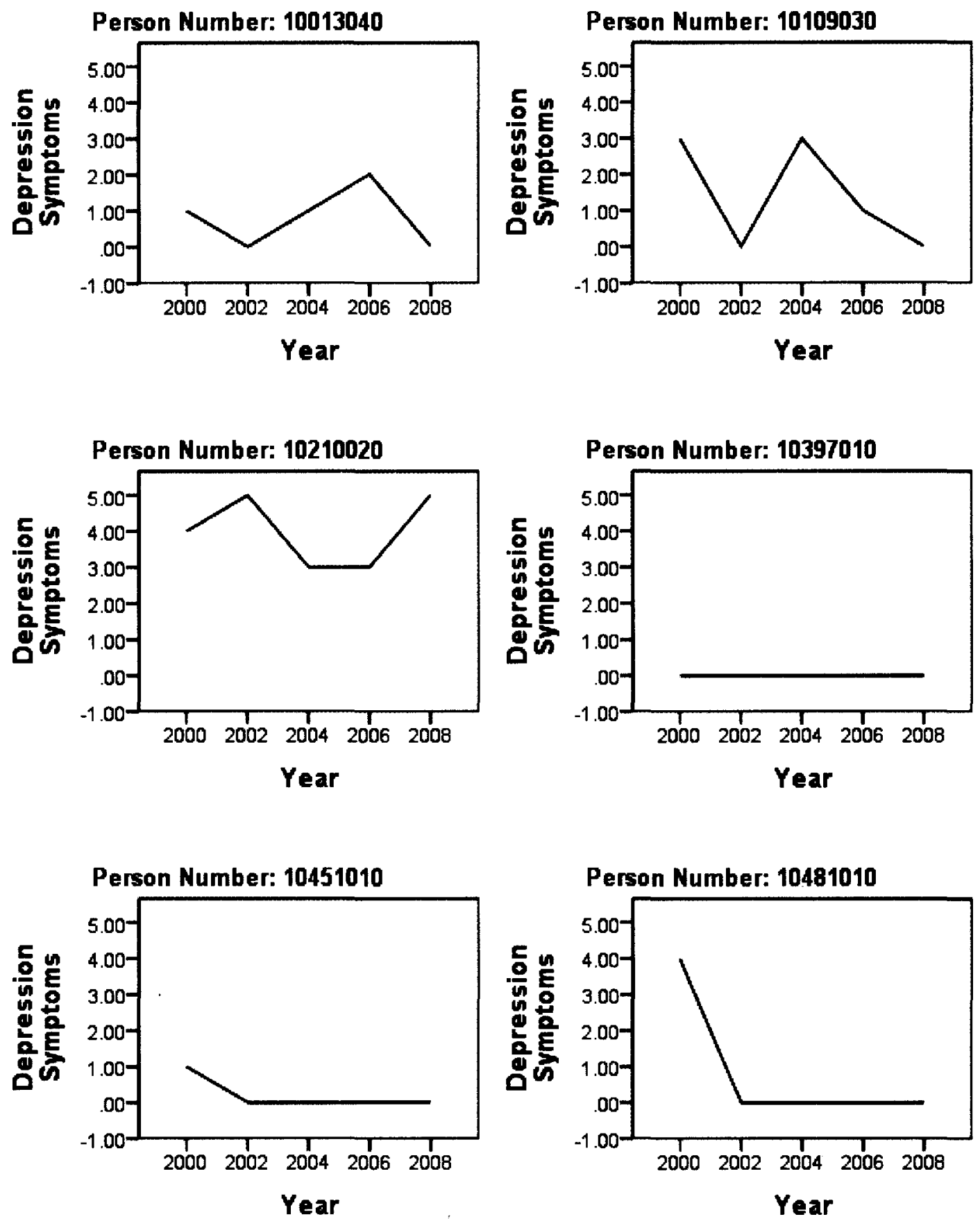

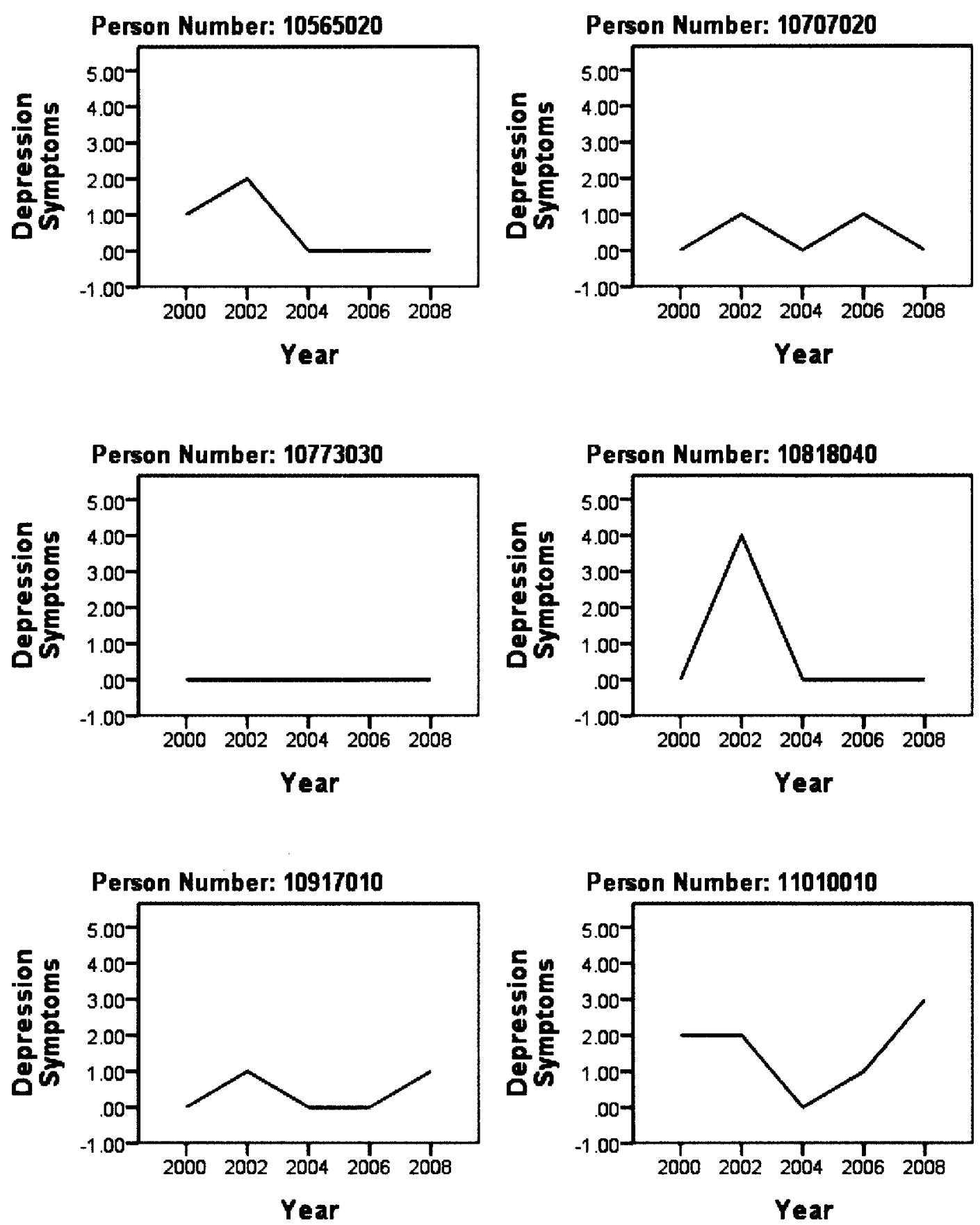

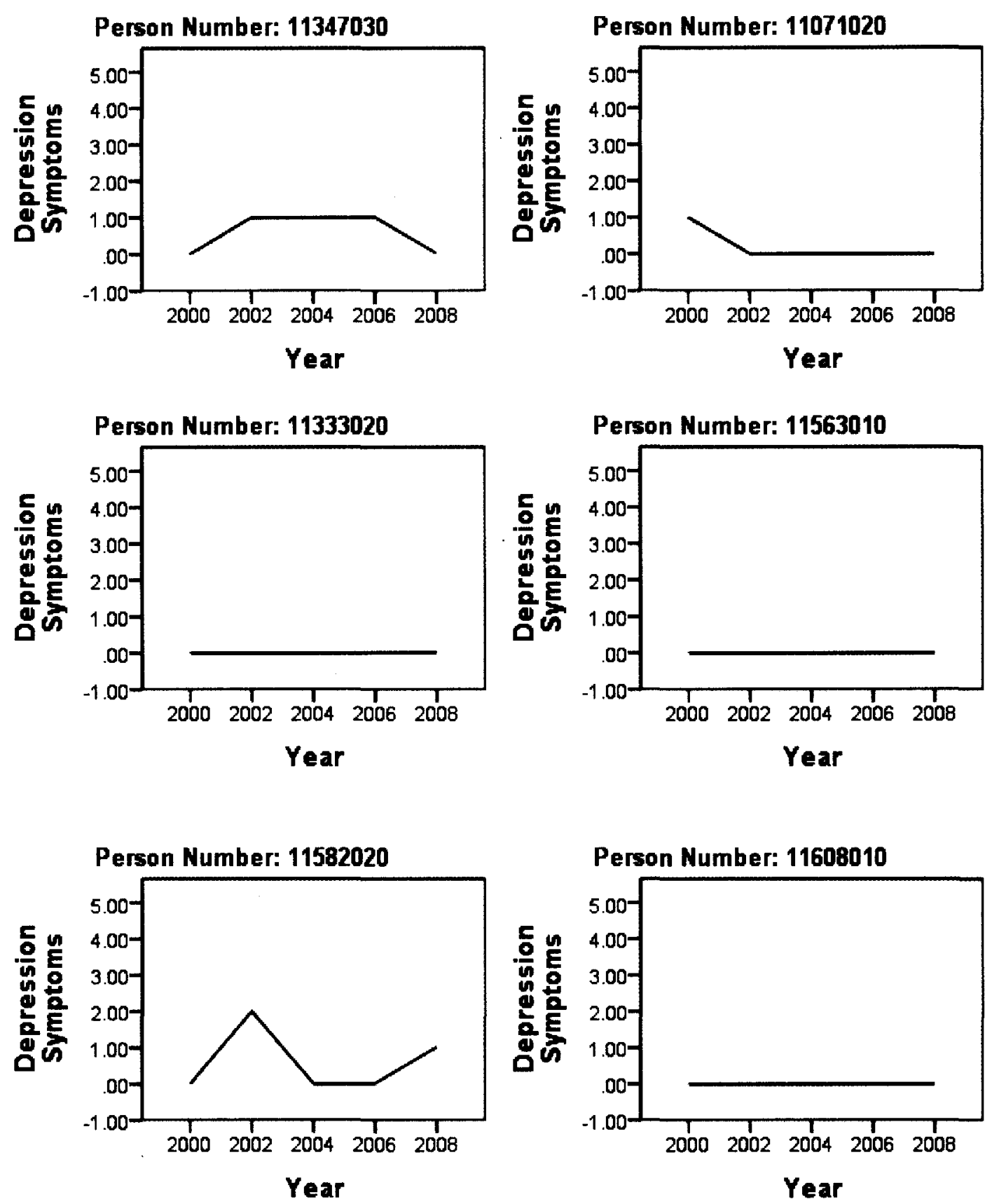

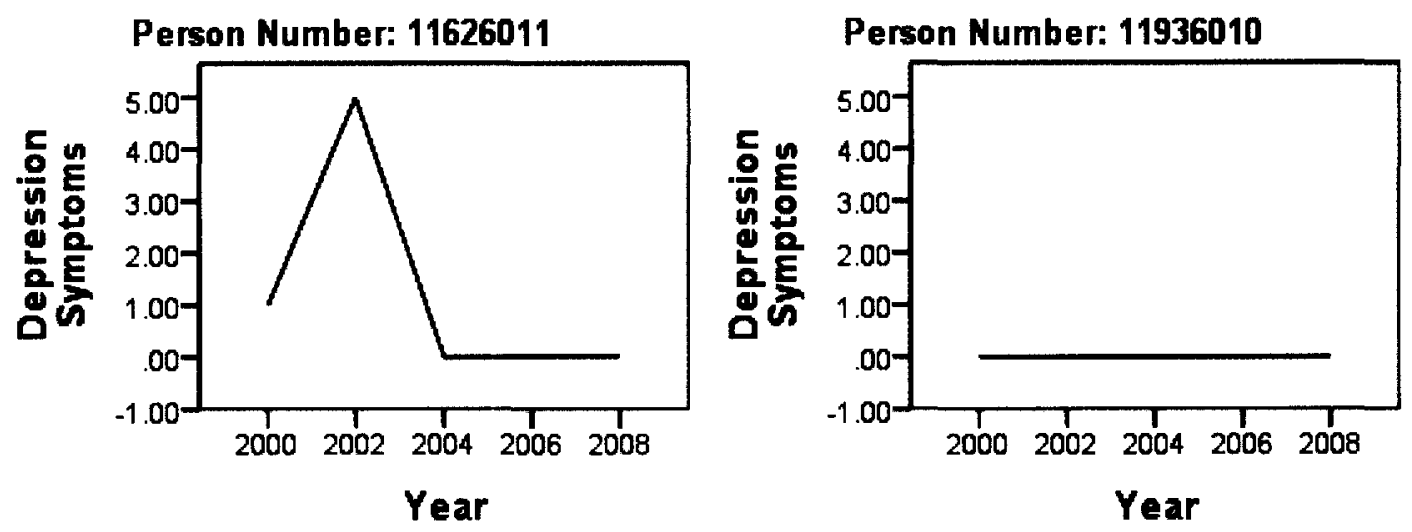

Figure 8. Empirical growth plots for a sample of the non-cancer cases.

\section{Unconditional Model}

Fitting the unconditional (null) model which describes the probability of having depression symptoms across individuals (Model A) was accomplished using the equation in Figure 9.

resp $_{i j k} \sim$ Ordered Multinomial (Constant ${ }_{j k} \pi_{i j k}$ )

$\gamma_{0 j k}=\pi_{0 j k} ; \gamma_{1 j k}=\pi_{0 j k}+\pi_{1 j k} ; \gamma_{2 j k}=\pi_{0 j k}+\pi_{1 j k}+\pi_{2 j k} ; \gamma_{3 j k}=\pi_{0 j k}+\pi_{1 j k}+$ $\pi_{2 j k}+\pi_{3 j k} ; \gamma_{4 j k}=\pi_{0 j k}+\pi_{1 j k}+\pi_{2 j k}+\pi_{3 j k}+\pi_{4 j k} ; \gamma_{5 j k}=1$

$\operatorname{logit}\left(\gamma_{0 j k}\right)=\beta_{0}$ Constant. $(<=\text { CESD_SOM_REM_0 })_{i j k}+h_{j k}$

$\operatorname{logit}\left(\gamma_{1 j k}\right)=\beta_{1}$ Constant. $(<=\text { CESD_SOM_REM_1 })_{i j k}+h_{j k}$

$\operatorname{logit}\left(\gamma_{2 j k}\right)=\beta_{2}$ Constant. $(<=\text { CESD_SOM_REM_2 })_{i j k}+h_{j k}$

$\operatorname{logit}\left(\gamma_{3 j k}\right)=\beta_{3}$ Constant. $\left(<=\right.$ CESD_SOM_REM_3) $i j k+h_{j k}$

$\operatorname{logit}\left(\gamma_{4 j k}\right)=\beta_{4}$ Constant. $(<=\text { CESD_SOM_REM_4 })_{i j k}+h_{j k}$

$h_{j k}=v_{5 k}$ Constant.01234

$\left[v_{5 k}\right] \sim \mathrm{N}\left(0, \Omega_{v}\right): \Omega_{v}=\left[\sigma_{5 k}^{2}\right]$

$\operatorname{cov}\left(y_{s j k}, y_{r j k}\right)=y_{s j k}\left(1-y_{r j k}\right) /$ Constant $_{j k} \mathrm{~s}<=\mathrm{r}$

Figure 9. Null model.

Table 23 reveals the estimated intercept, variance components and model fit for the three level null model using people at level 2 , and measurement points at level 1 response then becomes level 0 . As indicated before, there were 1390 
level 2 units (participants) and 6906 level 1 units (measurement occasions). As discussed in the analysis section, with a cumulative probability model, an additional level is included when the analysis is done, represented here by level 0 . This level is the response category level, indicating the amount of symptoms each person had. In essence this is a binary variable, with five rows for each measurement occasion, indicating if there was 0 symptoms present (yes/no); 1 symptom present (yes/no), etc. For this sample there were a total of 34,530 responses on level 0 .

Table 23 Null Model

\begin{tabular}{lc}
\hline Parameter & Model A \\
\hline \multicolumn{2}{c}{ Fixed effects } \\
O Depression Symptoms $\left(\gamma_{0 j k}\right)$ & $1.34^{\star \star *}(0.07)$ \\
<=1 Depression Symptom $\left(\gamma_{1 j k}\right)$ & $2.54^{\star \star *}(0.08)$ \\
<=2 Depression Symptoms $\left(\gamma_{2 j k}\right)$ & $3.48^{\star \star *}(0.09)$ \\
<=3 Depression Symptoms $\left(\gamma_{3 j k}\right)$ & $4.56^{\star \star *}(0.10)$ \\
<=4 Depression Symptoms $\left(\gamma_{4 j k}\right)$ & $5.65^{\star \star *}(0.13)$ \\
\hline \multicolumn{2}{c}{ Random parameters } \\
Level: Person & \\
Constant.01234/Constant.01234 $\left(\sigma_{5 k}^{2}\right)$ & $4.07^{\star \star *}(0.28)$ \\
DIC: & 11916.80 \\
pD: & 954.20 \\
\hline
\end{tabular}

Note: Standard errors are in parentheses.

${ }^{* \star *} p \leq 0.001 ;{ }^{* *} p \leq 0.01 ;{ }^{*} p \leq 0.05$

In this null model (Model A, Table 23) the "success" being modeled is that of having a response at or below each response level. The results of the first equation in Table 23 indicate that for the null model, without any predictors, the log-odds of having 0 symptoms of depression is 1.34 , which corresponds to a probability of $\exp (1.34) /[1+\exp (1.34)=0.70$. From the second equation, the logodds of having 0 or 1 symptom(s) of depression is 2.54 , which corresponds to a 
probability of $\exp (2.54) /[1+\exp (2.54)=0.83$. Similarly, in the third equation, the log-odds of having 0,1 , or 2 symptoms of depression is 3.48 , which corresponds to a probability of $\exp (3.48) /[1+\exp (3.48)=0.91$. The fourth equation indicates the log-odds of having $0,1,2$, or 3 symptoms of depression is 4.56 , from which a cumulative probability of 0.96 is obtained. Finally, the fifth equation indicates the log-odds of having $0,1,2,3$, or 4 symptoms of depression is 5.65 , from which a cumulative probability of 0.98 is obtained.

The intraclass correlation (ICC) coefficient provides an assessment of how much variability in responses lies at the highest level (person level). When a logistic model is used, the level one residuals are assumed to follow the standard logistic distribution which has a mean of 0 and a variance of $\pi^{2} / 3=3.29$. The ICC was calculated using this formula as suggested by O'Connell (2010):

$$
I C C=\frac{\tau_{00}}{\tau_{00}+3.29}=\frac{4.07}{4.07+3.29} .
$$

$\tau_{00}=$ value of the intercept.

Applying this formula to the null model (Model A, Table 23 above) suggested that 55 percent of the variance in depression symptoms was between people in 2000 . This supports the need for a multilevel model which accounts for variance between and within subjects.

The Deviance Information Criterion (DIC) is used as a diagnostic to assess the fit of models estimated with MCMC methods. According to Browne (2009, p. 28),

The DIC diagnostic is simple to calculate from an MCMC run as it simply involves calculating the value of the deviance at each iteration, and 
the deviance at the expected value of the unknown parameters $(D(\bar{\theta}))$.

Then we can calculate the 'effective' number of parameters $\left(p_{D}\right)$ by subtracting $D(\bar{\theta})$ from the average deviance from the 5000 iterations $(\bar{D})$.

The DIC diagnostic can then be used to compare models as it consists of the sum of two terms that measure the 'fit' and the 'complexity' of a particular model, $D / C=\bar{D}+p_{D}=D(\bar{\theta})+2 p_{D}=2 \bar{D}-D(\bar{\theta})$.

Because the DIC is already penalized for model complexity (number of effective parameters), it is not compared to a frequency distribution. Rather, DIC values can be directly compared to one another. Models being compared do not need to be nested, and lower values indicate a better, more parsimonious model. If the DIC value decreases by at least 10 points, the smaller value is considered to be a significant improvement (Jones, 2007, September 10-12). For the null model $($ Model A, Table 23) the DIC $=11916.80$.

\section{Unconditional Growth Model}

Fitting the unconditional growth model depicting probability of having depression symptoms over time across individuals (Model B) was accomplished using the following expanded equation in which time was added:

$$
\begin{aligned}
& \left.\operatorname{resp}_{i j k} \text { Ordered Multinomial (Constant } \operatorname{Ork}_{j k} \pi_{i j k}\right) \\
& \gamma_{0 j k}=\pi_{0 j k} ; \gamma_{1 j k}=\pi_{0 j k}+\pi_{1 j k} ; \gamma_{2 j k}=\pi_{0 j k}+\pi_{1 j k}+\pi_{2 j k} ; \gamma_{3 j k}=\pi_{0 j k}+\pi_{1 j k}+ \\
& \pi_{2 j k}+\pi_{3 j k} ; \gamma_{4 j k}=\pi_{0 j k}+\pi_{1 j k}+\pi_{2 j k}+\pi_{3 j k}+\pi_{4 j k} ; \gamma_{5 j k}=1 \\
& \left.\operatorname{logit}\left(\gamma_{0 j k}\right)=\beta_{0} \text { Constant.(<=CESD_SOM_REM_0 }\right)_{i j k}+h_{j k} \\
& \operatorname{logit}\left(\gamma_{1 j k}\right)=\beta_{1} \text { Constant. }(<=\text { CESD_SOM_REM_1 })_{i j k}+h_{j k} \\
& \left.\operatorname{logit}\left(\gamma_{2 j k}\right)=\beta_{2} \text { Constant.(<=CESD_SOM_REM_2 }\right)_{i j k}+h_{j k} \\
& \operatorname{logit}\left(\gamma_{3 j k}\right)=\beta_{3} \text { Constant.(<=CESD_SOM_REM_3) } i j k+h_{j k} \\
& \left.\operatorname{logit}\left(\gamma_{4 j k}\right)=\beta_{4} \text { Constant.(<=CESD_SOM_REM_4 }\right)_{i j k}+h_{j k} \\
& h_{j k}=\beta_{7} \text { Time. 01234 }{ }_{j k}+v_{5 k} \text { Constant.01234 } \\
& {\left[v_{5 k}\right] \sim \mathrm{N}\left(0, \Omega_{v}\right): \Omega_{v}=\left[\sigma_{5 k}^{2}\right]}
\end{aligned}
$$


$\operatorname{cov}\left(y_{s j k}, y_{r j k}\right)=y_{s j k}\left(1-y_{r j k}\right) /$ Constant $_{j k} \mathrm{~s}<=\mathrm{r}$

Figure 10. Unconditional growth model.

In Table 24, Model B is added for comparison with Model A.

Table 24 Comparison of Null Model to Growth Model

\begin{tabular}{|c|c|c|}
\hline Parameter & Model A & Model B \\
\hline \multicolumn{3}{|c|}{ Fixed effects } \\
\hline 0 Depression Symptoms $\left(\gamma_{0 j k}\right)$ & $1.34^{\star * \star}(0.07)$ & $1.24^{\star \star \star}(0.09)$ \\
\hline$<=1$ Depression Symptom $\left(\gamma_{1 j k}\right)$ & $2.54^{\star \star \star}(0.08)$ & $2.44^{\star \star \star}(0.10)$ \\
\hline$<=2$ Depression Symptoms $\left(\gamma_{2 j k}\right)$ & $3.48^{\star \star \star}(0.09)$ & $3.38^{\star \star \star}(0.11)$ \\
\hline$<=3$ Depression Symptoms $\left(\gamma_{3 j k}\right)$ & $4.56^{* \star *}(0.10)$ & $4.47^{* \star *}(0.12)$ \\
\hline$<=4$ Depression Symptoms $\left(\gamma_{4 j k}\right)$ & $5.65^{\star \star \star}(0.13)$ & $5.56^{\star \star \star}(0.14)$ \\
\hline Time $\left(\beta_{7}, 01234_{j k}\right)$ & & $0.06^{* *}(0.02)$ \\
\hline \multicolumn{3}{|c|}{ Random parameters } \\
\hline $\begin{array}{l}\text { Level: Person } \\
\text { Constant. } 01234 / \text { Constant. } 01234\left(\sigma_{5 k}^{2}\right)\end{array}$ & $4.07^{\star \star \star}(0.28)$ & $4.13^{\star \star \star}(0.30)$ \\
\hline $\begin{array}{l}\text { DIC: } \\
\text { pD: }\end{array}$ & $\begin{array}{c}11916.80 \\
954.20\end{array}$ & $\begin{array}{c}11904.64 \\
956.60\end{array}$ \\
\hline $\begin{array}{l}\text { Note: Standard errors are in parenthe } \\
\text { DIC: Diagnostic Information Criterion; } \\
\text { pD: estimated degrees of freedom; } \\
{ }^{* \star *} p \leq 0.001 ;{ }^{\star \star} p \leq 0.01\end{array}$ & & \\
\hline
\end{tabular}

Comparing the equations of Model A to Model B, it is clear that for each response category, the log-odds of $\mathrm{k}$ symptoms of depression went down slightly. Adding time to the model resulted in an improved model fit ( $D I C=11918.80$ for the null model versus $\mathrm{DIC}=11904.64$ for the growth model). Also, model fit was not possible with time as a random effect and had to be added as a fixed effect. As with the null model, log-odds were transformed to cumulative probabilities using customized predictions in MLwiN, then unique probabilities were calculated. In Figure 11, the unique probabilities of depression symptoms were modeled for the null model. 


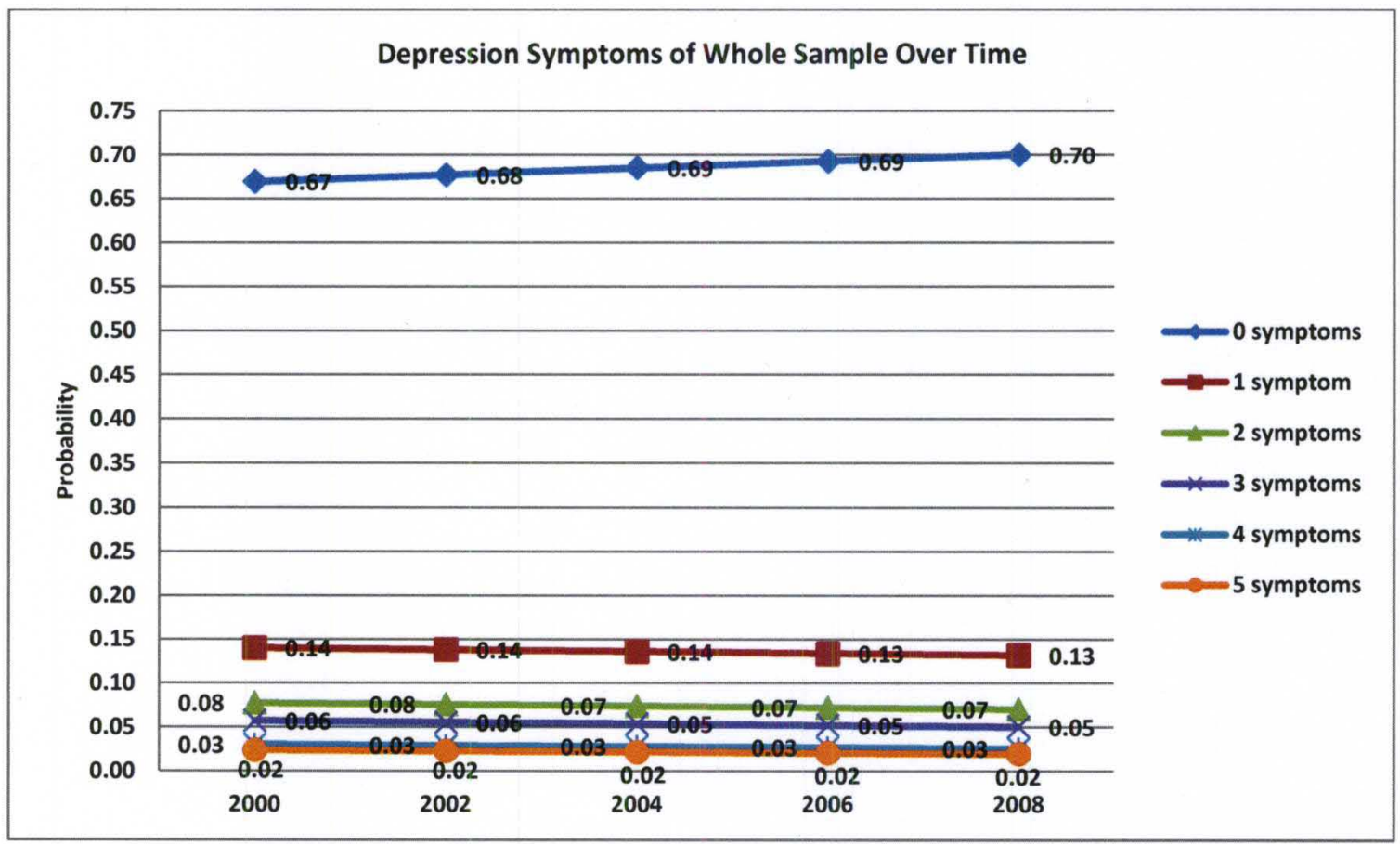

Figure 11. Depression symptoms of whole sample over time.

The sample overall had a 67 percent probability of not having any depression symptoms in 2000 . Over 8 years the probability increased by three percent to 70 percent in 2008 . The sample overall had a 14 percent probability of having one depression symptom in 2000 . Over 8 years the probability decreased by one percent to 13 percent. The sample overall had an eight percent probability of having two depression symptoms in 2000. Over eight years the probability decreased by one percent to seven percent. The sample overall had a six percent probability of having three depression symptoms in 2000. Over eight years the probability decreased by one percent to five percent. The sample had three percent probability over all eight years of having four depression symptoms. The sample had two percent probability over all 8 years of having five depression symptoms.

\section{Conditional Growth Model}


The conditioned growth model was expanded by adding explanatory

variables (Model $\mathrm{C}$ ) to the following equation:

resp $_{i j k} \sim$ Ordered Multinomial (Constant $j_{j k} \pi_{i j k}$ )

$\gamma_{0 j k}=\pi_{0 j k} ; \gamma_{1 j k}=\pi_{0 j k}+\pi_{1 j k} ; \gamma_{2 j k}=\pi_{0 j k}+\pi_{1 j k}+\pi_{2 j k} ; \gamma_{3 j k}=\pi_{0 j k}+\pi_{1 j k}+$

$\pi_{2 j k}+\pi_{3 j k} ; \gamma_{4 j k}=\pi_{0 j k}+\pi_{1 j k}+\pi_{2 j k}+\pi_{3 j k}+\pi_{4 j k} ; \gamma_{5 j k}=1$

$\operatorname{logit}\left(\gamma_{0 j k}\right)=\beta_{0}$ Constant. (<=CESD_SOM_REM_0 $)_{i j k}+h_{j k}$

$\operatorname{logit}\left(\gamma_{1 j k}\right)=\beta_{1}$ Constant. (<=CESD_SOM_REM_1 $)_{i j k}+h_{j k}$

$\operatorname{logit}\left(\gamma_{2 j k}\right)=\beta_{2}$ Constant. $(<=\text { CESD_SOM_REM_2 })_{i j k}+h_{j k}$

$\operatorname{logit}\left(\gamma_{3 j k}\right)=\beta_{3}$ Constant. (<=CESD_SOM_REM_3 $)_{i j k}+h_{j k}$

$\operatorname{logit}\left(\gamma_{4 j k}\right)=\beta_{4}$ Constant. (<=CESD_SOM_REM_4 $)_{i j k}+h_{j k}$

$h_{j k}=$

$\beta_{7 k}$ Time. 01234 $4_{j k}+\beta_{8}$ Cancer. 01234 ${ }_{j k}+\beta_{9}$ Age. $01243_{j k}+$

$\beta_{10}$ No History of Depression. $01234_{j k}+\beta_{11} 1$ Symptom Depression $1998.01234_{j k}+$ $\beta_{12}$ White. 01234 $k+\beta_{13}$ Female. 01234 $k+\beta_{14}$ Life Expectancy. 01234 ${ }_{j k}+$

$\beta_{15}$ Subjective Health. 01234 ${ }_{j k}+\beta_{16}$ Pessimism. 01234 ${ }_{j k}+\beta_{17}$ Optimism. 01234 ${ }_{j k}+$

$\beta_{18}$ Education. $01234+\beta_{19}$ Retired. 01234 ${ }_{j k}+$

$\beta_{20}$ Disabled, Unemployed, or Not in Workforce. $01234_{j k}+$

$\beta_{21}$ Healthplans. 01234 ${ }_{j k}+\beta_{22}$ Networth. 01234 $4_{j k}+$

$\beta_{23}$ Psych Problems with Support. 01234 ${ }_{j k}+$

$\beta_{24}$ Psych Problems No Support. 01234 $4_{j k}+\beta_{25}$ Social Support. 01234 $4_{j k}+$

$\beta_{26}$ Spouse or Partner Present. $01234_{j k}+\beta_{27} 1$ or More Days in Bed. 01234 ${ }_{j k}+$

$\beta_{28}$ Comorbid Conditions. 01234 ${ }_{j k}+\beta_{29}$ Pain. $01234_{j k}+$

$\beta_{30}$ Difficulty with ADLs \& IADLs. $01234_{j k}+v_{5 k}$ Constant.01234

$\left[v_{5 k}\right] \sim \mathrm{N}\left(0, \Omega_{v}\right): \Omega_{v}=\left[\sigma_{5 k}^{2}\right]$

$\operatorname{cov}\left(y_{s j k}, y_{r j k}\right)=y_{s j k}\left(1-y_{r j k}\right) /$ Constant $j_{j k} \mathrm{~s}<=\mathrm{r}$

Figure 12. Growth model with main effects.

Table 25 compares the null model with the unconditional growth model and the conditional growth model.

Table 25 Comparison of Null Model, Growth Model and Growth Model with Main Effects.

\begin{tabular}{|c|c|c|c|}
\hline Parameter & Model A & Model B & Model C \\
\hline \multicolumn{4}{|c|}{ effects } \\
\hline 0 Depression Symptoms $\left(\gamma_{0 j k}\right)$ & $1.34^{\star \star \star}(0.07)$ & $1.24^{\star \star \star}(0.09)$ & $-0.79^{\star \star \star}(0.19)$ \\
\hline
\end{tabular}




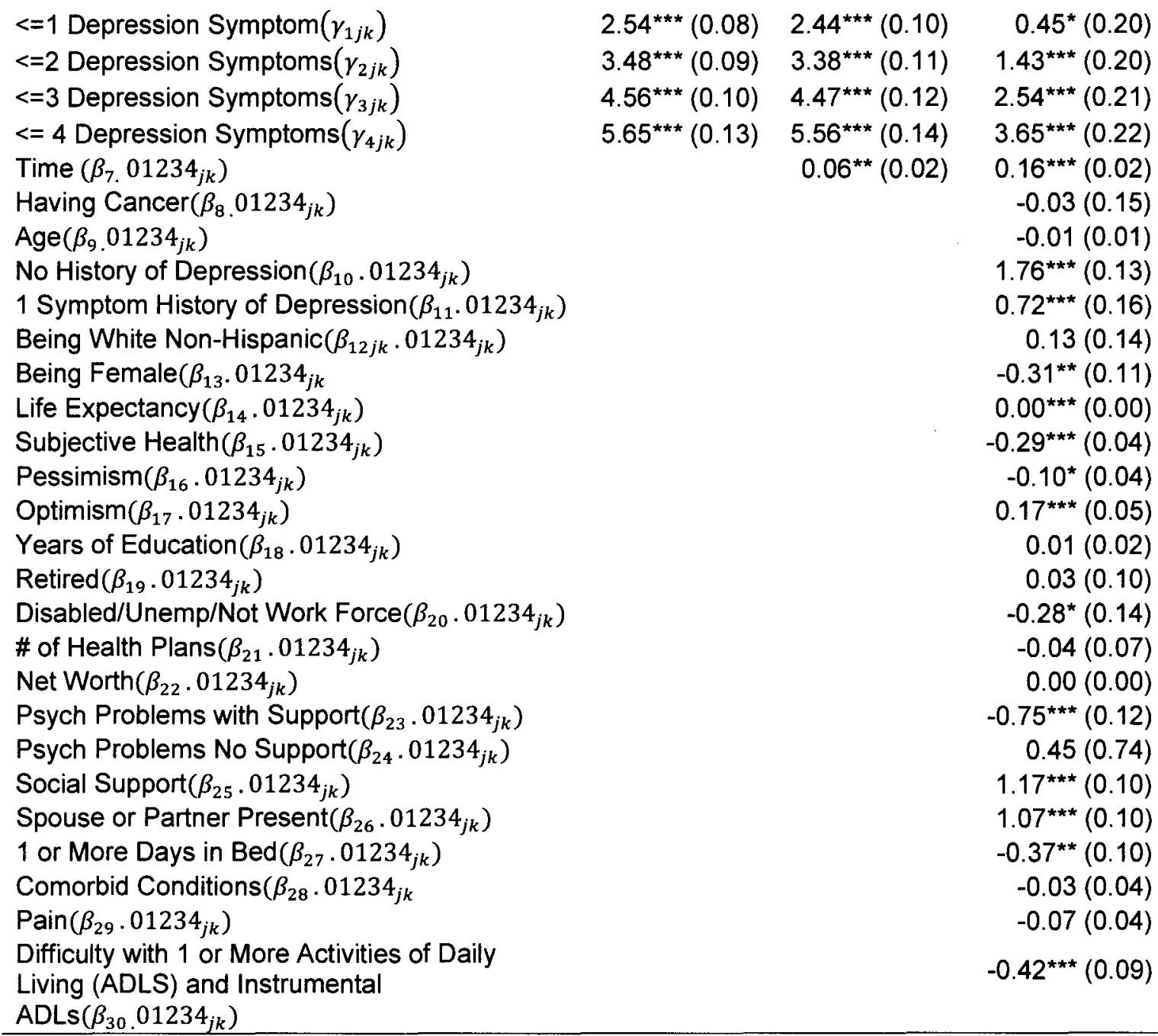
$\operatorname{ADLs}\left(\beta_{30} .01234_{j k}\right)$

Level: Person

Random parameters

Constant.01234/Constant. $01234\left(\sigma_{5 k}^{2}\right) \quad 4.07^{\star \star \star}(0.28) \quad 4.13^{* \star *}(0.30) \quad 1.74^{\star \star *}(0.15)$

DIC:

$11916.80 \quad 11904.64 \quad 11559.53$

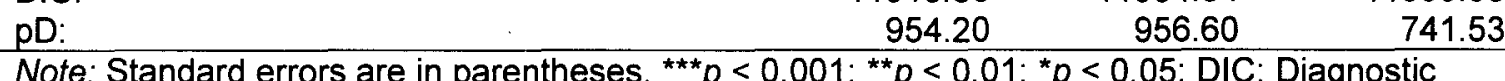
Information Criterion; $\mathrm{pD}$ : estimated degrees of freedom

Comparisons of the equations in Models $A, B$, and $C$ again reveal that the log- odds of each response category went down slightly. Typically, positive logits are associated with increased probability of success; in this cumulative odds model "success" represents the probability of being at or below a given cut point (k symptoms). In terms of symptoms of depression, individuals beyond a given 
cut point have more symptoms of depression, so negative logits are indicative of a kind of risk factor while positive logits indicate a kind of protective factor.

Adding the explanatory variables to the model resulted in significantly improved fit $(\mathrm{DIC}=11918.80$ for the null model versus $\mathrm{DIC}=11904.64$ for the growth model versus $\mathrm{DIC}=11559.53$ for the conditioned growth model). As with the null model and the unconditional growth model, log-odds were transformed to cumulative probabilities using customized predictions in MLwiN, then unique probabilities were calculated. In Figure 13, the unique probabilities of depression symptoms for the whole sample controlling for main effects were modeled.

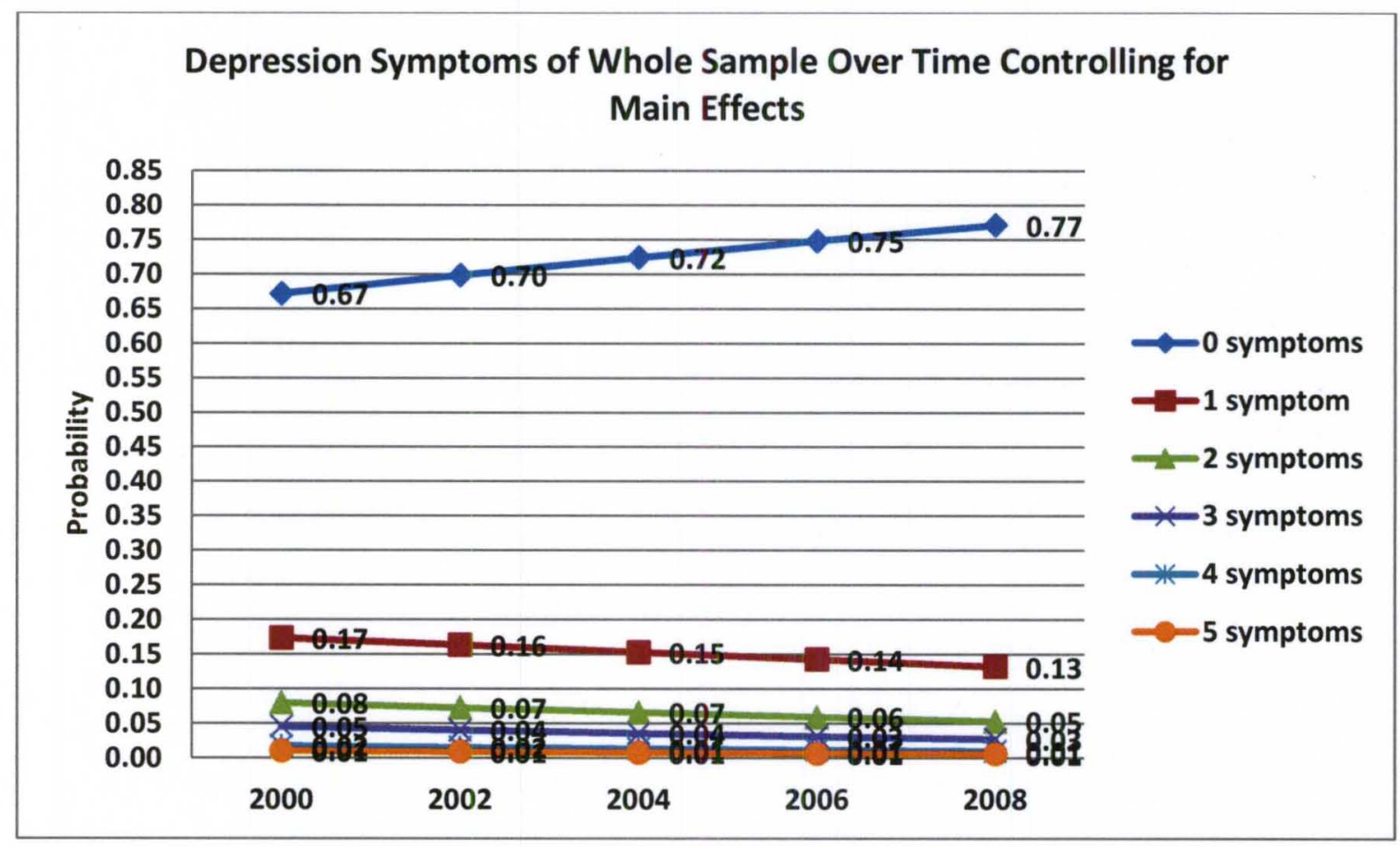

Figure 13. Depression symptoms of whole sample over time controlling for main effects.

Controlling for the main effects, the overall sample had a 33 percent chance of reporting one or more symptoms of depression in 2000 and by 2008 , the chances of reporting any symptoms decreased to 23 percent. The largest 
difference between this model and the null model was in the last 4 waves (2004, 2006 , and 2008), with a reduction in the probability of reporting symptoms of depression across all symptom categories.

\section{Conditional Growth Model with Interaction Effects}

The conditioned growth model was expanded by adding interaction effects of cancer with the main effects (Model D) in the equation in Figure 14:

$$
\begin{aligned}
& \text { resp }_{i j k} \sim \text { Ordered Multinomial (Constant }{ }_{j k}, \pi_{i j k} \text { ) } \\
& \gamma_{0 j k}=\pi_{0 j k} ; \gamma_{1 j k}=\pi_{0 j k}+\pi_{1 j k} ; \gamma_{2 j k}=\pi_{0 j k}+\pi_{1 j k}+\pi_{2 j k} ; \gamma_{3 j k}=\pi_{0 j k}+\pi_{1 j k}+ \\
& \pi_{2 j k}+\pi_{3 j k} ; \gamma_{4 j k}=\pi_{0 j k}+\pi_{1 j k}+\pi_{2 j k}+\pi_{3 j k}+\pi_{4 j k} ; \gamma_{5 j k}=1 \\
& \operatorname{logit}\left(\gamma_{0 j k}\right)=\beta_{0} \text { Constant. }(<=\text { CESD_SOM_REM_0 })_{i j k}+h_{j k} \\
& \operatorname{logit}\left(\gamma_{1 j k}\right)=\beta_{1} \text { Constant. }(<=\text { CESD_SOM_REM_1 })_{i j k}+h_{j k} \\
& \operatorname{logit}\left(\gamma_{2 j k}\right)=\beta_{2} \text { Constant. }(<=\text { CESD_SOM_REM_2 })_{i j k}+h_{j k} \\
& \operatorname{logit}\left(\gamma_{3 j k}\right)=\beta_{3} \text { Constant. }(<=\text { CESD_SOM_REM_3 })_{i j k}+h_{j k} \\
& \operatorname{logit}\left(\gamma_{4 j k}\right)=\beta_{4} \text { Constant. }(<=\text { CESD_SOM_REM_4 })_{i j k}+h_{j k} \\
& h_{j k}= \\
& \beta_{7 k} \text { Time. } 01234_{j k}+\beta_{8} \text { Cancer. } 01234_{j k}+\beta_{9} \text { Age. } 01243_{j k}+ \\
& \beta_{10} \text { No History of Depression. 01234 }{ }_{j k}+\beta_{11} 1 \text { Symptom Depression 1998.01234 }{ }_{j k}+ \\
& \beta_{12} \text { Female. } 01234_{k}+\beta_{13} \text { Life Expectancy. } 01234_{j k}+ \\
& \beta_{14} \text { Subjective Health. 01234 }{ }_{j k}+\beta_{15} \text { Pessimism. 01234 }{ }_{j k}+\beta_{16} \text { Optimism. 01234 } 4_{j k}+ \\
& \beta_{17} \text { Retired. 01234 }{ }_{j k}+\beta_{18} \text { Disabled, Unemployed, or Not in Workforce. 01234 }{ }_{j k}+ \\
& \beta_{19} \text { Healthplans. 01234 }{ }_{j k}+\beta_{20} \text { Psych Problems with Support. 01234 }{ }_{j k}+ \\
& \beta_{21} \text { Psych Problems No Support. 01234 }{ }_{j k}+\beta_{22} \text { Social Support. 01234 }{ }_{j k}+ \\
& \beta_{23} \text { Spouse or Partner Present. } 01234_{j k}+\beta_{24} 1 \text { or More Days in Bed. } 01234_{j k}+ \\
& \beta_{25} \text { Difficulty with ADLs \& IADLs. 01234 }{ }_{j k}++\beta_{26} \text { Comorbid Conditions. 01234 }{ }_{j k}+ \\
& \beta_{27} \text { Cancer * Spouse or Partner Present. 01234 }{ }_{j k}+\beta_{29} \text { Cancer * Optimism. 01234 }{ }_{j k}+ \\
& \beta_{28} \text { Cancer } * \text { Life Expectancy. } 01234_{j k}+\beta_{30} \text { Cancer } * \text { Female } * \\
& \text { Social Support. } 01234_{j k}+v_{5 k} \text { Constant.01234 } \\
& {\left[v_{5 k}\right] \sim \mathrm{N}\left(0, \Omega_{v}\right): \Omega_{v}=\left[\sigma_{5 k}^{2}\right]} \\
& \operatorname{cov}\left(y_{s j k}, y_{r j k}\right)=y_{s j k}\left(1-y_{r j k}\right) / \text { Constant }_{j k} \mathrm{~s}<=\mathrm{r}
\end{aligned}
$$

Figure 14. Growth model with main effects and interaction effects.

Table 26 compares all models. Adding the interaction effects of cancer with the main effects to the model resulted in significantly improved fit (DIC = 
11918.80 for the null model versus DIC $=11904.64$ for the growth model versus $\mathrm{DIC}=11559.53$ for the conditioned growth model versus $\mathrm{DIC}=11538.49$ for the conditioned growth model with main and interaction effects). Examination of DIC diagnostics in MLWin in the final stage of model building revealed that with 50,000 iterations, effective sample sizes were more than adequate $(E S S=$ 1022-9185). Significant two way interaction effects were detected between cancer and each the following respectively: spouse/partner presence, and life expectancy. A significant three-way interaction effect was detected between having cancer, gender, and social support. 
Table 26 Comparison of All Models

\begin{tabular}{|c|c|c|c|c|}
\hline Parameter & Model A & Model B & Model C & Model D \\
\hline \multicolumn{5}{|c|}{ Fixed effects } \\
\hline 0 Depression Symptoms $\left(\gamma_{0 j k}\right)$ & $1.34^{\star \star \star}(0.07)$ & $1.24^{\star \star \star}(0.09)$ & $-0.79^{\star \star \star}(0.19)$ & $-0.60^{* *}(0.19)$ \\
\hline$<=1$ Depression Symptom $\left(\gamma_{1 j k}\right)$ & $2.54^{\star \star \star}(0.08)$ & $2.44^{\star \star *}(0.10)$ & $0.45^{*}(0.20)$ & $0.65^{\star \star \star}(0.19)$ \\
\hline$<=2$ Depression Symptoms $\left(\gamma_{2 j k}\right)$ & $3.48^{* * *}(0.09)$ & $3.38^{* * *}(0.11)$ & $1.43^{\star \star \star}(0.20)$ & $1.63^{* * *}(0.19)$ \\
\hline$<=3$ Depression Symptoms $\left(\gamma_{3 j k}\right)$ & $4.56^{\star \star \star}(0.10)$ & $4.47^{\star \star \star}(0.12)$ & $2.54^{* \star *}(0.21)$ & $2.75^{\star \star \star}(0.20)$ \\
\hline$<=4$ Depression Symptoms $\left(\gamma_{4 j k}\right)$ & $5.65^{\star \star \star}(0.13)$ & $5.56^{\star \star *}(0.14)$ & $3.65^{\star \star \star}(0.22)$ & $3.86^{* * *}(0.19)$ \\
\hline $\operatorname{Time}\left(\beta_{7} .01234_{j k}\right)$ & & $0.06^{* *}(0.02)$ & $0.16^{\star \star \star}(0.02)$ & $0.16^{\star \star *}(0.02)$ \\
\hline Having Cancer $\left(\beta_{8} .01234_{j k}\right)$ & & & $-0.03(0.15)$ & $-0.81^{* *}(0.26)$ \\
\hline $\operatorname{Age}\left(\beta_{9} .01234_{j k}\right)$ & & & $-0.01(0.01)$ & $-0.01(0.01)$ \\
\hline No History of Depression $\left(\beta_{10} .01234_{j k}\right)$ & & & $1.76^{\star * *}(0.13)$ & $1.82^{\star \star *}(0.14)$ \\
\hline 1 Symptom History of Depression $\left(\beta_{11} \cdot 01234_{j k}\right)$ & & & $0.72^{\star \star \star}(0.16)$ & $0.76^{\star * *}(0.16)$ \\
\hline Being Female $\left(\beta_{12} .01234_{j k}\right)$ & & & $-0.31^{\star \star}(0.11)$ & $-0.35^{* *}(0.11)$ \\
\hline Life Expectancy $\left(\beta_{13} .01234_{j k}\right)$ & & & $0.00^{* * *}(0.00)$ & $0.00^{* *}(0.00)$ \\
\hline Subjective Health $\left(\beta_{14} .01234_{j k}\right)$ & & & $-0.29^{\star \star \star}(0.04)$ & $-0.32^{\star \star \star}(0.04)$ \\
\hline Pessimism $\left(\beta_{15} .01234_{j k}\right)$ & & & $-0.10^{*}(0.04)$ & $-0.12^{\star \star}(0.04)$ \\
\hline Optimism $\left(\beta_{16} .01234_{j k}\right)$ & & & $0.17^{\star \star \star}(0.05)$ & $0.20^{\star \star *}(0.05)$ \\
\hline $\operatorname{Retired}\left(\beta_{17} .01234_{j k}\right)$ & & & $0.03(0.10)$ & $0.03(0.09)$ \\
\hline Disabled/Unemp/Not Work Force $\left(\beta_{\mathbf{1 8}} \cdot \mathbf{0 1 2 3 4}_{j k}\right)$ & & & $-0.28^{*}(0.14)$ & $-0.31^{*}(0.14)$ \\
\hline \# of Health Plans $\left(\beta_{19} .01234_{j k}\right)$ & & & $-0.04(0.07)$ & $-0.08(0.07)$ \\
\hline Psych Problems with Support $\left(\beta_{20} .01234_{j k}\right)$ & & & $-0.75^{* * *}(0.12)$ & $-0.76^{\star * *}(0.12)$ \\
\hline Psych Problems No Support $\left(\beta_{21} .01234_{j k}\right)$ & & & $0.45(0.74)$ & $0.12(0.78)$ \\
\hline Social Support $\left(\beta_{22} .01234_{j k}\right)$ & & & $1.17^{\star * \star}(0.10)$ & $1.10^{\star \star \star}(0.19)$ \\
\hline Spouse or Partner Present $\left(\beta_{23} .01234_{j k}\right)$ & & & $1.07^{\star \star \star}(0.10)$ & $0.98^{\star \star \star}(0.11)$ \\
\hline 1 or More Days in $\operatorname{Bed}\left(\beta_{24.01234_{j k}}\right)$ & & & $-0.37^{\star \star}(0.10)$ & $-0.37^{\star \star \star}(0.10)$ \\
\hline Comorbid Conditions $\left(\beta_{25} .01234_{j k}\right)$ & & & $-0.03(0.04)$ & $-0.04(0.04)$ \\
\hline $\begin{array}{l}\text { Difficulty with } 1 \text { or More ADLS and } \\
\text { IADLs }\left(\beta_{26 .} .01234_{j k}\right)\end{array}$ & & & $-0.42^{\star \star \star}(0.09)$ & $-0.46^{\star \star \star}(0.10)$ \\
\hline $\begin{array}{l}\text { Having Cancer }{ }^{*} \text { Spouse or Partner } \\
\text { Present }\left(\beta_{27} .01234_{j k}\right)\end{array}$ & & & & $0.89^{\star \star \star}(0.26)$ \\
\hline Having Cancer*Life Expectancy $\left(\beta_{28} .01234_{j k}\right)$ & & & & $0.01^{*}(0.00)$ \\
\hline
\end{tabular}


Having Cancer ${ }^{*}$ Optimism $\left(\beta_{29} .0^{01234}{ }_{j k}\right)$

$-0.30^{*}(0.13)$

Having Cancer*Female* Social

$1.53^{*}(0.68)$

Support $\left(\beta_{30} .01234_{j k}\right)$

Level: Person

Constant.01234/Constant.01234 $\left(\sigma_{5 k}^{2}\right)$

Random parameters

DIC:

pD:

Units: Person

Units: Measurement Occasion

$(0.28)$

$4.13^{\star \star *}(0.30)$

$1.74^{\star \star \star}(0.15)$

$1.78^{\star \star \star}(0.16)$

Units: Response

11916.80

954.20

1384.00

11904.64

956.60

11559.53

741.53

11538.15

1384.00

1384.00

6906.00

6906.00

6906.00

747.87

1384.00

34530.00

34530.00

34530.00

6906.00

Note: Standard errors are in parentheses. ${ }^{\star \star \star} p \leq 0.001 ;{ }^{\star \star} p \leq 0.01 ;{ }^{*} p \leq 0.05$; DIC: Diagnostic Information Criterion; pD: estimated degrees of freedom. 
Although having cancer and its interaction with optimism showed significance, the significance was in a different direction than the first order interaction between these two variables. Also, the effect was very small, indicating together that this was a suppressor variable in the model. "The term suppression can be understood to indicate that the relationship between the independent or causal variables is hiding or suppressing their real relationship with $Y$, which would be larger or possibly of opposite sign were they not correlated" (J. Cohen, et al., 2003). Therefore, this interaction is not modeled in the section below.

ICC was calculated on the final model using the same formula as used with the null model: $I C C=\frac{\tau_{00}}{\tau_{00}+3.29}=\frac{1.78}{1.78+3.29}$, with $\tau_{00}$ being the value of the intercept. Applying this formula to the final model (Model D, Table 26) suggested that 35 percent of the variance in depression symptoms was between people in 2000. This suggests that after adding all the explanatory variables to the model 20 percent of the between person variance was explained.

As with Models $A, B$, and $C, \log$-odds were transformed to cumulative probabilities using customized predictions in MLwiN, then unique probabilities were calculated. In Figure 15, the unique probabilities of depression symptoms for the whole sample controlling for main effects were modeled. Adding the interaction effects to the model, then controlling for them, resulted in reduced probabilities of reporting depression symptoms in the third wave; specifically, the probability of reporting two symptoms in 2004 decreased by one percent. 


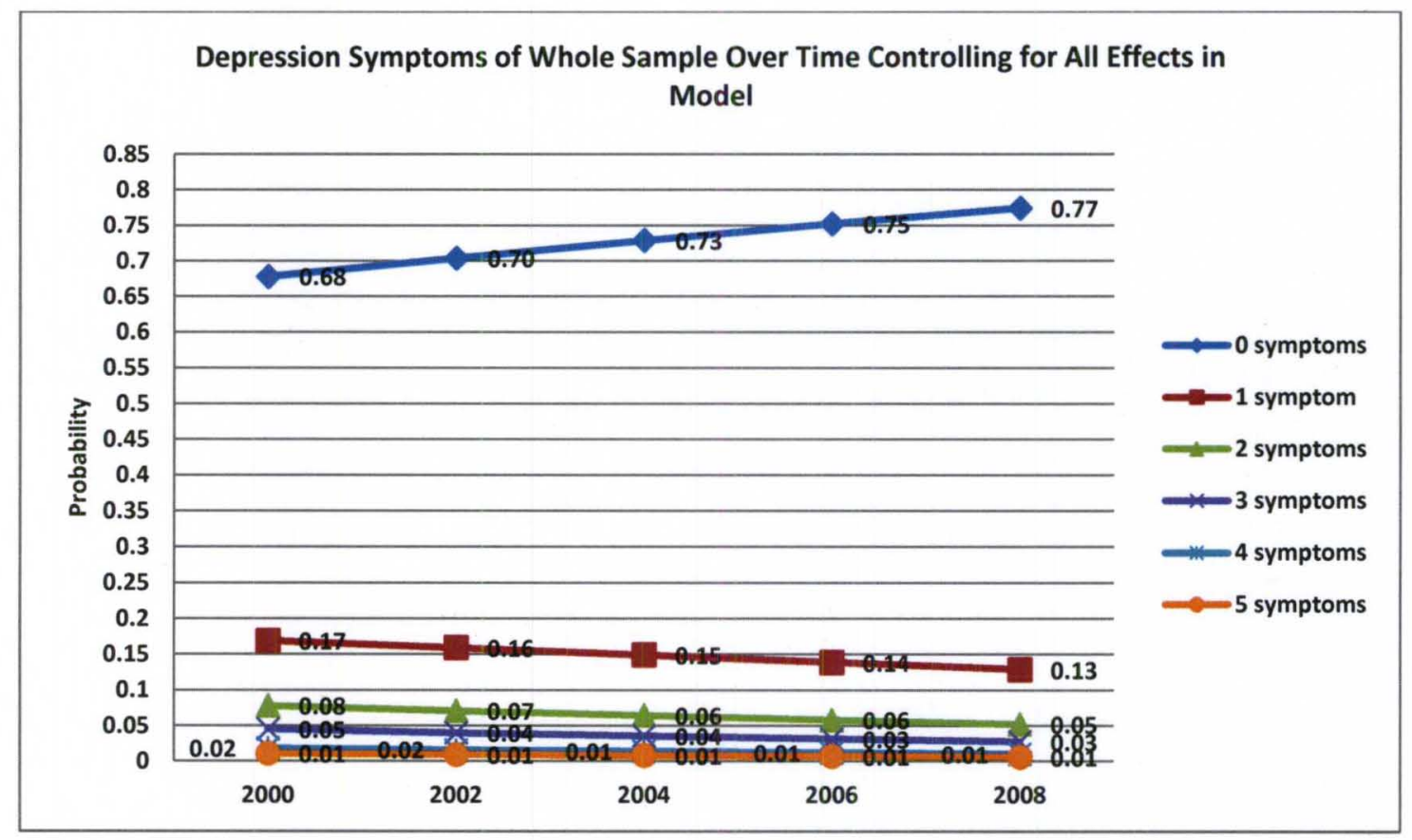

Figure 15. Depression symptoms for whole sample over time controlling for all main and interaction effects in Model D

This next section details the unique probabilities of depression symptoms as modeled for each of the significant main effects (Figures 16 through 29). For these models it was assumed that the effect of all the variables on the log-odds of having $\mathrm{k}$ depression symptoms or lower is the same wherever $\mathrm{k}$ is fixed. For example, it was assumed that the effects of the different variables on the logodds of having 0 depression symptoms was the same as the effect on the logodds of having 4 or less depression symptoms.

Demographics. Figure 16 highlights the unique predicted probabilities of having zero, one, two, three, four or five symptoms of depression by gender. 

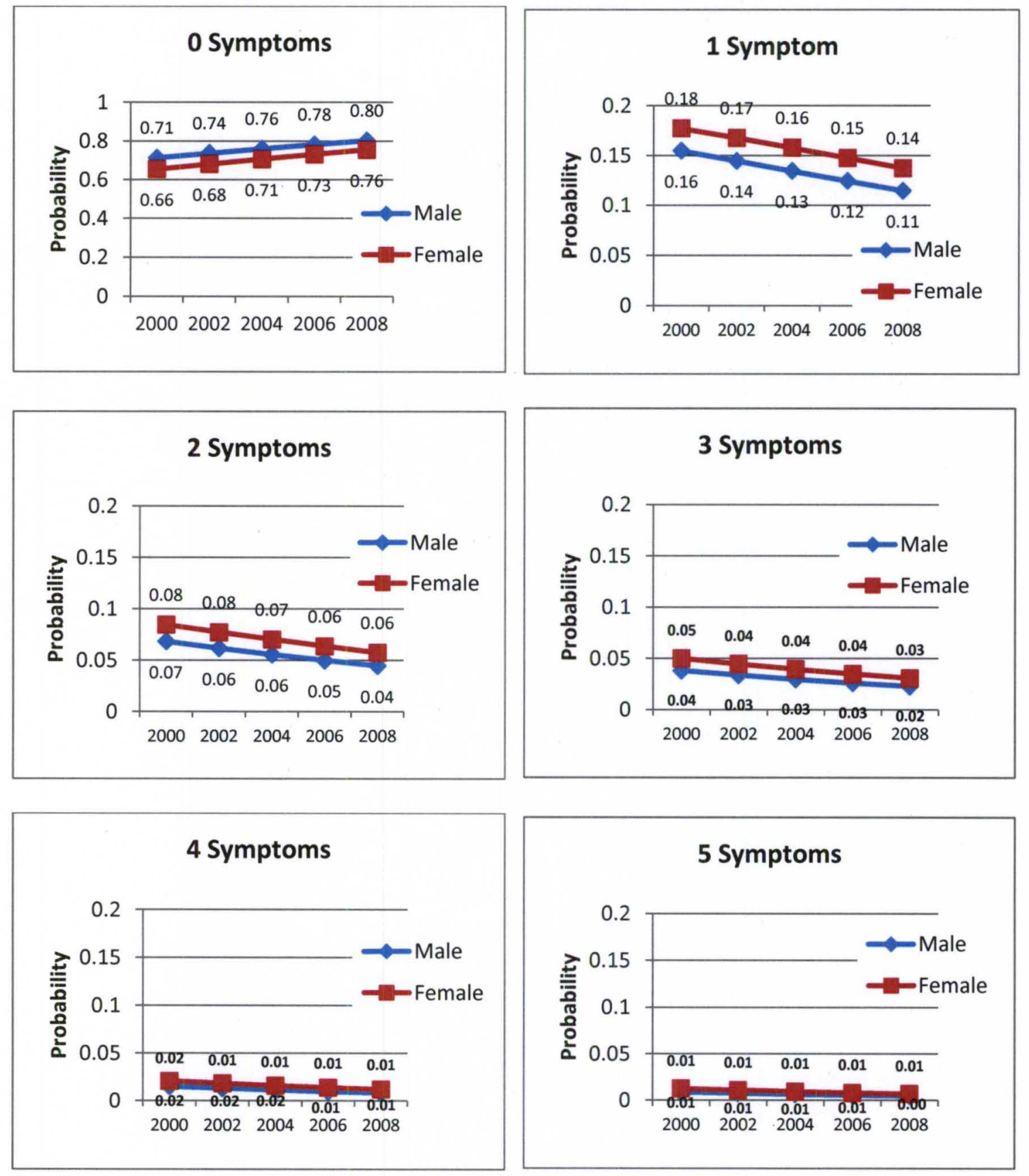

Figure 16. Unique predicted probabilities of symptoms of depression by gender.

Women were significantly more likely than men to report symptoms of depression across all symptom categories in Figure 16. The largest effect occurs in the one symptom category. As symptoms of depression increase, the difference between gender decreases. 
Life course factors. Figure 17 highlights the main effect of cancer modeled as unique probabilities of $\mathrm{k}$ symptoms of depression.
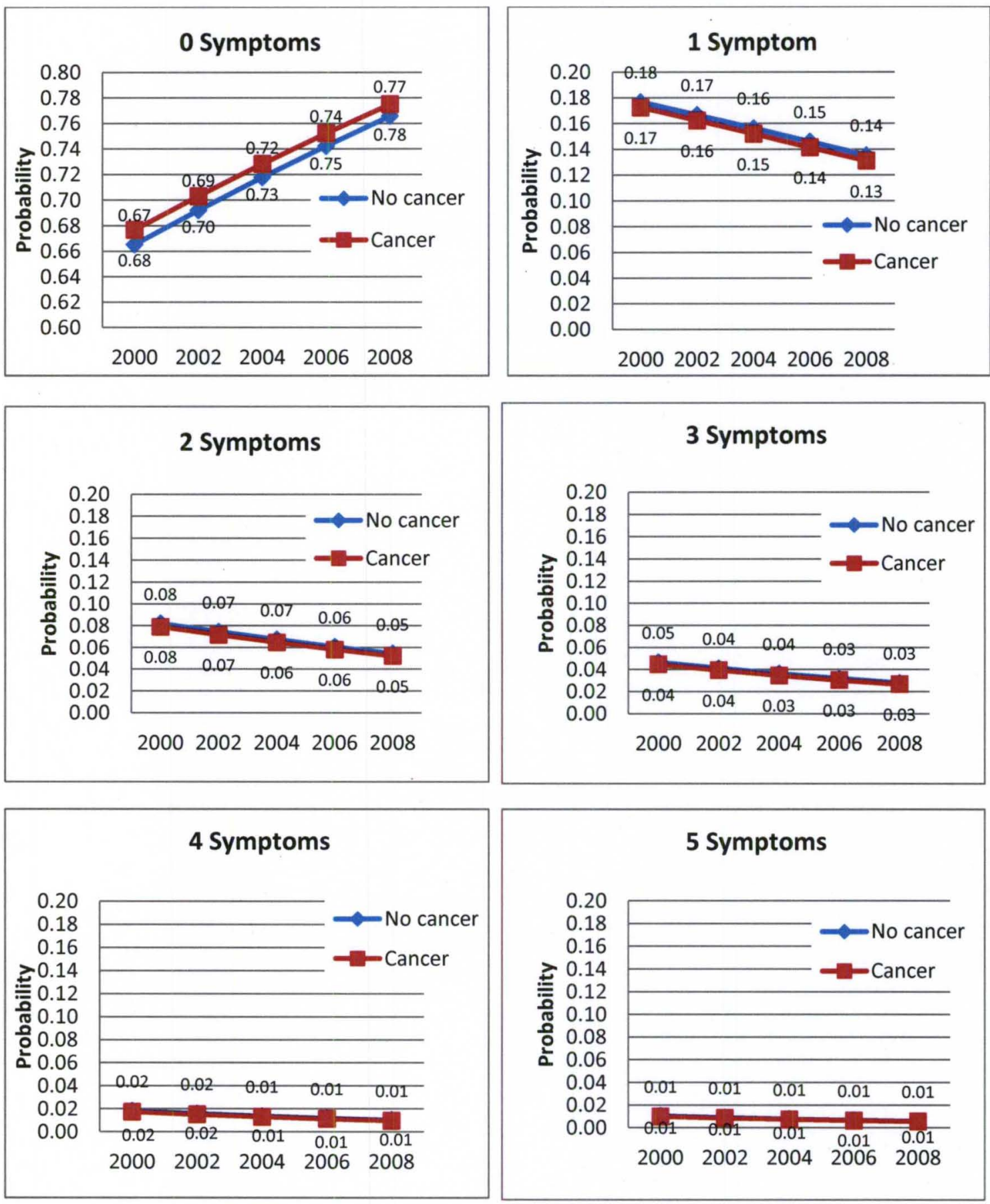

Figure 17. Unique predicted probabilities of symptoms of depression by cancer history. 
The graphs in Figure 17 confirm that those with cancer were less likely to report depression symptoms than those without cancer. Those with a history of cancer have a one percent lower probability than those without cancer of having one depression symptom; this percentage decreases as symptom categories increase from two symptoms through five symptoms. Therefore the first hypothesis is supported, indicating that people with cancer suffer less from depression symptoms than people without cancer. However, this effect was not very strong.

Figure 18 models main effect of history of depression as unique predicted probabilities of having $\mathrm{k}$ symptoms of depression.
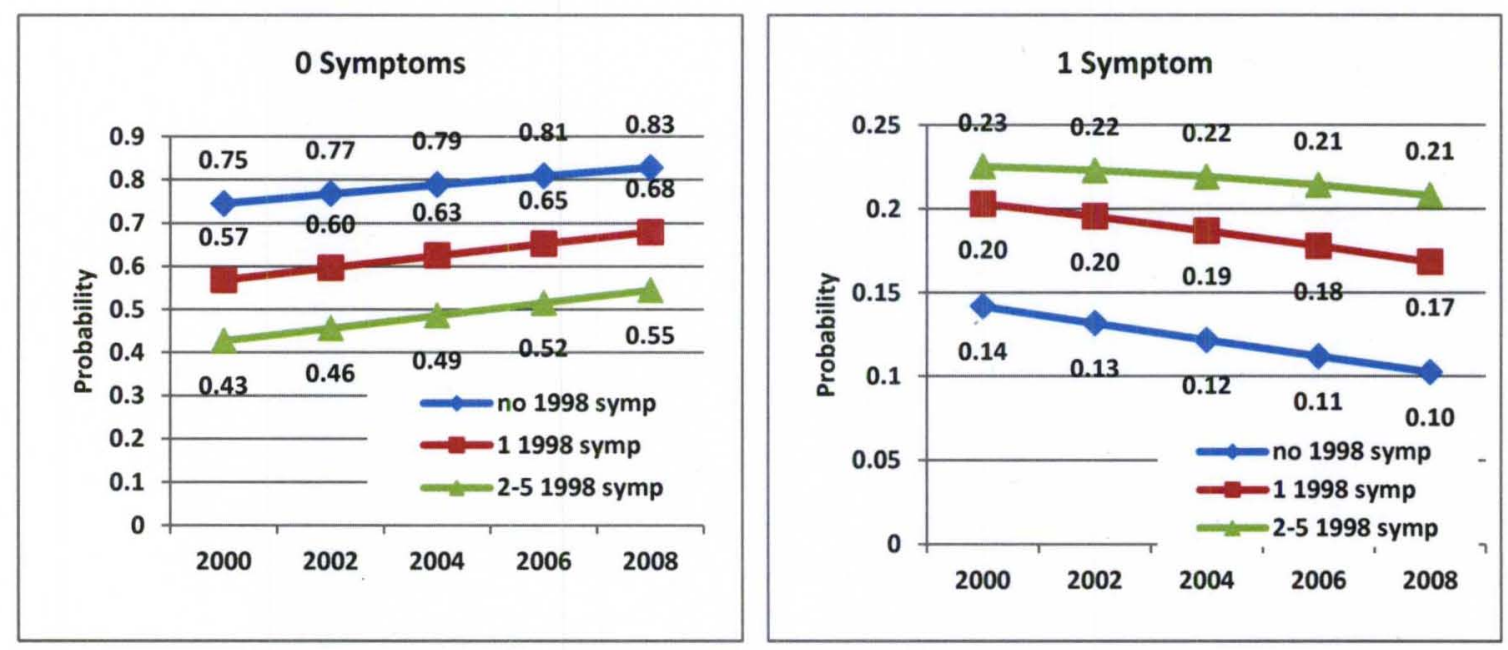

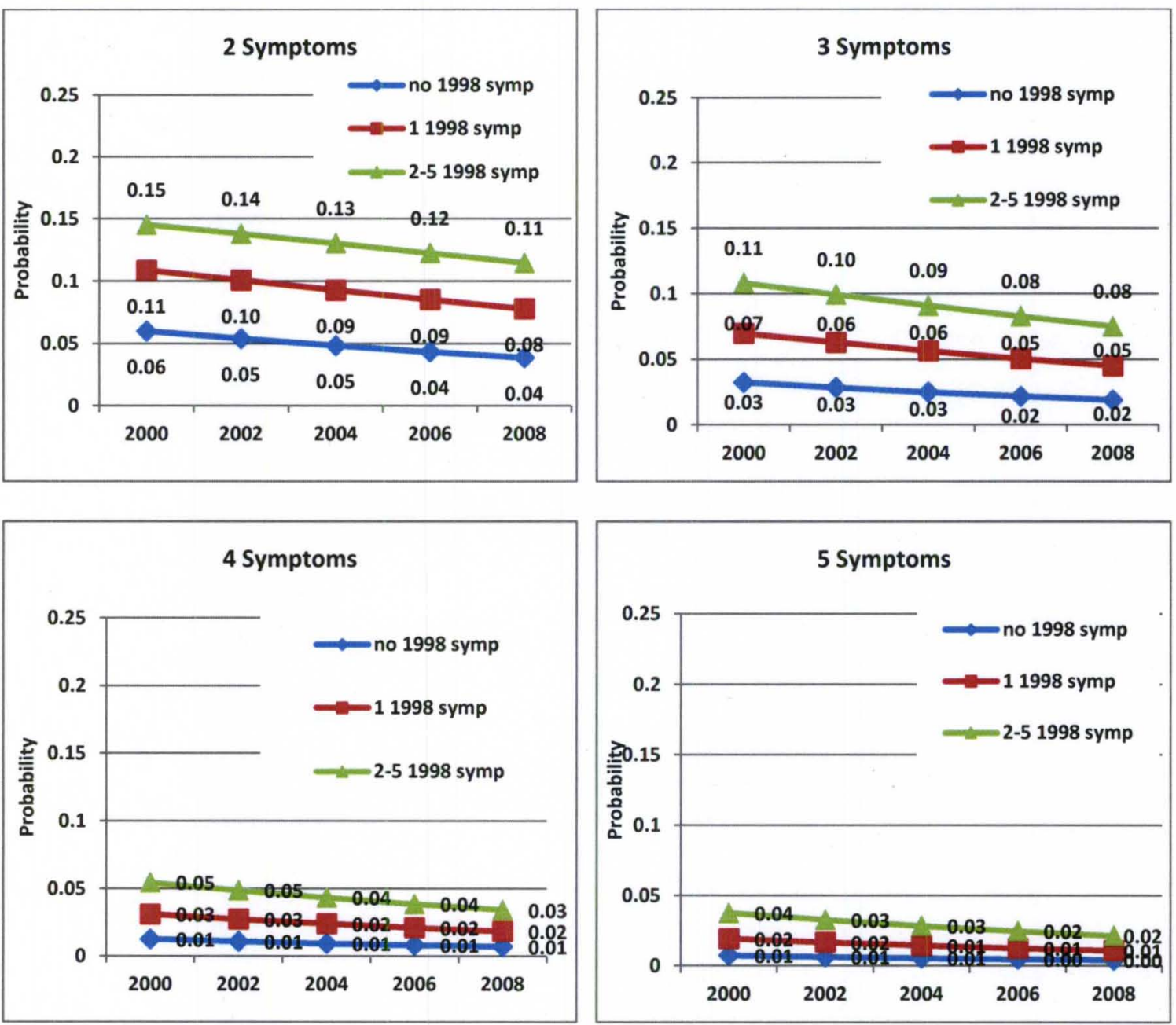

Figure 18. Unique predicted probabilities of symptoms of depression by history of depression.

As can be seen in Figure 18, those with a history of more symptoms of depression had a higher probability of reporting later symptoms of depression. The effect was largest for those with one, two, or three symptoms of depression; it decreased for those with four or five symptoms.

Internal resources. Figure 19 models main effect of subjective health as unique predicted probabilities of having $\mathrm{k}$ symptoms of depression. 

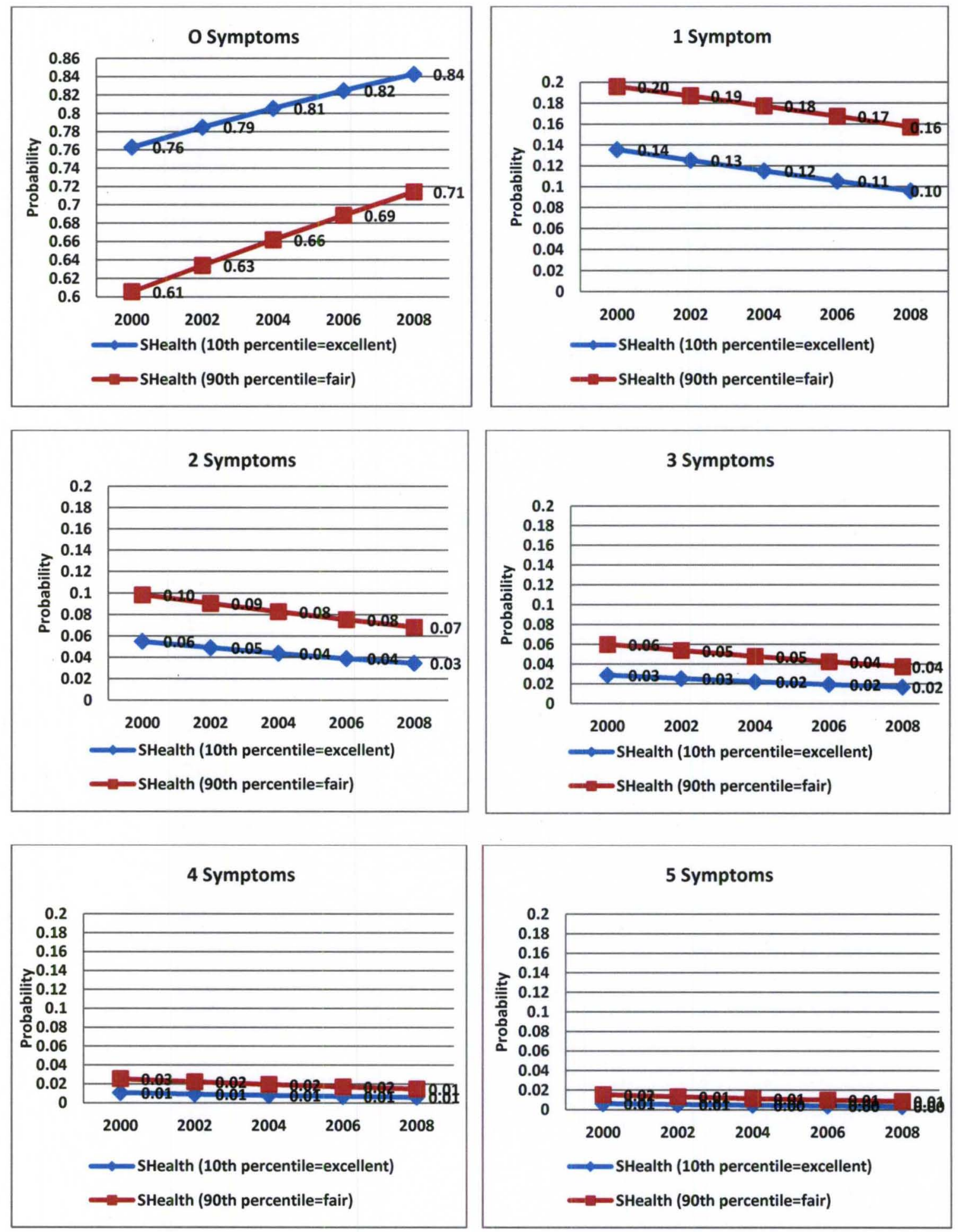

Figure 19. Unique predicted probabilities of symptoms of depression by subjective physical health. 
Those with poorer subjective physical health had greater likelihood of reporting depression symptoms (Figure 19); the effect was largest for those with one symptom. The effect size of subjective health decreased as number of depression symptoms increased.

Figure 20 models main effect of subjective life expectancy as unique predicted probabilities of having $\mathrm{k}$ symptoms of depression.
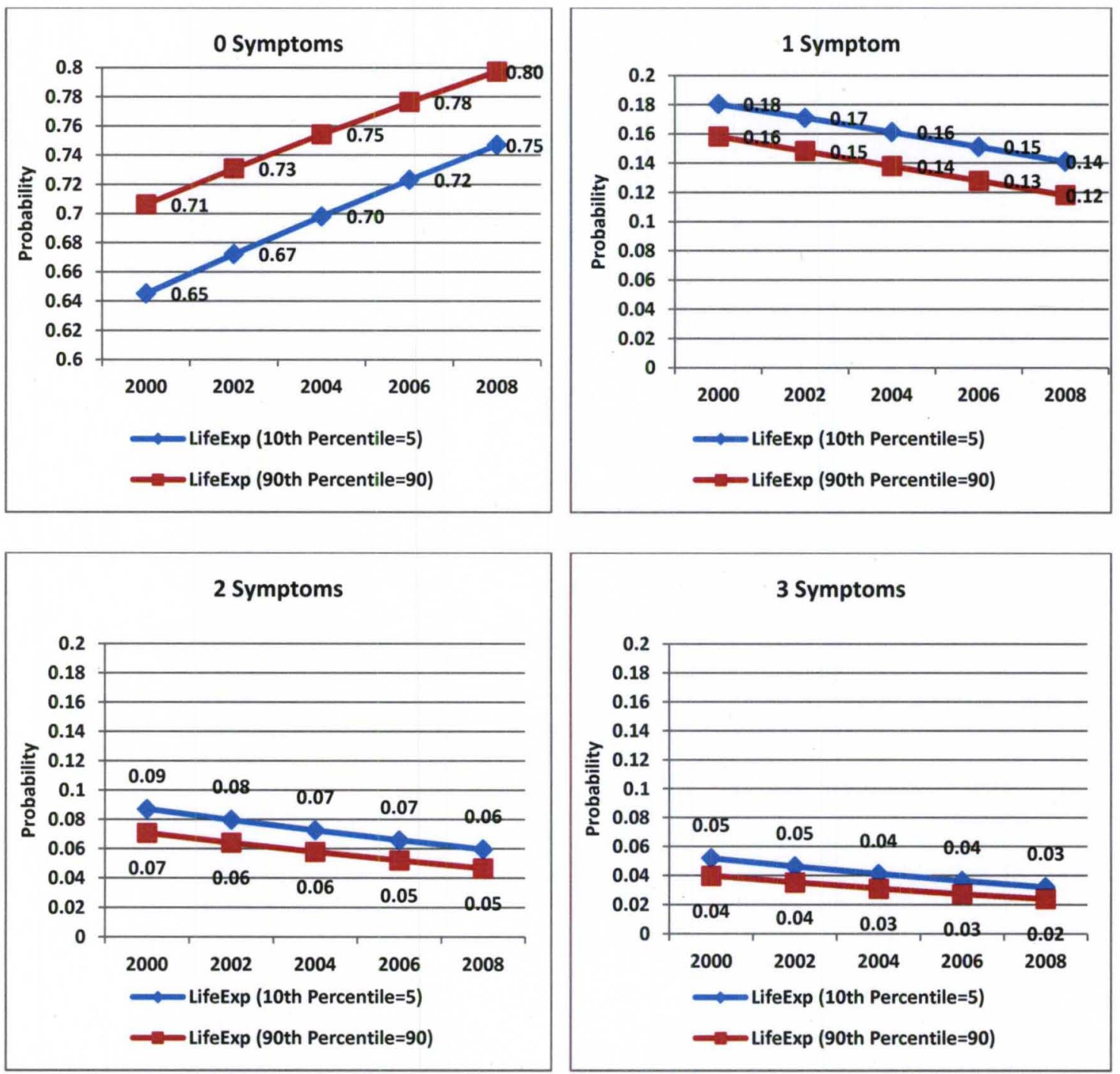

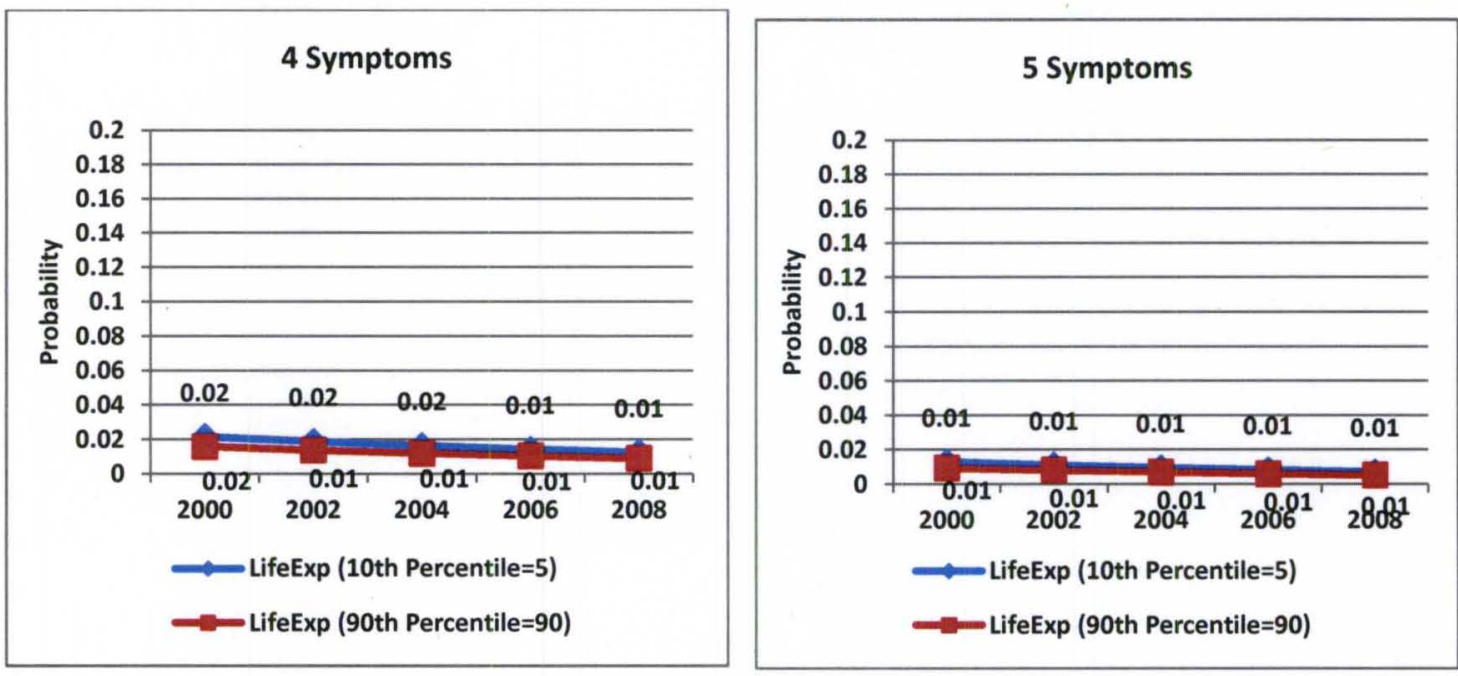

Figure 20. Unique predicted probabilities of symptoms of depression by subjective life expectancy.

Those with lower subjective life expectancy had highest probability of reporting depression symptoms. The effect was largest (Figure 20) for those with one or two symptoms and it decreased as the number of depression symptoms increases.

Figure 21 models main effect of optimism as unique predicted probabilities of having $\mathrm{k}$ symptoms of depression.
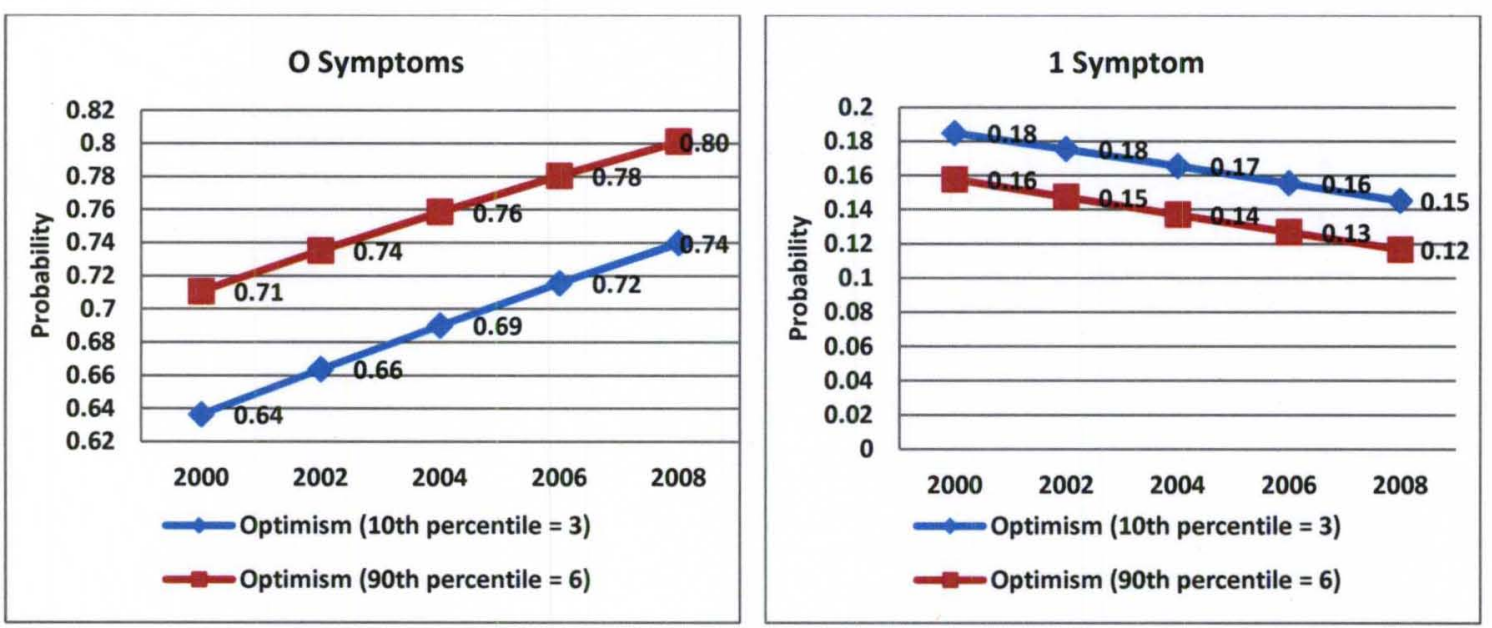

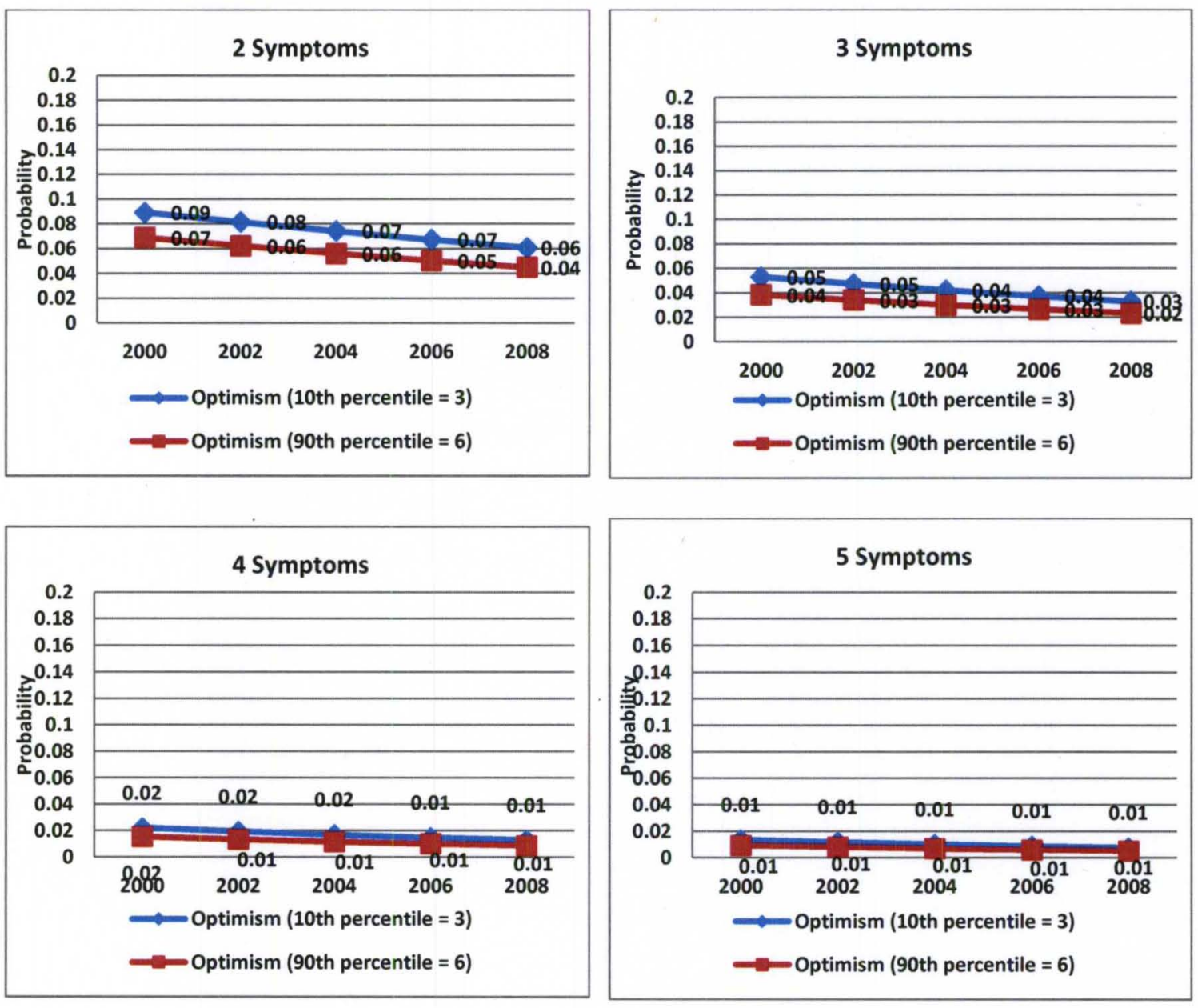

Figure 21. Unique predicted probabilities of symptoms of depression by level of optimism.

Those with higher levels of optimism had lower probabilities of reporting depression symptoms (Figure 21); the effect was largest for those with one or two symptoms and it decreased for those with three, four, or five symptoms of depression.

Figure 22 models main effect of pessimism as unique predicted probabilities of having $\mathrm{k}$ symptoms of depression. 

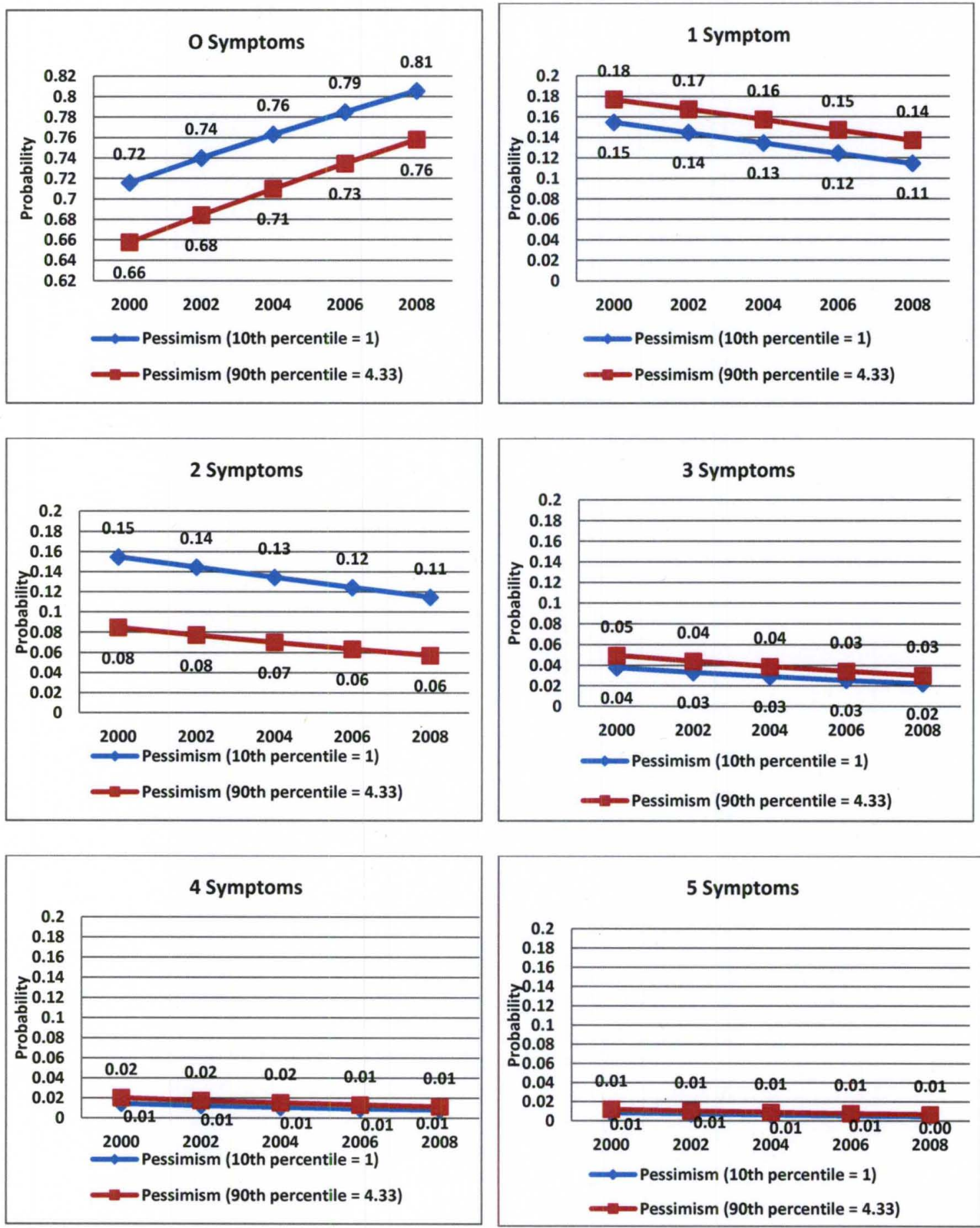

Figure 22. Unique probabilities of symptoms of depression by level of pessimism.

In Figure 22 overall, those with lower pessimism scores reported less depression symptoms. The only symptom category where the effect was 
reversed was with two symptoms of depression; for this group those who were highly pessimistic were less likely to report depression symptoms over time.

External resources. Figure 23 models main effect of employment as unique predicted probabilities of having $\mathrm{k}$ symptoms of depression.
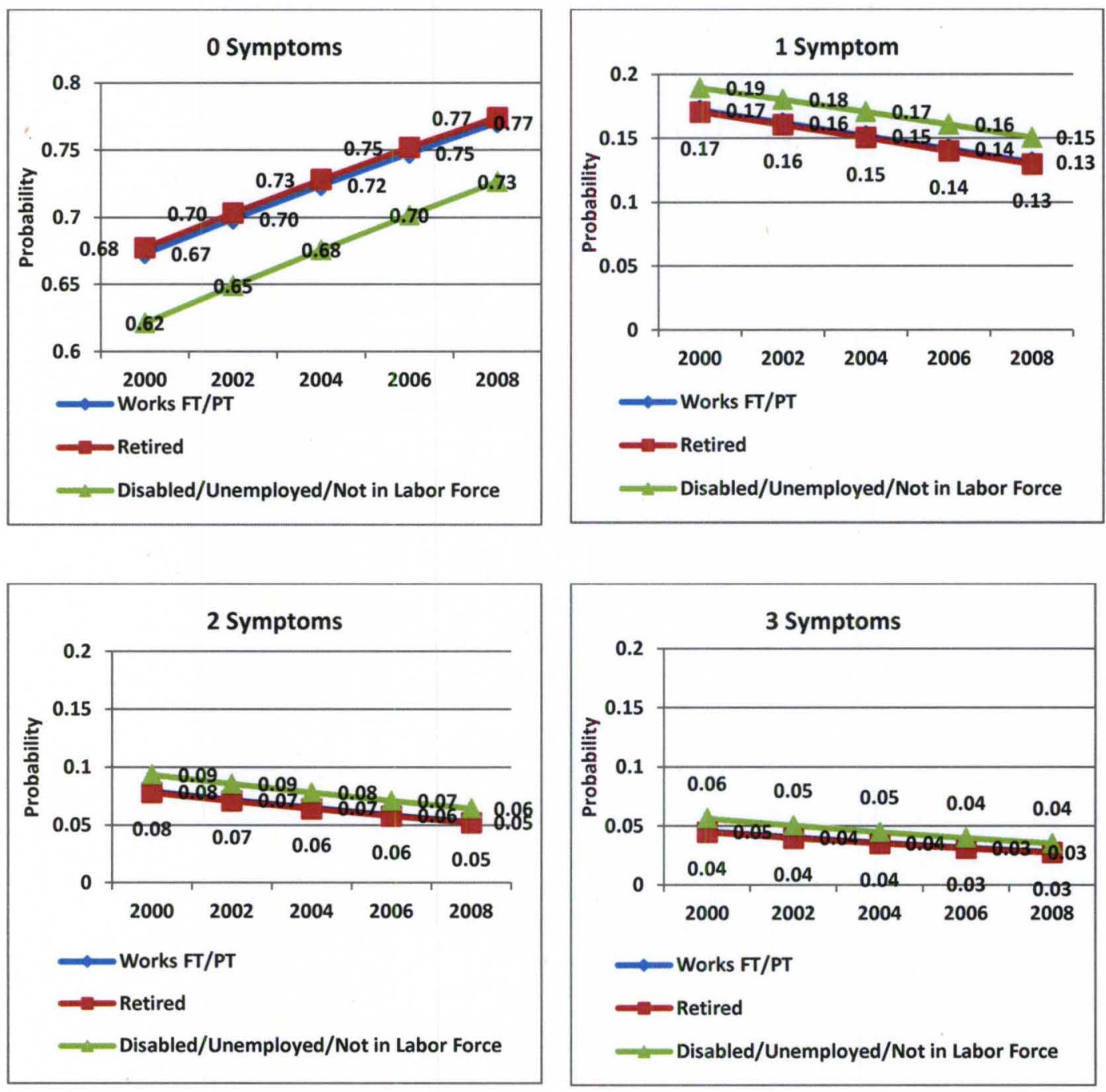

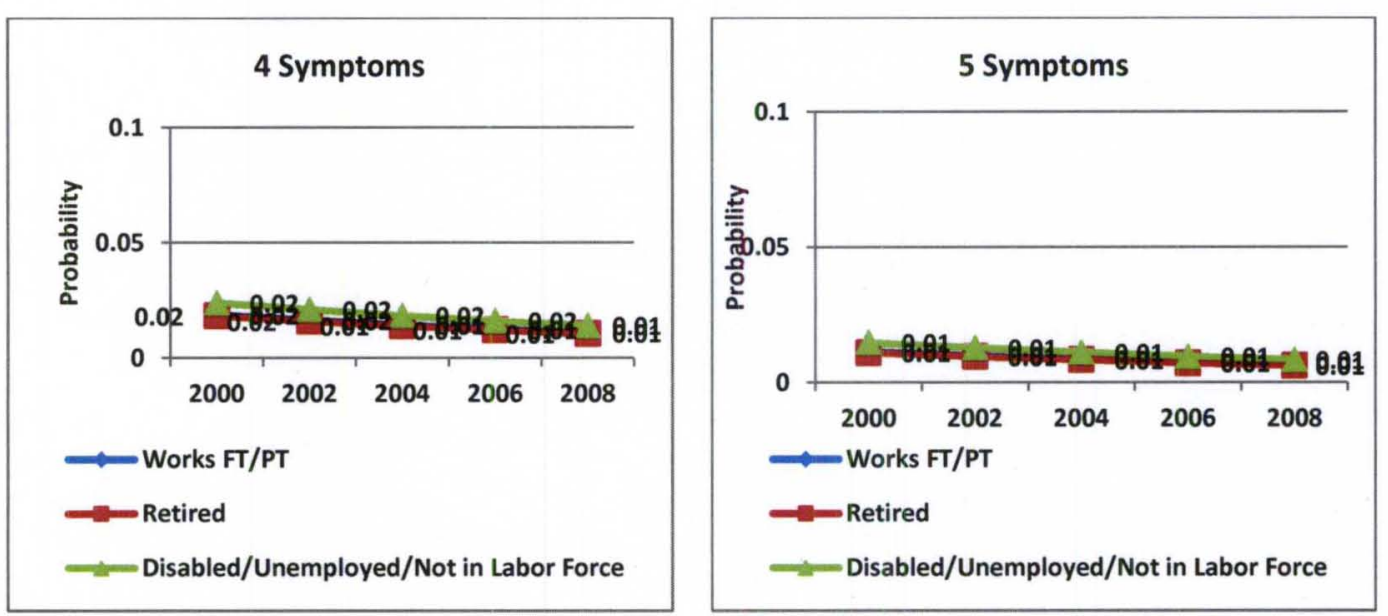

Figure 23. Unique predicted probabilities of symptoms of depression by employment.

Overall, there was a small significant main effect for employment with those who were disabled, unemployed, or not in the work force on likelihood of reporting symptoms of depression (see Figure 23) compared to those working or retired; the effect was largest for those with one symptom of depression and it decreased as symptoms of depression increased.

Figure 24 models main effect of social support as unique predicted probabilities of having $\mathrm{k}$ symptoms of depression.
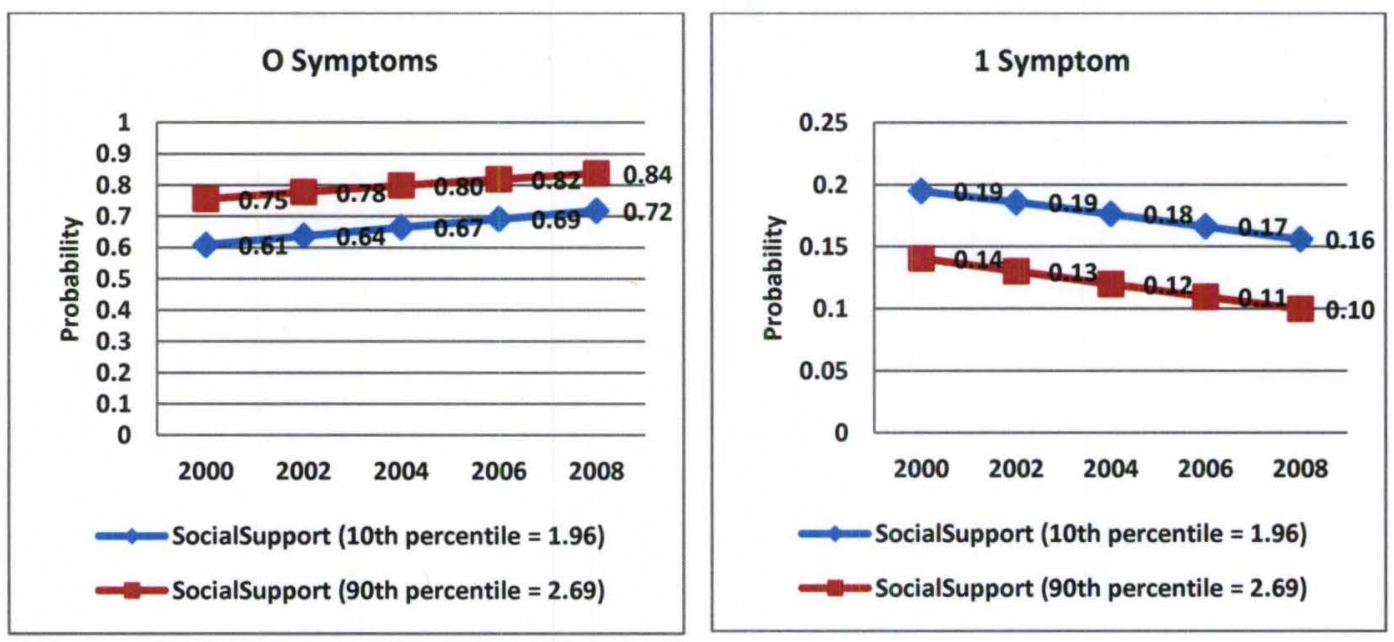

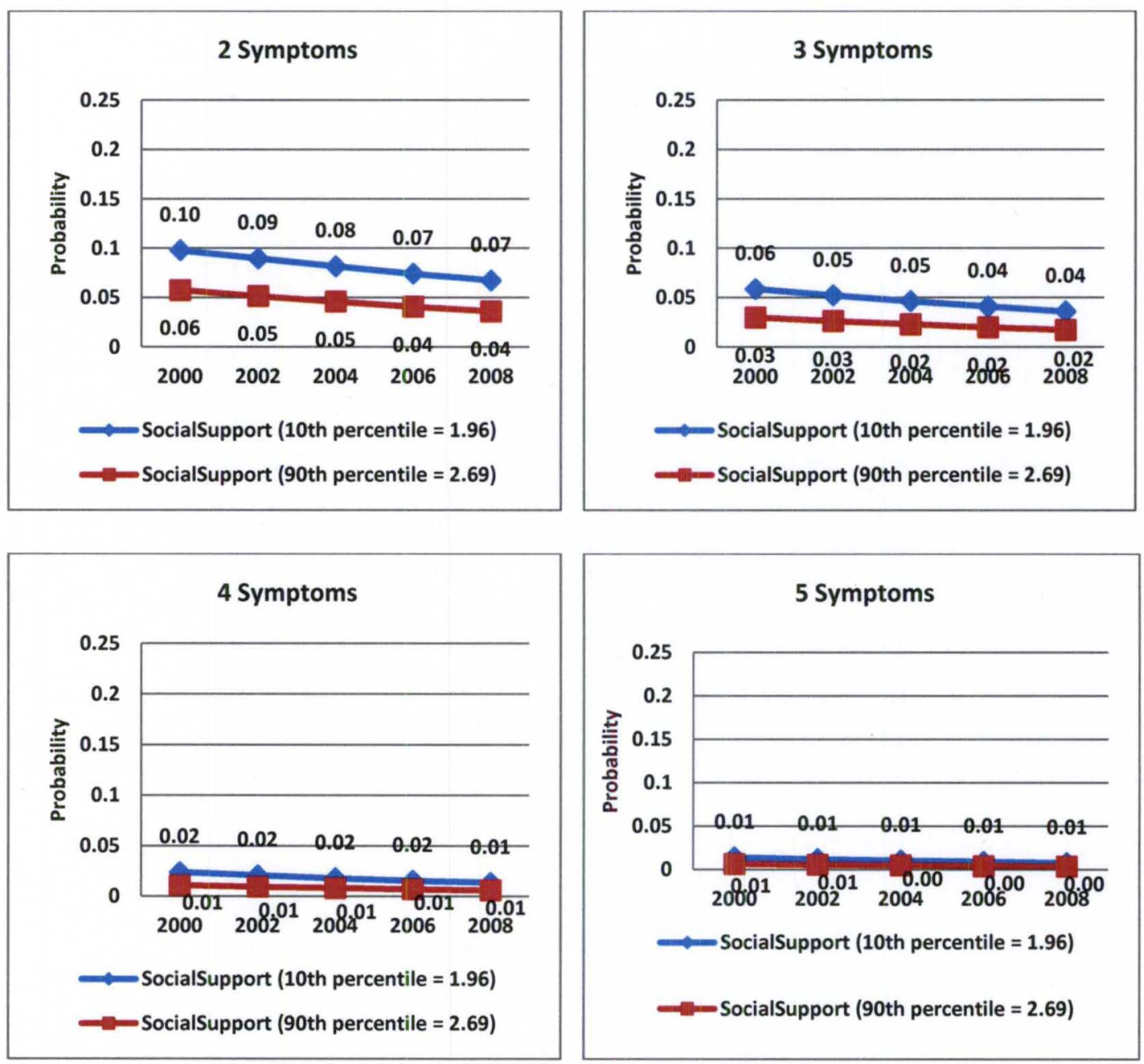

Figure 24. Unique predicted probabilities of symptoms of depression by social support.

Figure 24 models the moderate effect of social support on probabilities of $\mathrm{k}$ symptoms of depression. Those with low social support had the highest likelihood of reporting depression symptoms. The largest effect existed for those with one, two or three symptoms; as with other main effects, the effect size decreased as symptoms of depression increased.

Figure 25 models main effect of marital status as unique predicted probabilities of having $\mathrm{k}$ symptoms of depression. 

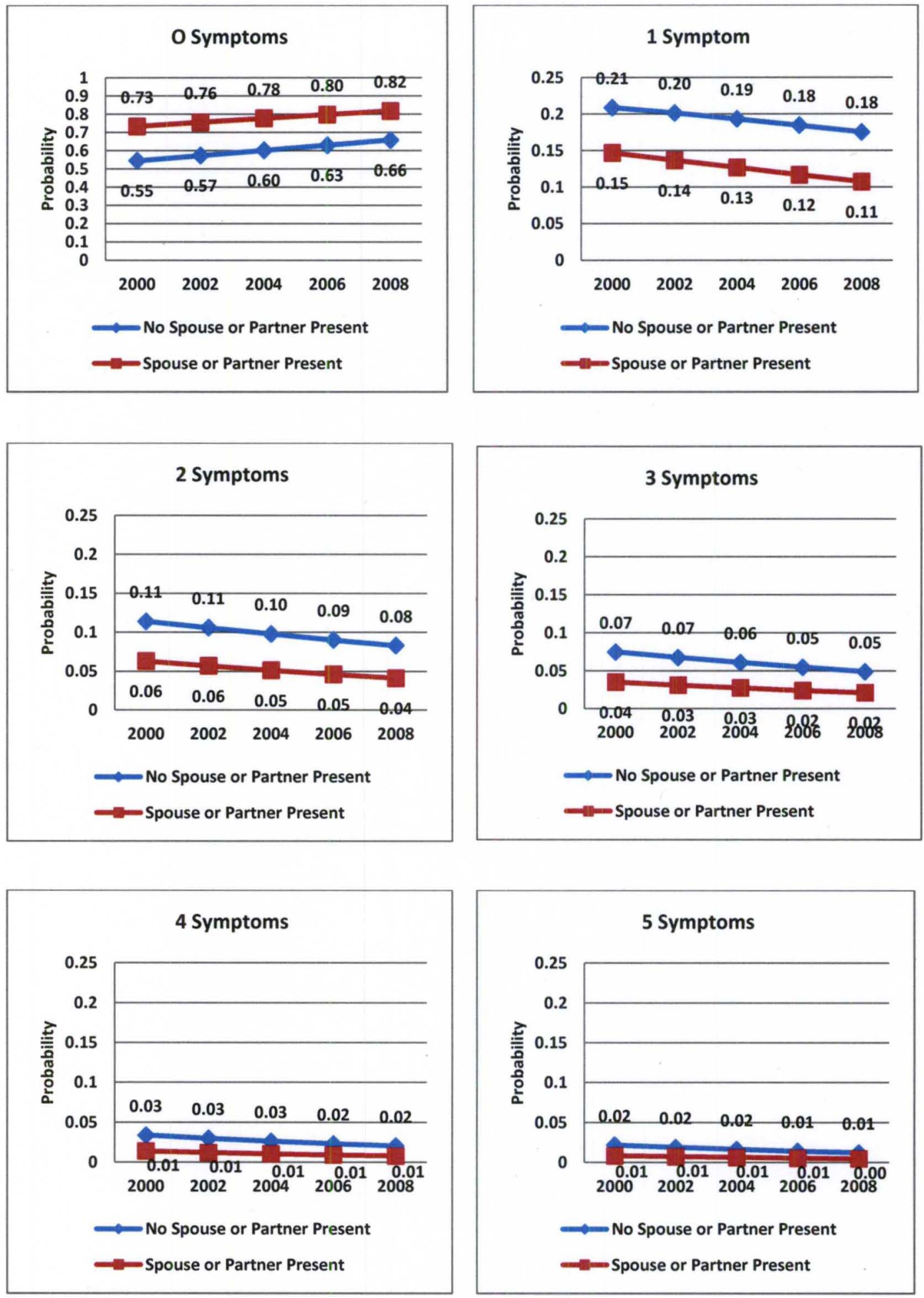

Figure 25. Unique predicted probabilities of symptoms of depression by marital status. 
A significant moderate effect of marital status was detected (see Figure 25) for $k$ depression symptoms. Those with a spouse or partner present in the home were less likely to report depression symptoms than those with no partner presence. The effect was largest for those with fewer symptoms of depression and, as with other main effects, the effect of partner presence decreased as depression symptoms increased.

Figure 26 models main effect of psychological problems and support as unique predicted probabilities of having $\mathrm{k}$ symptoms of depression.
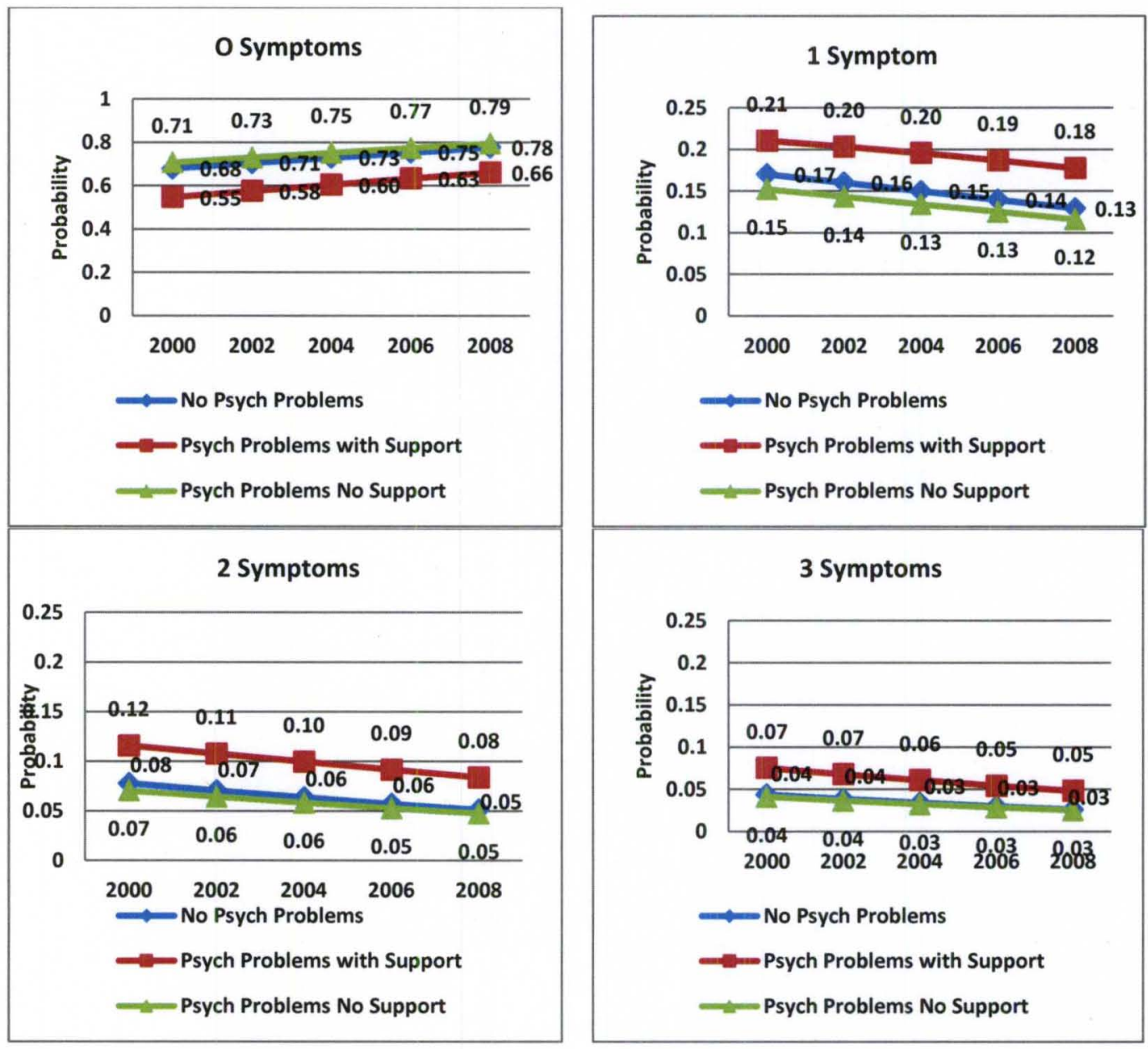

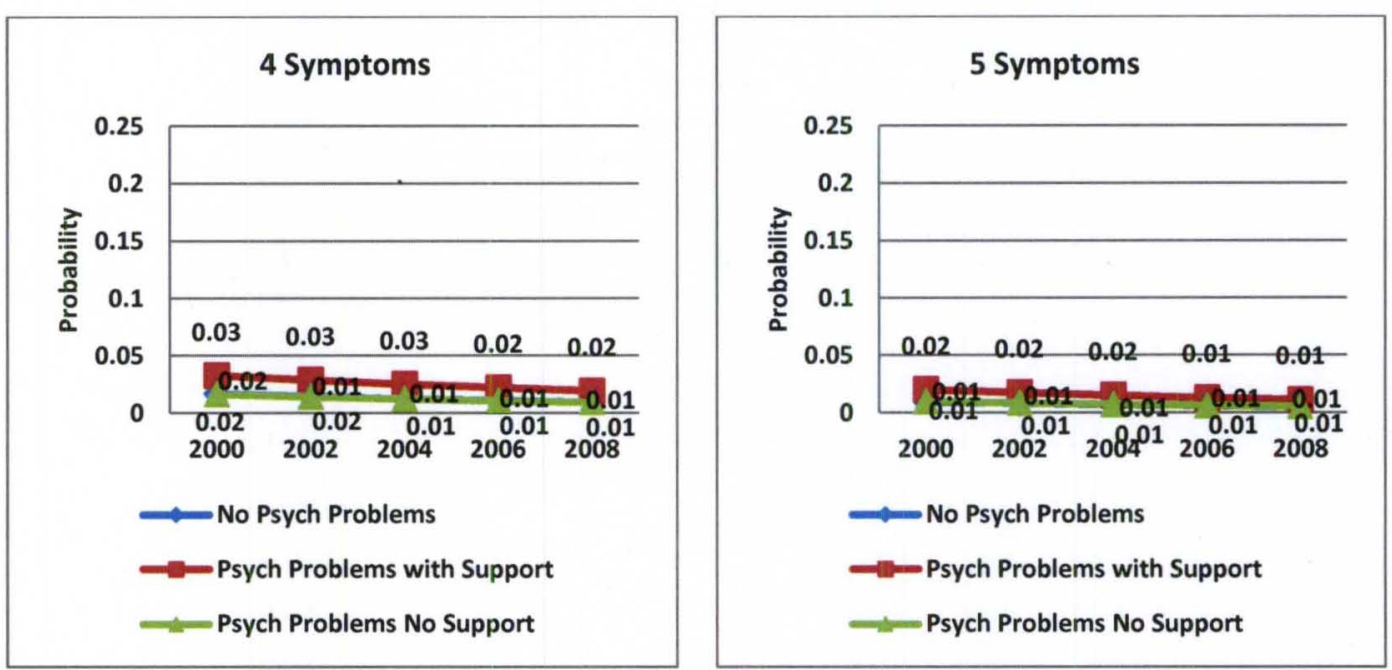

Figure 26. Unique predicted probabilities of symptoms of depression by psychological problems and support.

A significant moderate effect of psychological problems and support was detected in that those who had psychological problems with support were most likely to report symptoms of depression; they were followed by those with no psychological problems, while those with psychological problems and no support were least likely to report depression symptoms.

Health-related resources. Figure 27 models main effect of days in bed as unique predicted probabilities of having $\mathrm{k}$ symptoms of depression.
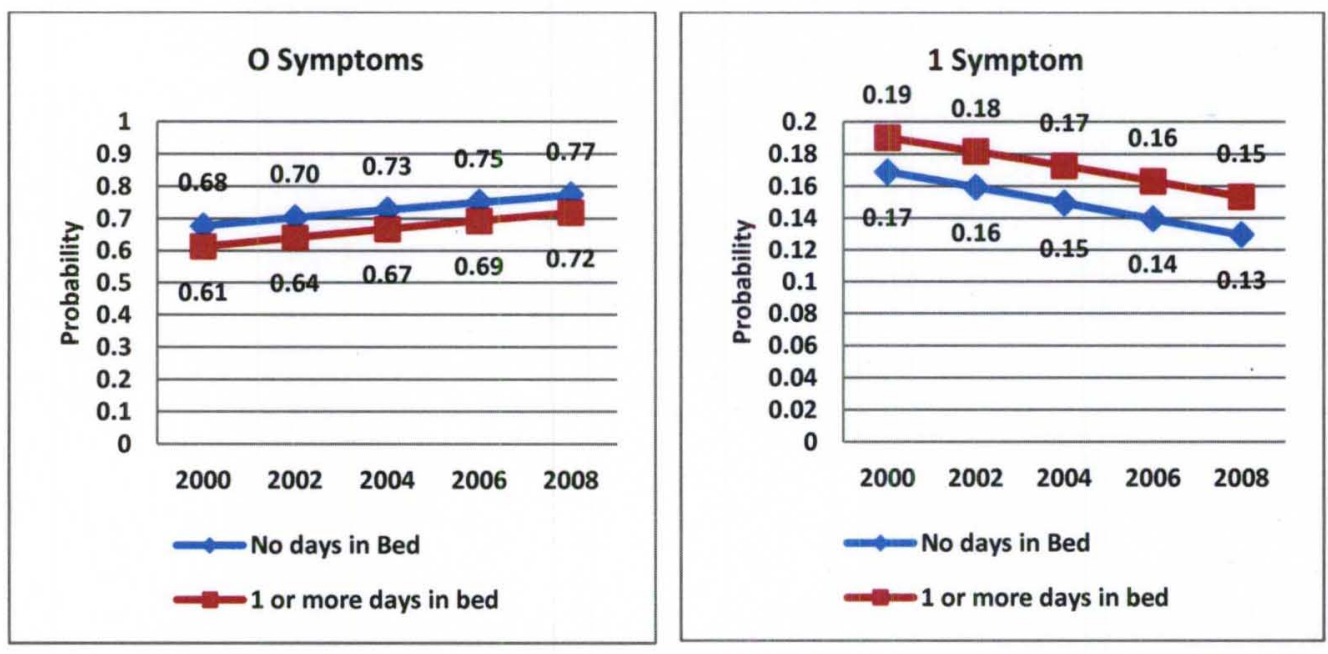

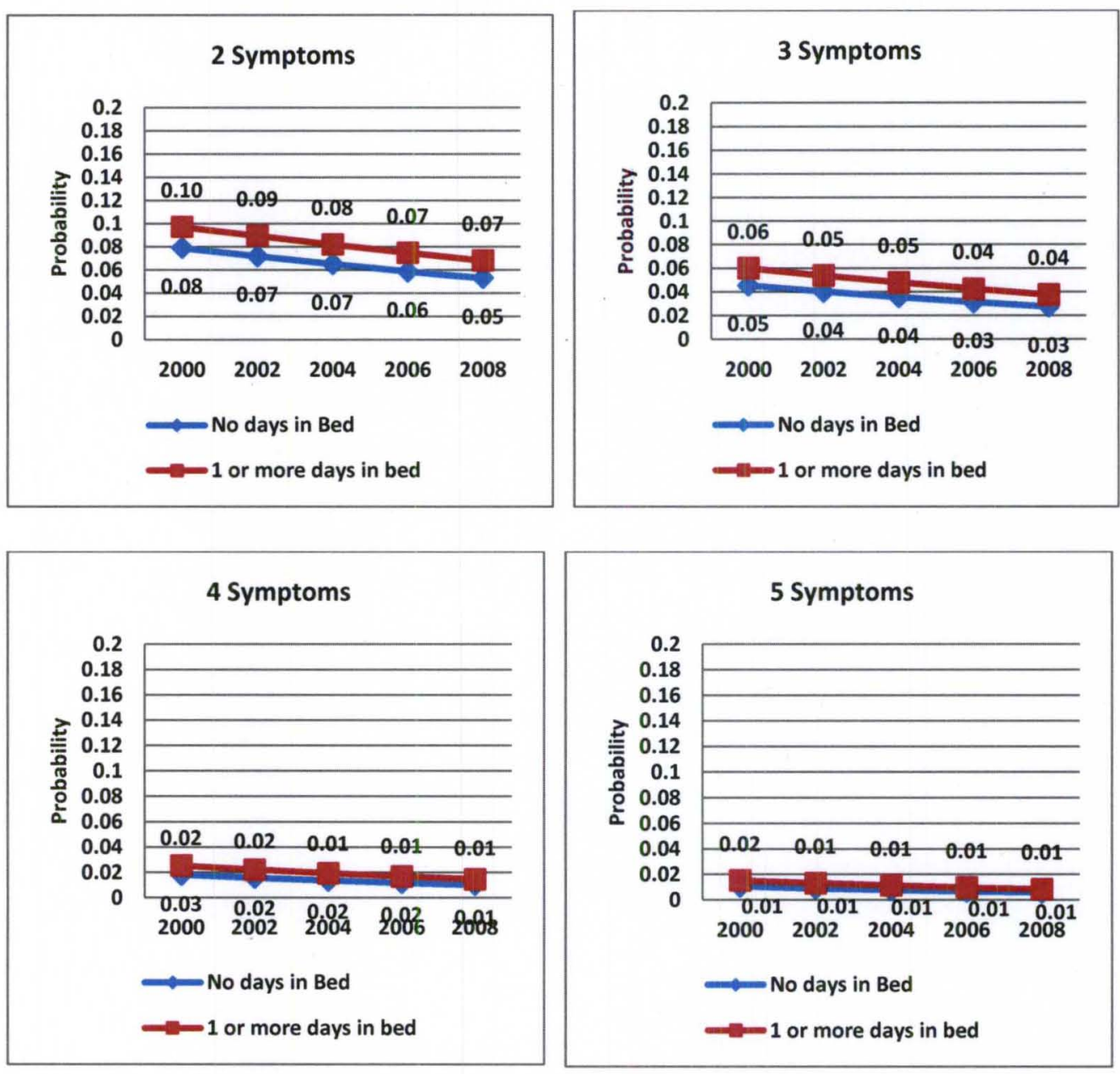

Figure 27. Unique predicted probabilities of symptoms of depression by number of days in bed.

A small effect of bed days was detected on symptoms of depression, with those who had one or more days in bed having higher probability of depression symptoms (see Figure 27). As with all other main effects, the effect decreased as symptoms of depression increased.

Figure 28 models main effect of difficulty with ADLs and IADLs as unique predicted probabilities of having $\mathrm{k}$ symptoms of depression. 

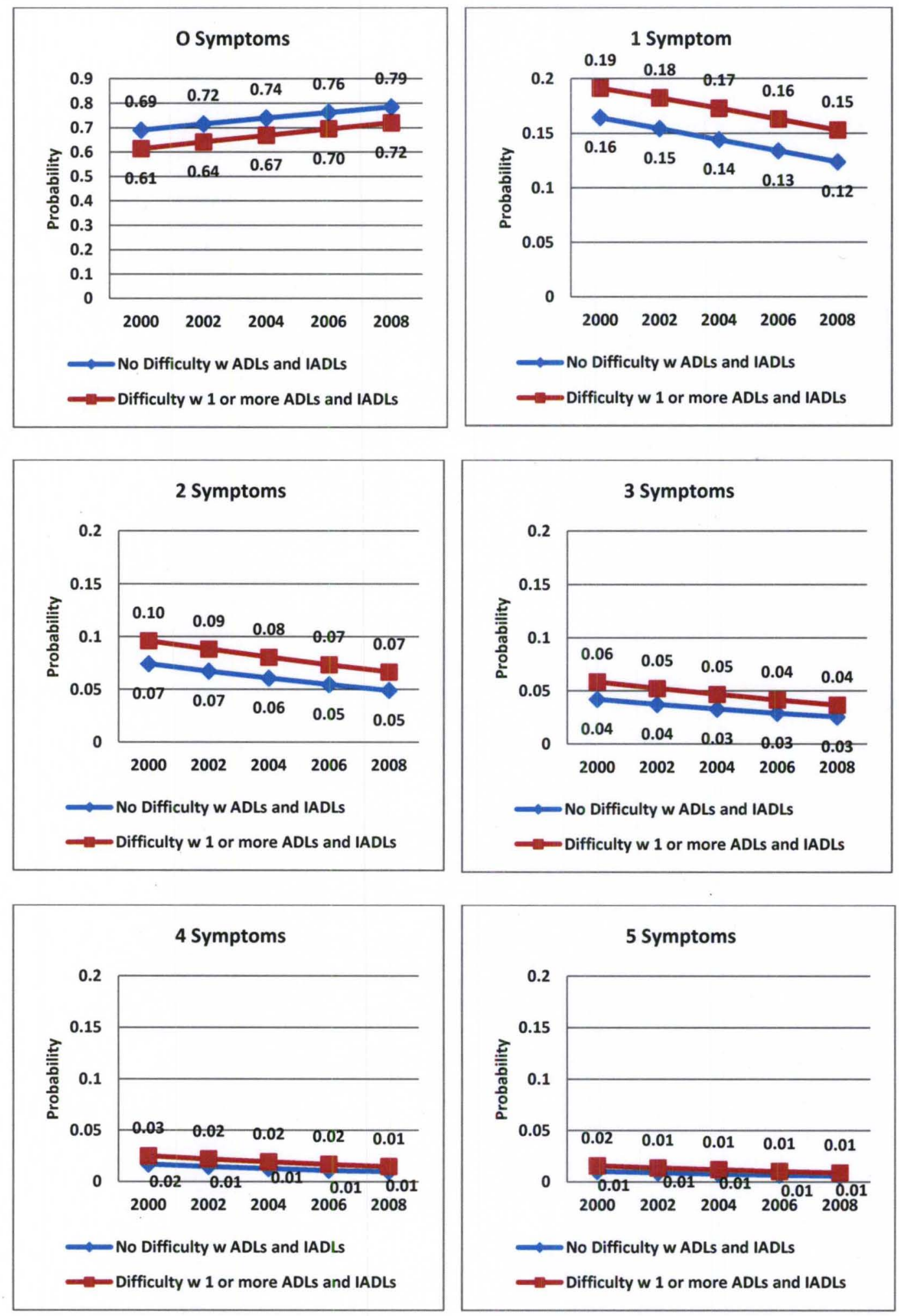

Figure 28. Unique predicted probabilities of symptoms of depression by difficulty with ADLs and IADLs. 
Difficulty with one or more activities or instrumental activities of daily living (ADLs or IADLs) had a moderate effect on symptoms of depression (see Figure 28). The effect was similar to other main effects in that the largest effect existed for those with fewer symptoms; the effect decreased as symptoms increased.

Interaction effects. In adding the interaction effects, the second aim and hypothesis was addressed, namely to investigate if the main effects were different for those with and without cancers. In Figures 29 through 33 the probabilities of depression symptoms were modeled for each of the significant interaction effects. All interaction effects were modeled as a function of time.

Figures 29 and 30 highlight a significant large interaction effect between cancer and having a partner present in the home; in Figure 29 the unique probabilities of each symptom category are modeled. Figure 30 displays the combined probabilities of reporting one or more symptoms of depression for each group. Those with cancer who had a partner present had the lowest probability of reporting any symptoms of depression (one or more symptoms combined total was 19 percent). They were followed by those with no history of cancer who had a partner present in the home (one or more symptoms combined total was 23 percent).

Those with no cancer history and no partner present were more likely to report symptoms of depression than the first two groups (one or more symptoms combined total was 38 percent), but those with the highest likelihood of reporting depression symptoms were those with a cancer history who had no partner present (one or more symptoms combined total was 46 percent). 


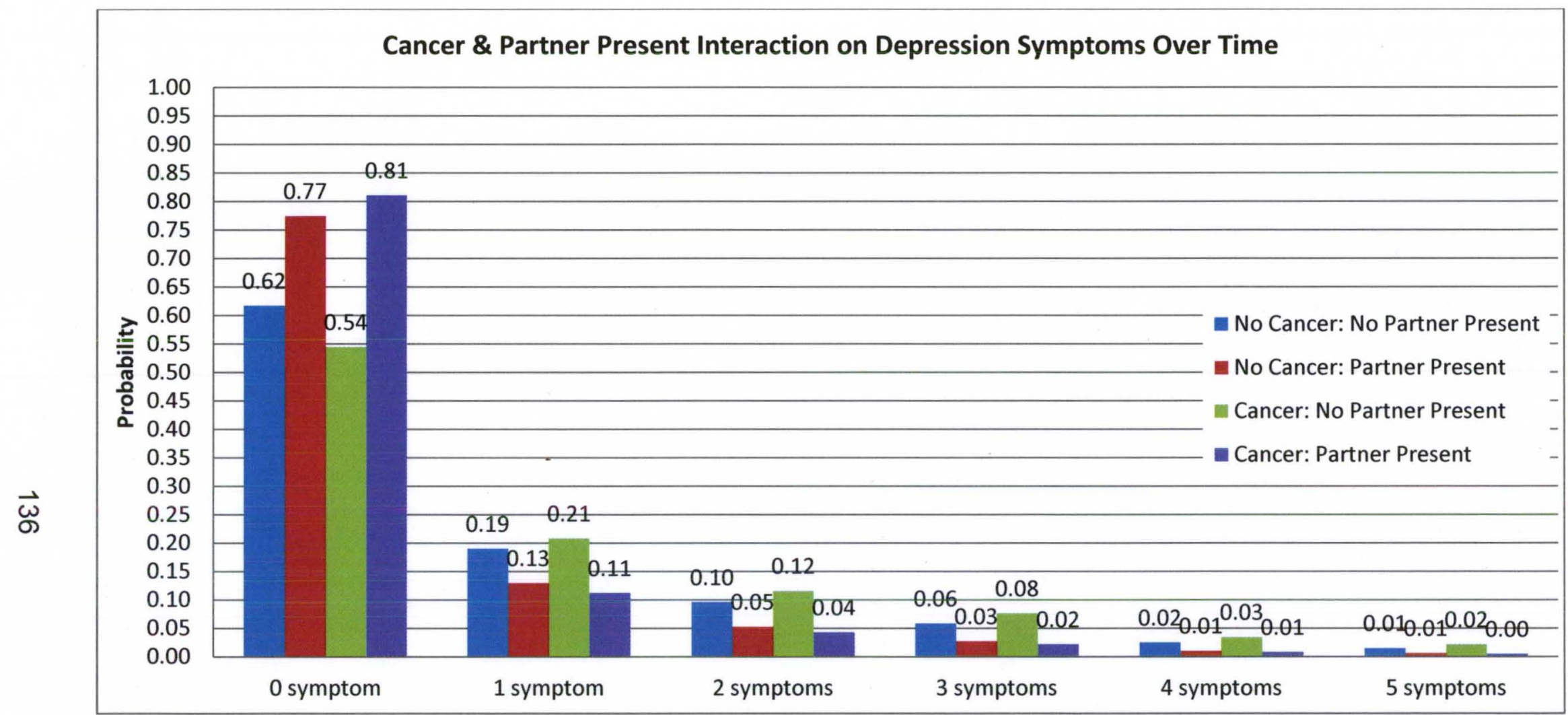

Figure 29. Cancer and partner presence interaction on unique probabilities of $\mathrm{k}$ depression symptoms. 


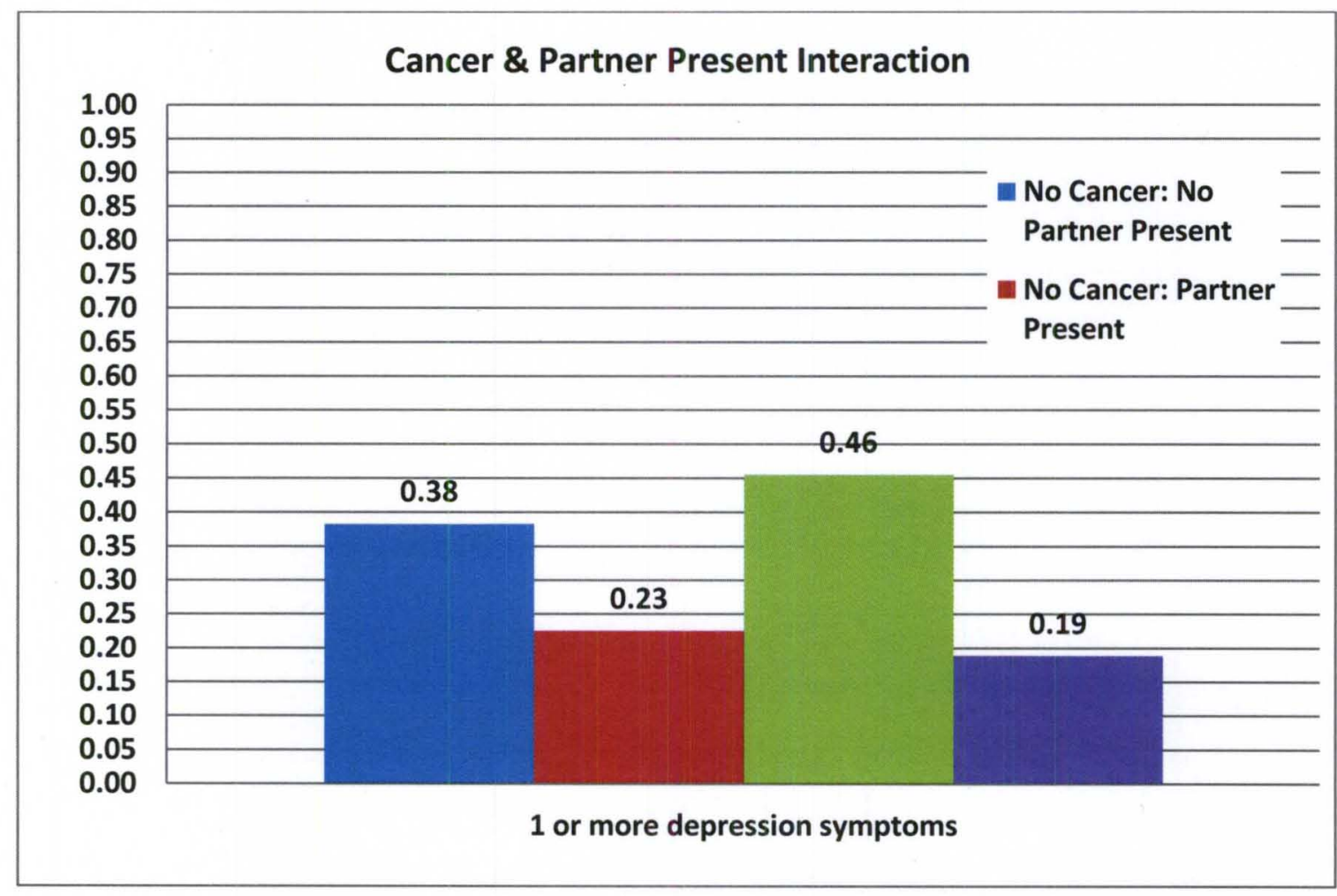

Figure 30. Cancer and partner presence interaction on predicted probabilities of one or more depression symptoms.

Figures 31 and 32 show a moderate significant interaction effect between cancer and life expectancy; figure 31 models the unique probabilities of each symptom category, while Figure 32 models the combined probabilities of one or more symptoms of depression. This effect is moderate and similar to the cancer and partner presence interaction. Those with the lowest probability of reporting one or more depression symptoms are those with a history of cancer and high life expectancy (one or more symptoms combined total was 21 percent). They were followed by those with no cancer history and high life expectancy, then those with no cancer history and low life expectancy (one or more symptoms combined total was 26 percent and 31 percent respectively). Finally, those with 
the highest probability of reporting symptoms of depression were those with a cancer history and low life expectancy (one or more symptoms combined total was 21 percent). 


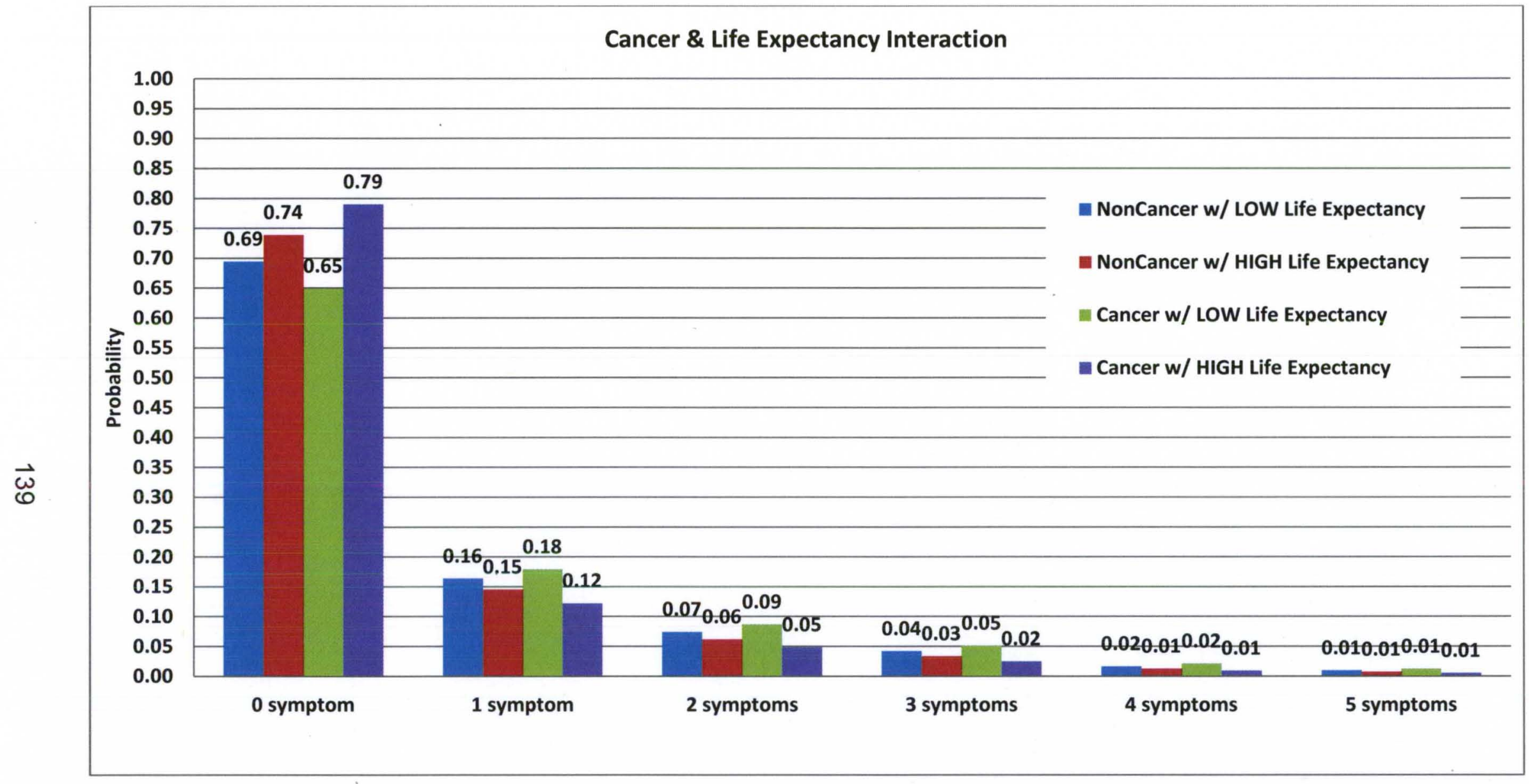

Figure 31. Cancer and life expectancy interaction on unique probabilities of $\mathrm{k}$ depression symptoms. 


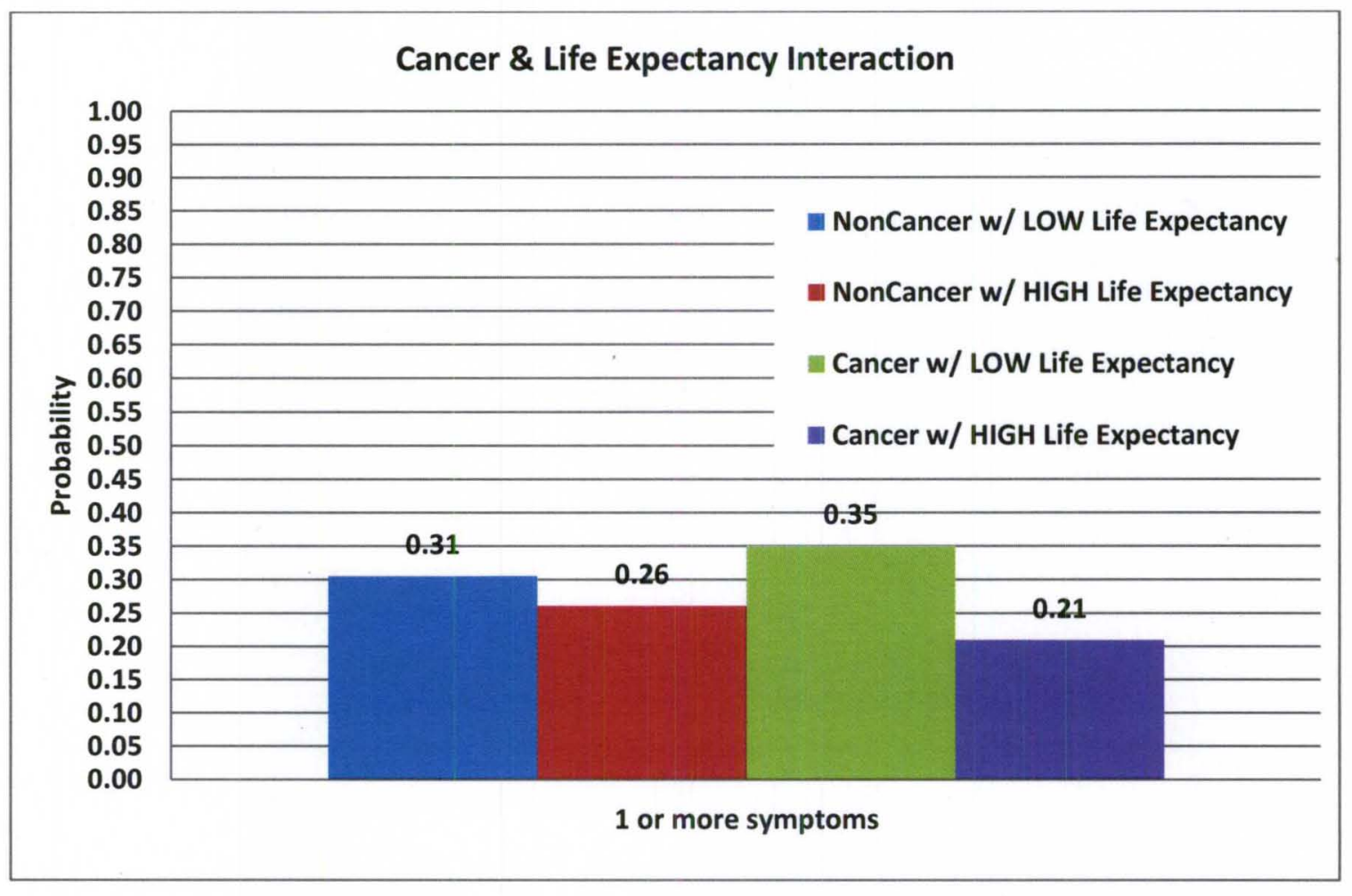

Figure 32. Cancer and life expectancy interaction modeled as predicted probabilities of one or more symptoms of depression.

Figure 33 models the combined probabilities of one or more symptoms of distress for the large interaction effect between cancer, gender, and social support. Unique probabilities are not presented here due to the complexity of such a figure. Those with the lowest likelihood of reporting one or more symptoms of depression were women with a cancer history and high social support (one or more symptoms combined total was 16 percent). Men with high social support followed; those with cancer had 18 percent probability of reporting depression symptoms and those without cancer followed at 19 percent. Women with no cancer and high social support came next with a 23 percent probability of reporting depression symptoms. Men with low social support had a 29 percent probability of reporting depression symptoms if they had a cancer history while 
men with low social support and no cancer history had a probability of 30 percent. Those with the highest probability of reporting one or more depression symptoms were women with cancer and low social support at 45 percent). 


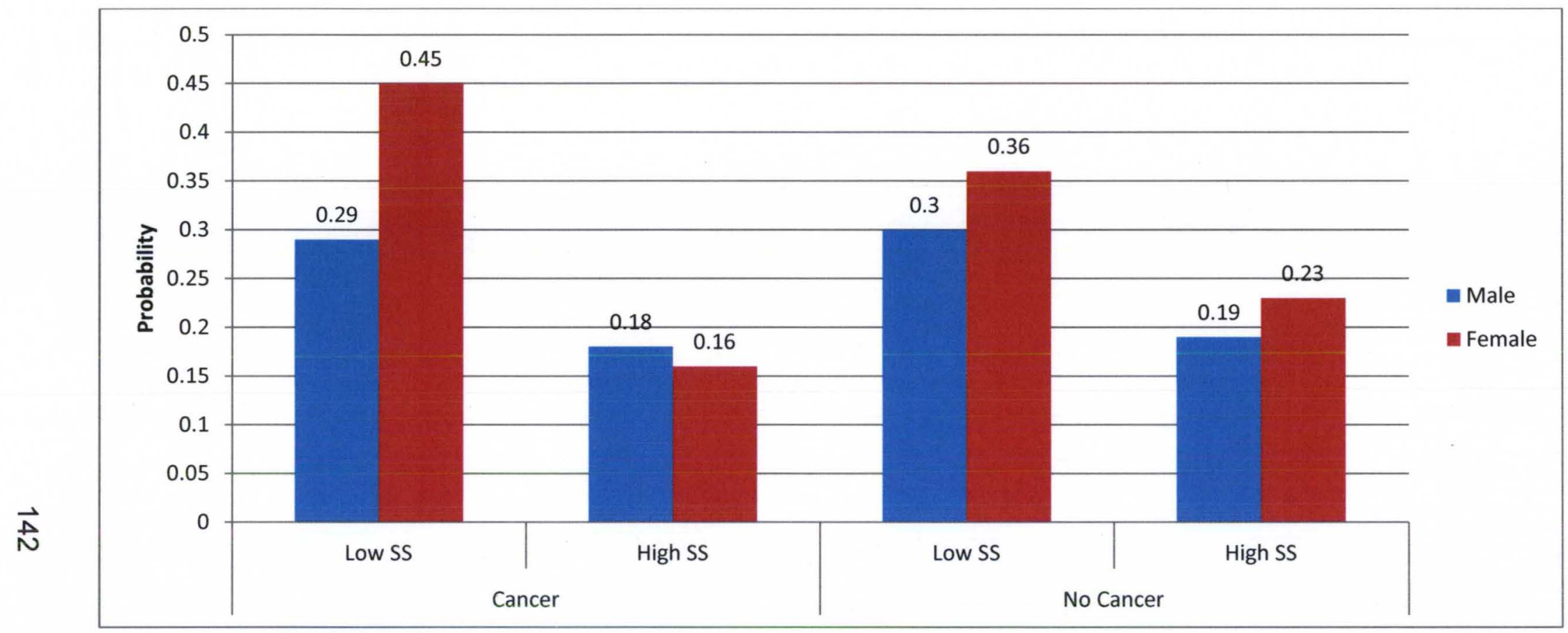

Figure 33. Cancer, gender, and social support interaction on unique probabilities of one or more depression symptoms. 


\section{Summary}

In each step, the model fit improved significantly using the DIC statistic. Overall, 33 percent of sample reported one or more depression symptoms in 2000 , and by 2008 the number decreased to 30 percent. Keeping all main effects constant, those with cancer had one percent lower probability of depression symptoms over time than those without cancer.

In the overall sample the following significant main effects were found: for demographics and life course factors, being female, not having a history of cancer, and having a history of distress all resulted in higher distress over time. Among internal resources that increased distress over time were poorer subjective health, lower life expectancy, lower optimism, and higher pessimism. Among external resources, being disabled/unemployed/not in workforce, lower social support, having no spouse or partner present in the home, and having psychological problems with support resulted in higher distress. Finally, among health related resources more days in bed and difficulty with one or mode ADLS or IADLs resulted in higher distress.

Significant two-way interaction effects were detected between having cancer and the following: absence of spouse/partner in the home and lower life expectancy resulted in higher probabilities of one or more depression symptoms. Finally, a significant three-way interaction effect was found between cancer history, gender, and social support. There was a large protective factor of cancer history against distress for women with high social support, but cancer history 
was a risk factor for distress among women with low social support. For men, the history of cancer resulted in a very small, one percent lower likelihood of reporting distress in each of the levels of social support. The largest difference between men and women was detected among those with cancer and low social support; among this group, one third of the men reported distress while almost half of the women reported distress.

The next chapter discusses the relevance of these findings, specifically addressing the implications for future health social work practice and education, and oncology social work research. 


\section{CHAPTER V: DISCUSSION}

The facts are always friendly, every bit of evidence one can acquire, in any area, leads one that much closer to what is true.

$\sim$ Carl Rogers

This chapter will discuss the implications of the results presented in the prior chapter. First, the findings of the analyses will be discussed, along with their convergence or divergence with previous literature. Next, practice and education implications will be presented. Finally, strengths, limitations, and future research implications will be delineated.

Using nationally representative longitudinal study data and a multilevel modeling methodology, this study responded to the following questions: (1) Is there a significant relationship between older cancer survivors' life course factors, internal, external, and health-related resources, and emotional distress over time?; and (2) How is this relationship different for those older adults with a cancer diagnosis vs. those without a cancer diagnosis? The findings will be discussed as they relate to the specific aims and hypotheses:

Specific Aim 1: To determine if older adults with cancer differ in their emotional distress levels from those without cancer over a period of eight years.

Hypothesis 1: Older adults with cancer will have a different eight year emotional distress change trajectory than those without cancer.

Findings supported this research hypothesis in that a small difference was found between the trajectories of the two groups. Among this nationally 
representative sample of older adults, overall, about 33 percent were distressed in 2000 and by 2008 this number reduced to 30 percent. Over time, older adults with cancer had a lower likelihood of reporting emotional distress than those without cancer.

Controlling for all the effects in the model, in 2000,32 percent of those with a history of cancer in the past two years reported distress; this finding supports prior research findings with mixed cancer samples in which about onethird of those with cancer are distressed (Carlson, et al., 2004; Fallowfield, et al., 2001; Farber, et al., 1984; Sellick \& Edwardson, 2007; Stefanek, et al., 1987; Zabora, et al., 2001). Similar to the longitudinal findings of Polsky, et al. (2005), likelihood of distress decreased over time for those with cancer. The probabilities of distress decreased by two to three percent per study wave; by 2008 , the probability of reporting distress for those with a cancer history decreased to 22 percent. When specifically examining where the decrease occurred, it was those with less distress (one, two or three symptoms) who tended to improve over time while those with higher distress (four or five symptoms) tended to stay highly distressed. Across all waves, those with no history of cancer were one percent more likely to report distress than those with a cancer history.

The findings related to the second aim and hypothesis will next be discussed along with the relevant theories presented in Chapter 2.

Specific Aim 2: To determine if differences and changes in life course factors, internal, external, and health-related resources within and between older 
adults will have a differential effect on eight year emotional distress change trajectories for those with and without a cancer diagnosis.

Hypothesis 2: Differences in life course factors, internal, external, and health-related resources within and between older adults will have a differential effect on eight year emotional distress change trajectories for individuals with and without a cancer diagnosis.

Results of this study supported this hypothesis. For those with a history of cancer, distress trajectories were moderated by partner presence in the home, life expectancy, and the combined effects of gender and social support.

One of the theoretical aims of the study was to examine life course factors and their influence on long term distress patterns among those with cancer. Results supported life course theory in that emotional distress is predicted, in part, by prior emotional distress; it also supports the life course notion that life events, like cancer, influence trajectories of emotional distress. There was a small but significant protective factor of cancer on distress over time. Age was not supported as a predictor of emotional distress among those with a history of cancer.

A second theoretical grouping was that of internal resources; all of these variables significantly affected distress in the sample as a whole. Yet, in examining them as interaction effects with cancer, subjective physical health and dispositional optimism were not ultimately significant predictors of distress. There was, however, a small interaction effect of cancer and life expectancy on distress. Cancer acted as a protective factor for older adults with longer life 
expectancy, but a history of cancer became a significant risk factor for distress for those older adults with a low life expectancy. This highlights the value of the internal subjective appraisals posited by stress and coping theory and the personal characteristics resources of COR theory and their effect on distress; support is provided here for the notion among these theorists that when demands exceed resources, distress results.

Mixed support was found for the third theoretical grouping, external resources, favored by the conservation of resources theorists. Hobfoll's energy resources (2002), such as education, net worth, and health insurance status had, unfortunately, no significant effects on distress in the overall sample. Yet, being disabled/unemployed/not in workforce, having lower social support, having no partner present in the home, and having psychological support (for those with psychological problems) all resulted in higher emotional distress levels.

Among those with cancer, an interesting picture emerged. A large protective factor of cancer existed for older adults with a partner present in the home, but with no spousal presence, cancer history became a significant risk factor for emotional distress. This finding provides very strong support for all three theories discussed earlier as all highlight the value of social support, and human relationships in particular (life course theory's linked or interdependent lives, COR's condition resources, and social support of stress and coping theory).

Interestingly, significant interactions between cancer, gender, and social support emerged; once again, having a history of cancer served as a protective 
factor for both men and women with high social support, while having low social support and a history of cancer resulted in higher risk of distress for both genders. The effect was very large for women and small for men. These findings also support all three theories with regard to social support as discussed above; yet for men, a cancer history only resulted in a small, one percent difference in distress levels across levels of social support.

Mixed results were found among the health-related resources; among the objective physical health measures, co-morbid conditions and pain were not significant predictors of distress, but spending one or more days in bed significantly increased distress in the overall sample, over time. Among the measures of physical functioning, having difficulty with one or more ADLs or IADLs also significantly increased distress. These findings provided some general support for stress and coping and COR theories, as both identify physical health as important resources.

An interesting question arises as to whether the lack of significance for comorbid conditions and pain might provide support for the notion of timing of events posited by Elder in life course theory (2002, November); might their nonsignificance indicate that comorbid conditions, and even pain, were considered by participants as normal events in aging and therefore, "on-time", thus not distressing?

None of the health-related resources interacted with cancer in affecting distress over time in this group of older adults. This finding did not support prior literature (Institute of Medicine, 2007; Ronson \& Body, 2002; Spiegel, et al., 
1994), but this may have been due to the fact that these resources could be less linked to cancer in the survivorship phase.

\section{Implications for Health Social Work Practice and Education}

Health social work practitioners and educators can be informed by understanding that long term adjustment to cancer involves more than a "fighting spirit". Internal resources are important, but there is much support for the person-in-environment work of social workers. Social workers are experts at helping people find external resources.

Perhaps the greatest areas for social work support are in how cancer affects relationships and how relationships-especially the presence of a spouse or partner in the home-affect emotional adjustment to illness. While there is some difficulty in exploring the implications of this finding-as much more information is needed to fully understand it—-findings highlight the need for ensuring that partnered older adults remain together. An important social work intervention with those affected by cancer might include a creative exploration of ways to help patients who need physical rehabilitation stay in their homes-with their partners-if they express this as an important goal when receiving cancer care. The Patient Protection and Affordable Care Act (ACA) is supporting this concept by including provisions designed to provide new options for states to provide home and community-based services in their Medicaid plans. The efforts of Congress to include these provisions in the ACA encourages state Medicaid plans to shift resources away from nursing homes and other forms of institutional care towards home and community-based settings in support of the concept of 
"aging in place" (Kaiser Family Foundation, 2012). Other promising ACA initiatives include Patient Centered Outcomes Research Institute whose goals include researching patient informed models of care. There is much opportunity for social work to inform the implementation of these initiatives and research.

Findings support the need to focus social work support on those with lower life expectancy, even eight years or more post cancer diagnosis. Many local and national community based supportive services are available to help these individuals, like the American Cancer Society, Cancer Support Community, Cancer Care, Inc., Association of Oncology Social Work, and Friend for Life. Survivorship care programs, such as those supported by LIVESTRONG and Journey Forward provide models for long term follow up of those affected by cancer.

\section{Conclusion}

\section{Limitations of the Study}

Threats and limitations related to the design used in this existing data study should be acknowledged. Most importantly, the choice and measurement of variables was limited to those measured in the HRS; thus, for example, type of cancer could not be differentiated because participants were not asked to clarify specific cancer diagnoses. This is an important limitation as certain cancers are known to cause greater distress than others (i.e. lung and brain cancers) (Zabora, et al., 2001). Stage of cancer was also not measured, and differences exist in levels of distress between those with earlier and later cancer stages (Carlson \& Bultz, 2003). Additionally, there is the possibility that there were 
individuals who were diagnosed with cancer between the 1998 and 2000 waves who did not participate in the $\mathbf{2 0 0 0}$ wave due to advanced or aggressive cancers or death. Had they been able to participate, even for only one wave, the differences in distress between the two groups may have looked very different. This leads to another important limitation related to racial representation in this study. It is well known that African Americans are diagnosed with cancer later than whites, they are also diagnosed in more advanced stages and they have shorter life expectancies (Institute of Medicine, 2003). This study highlights that knowledge as there was a difference in the racial makeup of those with a cancer history and those without ( 87 percent and 81 percent respectively). Given this knowledge, and the underrepresentation of African Americans and other racial groups in this study, conclusions should not be drawn about long term distress and cancer in these groups. This is also the case for those in lower socioeconomic groups.

Instances of distress symptomatology between the biennial interviews may have been missed; however enduring episodes were more likely to be identified. It is important to note that the measure of distress in this study was not cancer specific; therefore, even for participants with cancer, levels of distress may have been related to other factors. However, the use of the CES-D has been growing in popularity in oncology over the past several years (Pirl, 2010). Ever present measurement error (Meyers, Gamst, \& Guarino, 2006) is a consideration, although rigorous attempts to limit systematic measurement error have been made by HRS researchers as it is a threat to the internal validity of a 
study (Hauser \& Willis, 2005; Health and Retirement Study, 2008; Steffick, et al., 2000). Random errors, in which scores on the measure of distress, the CES-D, could be affected by the random fluctuations in how each participant felt on any given day, are less of a concern due to repeated measures.

Another possible threat to internal validity is history, which include events that coincide in time with the manipulation of the independent variable (Rubin \& Babbie, 2008); one such threat might be illnesses of significant others which may affect distress levels of participants. Finally, while there may be other important resource factors that influence emotional distress which are measured by the HRS study, inclusion of too many variables would lead to a complex model and complicated analysis.

\section{Strengths of the Study}

One of the strengths of this study was its use of a longitudinal growth model in which time variant variables were examined five times over the eight year period which provided for the explicit measurement of and accounting for the effects of maturation in the sample. Additionally, panel studies are considered more powerful and accurate than trend and cohort studies because they study the same individuals over time (Rubin \& Babbie, 2008). The use of a nationally representative probabilistic sample which included oversamples of minority populations is another strength which increases the external validity of the design. This study answers a timely and relevant question about older adults' long term adjustment to cancer.

\section{Future Research}


Social work provides the much needed ecological approach to the study of cancer. Future research should explore prospective multilevel cohort designs and three way interactions between various cancer types and stages, and predictor variables. These future studies could focus solely on the marital status/social support/partner presence variables, along with gender differences, and could explore theories of attachment, fear of dependence issues, etc. While the goal of understanding long term distress in a group of cancer survivors was met, the important social work value of social justice mandates further exploration of the issue of race in research. With regard to increasing participation of racial and ethnic minorities in future research, prospective designs might include community based participatory approaches and an awareness of important enablers (such as working with community agencies and gatekeepers who share a common vision with researchers and gaining the trust of potential respondents), and barriers (such as demanding too much from these same community agencies and gatekeepers and ignoring factors that could delay the completion of the research) (Mier et al., 2006). 


\section{REFERENCES}

Akechi, T., letsugu, T., Sukigara, M., Okamura, H., Nakano, T., Akizuki, N., . . Uchitomi, Y. (2009). Symptom indicator of severity of depression in cancer patients: A comparison of the DSM-IV criteria with alternative diagnostic criteria. General Hospital Psychiatry, 31(3), 225-232. doi:

10.1016/j.genhosppsych.2008.12.004

Alfano, C. M., \& Rowland, J. H. (2009). The experience of survival for patients: Psychosocial adjustment. In S. M. Miller, D. J. Bowen, R. T. Croyle \& J. H. Rowland (Eds.), Handbook of cancer control and behavioral science (pp. 413-430). Washington DC: American Psychological Association.

Alferi, S. M., Carver, C. S., Antoni, M. H., Weiss, S., \& Duran, R. E. (2001). An exploratory study of social support, distress, and life disruption among low-income hispanic women under treatment for early stage breast cancer. Health Psychology, 20(1), 41-46. doi:

http://dx.doi.org/10.1037/0278-6133.20.1.41

American Cancer Society. (2010). The history of cancer. Retrieved April 1st, 2010, from

http://www.cancer.org/docroot/CRI/content/CRI $26 x$ the history of can cer 72.asp?sitearea= 
American Psychiatric Association. (2000). Diagnostic and Statistical Manual of Mental Disorders (4th ed.). Washington, DC: American Psychiatric Association.

Andrykowski, M. A., \& Cordova, M. J. (1998). Factors associated with PTSD symptoms following treatment for breast cancer: Test of the Andersen model. Journal of Traumatic Stress, 11(2), 189-203. doi: http://dx.doi.org/10.1023/A:1024490718043

Andrykowski, M. A., Lykins, E., \& Floyd, A. (2008). Psychological health in cancer survivors. Seminars in Oncology Nursing, 24(3), 193-201.

Angel, J. L., Jimenez, M. A., \& Angel, R. J. (2007). The economic consequences of widowhood for older minority women. Gerontologist, 47(2), 224-234.

Angner, E., Ray, M. N., Saag, K. G., \& Allison, J. J. (2009). Health and happiness among older adults: A community-based study. Journal of Health Psychology, 14(4), 503-512. doi: http://dx.doi.org/10.1177/1359105309103570

Antonovsky, A. (1979). Health, stress and coping. San Fransisco: Jossey-Bass.

Avendano, M., \& Glymour, M. M. (2008). Stroke disparities in older Americans: Is wealth a more powerful indicator of risk than income and education? Stroke, 39(5), 1533-1540.

Baltes, P. B. (1987). Theoretical propositions of life-span developmental psychology: On the dynamics between growth and decline. Developmental Psychology, 23(5), 611-626. 
Baltes, P. B. (1997). On the incomplete architecture of human ontogeny:

Selection, optimization, and compensation as foundation of developmental theory. American Psychologist, 52(4), 366-380.

Bandura, A. (1986). Social foundations of thought and action: A social cognitive theory. Englewood Cliffs, N.J.: Prentice-Hall, Inc.

Bandura, A. (1997). Self-Efficacy: The exercise of control. New York, N.Y.: W.H. Freeman and Company.

Banou, E., Hobfoll, S. E., \& Trochelman, R. D. (2009). Loss of resources as mediators between interpersonal trauma and traumatic and depressive symptoms among women with cancer. Joumal of Health Psychology, 14(2), 200-214.

Bardwell, W. A., Natarajan, L., Dimsdale, J. E., Rock, C. L., Mortimer, J. E., Hollenbach, K., \& Pierce, J. P. (2006). Objective cancer-related variables are not associated with depressive symptoms in women treated for earlystage breast cancer. Journal of Clinical Oncology, 24(16), 2420-2427.

Barrera, M. (1986). Distinctions between social support concepts, measures, and models. American Journal of Community Psychology, 14, 413-435.

Beck, A. T., Rush, A. J., Shaw, B., \& Emery, G. (1979). Cognitive therapy of depression. New York: Guilford.

Blank, T. O., \& Bellizzi, K. M. (2008). A gerontologic perspective on cancer and aging. Cancer, 112(11 Suppl), 2569-2576. 
Blank, T. O., Bellizzi, K. M., Murphy, K., \& Ryan, K. (2003). How do men "make sense" of their prostate cancer? Age and treatment factors [abstract]. Gerontologist, 43(S1), 342-343.

Blazer, D. (1989). The epidemiology of depression in late life. Joumal of Geriatric Psychiatry, 22(1), 35-52.

Blazer, D. G. (2003). Depression in late life: Review and commentary. The Journals of Gerontology: Series A: Biological Sciences and Medical Sciences, 3(3), 249-265.

Blossfeld, H.-P. (2009). Comparative life course research: A cross-national and longitudinal perspective. In G. H. Elder Jr. \& J. Z. Giele (Eds.), The craft of life course research (pp. 280-306). New York: The Guilford Press.

Bottomley, A. (1998). Depression in cancer patients: A literature review. European Journal of Cancer Care, 7(3), 181-191.

Bower, J. E., Meyerowitz, B. E., Desmond, K. A., Bernaards, C. A., Rowland, J. H., \& Ganz, P. A. (2005). Perceptions of positive meaning and vulnerability following breast cancer: Predictors and outcomes among long-term breast cancer survivors. Annals of Behavioral Medicine, 29(3), 236-245.

Box, G., \& Draper, N. (1987). Empirical model-building and response surfaces. Hoboken, New Jersey: Wiley.

Breitbart, W. S. (2010). Key supportive care studies in managing psychological issues from ASCO 2009: Treating depression. Journal of Supportive Oncology, 8(S1), 20. 
Brown, C., Crimmins, E. M., Hurd, M. D., Langa, K. M., McArdle, J. J., McGarry, K., . . Willis, R. J. (2008). Health and Retirement Study, public use dataset. Retrieved July 1, 2009, from University of Michigan http://hrsonline.isr.umich.edu/index.php

Browne, W. J. (2009). MCMC Estimation in MLwiN, v2.13. Bristol, UK: Centre for Multilevel Modeling: University of Bristol.

Browne, W. J., Clarke, P., Jones, K., Leckie, G., \& Steele, F. (2012, April). MCMC methods for discrete response models. Paper presented at the Advanced Multilevel Modelling Using Markov chain Monte Carlo (MCMC) Workshop, Bristol, England.

Bultz, B. D., \& Carlson, L. E. (2006). Emotional distress: The sixth vital sign Future directions in cancer care. Psycho-Oncology, 15, 93-95.

Bultz, B. D., \& Holland, J. C. (2006). Emotional distress in patients with cancer: The sixth vital sign. Community Oncology, 3(5), 311-314.

Cannon, W. B. (1932). The wisdom of the body. New York: W. W. Norton.

Carlson, L. E., Angen, M., Cullum, J., Goodey, E., Koopmans, J., Lamont, L., . . . Bultz, B. D. (2004). High levels of untreated distress and fatigue in cancer patients. British Journal of Cancer, 90(12), 2297-2304.

Carlson, L. E., \& Bultz, B. D. (2003). Cancer distress screening: Needs, models, and methods. Journal of Psychosomatic Research, 55(5), 403-409. doi: http://dx.doi.org/10.1016/S0022-3999\%2803\%2900514-2

Carter, B. J. (1993). Long-term survivors of breast cancer. A qualitative descriptive study. Cancer Nursing, 16(5), 354-361. 
Carver, C. S., Pozo, C., Harris, S. D., Noriega, V., Scheier, M. F., Robinson, D. S., . . Clark, K. C. (1993). How coping mediates the effect of optimism on distress: A study of women with early stage breast cancer. Journal of Personality and Social Psychology, 65(2), 375-390. doi:

http://dx.doi.org/10.1037/0022-3514.65.2.375

Cella, D. F. (1992). Quality of life: The concept. Journal Of Palliative Care, 8(3), 8-13.

Cella, D. F. (1994). Quality of life: Concepts and definition. Journal of Pain \& Symptom Management, 9(3), 186-192.

Cella, D. F. (1998). Quality of life. In J. C. Holland (Ed.), Psycho-Oncology (pp. 1135-1146). New York: Oxford University Press.

Centers for Disease Control and Prevention. (2009). Chronic diseases: The power to prevent, the call to control Retrieved March 31st, 2010, from http://www.cdc.gov/chronicdisease/resources/publications/AAG/pdf/chroni c.pdf

Charney, D. S., Reynolds, C. F., 3rd, Lewis, L., Lebowitz, B. D., Sunderland, T., Alexopoulos, G. S., . . Bipolar Support, A. (2003). Depression and Bipolar Support Alliance consensus statement on the unmet needs in diagnosis and treatment of mood disorders in late life. Archives of General Psychiatry, 60(7), 664-672.

Clarke, P., Fisher, G. G., House, J., Smith, J., \& Weir, D. (2008). Guide to content of the HRS Psychosocial Leave-Behind Participant Lifestyle questionnaires: 2004 \& 2006. Ann Arbor: University of Michigan. 
Coates, A., Porzsolt, F., \& Osoba, D. (1997). Quality of life in oncology practice: Prognostic value of EORTC QLQ-C30 scores in patients with advanced malignancy. European Journal of Cancer, 33(7), 1025-1030.

Cohen, J., Cohen, P., West, S. G., \& Aiken, L. S. (2003). Applied multiple regression/correlation analysis for the behavioral sciences (3rd ed. ed.). Mahwah, N.J.: Lawrence Erlbaum Associates.

Cohen, S., \& Wills, T. A. (1985). Stress, social support, and the buffering hypothesis. Psychological Bulletin, 98(2), 310-357. doi: http://dx.doi.org/10.1037/0033-2909.98.2.310

Conwell, Y., Duberstein, P. R., \& Caine, E. D. (2002). Risk factors for suicide in later life. Biological Psychiatry, 52(3), 193-204.

Cooper, I., Hill, M., Powe, N. (2002). Designing and evaluating inverventions to eliminate racial and etnic diparities in health care. Perspectives, 17, 477 486.

Culica, D., Rohrer, J., Ward, M., Hilsenrath, P., \& Pomrehn, P. (2002). Medical checkups: Who does not get them? American Journal of Public Health, 92(1), 88-91.

Dabrowski, M., Boucher, K., Ward, J. H., Lovell, M. M., Sandre, A., Bloch, J., . . . Buys, S. S. (2007). Clinical experience with the NCCN distress thermometer in breast cancer patients. Journal of the National Comprehensive Cancer Network, 5(1), 104-111. 
Deimling, G. T., Bowman, K. F., Sterns, S., Wagner, L. J., \& Kahana, B. (2006). Cancer-related health worries and psychological distress among older adult, long-term cancer survivors. Psycho-Oncology, 15(4), 306-320.

Dember, W. N. (1974). Motivation and the cognitive revolution. American Psychologist, 29(3), 161-168. doi: http://dx.doi.org/10.1037/h0035907

Derogatis, L. R., Morrow, G. R., Fetting, J., Penman, D., Piasetsky, S., Schmale, A. M., . . Carnicke, C. L., Jr. (1983). The prevalence of psychiatric disorders among cancer patients. JAMA, 249(6), 751-757.

Diener, E., Diener, M., \& Diener, C. (1995). Factors predicting the subjective well-being of nations. Journal of Personality and Social Psychology, 69(5), 851-864.

DiMatteo, M. R. (2004). Variations in patients' adherence to medical recommendations: A quantitative review of 50 years of research. Medical Care, 42(3), 200-209.

Elder, G. H., Jr. (1998). The life course as developmental theory. Child Development, 69(1), 1-12. doi: http://dx.doi.org/10.2307/1132065

Elder, G. H., Jr. (2000). Life course theory. [Encyclopedia Entry]. Kazdin, Alan E, 5(pp. 50-52), 50-52. doi: http://dx.doi.org/10.1037/10520-020

Elder, G. H., Jr., \& Shanahan, M. J. (2006). The life course and human development. In R. M. Lerner \& W. Damon (Eds.), Handbook of child psychology: Theoretical models of human development (Vol. 1, pp. 665715). Hoboken, NJ: John Wiley \& Sons Inc. 
Elder Jr., G. H. (2002, November). The life course and aging: Some accomplishments, unfinished tasks, and new directions. Paper presented at the Annual Meeting of the Gerontological Society of America, Boston, Massachusetts.

Ellis, A. (1957). Outcome of employing three techniques of psychotherapy. Journal of Clinical Psychology, 13, 344-350.

Endicott, J. (1984). Measurement of depression in patients with cancer. Cancer, 53(10 Suppl), 2243-2249.

Epping-Jordan, J. E., Compas, B. E., Osowiecki, D. M., Oppedisano, G., Gerhardt, C., Primo, K., \& Krag, D. N. (1999). Psychological adjustment in breast cancer: Processes of emotional distress. Health Psychology, 18(4), 315-326. doi: $\underline{\text { http://dx.doi.org/10.1037/0278-6133.18.4.315 }}$

Fallowfield, L., Ratcliffe, D., Jenkins, V., \& Saul, J. (2001). Psychiatric morbidity and its recognition by doctors in patients with cancer. British Journal of Cancer, 84(8), 1011-1015.

Farber, J. M., Weinerman, B. H., \& Kuypers, J. A. (1984). Psychosocial distress in oncology outpatients. Journal of Psychosocial Oncology, 2(3-4), 109118. doi: http://dx.doi.org/10.1300/J077v02n03 09

Fayers, P. M., \& Sprangers, M. A. (2002). Understanding self-rated health. Lancet, 359(9302), 187-188.

Fechner-Bates, S., Coyne, J. C., \& Schwenk, T. L. (1994). The relationship of self-reported distress to depressive disorders and other psychopathology. Journal of Consulting \& Clinical Psychology, 62(3), 550-559. 
Ferraro, K. F. (1980). Self-ratings of health among the old and the old-old. Journal of Health \& Social Behavior, 21(4), 377-383.

Ferrell, B. R., Grant, M., \& Hassey Dow, K. (2004). Quality of life: Conceptual model. Retrieved June 30th, 2009, from http://prc.coh.org/pdf/cancer survivor QOL.pdf

Fife, B. L., Huster, G. A., Cornetta, K. G., Kennedy, V. N., Akard, L. P., \& Broun, E. R. (2000). Longitudinal study of adaptation to the stress of bone marrow transplantation. Journal of Clinical Oncology, 18(7), 1539-1549.

Finucane, M. L., Slovic, P., Hibbard, J. H., Peters, E., Mertz, C., \& MacGregor, D. G. (2002). Aging and decision-making competence: An analysis of comprehension and consistency skills in older versus younger adults considering health-plan options. Journal of Behavioral Decision Making, 15(2), 141-164. doi: http://dx.doi.org/10.1002/bdm.407

Fisher, G. G., Faul, J. D., Weir, D. R., \& Wallace, R. B. (2005). Documentation of chronic disease measures in the Health and Retirement Study (HRS/AHEAD). Ann Arbor: University of Michigan.

Folkman, S., \& Moskowitz, J. T. (2004). Coping: Pitfalls and promise. Annual Review of Psychology, 55, 745-774.

Fonda, S., \& Herzog, A. R. (2004). Documentation of physical functioning measured in the Health and Retirement Study and the Asset and Health Dynamics among the Oldest Old Study. Ann Arbor: University of Michigan.

Freund, A. M., \& Riediger, M. (2001). What I have and what I do--The role of resource loss and gain throughout life. Applied Psychology: An 
International Review, 50(3), 370-380. doi: http://dx.doi.org/10.1111/1464$\underline{0597.00063}$

Fuemmeler, B., Masse, L., Yaroch, A., Resnicow, K., Campbell, M.K., Carr, C., Wang, T. (2006). Psychosocial mediation of fruit and vegetable consumption in the body and soul effectiveness trial. Health Psychology, 25(4), pp. 474-483.

Gallo, W. T., Bradley, E. H., Dubin, J. A., Jones, R. N., Falba, T. A., Hsun-Mei, T., \& Stanislav, V. K. (2006). The persistence of depressive symptoms in older workers who experience involuntary job loss: Results from the Health and Retirement Survey. Journals of Gerontology Series B: Psychological Sciences \& Social Sciences, 61B(4), S221-S228.

George, L. K. (2009). Conceptualizing and measuring trajectories. In G. H. Elder Jr. \& J. Z. Giele (Eds.), The craft of life course research (pp. 163-186). New York: The Guilford Press.

Giele, J. Z., \& Elder Jr., G. H. (1998). Life course research: Development of the field. In J. Z. Giele \& G. H. Elder Jr. (Eds.), Methods of life course research: Qualitative and quantitative approaches (pp. 5-27). Thousand Oaks, CA: Sage Publications.

Giele, J. Z., \& Elder Jr., G. H. (1998a). Methods of life course research: Qualitative and quantitative approaches. Thousand Oaks, CA: Sage.

Given, B. A., \& Given, C. W. (2010). The older patient. In J. C. Holland, W. S. Breitbart, P. B. Jacobsen, M. S. Lederberg, M. J. Loscalzo \& R. McCorkle 
(Eds.), Psycho-Oncology (2nd ed., pp. 491-496). New York: Oxford University Press.

Glanz, K., \& Schwartz, M. D. (2008). Stress, coping, and health behavior. In K. Glanz, B. K. Rimer \& K. V. Viswanath (Eds.), Health behavior and health education: Theory, research, and practice (4th ed., pp. 211-236). San Fransisco: Jossey-Bass.

Glenn, N. (1977). Cohort analysis. Bevery Hills, CA: Sage.

Graves, K. D., Arnold, S. M., Love, C. L., Kirsh, K. L., Moore, P. G., \& Passik, S. D. (2007). Distress screening in a multidisciplinary lung cancer clinic: Prevalence and predictors of clinically significant distress. Lung Cancer, 55(2), 215-224.

Hareven, T. (Ed.). (1996). Aging and generation relations over the life course: $A$ historical and cross-cultural perspective. New York: Walter de Gruyter.

Harrison, J., \& Maguire, P. (1994). Predictors of psychiatric morbidity in cancer patients. British Journal of Psychiatry, 165(5), 593-598. doi: http://dx.doi.org/10.1192/bjp.165.5.593

Hauser, R. M., \& Willis, R. J. (2005). Survey design and methodology in the Health and Retirement Study and the Wisconsin Longitudinal Study. Aging, Health, and Public Policy: Demographic and Economic Perspectives, a supplement to Population and Development Review. Retrieved from http://hrsonline.isr.umich.edu/sitedocs/background/PDR30suppHAUSER.p df 
Head, B. A., \& Faul, A. C. (2008). Development and validation of a scale to measure socioeconomic well-being in persons with cancer. The Journal of Supportive Oncology, 6(4), 183-192.

Health and Retirement Study. (2008). Design History. Retrieved from http://hrsonline.isr.umich.edu/sitedocs/DesignHistory.pdf

Health and Retirement Study. (2008a). Sample sizes and response rates (2002 and beyond). Retrieved from http://hrsonline.isr.umich.edu/sitedocs/sampleresponse.pdf

Heeringa, S. G., \& Connor, J. H. (1995). Technical description of the Health and Retirement Survey sample design. Retrieved from http://hrsonline.isr.umich.edu/sitedocs/userg/HRSSAMP.pdf

Hegel, M. T., Moore, C. P., Collins, E. D., Kearing, S., Gillock, K. L., Riggs, R. L., ... Ahles, T. A. (2006). Distress, psychiatric syndromes, and impairment of function in women with newly diagnosed breast cancer. Cancer, 107(12), 2924-2931.

Helgeson, V. S., \& Cohen, S. (1996). Social support and adjustment to cancer: Reconciling descriptive, correlational, and intervention research. Health Psychology, 15(2), 135-148.

Helgeson, V. S., Snyder, P., \& Seltman, H. (2004). Psychological and physical adjustment to breast cancer over 4 years: Identifying distinct trajectories of change. Health Psychology, 23(1), 3-15.

Hetherington, E. M., \& Baltes, P. B. (1988). Child psychology and life-span development. In E. M. Hetherington, R. M. Lerner \& M. Perlmutter (Eds.), 
Child development in life-span perspective (pp. 1-19). Hillsdale, $\mathrm{NJ}$ : Erlbaum.

Hewitt, M., Rowland, J. H., \& Yancik, R. (2003). Cancer survivors in the United States: age, health, and disability. Journals of Gerontology Series ABiological Sciences \& Medical Sciences, 58(1), 82-91.

Hobfoll, S. E. (1988). The ecology of stress. New York: Hemisphere.

Hobfoll, S. E. (1989). Conservation of resources: A new attempt at conceptualizing stress. American Psychologist, 44, 513-524.

Hobfoll, S. E. (1998). Stress, culture, and community: The psychology and philosophy of stress. NY: Plenum Press.

Hobfoll, S. E. (2001). The influence of culture, community, and the nested-self in the stress process: Advancing Conservation of Resources theory. Applied Psychology: An International Review, 50(3), 337.

Hobfoll, S. E. (2002). Social and psychological resources and adaptation. Review of General Psychology, 6(4), 307-324.

Hobfoll, S. E. (2009). Social support: The movie. Journal of Social \& Personal Relationships, 26(1), 93-101.

Hobfoll, S. E., Freedy, J., Lane, C., \& Geller, P. (1990). Conservation of social resources: Social support resource theory. Journal of Social and Personal Relationships, 7(4), 465-478. doi:

http://dx.doi.org/10.1177/0265407590074004 
Hobfoll, S. E., Johnson, R. J., Ennis, N., \& Jackson, A. P. (2003). Resource loss, resource gain, and emotional outcomes among inner city women. Journal of Personality and Social Psychology, 84(3), 632-643.

Hobfoll, S. E., \& Schumm, J. A. (2002). Conservation of Resources Theory: Application to public health promotion. In R. J. DiClemente, R. A. Crosby \& M. C. Kegler (Eds.), Emerging theories in health promotion practice and research (pp. 285-312). San Fransisco, C.A.: Jossey-Bass.

Hobfoll, S. E., \& Schumm, J. A. (2009). Conservation of Resources Theory: Application to public health promotion. In R. J. DiClemente, R. A. Crosby \& M. C. Kegler (Eds.), Emerging theories in health promotion practice and research (2nd ed.). San Francisco: Jossey-Bass.

Hoffman, K. E., McCarthy, E. P., Recklitis, C. J., \& Ng, A. K. (2009).

Psychological distress in long-term survivors of adult-onset cancer: Results from a national survey. Archives of Internal Medicine, 169(14), $1274-1281$.

Holahan, C. J., \& Moos, R. H. (1987). Personal and contextual determinants of coping strategies. Joumal of Personality \& Social Psychology, 52(5), $946-$ 955.

Holahan, C. J., \& Moos, R. H. (1991). Life stressors, personal and social resources, and depression: A 4-year structural model. Journal of Abnormal Psychology, 100(1), 31-38. 
Holahan, C. J., Moos, R. H., Holahan, C. K., \& Cronkite, R. C. (1999). Resource loss, resource gain, and depressive symptoms: A 10-year model. Journal of Personality and Social Psychology, 77(3), 620-629.

Holahan, C. J., Moos, R. H., Holahan, C. K., \& Cronkite, R. C. (2000). Long-term posttreatment functioning among patients with unipolar depression: An integrative model. Journal of Consulting and Clinical Psychology, 68(2), 226-232. doi: http://dx.doi.org/10.1037/0022-006X.68.2.226

Holland, J. C. (1997). Preliminary guidelines for the treatment of distress. Oncology, 11(11A), 109-114.

Holland, J. C., \& Alici, Y. (2010). Management of distress in cancer patients. The Journal of Supportive Oncology, 8(1), 4-12.

Holland, J. C., \& Bultz, B. D. (2007). The NCCN guideline for distress management: A case for making distress the sixth vital sign. Journal of the National Comprehensive Cancer Network, 5(1), 3-7.

Horner, M. J., Reis, L. A. G., Krapcho, M., Neyman, N., Aminou, R., Howlader, N., . . eds. (2009). SEER cancer statistics review, 1975-2006 National Cancer Institute Retrieved June 30, 2009, from http://seer.cancer.gov/csr/1975 2006/

Hurd, M. D., \& McGarry, K. (1995). Evaluation of the subjective probabilities of survival in the Health and Retirement Study. The Journal of Human Resources, 30, S268-S292.

Hurd, M. D., \& McGarry, K. (2002). The predictive validity of subjective probabilities of survival. The Economic Journal, 112(482), 966-985. 
Hutchison, E. D. (2008). Dimensions of human behavior: The changing life course (3rd ed.). Thousand Oaks, CA: Sage.

Institute of Medicine. (2002). Care without coverage: Too little, too late.

Washington DC: The National Academies Press.

Institute of Medicine. (2003). Unequal Treatment. Washington DC: National Academies Press.

Institute of Medicine. (2007). Cancer in elderly people: Workshop proceedings.

Washington D.C.: The National Academies Press.

Institute of Medicine [IOM]. (2008). Cancer care for the whole patient: Meeting psychosocial health needs. Washington, D.C.: The National Academies Press.

Jacobsen, P. B., Sadler, I. J., Booth-Jones, M., Soety, E., Weitzner, M. A., \& Fields, K. K. (2002). Predictors of posttraumatic stress disorder symptomatology following bone marrow transplantation for cancer. Journal of Consulting \& Clinical Psychology, 70(1), 235-240.

Jemal, A., Thun, M. J., Ries, L. A. G., Howe, H. L., Weir, H. K., Center, M. M., . . . Edwards, B. K. (2008). Annual report to the nation on the status of cancer, 1975-2005, featuring trends in lung cancer, tobacco use, and tobacco control. Journal of the National Cancer Institute, 100(23), 1672-1694.

Jones, K. (Producer). (2007, September 10-12). Significance testing [PowerPoint slides and audio file]. Retrieved from http://www.cmm.bristol.ac.uk/MLwiN/techsupport/workshops/materials/workshopday2-3sep07.ppt. [Audio lecture] 
Retrieved from http://www.cmm.bristol.ac.uk/MLwiN/techsupport/workshops/materials/workshopday2-3sep07.ppt

Kaiser Family Foundation. (2012). Health Reform Source. Retrieved April 1st, 2012, from http://healthreform.kff.org/

Kaplan, H. B. (1996). Perspectives on psychosocial stress Psychosocial stress: Perspectives on structure, theory, life-course, and methods. (pp. 3-24). San Diego, CA US: Academic Press.

Keir, S. T., Calhoun-Eagan, R. D., Swartz, J. J., Saleh, O. A., \& Friedman, H. S. (2008). Screening for distress in patients with brain cancer using the NCCN's rapid screening measure. Psycho-Oncology, 17(6), 621-625.

Kennard, B. D., Stewart, S. M., Olvera, R., Bawdon, R. E., Lewis, C. P., \& Winick, N. J. (2004). Nonadherence in adolescent oncology patients:

Preliminary data on psychological risk factors and relationships to outcome. Journal of Clinical Psychology in Medical Settings, 11(1), 30-39. doi: http://dx.doi.org/10.1023/B:JOCS.0000016267.21912.74

Kreft, I., \& De Leeuw, J. (1998). Introducing multilevel modeling. Thousand Oaks, CA.: Sage Publications.

Krejcie, R. V., \& Morgan, D. W. (1970). Determining sample sizes for research activities. Educational and Psychological Measurement, 30, 607-610.

Lazarus, R. S. (1966). Psychological stress and the coping process. New York: McGraw-Hill. 
Lazarus, R. S. (1990). Stress, coping, and illness. In H. S. Friedman (Ed.), Personality and disease (pp. 97-120). Oxford, England: John Wiley \& Sons.

Lazarus, R. S. (1990). Theory-based stress measurement. Psychological Inquiry, 1(1), 3.

Lazarus, R. S. (1993). Why we should think of stress as a subset of emotion. In L. Goldberger \& S. Breznitz (Eds.), Handbook of stress: Theoretical and clinical aspects (2nd ed., pp. 21-39). New York, NY: Free Press.

Lazarus, R. S., \& Folkman, S. (1984). Stress, appraisal, and coping. New York: Springer.

Lebowitz, B. D., Pearson, J. L., Schneider, L. S., Reynolds, C. F., 3rd, Alexopoulos, G. S., Bruce, M. L., . . Parmelee, P. (1997). Diagnosis and treatment of depression in late life. Consensus statement update. JAMA, 278(14), 1186-1190.

Leigh, S. (2004). Cancer survivorship:Defining our destiny. In B. Hoffman (Ed.), A Cancer Survivor's Almanac (3rd ed.). Hoboken, NJ: John Wiley \& Sons.

Lerman, C., Daly, M., Sands, C., Balshem, A., Lustbader, E., Heggan, T., . . Engstrom, P. (1993). Mammography adherence and psychological distress among women at risk for breast cancer. Journal of the National Cancer Institute, 85(13), 1074-1080.

Levy, H., \& Meltzer, D. (2001). What do we really know about whether health insurance affects health? Ann Arbor: Economic Research Initiative on the Uninsured, University of Michigan. 
Lockenhoff, C. E., \& Carstensen, L. L. (2004). Socioemotional selectivity theory, aging, and health: The increasingly delicate balance between regulating emotions and making tough choices. Journal of Personality, 72(6), 13951424. doi: http://dx.doi.org/10.1111/j.1467-6494.2004.00301.x

Loescher, L. J., Clark, L., Atwood, J. R., Leigh, S., \& Lamb, G. (1990). The impact of the cancer experience on long-term survivors. Oncology Nursing Forum, 17(2), 223-229.

Lorig, K., Stewart, A., Ritter, P., Gonzalez, V., Laurent, D., \& Lynch, J. (1996). Outcome measures for health education and other health care interventions. Thousand Oaks, CA: Sage.

Luyster, F. S., Hughes, J. W., Waechter, D., \& Josephson, R. (2006). Resource loss predicts depression and anxiety among patients treated with an implantable cardioverter defibrillator. Psychosomatic Medicine September/October, 68(5), 794-800.

Lyness, J. M. (2004). Treatment of depressive conditions in later life: real-world light for dark (or dim) tunnels. JAMA, 291(13), 1626-1628.

Lyons, R. F., Mickelson, K. D., Sullivan, M. J., \& Coyne, J. C. (1998). Coping as a communal process. Journal of Social and Personal Relationships, 15(5), 579-605. doi: http://dx.doi.org/10.1177/0265407598155001

Massie, M. J. (2004). Prevalence of depression in patients with cancer. Journal of the National Cancer Institute Monographs, 32(32), 57-71. 
McWilliams, J. M., Meara, E., Zaslavsky, A. M., \& Ayanian, J. Z. (2007). Health of previously uninsured adults after acquiring Medicare coverage. JAMA, 298(24), 2886-2894.

Meyerowitz, B. E., \& Oh, S. (2009). Psychosocial response to cancer diagnosis and treatment. In S. M. Miller, D. J. Bowen, R. T. Croyle \& J. H. Rowland (Eds.), Handbook of cancer control and behavioral science: A resource for researchers, practitioners, and policymakers (pp. 361-377). Washington D.C.: American Psychological Association.

Meyers, L. S., Gamst, G., \& Guarino, A. J. (2006). Applied multivariate research: Design and interpretation. Thousand Oaks, CA: Sage.

Mier, N., Medina, A. A., Bocanegra-Alonso, A., Castillo-Ruiz, O., AcostaGonzalez, R. I., \& Ramirez, J. A. (2006). Finding respondents from minority groups. Journal of Research Practice, 2(2).

Mirowsky, J. (1997). Age, subjective life expectancy, and the sense of control: The horizon hypothesis. The Journals of Gerontology: Series B: Psychological Sciences and Social Sciences, 3(3), S125-S134.

Molassiotis, A., Van Den Akker, O., \& Boughton, B. (1997). Perceived social support, family environment and psychosocial recovery in bone marrow transplant long-term survivors. Social Science \& Medicine, 44(3), 317-325. doi: http://dx.doi.org/10.1016/S0277-9536\%2896\%2900101-3

Morley, J. E. (2004). The top 10 hot topics in aging. Journals of Gerontology Series A Biological Sciences \& Medical Sciences, 59(1), 24-33. 
Morrow, G. R., Roscoe, J. A., Mustian, K. M., Hickok, J. T., Ryan, J. L., \& Matteson, S. (2009). Behavioral interventions for side effects related to cancer and cancer treatments. In S. M. Miller, D. J. Bowen, R. T. Croyle \& J. H. Rowland (Eds.), Handbook of cancer control and behavioral science: A resource for researchers, practitioners, and policymakers (pp. 347-360). Washington D.C.: American Psychological Association.

National Cancer Institute. (2003). NIH funds eight new grants focused on aging and cancer Retrieved March 29th, 2010, from http://www.cancer.gov/newscenter/pressreleases/AgingGrants

National Cancer Institute [NCl]. (2006). Fact sheet: Cancer advances in focus: Cancer Retrieved March 29th, 2010, from http://www.cancer.gov/cancertopics/factsheet/cancer-advances-infocus/cancer

National Comprehensive Cancer Network [NCCN]. (2009). NCCN clinical practice guidelines in oncology: Distress management. v.2.2009 (Vol. 1). Jenkintown, PA.

National Institute on Aging [NIA]. (2007). Growing old in America: The Health and Retirement Study. (07-5757). Bethesda, Maryland: National Institutes of Health.

Nelson, C. J., Weinberger, M. I., Balk, E., Holland, J. C., Breitbart, W., \& Roth, A. J. (2009). The chronology of distress, anxiety, and depression in older prostate cancer patients. Oncologist, 14(9), 891-899. 
Neugarten, D. A. (Ed.). (1996). The meanings of age: Selected papers of Bernice L. Neugarten. Chicago: University of Chicago Press.

Norton, T. R., Manne, S. L., Rubin, S., Carlson, J., Hernandez, E., Edelson, M. I., ... Bergman, C. (2004). Prevalence and predictors of psychological distress among women with ovarian cancer. Journal of Clinical Oncology, 22(5), 919-926.

Norton, T. R., Manne, S. L., Rubin, S., Hernandez, E., Carlson, J., Bergman, C., \& Rosenblum, N. (2005). Ovarian cancer patients' psychological distress: The role of physical impairment, perceived unsupportive family and friend behaviors, perceived control, and self-esteem. Health Psychology, 24(2), 143-152.

O' Rand, A. M. (1998). The craft of life course studies. In J. Z. Giele \& G. H. Elder Jr. (Eds.), Methods of life course research: Qualitative and quantitative approaches. Thousand Oaks, CA: Sage Publications.

O'Connell, A. A. (2010). An illustration of multilevel models for ordinal response data Retrieved January 10th, 2012, from http://www.stat.auckland.ac.nz/ iase/publications/icots8//COTS8 4C3 OC ONNELL.pdf

Oh, S., Heflin, L., Meyerowitz, B. E., Desmond, K. A., Rowland, J. H., \& Ganz, P. A. (2004). Quality of life of breast cancer survivors after a recurrence: A follow-up study. Breast Cancer Research \& Treatment, 87(1), 45-57. Ohmori, K., Ebihara, S., Kuriyama, S., Ugajin, T., Ogata, M., Hozawa, A., . . . Tsuji, I. (2005). The relationship between body mass index and a plasma 
lipid peroxidation biomarker in an older, healthy Asian community. Annals Of Epidemiology, 15(1), 80-84.

Osoba, D. (1999). What has been learned from measuring health-related quality of life in clinical oncology. European Journal of Cancer, 35(11), 15651570.

Pirl, W. F. (2010). Instruments in psycho-oncology. In J. C. Holland, W. S. Breitbart, P. B. Jacobsen, M. S. Lederberg, M. J. Loscalzo \& R. McCorkle (Eds.), Psycho-Oncology (2nd ed., pp. 119-130). New York: Oxford University Press.

Polsky, D., Doshi, J. A., Marcus, S., Oslin, D., Rothbard, A., Thomas, N., \& Thompson, C. L. (2005). Long-term risk for depressive symptoms after a medical diagnosis. Archives of Internal Medicine, 165(11), 1260-1266.

Rabkin, J. G., McElhiney, M., Moran, P., Acree, M., \& Folkman, S. (2009).

Depression, distress and positive mood in late-stage cancer: A longitudinal study. Psycho-Oncology, 18(1), 79-86.

Radloff, L. S. (1977). The CES-D scale: A self report depression scale for research in the general population. International Journal of Social Psychiatry, 36(2), 143-151.

RAND Center for the Study of Aging. (2010). The RAND HRS Data (Version J) Retrieved June 30th, 2010, from http://hrsonline.isr.umich.edu/modules/meta/rand/index.html 
RAND Center for the Study of Aging. (2010). RAND HRS data documentation:

Version J Retrieved June 15th, 2010, from

http://hrsonline.isr.umich.edu/modules/meta/rand/randhrsj/randhrsj.pdf

Rasbash, J., Steele, F., Browne, W. J., \& Goldstein, H. (2009). A User's Guide to MLwiN. Retrieved from

http://www.cmm.bristol.ac.uk/MLwiN/download/MLwiN-userman-09.pdf

Raudenbush, S. W., \& Bryk, A. S. (2002). Hierarchichal linear models:

Applications and data analysis methods. Thousand Oaks, CA: Sage.

Rayner, L., Loge, J. H., Wasteson, E., Higginson, I. J., \& European Palliative

Care Research Collaborative. (2009). The detection of depression in palliative care. Current Opinion in Supportive \& Palliative Care, 3(1), 5560.

Redd, W. H., DuHamel, K. N., Johnson-Vickberg, S. M., Ostroff, J. L., Smith, M. Y., Jacobsen, P. B., \& Manne, S. (2001). Long-term adjustment in cancer survivors: Integration of classical-conditioning and cognitive processing models. In A. Baum \& B. L. Andersen (Eds.), Psychosocial interventions for cancer (pp. 77-97). Washington DC: American Psychological Association.

Riley, M. W., Johnson, M. E., \& Foner, A. (1972). Aging and society: A sociology of age stratification (Vol. 3). New York: Russell Sage Foundation.

Ronson, A., \& Body, J. J. (2002). Psychosocial rehabilitation of cancer patients after curative therapy. Supportive Care in Cancer, 10(4), 281-291. 
Ross, C. E., \& Mirowsky, J. (2002). Family relationships, social support and subjective life expectancy. Journal of Health and Social Behavior, 43(4), 469-489. doi: http://dx.doi.org/10.2307/3090238

Rubin, A., \& Babbie, E. R. (2008). Research methods for social work (6th ed.). Belmont, CA: Thomson Brooks/Cole.

Russell, L. B., Suh, D.-C., \& Safford, M. A. (2005). Time requirements for diabetes self-management: Too much for many? The Journal Of Family Practice, 54(1), 52-56.

Ryder, N. B. (1965). The cohort as a concept in the study of social change. American Sociological Review, 30(6), 843-861.

Sanmartin, C., Berthelot, J. M., Ng, E., Murphy, K., Blackwell, D. L., Gentleman, J. F., . . Simile, C. M. (2006). Comparing health and health care use in Canada and the United States. Health Affairs, 25(4), 1133-1142.

Sarason, I. G., Sarason, B. R., Shearin, E. N., \& Pierce, G. R. (1986). Social support as an individual difference variable: Its stability, origins, and relational aspects. Journal or Social and Personal Relationships, 4, 497510.

Scheier, M. F., \& Carver, C. S. (1992). Effects of optimism on psychology and physical well-being: Theoretical overview and empirical update. Cognitive Therapy and Research, 16, 201-228.

Scheier, M. F., \& Carver, C. S. (2001). Adapting to cancer: The importance of hope and purpose. In A. Baum \& B. L. Andersen (Eds.), Psychosocial 
interventions for cancer (pp. 15-36). Washington DC: American Psychological Association.

Schnoll, R. A., \& Harlow, L. L. (2001). Using disease-related and demographic variables to form cancer-distress risk groups. Journal of Behavioral Medicine, 24(1), 57-74. doi: http://dx.doi.org/10.1023/A:1005686404723

Schwartz, M. D., Lerman, C., Miller, S. M., Daly, M., \& Masny, A. (1995). Coping disposition, perceived risk, and psychological distress among women at increased risk for ovarian cancer. Health Psychology, 14(3), 232-235. doi: http://dx.doi.org/10.1037/0278-6133.14.3.232

Schwarzer, R. (2001). Stress, resources, and proactive coping. Applied Psychology: An International Review, 50(3), 400-407.

Sellick, S. M., \& Edwardson, A. D. (2007). Screening new cancer patients for psychological distress using the Hospital Anxiety and Depression Scale. Psycho-Oncology, 16(6), 534-542.

Selye, H. (1956). The stress of life. New York: McGraw-Hill.

Servais, M. A. (2009). Overview of HRS public data files for cross-sectional and longitudinal analysis. Ann Arbor: University of Michigan.

Silveira, M. J., Kabeto, M. U., \& Langa, K. M. (2005). Net worth predicts symptom burden at the end of life. Journal of Palliative Medicine, 8(4), 827-837.

Singer, J., \& Willett, J. B. (2003). Applied longitudinal data analysis. Modeling change and event occurrence. Oxford, NY.: Oxford University Press.

Skarstein, J., Aass, N., Fossa, S. D., Skovlund, E., \& Dahl, A. A. (2000). Anxiety and depression in cancer patients: Relation between the Hospital Anxiety 
and Depression Scale and the European Organization for Research and Treatment of Cancer Core Quality of Life Questionnaire. Journal of Psychosomatic Research, 49(1), 27-34.

Smith, E. M., Gomm, S. A., \& Dickens, C. M. (2003). Assessing the independent contribution to quality of life from anxiety and depression in patients with advanced cancer. Palliative Medicine, 17(6), 509-513.

Snijders, T. A. B. (Ed.). (2005). Power and Sample Size in Multilevel Linear Models (Vol. 3). Chicester: Wiley.

Sormanti, M., Kayser, K., \& Strainchamps, E. (1997). A relational perspective of women coping with cancer: a preliminary study. Social Work in Health Care, 25(1-2), 89-106.

Spiegel, D., \& Bloom, J. R. (1983). Pain in metastatic breast cancer. Cancer, 52(2), 341-345.

Spiegel, D., \& Giese-Davis, J. (2003). Depression and cancer: Mechanisms and disease progression. Biological Psychiatry, 54(3), 269-282. doi: http://dx.doi.org/10.1016/S0006-3223\%2803\%2900566-3

Spiegel, D., Sands, S., \& Koopman, C. (1994). Pain and depression in patients with cancer. Cancer, 74(9), 2570-2578.

Spybrook, J., Raudenbush, S. W., Liu, X., Congdon, R., \& Martinez, A. (2008). Optimal design for longitudinal and multilevel research: Documentation for the "Optimal Design" software. Ann Arbor: Survey Research Center of the Institute of Social Research, University of Michigan. 
Stanton, A. L., Bower, J. E., \& Low, C. A. (2006). Posttraumatic growth after cancer. In L. G. Calhoun \& R. G. Tedeschi (Eds.), Handbook of posttraumatic growth: Research and practice (pp. 138-175). Mahwah, NJ: Lawrence Erlbaum Associates, Inc.

Stanton, A. L., Revenson, T. A., \& Tennen, H. (2007). Health psychology: Psychological adjustment to chronic disease. Annual Review of Psychology, 58, 565-592.

Stanton, A. L., \& Snider, P. R. (1993). Coping with a breast cancer diagnosis: A prospective study. Health Psychology, 12(1), 16-23. doi: http://dx.doi.org/10.1037/0278-6133.12.1.16

Stefanek, M. E., Derogatis, L. P., \& Shaw, A. (1987). Psychological distress among oncology outpatients: Prevalence and severity as measured with the Brief Symptom Inventory. Psychosomatics, 28(10), 530-532.

Steffick, D. E., Wallace, R. B., Herzog, A. R., Ofstedal, M. B., Steffick, D., Fonda, S., \& Langa, K. M. (2000). Documentation of affective functioning measures in the Health and Retirement Study. HRS/AHEAD Documentation Report. University of Michigan. Ann Arbor.

Stiegelis, H. E., Hagedoorn, M., Sander-man, R., van der Zee, K. I., Buunk, B. P., \& van den Bergh, A. C. (2003). Cognitive adaptation: A comparison of cancer patients and healthy references. British Journal of Health Psychology, 8(3), 303-318. doi:

http://dx.doi.org/10.1348/135910703322370879 
Taylor, S. E. (1991). Asymmetrical effects of positive and negative events: The mobilization-minimization hypothesis. Psychological Bulletin, 110(1), 6785.

Taylor, S. E., \& Brown, J. D. (1999). Illusion and well-being: A social psychological perspective on mental health. . In R. F. Baumeister (Ed.), The self in social psychology (pp. 43-68). New York, NY: Psychology Press.

The Research Advisors. (2006). Sample Size Table. Retrieved November 1st, 2010, from http://research-advisors.com/tools/SampleSize.htm

Thoits, P. A. (1991). On merging identity theory and stress research. Social Psychology Quarterly 54(2), 101-112.

Thomas, B. C., \& Bultz, B. D. (2008). The future in psychosocial oncology: Screening for emotional distress—-the sixth vital sign. Future Oncology, 4(6), 779-784.

Thompson, M. S., \& Cooper, C. L. (2001). A rose by any other name...: A commentary on Hobfoll's Conservation of Resources theory. Applied Psychology: An International Review, 50(3), 408-418.

Tu, H. T. (2004). Rising health costs, medical debt, and chronic conditions: Issue Brief No. 88. Washington DC: Center for Studying Health System Change.

Turvey, C. L., Wallace, R. B., \& Herzog, A. R. (1999). A revised CES-D measure of depressive symptoms and a DSM-based measure of major depressive episodes in the elderly. International Psychogeriatrics, 11(2), 139-148. doi: http://dx.doi.org/10.1017/S1041610299005694 
U.S. Department of Health and Human Services: Centers for Disease Control and Prevention. (2004). Cancer survivorship: Survive cancer and live Retrieved from http://www.cdc.gov/cancer/survivorship/pdf/brochure.pdf University of Michigan. (2003). Health and Retirement Study 1998: Final core data release, version 2. Retrieved from http://hrsonline.isr.umich.edu/modules/meta/1998/core/desc/hrs98dd.pdf

Von Essen, L., Larsson, G., Oberg, K., \& Sjoden, P. O. (2002). 'Satisfaction with care': Associations with health-related quality of life and psychosocial function among Swedish patients with endocrine gastrointestinal tumours. European Journal of Cancer Care, 11(2), 91-99.

Wefel, J. S., Lenzi, R., Theriault, R. L., Davis, R. N., \& Meyers, C. A. (2004). The cognitive sequelae of standard-dose adjuvant chemotherapy in women with breast carcinoma: Results of a prospective, randomized, longitudinal trial. Cancer, 100(11), 2292-2299.

Welch, H. G., Schwartz, L. M., \& Woloshin, S. (2000). Are increasing 5-year survival rates evidence of success against cancer? JAMA, 283(22), 29752978.

Wells, J. D., Hobfoll, S. E., \& Lavin, J. (1997). Resource loss, resource gain, and communal coping during pregnancy among women with multiple roles. Psychology of Women Quarterly, 21(4), 645-662. doi: http://dx.doi.org/10.1111/j.1471-6402.1997.tb00136.x

Wells, J. D., Hobfoll, S. E., \& Lavin, J. (1999). When it rains, it pours: The greater impact of resource loss compared to gain on psychological distress. 
Personality and Social Psychology Bulletin, 25(9), 1172-1182. doi:

\section{http://dx.doi.org/10.1177/01461672992512010}

Zabora, J. (1998). Screening procedures for psychosocial distress. In J. C. Holland (Ed.), Psycho-oncology (pp. 653-661). New York: Oxford University Press.

Zabora, J., Brintzenhofeszoc, K., Curbow, B., Hooker, C., \& Piantadosi, S. (2001). The prevalence of psychological distress by cancer site. PsychoOncology, 10(1), 19-28.

Zebrack, B. J. (2000). Cancer survivor identity and quality of life. Cancer Practice, 8(5), 238-242.

Zebrack, B. J. (2000). Cancer survivors and quality of life: A critical review of the literature. Oncology Nursing Forum, 27(9), 1395-1401.

Zebrack, B. J., Ganz, P. A., Bernaards, C. A., Petersen, L., \& Abraham, L. (2006). Assessing the impact of cancer: Development of a new instrument for long-term survivors. Psycho-Oncology, 15(5), 407-421.

Zebrack, B. J., Zevon, M. A., Turk, N., Nagarajan, R., Whitton, J., Robison, L. L., \& Zeltzer, L. K. (2007). Psychological distress in long-term survivors of solid tumors diagnosed in childhood: A report from the Childhood Cancer Survivor Study. Pediatric Blood \& Cancer, 49(1), 47-51.

Ziegelmann, J. P., \& Lippke, S. (2009). Introduction to the special section: Theory-based approaches to stress and coping - emerging themes and contemporary research. European Psychologist, 14(1), 3-6. 
Ziegelmann, J. P., Lippke, S., \& Schwarzer, R. (2006). Subjective residual life expectancy in health self-regulation. Journals of Gerontology Series B Psychological Sciences \& Social Sciences, 61(4), 195-201. 


\section{CURRICULUM VITAE}

\section{EDUCATION}

\section{Tara J. Schapmire}

\section{Doctor of Philosophy in Social Work}

2007-2012 University of Louisville, Kent School of Social Work

* American Cancer Society Oncology Social Work Fellow

* Dissertation: Distress in Older Adults with Cancer: A Multilevel Longitudinal Analysis

Master of Science in Social Work

1995-1996 University of Louisville

Bachelor of Arts - Psychology with a minor in Health Care Administration 1990-1994 Western Kentucky University

\section{RESEARCH INTERESTS}

Psycho-social Care of Cancer Survivors and Their Families; Gerontology; Health Disparities; Communication and Cancer; Caregiver Issues; Survivorship and End of Life Care; Social Work Education; Program Development and Evaluation

\section{PROFESSIONAL EXPERIENCE}

\section{6-2007 Baptist Hospital East, Louisville, KY}

Medical Social Worker

- Full case responsibility including psychosocial assessments, crisis intervention, financial counseling, patient and family education and counseling, resource linkage, and discharge planning.

- Collaborative work with physicians, nursing staff, ancillary staff, and out of hospital organizations to insure optimal patient/family care.

- Co-facilitation of various cancer support groups for patients and families.

- Grant writing, administration and reporting. Grants awarded include those from American Cancer Society and Susan G. Komen for the Cure.

- Participation in the creation of the Cooperative Care Program: a collaborative effort among the social service and the quality resources departments to insure that the patient can pass through the continuum of care and progress on to home in a more efficient manner. 
- Practicum supervisor for masters level social work students for the Kent School of Social Work.

- Participation in the planning and implementation of the annual Oncology Symposium at BHE.

- Service on the following committees: Cancer Committee, Acute Pain Team, Oncology Line Team, and Palliative Care Team.

- Key participant in the design and realization of the Palliative Care Team and Palliative Care Unit at Baptist East.

- Continuing education provider and speaker for Baptist East and the community on various topics related to above experience.

1995-1996 University of Louisville Hospital, Louisville, KY Social Work Discharge Planner, Intern

- Discharge planning, case management, and the coordination of services which met the health-related needs of adult patients in an acute care setting.

- Major functions included assessment, planning, coordination, implementation, monitoring and evaluation.

- Consultations with others on the medical team and community resource representatives.

\section{RESEARCH AND SCHOLARSHIP}

\section{ACADEMIC APPOINTMENTS}

2008-present Adjunct Faculty

University of Louisville, Kent School of Social Work

2010-2011

Adjunct Faculty, MSW Program

Continuing Education Instructor

Spalding University School of Social Work

\section{FELLOWSHIPS AND SCHOLARSHIPS}

2007-2009

2008-2010

2010-2012
University of Louisville Doctoral Assistantship American Cancer Society Oncology Social Work Doctoral Fellow (DSW-08-210-01-SW)

American Cancer Society Oncology Social Work Doctoral Fellow (DSW-08-210-03-SW) 
RESEARCH ASSISTANTSHIPS

7/2009-5/2012

School of Medicine, Interdisciplinary Program for Palliative

Care and Chronic Illness, University of Louisville

Graduate Research Assistant

- Grant and research study application writing

- Implementation of funded studies

- Data collection and analysis for funded studies

- Assisting with university-wide educational programs related to chronic disease, oncology and palliative care

- Professional writing and preparation of abstracts, manuscripts, posters and presentations related to completed projects

- Project Director for Improved Health Outcomes Program (IHOP)

7/2007-7/2009

Kent School of Social Work, University of Louisville Graduate Research Assistant

- Alternate Member-University Institutional Review Board: Social / Behavioral / Educational Committee, Human Subjects Protection Program

- Digital Bibliographic Referencing in Endnote

\section{HONORS AND AWARDS}

Guy Stevenson Award for Excellence in Graduate Studies, the university's most outstanding doctoral degree recipient who excels in scholarship, leadership, and other areas within their discipline, Spring 2012

University Commencement Speaker, Spring 2012

Graduate Dean's Citation, Spring 2012

Tuition Award for Outstanding PhD Students, University of Louisville, School of Interdisciplinary and Graduate Studies, Summer 2009_-Spring 2012

Outstanding Volunteer 2009, Gilda's Club, Louisville

University of Louisville President's Commission on Diversity and Racial Equality (CODRE) 2007, for research with underserved and minority populations

Association of Oncology Social Workers-National Conference Scholarship 2003 (award based on excellence in Oncology Social Work)

Dean's Scholar - Fall 1992, Spring 1993, Summer 1993 - Western Kentucky University President's Scholar - Spring 1992 - Western Kentucky University Greek Scholar of the Month - October 1992 - Western Kentucky University Highest G.P.A. in Alpha Gamma Delta - Spring 1992 - Western Kentucky University 


\section{GRANTS AWARDED}

American Cancer Society Doctoral Training in Oncology Social Work

2008-10

$\$ 40,000$ (DSW-08-210-01-SW)

2010-12

$\$ 40,000$ (DSW-08-210-03-SW) (Dissertation Grant)

University of Louisville President's Commission on Diversity and Racial Equality (CODRE): An Exploratory Study of the Experience and Needs of Medicaid Recipients with Advanced Cancer

2008-09 \$1,000

Susan G. Komen for the Cure, Louisville Affiliate

Living Beyond - twice monthly support group for women with recently diagnosed advanced, recurrent, metastatic breast cancer

$2007-08$

$\$ 3,000$

2008-09

2009-10

$\$ 12,600$ (combined Healing Choices and Living Beyond)

2010-11

$\$ 12,680$

2011-12

$\$ 10,080$

2012-13

$\$ 10,080$

$\$ 11,080$

Susan G. Komen for the Cure, Louisville Affiliate

Healing Choices -8 week support group for women with recently diagnosed advanced, recurrent, metastatic breast cancer

2005-06

$\$ 11,000$

2006-07

$\$ 11,000$

2007-08

$\$ 12,000$

2008-present Combined with Living Beyond (above)

Links for Life

Individual and Family Counseling for Breast Cancer Survivors

2007-11

$\$ 8,000$

American Cancer Society

Radiation Transportation Grant

2002-2007

$\$ 6000$ (initial award - annual adjustments based on hospital need)

\section{PEER REVIEW ACTIVITIES}

Member, National Conference Planning Committee, Association of Oncology Social Work: Abstract Review and Selection (2008)

\section{EDITORIAL SERVICES}

Advisory Board, Oxford Oncology Social Work Handbook, 2012-present Section Head, Integrating Adult Lifespan Issues, Oxford Oncology Social Work Handbook, 2012-present 


\section{TEACHING}

TEACHING EXPERIENCE - Ph.D. Level Courses

Title Section

Doctoral Preparation course for the incoming SW-766-

2008 Cohort to the Ph.D. Program in Social 01

Semester

Enrollment Summer, 8

Work

$\begin{array}{lccc}\begin{array}{l}\text { TEACHING EXPERIENCE - Graduate Level Courses } \\ \text { University of Louisville } \\ \text { Title }\end{array} & \text { Section } & \text { Semester } & \text { Enrollment } \\ \text { Advanced Research Practice I } & \text { SW-668-79 } & \text { Fall, 2008 } & 22 \\ & \text { SW-668-01 } & \text { Fall, 2009 } & 22 \\ & \text { SW-668-01 } & \text { Fall, 2010 } & 15 \\ \text { Advanced Research Practice II } & \text { SW-669-80 } & \text { Spring, 2008 } & 18 \\ & \text { SW-669-80 } & \text { Spring, 2009 } & 20 \\ & \text { SW-669-01 } & \text { Spring, 2010 } & 23 \\ & \text { SW-669-01 } & \text { Spring, 2011 } & 15 \\ \text { Advanced Practice Practicum I } & \text { SW-672-20 } & \text { Fall, 2011 } & 3 \\ \text { Advanced Practice Practicum II } & \text { SW-673-20 } & \text { Spring, 2012 } & 3\end{array}$

Spalding University

Health-Related Social Work

SW-638

Spring, 2011

\section{SERVICE}

\section{UNIVERSITY ACTIVITIES}

University Institutional Review Board: Social / Behavioral / Educational Committee, Human Subjects Protection Program (2007-present)

Faculty Search Committee member for the Endowed Chair in Oncology Social Work at Kent School of Social Work (2010-2011)

Funds Development Committee member for the Endowed Chair in Oncology Social Work at Kent School of Social Work (2006-present)

Kent School Alumni Council

Elected, (2008-09)

\section{CONSULTATION AND ADVISORY ACTIVITIES}

Social Networking Task Force, Association of Oncology Social Work (2009-present)

Past membership on the Patient Services Committee of the Leukemia and Lymphoma Society 


\section{PROFESSIONAL SOCIETIES}

American Psychosocial Oncology Society (APOS), 2010-present

Association of Gerontology Education in Social Work (AGE-SW), 2008-present

Association of Oncology Social Workers (AOSW), 1997-present

Elected, Board of Directors, 2011-2013

KY State Representative, 2009-present

Member, National Conference Planning Committee, 2008

American Clinical Social Work Association / American Board of Examiners of Clinical

Social Work (ABE), 2010-present

Elected, Board of Directors, 2010-2013

Council on Social Work Education (CSWE), 2007-present

Student Volunteer, Annual Program Meeting, 2007

Public Responsibility in Medicine \& Research (PRIM\&R), 2007-present

Society of Social Work and Research (SSWR), 2008-present

Past Memberships:

Case Management Society of America (CMSA), 2000-2002

National Association of Social Workers (NASW), 1995-1999, 2009-2010

\section{LICENSURES AND CERTIFICATIONS}

Certified Social Worker

KY Board of Social Work, 1997 to present

Certified Case Manager

Commission for Case Manager Certification, 2002-present

Oncology Social Worker, Certified

Board of Oncology Social Work, 2004-present

Clinical Trials Educator

National Institutes of Health, 1999

Education for Physicians on End of Life Care (EPEC), Certified Trainer

Robert Wood Johnson Foundation, 2000-present

End of Life Nursing Education Consortium (ELNEC), Certified Trainer

American Association of Colleges of Nursing and City of Hope National Medical

Center, 2011-present

\section{COMMUNITY ORGANIZATIONS AND ACTIVITIES}

Gilda's Club Louisville volunteer (2008-present)

Psychosocial Facilitator for Casting for Recovery Retreats for women with breast cancer (2006-present) 


\section{PROFESSIONAL AND PATIENT EDUCATION PROGRAMS}

1. Schapmire, T. J. Guest Speaker (2010, November). Reducing hospital readmission rates: Health maintenance outside the acute care setting. Presented to Jewish Hospital Case Management Department, Louisville, Kentucky.

2. Schapmire, T. J. Guest Speaker (2010, September). Reducing hospital readmission rates: Health maintenance outside the acute care setting. Presented to Norton Hospital Discharge Planning Department, Louisville, Kentucky.

\section{INVITED ACADEMIC PRESENTATIONS AND SYMPOSIA}

1. Schapmire, T. J., \& Clark, R. A. (2011, April). IRB: Doctoral students' glimpse into the mystery. Paper presented to Graduate Student Ethics Roundtable of the Research Integrity Program, University of Louisville, Louisville, Kentucky.

2. Schapmire, T. J. (2010, July). Psychosocial adjustment older adults with cancer: A multilevel longitudinal analysis. Poster presented at the American Cancer Society's Research Day, University of Louisville, Louisville, Kentucky.

3. Schapmire, T. J., (2007, September). Healing Choices: Redefining hope. Paper presented at the Joint Hungarian-American Conference on Social Work in Health Care: College of Health \& Social Work, University of Debrecen, Hungary; \& Kent School of Social Work, University of Louisville, Kentucky.

4. Morris, J. S., \& Schapmire, T. J., (2006, June). Healing Choices: Redefining hope. Paper presented at the $9^{\text {th }}$ Annual Mission Conference of the Susan G. Komen for the Cure, Washington D.C.

\section{CONFERENCE PRESENTATIONS (Refereed Papers and Posters)}

1. Burg, M., Perry, C., Schapmire, T. (2012, May). Embrace Your Expertise: Research Pathways for Practicing Oncology Social Workers. Panel presented at the 28th Annual Association of Oncology Social Work Conference, Boston, MA.

2. Tamas, R., Pfeifer, M., Head, B., Schapmire, T., \& Jones, C. (2012, February). Process of Developing an Interdisciplinary Oncology Palliative Care Curriculum. Paper presented at the American Psychosocial Oncology Society 9th Annual Conference, Miami, Florida.

3. Charlot, C., Pfeifer, M. P., Keeney, C. E., Head, B. A., \& Schapmire, T. J. (2011, October). Quality of life and symptom burden comparisons between lung and head and neck cancer populations. Poster presented at Research Louisville, University of Louisville, Louisville, Kentucky. 


\section{CONFERENCE PRESENTATIONS (Refereed Papers and Posters) CONTINUED}

4. Pfeifer, M. P., Head, B. A., Keeney, C. E., Scharfenberger, J. A., Schapmire, T.J., \& Jones, C. K. (2011, August). Developing an interdisciplinary oncology palliative care curriculum. Poster presented at the National Institute of Nursing Research and Partners Summit: The Science of Compassion: Future Directions in End-of-Life and Palliative Care, Bethesda, Maryland.

5. Keeney, C. E., Head, B. A., Myers, J. A., Schapmire, T. J., Appana, S. N., \& Pfeifer, M. P. (2010, November). The impact of a telehealth intervention on symptom burden and quality of life for head and neck cancer patients. Poster presented at the National Institute of Nursing Research and Partners Summit: The Science of Compassion: Future Directions in End-of-Life and Palliative Care, Bethesda, Maryland.

6. Buckingham, S. L., Schapmire, T. J., \& Van Gorp, W. G. (2011, May). Cancerrelated neurocognitive challenges: Early detection, differential diagnosis and clinical considerations. Paper presented at the 27th Annual Conference of the Association of Oncology Social Work, St. Louis, Missouri.

7. Zabora, J. R., BrintzenhofeSzoc, K., Schapmire, T. J., Bolte, S., Daratsos, L., Callahan, C., et al. (2011, May). The next challenge for MSW oncology social workers: Increasing oncology leadership roles through the PhD in social work. Panel discussion presented at the 27th Annual Meeting of the Association of Oncology Social Work, St. Louis, Missouri.

8. Head, B. A., Schapmire, T. J., \& Faul A. C. (2011, February). "Just give me hope": The lived experiences of Medicaid patients with advanced cancer. Poster presented at the Annual Assembly of the American Academy of Hospice and Palliative Medicine and the Hospice and Palliative Nurses Association, Vancouver, Canada.

9. Schapmire, T. J., \& Faul, A. C. (2011, January). Distress in older adults with cancer: A multilevel longitudinal study. Paper presented at the 2011 American Cancer Society Institute for Oncology Social Work Doctoral Grant Awardees, Tampa, Florida.

10. Keeney, C. E., Head, B. A., Myers, J. A., Schapmire, T. J., Appana, S. N., \& Pfeifer, M. P. (2010, November). The impact of a telehealth intervention on symptom burden and quality of life for head and neck cancer patients. Poster presented at the 2010 mHealth Summit, Washington, DC.

11. Keeney, C. E., Head, B. A., Myers, J. A., Schapmire, T. J., Appana, S. N., \& Pfeifer, M. P. (2010, October). The impact of a telehealth intervention on symptom burden and quality of life for head and neck cancer patients. Poster presented at the $6^{\text {th }}$ Annual Chicago Supportive Oncology Conference, Chicago, Illinois. 


\section{CONFERENCE PRESENTATIONS (Refereed Papers and Posters) CONTINUED}

12. Schapmire, T. J., Faul, A. C., \& Head, B. A. (2010, October). "Just give me hope": The lived experiences of Medicaid patients with advanced cancer. Paper presented at the $56^{\text {th }}$ Annual Program Meeting of the Council on Social Work Education, Portland, Oregon.

13. Head, B. A., Schapmire, T. J., \& Faul, A. C. (2010, June). “Just give me hope”: The lived experiences of Medicaid patients with advanced cancer. Paper presented at the 22nd Annual Ethnographic and Qualitative Research Conference, Cedarville, Ohio.

14. Schapmire, T. J., Buckingham, S. L., van Gorp, W. G., \& Head, B. A. (2010, May) Neurocognitive alterations and cancer: Emerging questions, challenges, and critical considerations for practice and research. Paper presented at the $26^{\text {th }}$ Annual Conference of the Association of Oncology Social Work, Phoenix, Arizona.

15. Schapmire, T. J., Head, B. A., \& Faul, A. C. (2010, March). “Just give me hope”: The lived experiences of Medicaid patients with advanced cancer. Poster presented at the Second Annual Graduate Research Symposium of the University of Louisville, Louisville, Kentucky.

16. Schapmire, T. J., Head, B. A., \& Faul, A. C. (2010, February). "Just give me hope": The lived experiences of Medicaid patients with advanced cancer. Poster presented at the 7th Annual Conference of the American Psychosocial Oncology Society, New Orleans, Louisiana.

17. Keeney, C. E., Head, B. A., Schapmire, T. J., Khayat, M., Scharfenberger, J. A., Bumpous, J., et al. (2010, February). Feasibility and acceptance of a Telehealth intervention for head and neck cancer patients. Poster presented at the 10th Annual Nursing Conference: Current Perspectives in Oncology Nursing, Tampa, Florida.

18. Barney, R. J., Schapmire, T. J., Conley, C. L., Dickerson, J., Leitsch, P. K., \& Huber, R. (2009, November). Innovative PhD. education: Student membership on university Institutional Review Boards. Paper presented at the $55^{\text {th }}$ Annual Program Meeting of the Council on Social Work Education, San Antonio, TX.

19. Siritsky, N., Conley, C. L., \& Schapmire, T. J., (2009, November). The impact of self-awareness on culturally competent practice. Paper presented at the $55^{\text {th }}$ Annual Program Meeting of the Council on Social Work Education, San Antonio, TX. 


\section{CONFERENCE PRESENTATIONS (Refereed Papers and Posters) CONTINUED}

20. Davis, L., Issis, J., \& Schapmire, T. J. (2009, November). EBP for at risk students: Results of two MSSW student projects. Poster presented at the $55^{\text {th }}$ Annual Program Meeting of the Council on Social Work Education, San Antonio, TX.

21. Schapmire, T. J., Head B. A., \& Faul, A. C. (2009, May) Portraits of the dying poor: The lived experience of Medicaid patients with advanced cancer. Paper presented at the Association of Oncology Social Work 25th Annual Conference, Savannah, GA.

22. Issis, J., Davis, L., \& Schapmire, T. J. (2009, April). Working the steps: EBP curriculum, student perspective and practicum integration. Paper presented at the Kentucky Association Social Work Educators 2009 Spring Conference, Bowling Green, KY.

23. Conley, C. L., Barney, R. J., Schapmire, T. J., Leitsch, P. K., \& Huber, R. (2008, November). Institutional review boards and be strengthened by doctoral students' participation. Paper presented at the 2008 Public Responsibility in Medicine and Research Conference, Orlando, FL.

24. Faul, A. C., D'Ambrosio, J. G., Farley, A. J., Feaster, D., Oak, C. S., \& Schapmire, T. J. (2008, November). An aging society: Job risks and opportunities facing the frontline caregivers of elders who prefer to age in place. Paper presented at the $61^{\text {st }}$ Annual Scientific Meeting of the Gerontological Society of America, National Harbor, Maryland.

25. Faul, A. C., D'Ambrosio, J. G., Farley, A. J., Feaster, D., Oak, C. S., \& Schapmire, T. J. (2008, October). Problem-Based Learning: Integrating gerontology with research to develop new doctoral scholars. Paper presented at the $54^{\text {th }}$ Annual Program Meeting of the Council on Social Work Education, Philadelphia, PA.

26. Schapmire, T. J., Hochberg, I., \& Irish, K. C., (2008, May). An oncology social work practice course for master's students: An international effort. Poster presented at the Association of Oncology Social Work 24th Annual Conference, Louisville, KY.

\section{BIBLIOGRAPHY}

\section{Peer-reviewed Publications}

1. Schapmire, T. J., Head, B. A., \& Faul, A. C. (2012). "Just give me hope": The lived experiences of Medicaid patients with advanced cancer. Journal Of Social Work In End-Of-Life \& Palliative Care, 8(1), 29-52. doi:

DOI:10.1080/15524256.2012.650672 


\section{BIBLIOGRAPHY (Peer Reviewed Publications) CONTINUED}

2. Head, B., Schapmire, T., Keeney, C., Deck, S., Studts, J., Hermann, C., . . Pfeifer, M. (2012). Use of the Distress Thermometer to discern clinically relevant quality of life differences in women with breast cancer. Quality of Life Research, 2l(2), 215-223. doi: 10.1007/s11136-011-9934-3

3. Keeney, C. E., Hermann, C. P., Head, B. A., Schapmire, T. J., \& Scharfenberger, J. (2012). Kentucky's Efforts to Reduce the Burden of Lung Cancer: Are We Making Progress? Journal of the Kentucky Medical Association.

4. Faul, A. C., Schapmire, T. J., D'Ambrosio, J., Feaster, D., Oak, C. S., \& Farley, A. (2010). Promoting sustainability in frontline home care aides: Understanding factors affecting job retention in the home care workforce. Home Health Care Management \& Practice, 22(6), 408-416. doi: 10.1177/1084822309348896

5. Farley, A. J., Feaster, D., Schapmire, T. J., D'Ambrosio, J. G., Bruce, L. E., Oak, C., Shawn, et al. (2009). The challenges of implementing evidence based practice: Ethical considerations in practice, education, policy, and research. Social Work \& Society, 7(2), 246-259.

6. Head, B. A., Keeney, C. E., Schapmire, T. J., Studts, J. L., \& Pfeifer, M. P. (in progress). Quality of life in head and neck cancers: A randomized trial of a telehealth intervention.

7. Schapmire, T. J., D'Ambrosio, J. G., Feaster, D. \& Faul, A. C. (in progress). Problem-Based Learning: Integrating gerontology with research to develop new doctoral scholars.

\section{Book Chapters}

1. Schapmire, T. J., \& Faul, A. C. (in progress). Oncology Social Work with Older Adults. In C. Messner, G. Christ \& L. Behar (Eds.), Handbook of Oncology Social Work: Oxford University Press.

2. Schapmire, T.J., \& Morris, J.S., (2009). Healing Choices: Redefining hope. In Lawson, T. (Eds.). College of Health and Social Work, University of Debrecen, Hungary. 